\title{
Concepciones y prácticas sobre la oralidad en la educación media colombiana
}

Mirta Yolima Gutiérrez Ríos

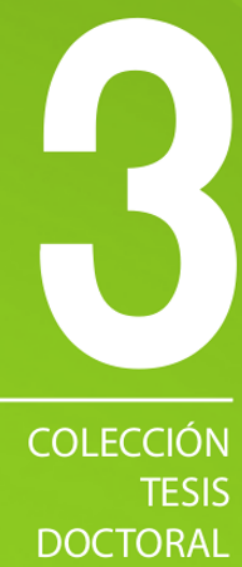


CONCEPCIONES Y PRÁCTICAS SOBRE LA ORALIDAD EN LA EDUCACIÓN MEDIA COLOMBIANA 


\section{COLECCIÓN TESIS DOCTORAL \\ TES IS \\ D O C T O RAL \\ PRESENTADA POR \\ Mirta Yolima \\ GutiérRez Ríos}

DIRIGIDA POR

María Elvira

RODRÍGUEZ LUNA

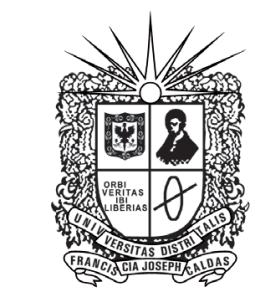

UNIVERSIDAD DISTRITAI FranCISCO José de CALDAS 


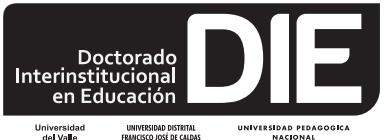

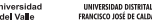

\section{Comité Editorial Interinstitucional-CAIDE}

Carlos Javier Mosquera Suárez

Director nacional

Edgar Alberto Mendoza Parada

Coordinador (E) DIE,

Universidad Pedagógica Nacional

Sandra Soler Castillo

Directora DIE,

Universidad Distrital Francisco José de Caldas

\section{Jaime Humberto Leiva \\ Coordinador DIE, \\ Universidad del Valle}

\section{Comité Editorial CADE}

Sandra Soler Castillo

Presidenta CADE

William Manuel Mora Penagos

Representante grupos de investigación:

Interculturalidad, Ciencia y Tecnología-INTERCITEC, y del Grupo Didáctica de la Química-DIDAQUIM, del Énfasis de Educación en Ciencias.

\section{Dora Inés Calderón}

Representante de los grupos de investigación:

Moralia, Estudios del Discurso, Filosofía y Enseñanza de la Filosofía, Grupo de investigación

Interdisciplinaria en Pedagogía de Lenguaje y las Matemáticas-GIIPLyM y Jóvenes, Culturas y Poderes, del Énfasis de Lenguaje y Educación.

Martín Eduardo Acosta Gempeler

Representante de los grupos de investigación: Grupo de Investigación Interdisciplinaria en Pedagogía de Lenguaje y las Matemáticas

GIIPLyM, Matemáticas Escolares Universidad Distrital-mescud y Edumat, del Énfasis de Educación Matemática.

Bárbara García Sánchez

Representante de los grupos de investigación: Formación de Educadores, del énfasis de Historia de la Educación, Pedagogía y Educación Comparada.
UNIVERSIDAD DISTRITAL

FRANCISCO JOSÉ DE CALDAS

\section{Roberto Vergara Portela}

Rector $(E)$

Universidad Distrital Francisco José de Caldas

\section{Borys Bustamante Bohórquez}

Vicerrector Académico

Universidad Distrital Francisco José de Caldas

ISBN impreso: 978-958-8832-58-6

ISBN digital: 978-958-8832-59-3

Primera edición, 2014

(C) U. Distrital Francisco José de Caldas

\section{Preparación Editorial}

Doctorado Interinstitucional en Educación Sede U. Distrital Francisco José de Caldas http://die.udistrital.edu.co

\section{Elban Gerardo Roa Díaz}

Asistente Editorial

eventosdie@udistrital.edu.co

Fondo de publicaciones

U. Distrital Francisco José de Caldas

Cra. 19 No. 33-39. Piso 2.

PBX: (57+1) 3238400, ext. 6203

publicaciones@udistrital.edu.co

Corrección de estilo

Luisa Juliana Avella Vargas

Impreso en Javegraf

Bogotá, Colombia, 2014

Prohibida la reproducción total o parcial de la presente obra por cualquier medio sin permiso escrito de la Universidad Distrital Francisco José de Caldas. 


\section{CONTENIDO}

$\begin{array}{ll}\text { PResentaCión } & 7\end{array}$

Agradecimientos $\quad 15$

$\begin{array}{ll}\text { PRÓLOGO } & 19\end{array}$

\section{Capítulo I}

LA ORALIDAD COMO OBJETO DE ESTUDIO

LA ORALIDAD EN EL CONTEXTO SOCIOCULTURAL ACTUAL

DiMENSIÓN INSTITUYENTE DE LA ORALIDAD

Perspectivas teóricas y CONTEXTOS DE DesarRollo de la ORALIDAD CONTEMPORÁNEA

LA ORALIDAD EN EL CONTEXTO ESCOLAR ACTUAL 35

DiMENSIÓN INSTITUIDA DE LA ORALIDAD 36

FuENTES PARA LA ENSEÑANZA SISTEMÁTICA Y PROCESUAL DE LA

LENGUA ORAL FORMAL 38

ENFOQUE SOCIODISCURSIVO PARA EL DESARROLLO DE LA

COMPETENCIA DISCURSIVA ORAL EN EL AULA 44

\section{Capítulo II}

LA ORALIDAD COMO OBJETO DE ENSEÑANZA Y APRENDIZAJE 55

A. Concepciones y PRÁcticas de docentes de ESPAÑol Y LiTERATURA SOBRE LA ORALIDAD. AsPectos EPISTEMOLÓgicos 61

SigNIFICADOS Y SENTIDOS DADOS A LA ORALIDAD 62

CONDICIONES PARA LA ENSEÑANZA DE LA ORALIDAD 79 
$\begin{array}{ll}\text { Procesos DE Formación DOCENTE EN ORALIdAd } & 90\end{array}$

B. Aspectos Curriculares 98

OBJETIVOS DE LA ENSEÑANZA DE LA ORALIDAD 99

$\begin{array}{ll}\text { CONTENIDOS DE APRENDIZAJE } & 114\end{array}$

LA ACTIVIDAD DE ENSEÑANZA DE LA ORALIDAD $\quad 125$

$\begin{array}{lc}\text { ESTRATEGIAS DE ENSEÑANZA } & 146\end{array}$

EVALUACIÓN DE LOS APRENDIZAJES 156

$\begin{array}{lr}\text { CARACTERIZACIÓN } & 165\end{array}$

COMPLEJIDAD ENTRE CONCEPCIONES Y PRÁCTICAS SOBRE LA ORALIDAD 170

$\begin{array}{ll}\text { REFERENCIAS } & 175\end{array}$ 
Sin perder de vista la espontaneidad y el caudal de la palabra oral, nos vamos construyendo a través de la voz propia y la de otros, acogiendo sus ecos, sus resonancias, sus quejas y evocaciones. En este sinfín de voces presentes y ausentes, la simultaneidad de la memoria y la escucha se constituyen en elementos vitales de la impronta que deja en nosotros aquellos relatos primigenios que hoy conforman nuestra experiencia narrativa y que, al decir de Raymundo Mier (2009), comprometen el deseo de la palabra y el deseo de la escucha; es decir, el acto de narrar a viva voz, pone de relieve la asimetría entre hablar y escuchar. Oír que nos narran significa recobrar la propia voz en boca del otro, y escuchar la voz de este, implica asumir la propia escucha como prefiguración de la experiencia narrativa del otro.

Sin perder de vista esta naturaleza espontánea de la oralidad y el hecho mismo de que nacemos y nos constituimos en y desde los intercambios verbales, también reconocemos que necesitamos de ciertas condiciones comunicativas, socio-afectivas y culturales para establecer interacciones más democráticas con el mundo actual desde un ejercicio de ciudadanía y participación responsable en el espacio público común.

Desde esta perspectiva actuativa e interactiva de la oralidad que adquiere un poder performativo, se presenta a continuación un análisis de las concepciones disciplinares y didácticas sobre la lengua oral en la escuela colombiana actual, como resultado de una tesis doctoral sobre el desarrollo de la competencia discursiva oral en la educación media. Se trata de un estudio que surge de la preocupación por la ausencia de una tradición pedagógica en torno a la 
enseñanza progresiva y sistemática de la oralidad frente a los ideales de la escuela contemporánea de formar ciudadanos, cuyo dominio discursivo oral constituya un factor de inclusión en diversos ámbitos de la acción social.

Sin duda se trata de compleja tarea que, sin ser nueva, exige al mismo tiempo situarse en un escenario global cuyos actores sociales representan nuevas resistencias e identidades, otras maneras de interrelación, diversas formas de emancipación y creación.

Por lo anterior, se optó por una investigación social con enfoque fenomenológico e interpretativo de la enseñanza, la cual se propuso contribuir a la construcción de un marco teórico y metodológico que coadyuvara no solo a la mejora de las capacidades comunicativas de los educandos, sino también al estudio de la lengua oral como objeto de conocimiento. Por tanto, se asume el estudio de la oralidad desde una visión interaccionista socio-discursiva, que considera su naturaleza, usos sociales, formas de realización y procesos implicados en la transformación de su conocimiento per se en representaciones didácticas posibles de ser comprendidas en el campo educativo.

Esta motivación dio lugar a una primera hipótesis planteada en los siguientes términos: En la sociedad y en la escuela contemporánea persiste un desbalance entre la valoración dada a la lengua oral frente a la lengua escrita y a otros lenguajes, proveniente de un sistema de creencias, significados y reglas de acción, es decir, de concepciones derivadas de la historia y evolución de las sociedades. Por ello, este estudio se centra en las concepciones de los profesores de lengua castellana como lengua materna, quienes se consideran los llamados a comprender y sustentar la importancia de esta actividad del lenguaje y a proponer acciones didácticas para su desarrollo reflexivo y sistemático.

El estado del arte de esta investigación reveló la necesidad de articular de manera real y efectiva los procesos de comprensión y producción oral en el currículo escolar. Esto es, reconocer las implicaciones de las actividades de hablar y escuchar en los procesos de enseñanza y aprendizaje, de donde se estaría reconociendo la dimensión interdisciplinar de la oralidad y, por tanto, un conjunto de condiciones socioculturales, psicopedagógicas, lingüísticas y discursivas que posibilitan su valoración y comprensión en los aprendizajes escolares. 
Además, investigaciones precedentes evidenciaron que las propuestas sobre didáctica de la oralidad en la educación secundaria responden fundamentalmente al propósito de reconocer la problemática y proponer estrategias de cambio, lo cual confirmó la segunda hipótesis: El contexto escolar actual carece de una tradición pedagógica y de una reflexión didáctica sobre la oralidad; por tanto, el estudio de las concepciones de los profesores sobre la enseñanza de la lengua oral constituye un primer paso para comprender y conceptualizar este fenómeno. El estudio y transformación progresiva de concepciones disciplinares y didácticas sobre la enseñanza de las lenguas supone la toma de decisiones pedagógicas y políticas, lo que a su vez exige un cambio drástico en la tradicional enseñanza distributiva y clasificatoria de la lengua.

En Colombia, esta problemática no ha sido abordada con suficiencia por las reformas curriculares y los programas de formación docente en el campo del lenguaje. Hay, por el contrario, en los programas de docencia en lengua materna y literatura, un marcado distanciamiento entre teoría y práctica pedagógica, saberes que fundamentan la labor docente. Existe, empero, una transición de una formación centrada en la gramática y la estructura de la lengua a una formación docente con énfasis en el humanismo filosófico y la investigación social. No obstante, persiste la desarticulación entre sus marcos epistemológicos, disciplinares y metodológicos, y con los aspectos problemáticos de las realidades educativas.

Una evidencia contundente es el tratamiento ocasional e intuitivo dado a la enseñanza y aprendizaje de la lengua oral en la escuela, debido a que el profesorado no cuenta con una formación sólida que oriente estas prácticas. Estos y otros presupuestos teóricos y metodológicos desarrollados en la presente obra dan lugar a sus interrogantes: ¿cuáles son las concepciones disciplinares y didácticas de la lengua oral que se manifiestan en el discurso y las prácticas de los profesores de lengua castellana?, ¿qué relaciones se dan y qué implicaciones tienen estas concepciones en las prácticas de enseñanza de la lengua oral en el aula de educación media? y, en general, ċcuáles son los fundamentos, lineamientos y estrategias que sustentan una propuesta de formación docente orientada a la enseñanza reflexiva y sistemática de la lengua oral en la educación media? 
Por consiguiente, pensar la oralidad como objeto de enseñanza implica un proceso complejo de toma de conciencia y transformación de un saber de referencia -ausente, en gran medida, en la escuela- a un saber enseñable. De ahí la importancia de un acercamiento a las concepciones disciplinares y didácticas de los maestros de lengua castellana en torno a la enseñanza de la lengua oral, para saber con qué operan y cómo lo hacen.

De este análisis se desprende la pertinencia disciplinar, pedagógica y social de la presente obra, cuya relevancia se sustenta en la ausencia de estudios que trabajen estos temas específicos, de manera que esta se constituye en un objeto de referencia y de reflexión docente para confrontar la incidencia de las concepciones que orientan los propósitos de su acción educativa. Este vacío de conocimiento teórico-práctico y la particularidad de la autora de pertenecer a la comunidad docente, marcaron la ruta de la investigación y con ello dieron sentido al objetivo central de «contribuir al estudio sobre el desarrollo de la competencia discursiva oral en la educación media con base en el análisis de las concepciones disciplinares y didácticas sobre la lengua oral en la escuela colombiana actual».

La obra se ubica en los campos de la educación, la pedagogía y la didáctica, y encuentra su primera tensión conceptual cuando indaga por el qué, el cómo y el para qué de la enseñanza de la lengua oral. La alusión a «enseñar lengua oral» se hace de manera intencionada y con la pretensión de otorgar sentido a este postulado, ya que para algunos resulta paradójico pensar en «enseñar a hablar y a escuchar», sobre todo, si se refiere a niveles escolares avanzados, como en este caso. Se trata entonces de reconstruir y darle sentido a la oralidad como objeto de enseñanza, a partir de la complejidad de relaciones que se puedan establecer entre la práctica pedagógica y las concepciones disciplinares y didácticas de la oralidad.

En el primer capítulo se presentan de manera sucinta las tensiones, aperturas y necesidades relacionadas con las diversas nociones de la oralidad (significados), sus formas de materialización y configuración (manifestaciones), su abordaje desde distintos campos disciplinares (perspectivas) y los usos dados (funcionalidad) en el contexto sociocultural y escolar. Para tal fin se adopta la dimensión instituyente e instituida de la oralidad. 
En el segundo capítulo se presenta el análisis, interpretación y discusión de las concepciones didácticas y disciplinares sobre la enseñanza de la lengua oral. Teniendo en cuenta que de esta metacategoría central se derivan diversas concepciones con distintas gradaciones, estas se presentan mediante hipótesis de progresión derivadas de las declaraciones más recurrentes en las entrevistas y los grupos de discusión, así como de las acciones predominantes en las secuencias didácticas y su autoconfrontación. Se analizan las contingencias y correspondencias entre concepciones y prácticas referidas a la enseñanza y el aprendizaje de la lengua oral y, finalmente, se discuten los resultados y se hacen aportes de orden teórico y metodológico.

En otra publicación se darán a conocer algunos lineamientos para la formulación de una propuesta de formación docente, tendiente al desarrollo de la competencia discursiva oral. Esta propuesta se deriva de los resultados obtenidos y se fundamenta en los presupuestos teóricos del conocimiento profesional del profesor. El aporte consiste, específicamente, en plantear un marco de referencia que integre dimensiones socioculturales, psicopedagógicas, lingüísticas y discursivas como fundamentos esenciales para la elaboración de los lineamientos referidos.

Lo anterior, sin perder de vista la capacidad de sensación de la palabra oral, de contacto, de fascinación, de reconocimiento de cierto sabor, olor y fluidez de la palabra que hacen que la oralidad despierte la actividad sensorial y adquiera una mayor sensualidad que la escritura. 
A Martín, Laura y Juan Felipe, como retribución simbólica por mi ausencia en aquellos momentos... a los cuales sobrevivimos gracias a nuestro infinito amor.

A todos los maestros de Bogotá y Colombia, por constituirse en arquitectos y faros de las presentes y futuras generaciones. 


\section{A G R A D E C I M I E N T O S}

Al Todopoderoso, al Dios de la vida y del amor que día a día renovó mis energías y guió mis búsquedas espirituales e intelectuales.

Quizás la tarea más compleja que haya enfrentado en mi vida académica y la que más sentimientos encontrados e irreconciliables ha suscitado en mí, durante cuatro años y seis meses, es la investigación que dio lugar a esta obra. $\mathrm{Si}$ bien la riqueza de los aprendizajes y la diversidad de experiencias fueron absolutamente vitales, únicas e irrepetibles, y además hicieron posible la realización de los objetivos perseguidos, también es innegable que en cada una subyace un largo y sinuoso camino, cuyos desafíos oscilaron entre la domesticación de la propensión a la dispersión, la moderación de la tendencia ambiciosa del investigador y, sobre todo, la lucha interna que he tenido que librar contra ciertas inseguridades derivadas de mi carácter perfeccionista.

En este proceso fueron muchas las personas e instituciones que me acompañaron y me apoyaron en la delimitación del camino, en su trasegar y en la llegada a la meta propuesta; por ello y más allá de cumplir con el formalismo de los agradecimientos, siento que me debo a ellas y que este es un espacio justo y consecuente con el deseo de manifestarles mi gratitud y dejar una inequívoca impronta de lo que ha significado su presencia en la gestación y alumbramiento de este estudio. Para tal fin, a continuación intentaré realizar un ejercicio de razonamiento y objetivación de esta experiencia. 
Las condiciones en que surge la investigación facilitan su planteamiento y desarrollo. En este caso mi condición de miembro del grupo de investigación Lenguaje, Cultura e Identidad (clasificado en la categoría A1 de Colciencias), hizo que además de las tutoras, me rodearan todos los integrantes del equipo, quienes poseen una amplia trayectoria investigativa en diferentes tópicos relacionados con los campos del lenguaje y la educación. A todos ellos, a Raquel Pinilla, Blanca Bojacá, Rosita Morales, Ivoneth Lozano, Sandra Patricia Quitián y a Mario Montoya, mi agradecimiento especial por su apoyo incondicional y sus palabras de aliento.

El acompañamiento permanente del director de tesis, su denodado e inmenso compromiso y su condición humana son factores decisivos en el éxito de la investigación. A la Dra. María Elvira, quien fungió como directora oficial, agradezco infinitamente su disposición constante y siempre atenta a apoyarme, a escuchar mis llamados de auxilio y a orientar mis pasos, procurando en todo momento potenciar mi autonomía e iniciativa personal. A ella le debo el aprendizaje del rigor intelectual y la disciplina estoica del investigador que persiste en su empeño, no obstante las adversidades e incertidumbres. A la Dra. Gladys, agradezco de manera especial la codirección que asumió, a pesar de la omisión institucional derivada de situaciones coyunturales de la Universidad. A ella le debo el aprendizaje de la introspección y el análisis profundo, valores intelectuales que se suman al de su admirable calidad humana.

Sus apreciaciones críticas, sus cuestionamientos y su coherencia para guiar a dúo mis ideas, constituyeron aportes fundamentales para el éxito de la investigación, y además revelaron su firmeza y capacidad de trabajo en equipo. Cada una ha sido, y seguirá siendo, una fuente singular de inspiración y un ejemplo a seguir.

La calidad de los espacios académicos y la formación que ofrece el Programa de Doctorado constituyen la piedra angular de la tesista. Sin desconocer que el programa adolece de algunas condiciones académicas y administrativas que podrían facilitar en mayor medida las tareas investigativas y productivas de los doctorandos, es indiscutible la calidad de los espacios académicos en los que participé, como también los valiosos aportes del equipo de profesores e invitados, compañeros y de la Dra. Adela Molina, fundadora del programa. 
A la Universidad Distrital, mi reconocimiento de siempre, pues a ella debo mi formación profesional y mi experiencia como formadora de formadores. Valoro infinitamente la riqueza de las discusiones y análisis con los estudiantes de práctica docente de la Licenciatura en Educación Básica con énfasis en Humanidades y Lengua Castellana, alrededor de la educación lingüística en las escuelas bogotanas. Especialmente, a Giovanna Medina y Viviana Urquina, quienes en calidad de pasantes y auxiliares de investigación, participaron en el proceso de muestreo y recolección de datos y desde sus propios intereses investigativos se acoplaron a las circunstancias de este.

El apoyo decidido de la Secretaría de Educación Distrital y de la Normal Superior María Montessori en la formación continua de profesores de diferentes áreas y grados de escolaridad. Reconozco a la SED la oportunidad dada a los niños, niñas y jóvenes de contar con profesores con un alto nivel de formación. En mi caso particular agradezco el incentivo educativo condonable, representado en apoyo financiero y en un tiempo de dos años. De igual forma, agradezco a la Normal Superior Distrital María Montessori, especialmente a mis estudiantes, a la Rectora María Cristina Cermeño y a la Coordinadora Luz Helena Pastrana, de quienes recibí su comprensión y apoyo irrestricto, pese a la resistencia de algunos colegas y a la anuencia y colaboración de muchos otros.

El establecimiento de lazos interinstitucionales y la generación de vínculos académicos e investigativos. Gracias a la gestión de María Elvira Rodríguez, Isabel Contreras y Pilar Núñez, profesoras de las Universidades Distrital (Colombia), Iberoamericana (México) y de Granada (España), respectivamente, se generó y fortaleció el convenio de cooperación académica y se creó la Red Iberoamericana de Estudios sobre la Oralidad. Además, agradezco a las Doctoras Contreras y Núñez, como también a la Doctora Dora Calderón, por sus valiosos aportes, derivados de los conceptos emitidos como jurados, tanto del proyecto de investigación como de la tesis.

La colaboración del grupo piloto de profesores de lengua castellana de diez colegios públicos y privados de Bogotá, Meta, Santander, Nariño y Valle del Cauca. Un agradecimiento especial a los profesores $\mathrm{P} 1, \mathrm{P} 2, \mathrm{P}_{3}, \mathrm{P} 4, \mathrm{P} 5, \mathrm{P} 6$, P7, P8, P9, P10, P11, P12 y P13, por abrir las puertas de sus aulas para dar paso a la emergencia de los datos y lograr así un corpus con una riqueza infinita, el cual me permitió configurar la realidad de la enseñanza de la lengua oral 
en las aulas de educación media. Además, porque amablemente dedicaron su tiempo a conversar con nosotras, a participar en los grupos de discusión y en los encuentros de autoconfrontación conjunta. Su disposición e interés representan el poder multiplicador del anhelado cambio y transformación de la escuela.

El apoyo moral y emocional de la familia y los amigos. Por su puesto, el agradecimiento más sentido y profundo es para mis hijos y mi esposo, artífices de este proyecto familiar y, por tanto, fuentes inagotables de inspiración y perseverancia. A Martín, gracias por asumir el papel de padre y madre con dedicación absoluta e indeclinable paciencia y comprensión; a Juan Felipe, gracias porque nuestras conversaciones constituyeron la búsqueda del equilibrio entre mi papel como madre, maestra y estudiante, y a Laura Daniela, porque a pesar de mis ausencias, logró sobreponerse con fortaleza y tenacidad a las circunstancias propias de su adolescencia. A mis padres y hermanos, por su ejemplo de lucha y su colaboración permanente. A mi madre Otilia, por el amor, el cuidado y el tiempo dedicado a mis hijos.

$\mathrm{Y}$ a todos aquellos que de una u otra manera estuvieron presentes en la realización de este sueño, mil y mil gracias.

A todos, mi cariño y gratitud infinita. 


\section{P R Ó L O G O}

Ha sido gratificante presentar este libro, destinado a compartir los resultados de la investigación doctoral realizada por Yolima Gutiérrez Ríos, que a su vez representa la culminación de un largo proceso de formación que he acompañado desde cuando la autora comenzó a transitar por los caminos del lenguaje y la investigación. Tempranamente orientó sus intereses hacia una lingüística destinada a la comprensión de los usos de la lengua oral y escrita, a la interpretación de las funciones que cumplen los discursos en la vida social y a la necesidad de llevar a la escuela los desarrollos teóricos y metodológicos de las ciencias del lenguaje, con la intención constante de alcanzar mejores condiciones para la enseñanza y el aprendizaje de la lengua y la literatura.

En el centro de sus preocupaciones situó la formación de docentes, de normalistas y de licenciados, como espacio fundamental para la generación de nuevas relaciones entre las teorías y las prácticas pedagógicas, y la exploración de formas creativas dirigidas al desarrollo de la competencia comunicativa de niñas, niños y jóvenes en la educación pública, siempre en la perspectiva de la inclusión y la equidad social. Como parte de ese continuum, en su formación doctoral se detuvo a investigar sobre la oralidad en el aula, hallazgos que se condensan en la presente obra, donde se advierte la madurez en sus acercamientos a las teorías que fundamentan el proceso investigativo y la profundización en torno a preocupaciones que la han acompañado en su trayectoria académica.

Junto con los aportes de esta obra, que sin duda son mayores a los aludidos en esta breve presentación, quiero resaltar la dedicación y el compromiso de la autora frente a su quehacer docente e investigativo, y la manera paciente y rigurosa como emprendió y culminó el trabajo. A lo largo de la obra, teje de manera ágil y comprensible el entramado teórico y práctico desde el cual es 
posible urdir los hilos que ponen en relación las concepciones de los docentes y las prácticas de aula en torno a la oralidad. Desde esa trama propone alternativas para emprender nuevas aproximaciones a un problema fundamental en el desarrollo humano, en la interacción social y en la apropiación social de conocimientos: la oralidad. Sin duda, es una obra delicada y compleja, adelantada de manera sistemática, rigurosa y comprometida.

¿Por qué ocuparse de las concepciones que orientan las prácticas docentes sobre la oralidad? ¿Por qué convertir en objeto de estudio lo que se percibe como un hecho natural? ¿Por qué ocuparse de actividades que aparentemente no requieren procesos específicos para su apropiación y desarrollo? y ¿Por qué dedicar parte del currículo formal a la promoción de estas capacidades en los estudiantes de la educación media colombiana?

Probablemente muchos más interrogantes ocuparon a la autora en la definición de su objeto de investigación. También le sobrarían razones teóricas y empíricas para justificar la pertinencia de un estudio centrado en el desarrollo de la oralidad y en la formación de ciudadanos críticos, participativos, deliberantes, para la sociedad democrática y plural que aspiramos construir. Al respecto señala: «Se trata de un estudio que surge de la preocupación por la ausencia de una tradición pedagógica en torno a la enseñanza progresiva y sistemática de la oralidad frente a los ideales de la escuela contemporánea de formar ciudadanos, cuyo dominio discursivo oral constituya un factor de inclusión en diversos ámbitos de la acción social».

Pese a su importancia, la enseñanza de la lengua oral está lejos aún de superar ciertas concepciones de orden sociocultural, pedagógico y epistemológico que impiden abordarla desde perspectivas renovadoras que propicien la construcción de prácticas configuradoras de nuevos modos de entender las relaciones que se tejen entre los interlocutores. Según la investigación, existen múltiples motivos que explican este estado de cosas en torno a la oralidad, entre los cuales destaca: «a) la subvaloración de la oralidad en el desarrollo e identidad individual y sociocultural del ciudadano; b) el tratamiento ocasional e intuitivo de la oralidad como objeto de enseñanza y aprendizaje en la escuela; c) la ausencia de programas de investigación sobre formación docente en didáctica de la oralidad y de bases teórico-prácticas para la enseñanza de la lengua oral en la educación básica, media y superior».

¿Será que la búsqueda de caminos conducentes a la superación de tales problemas no ha tenido el suficiente eco en las instituciones formadoras de docentes en lengua materna, como tampoco se les ha otorgado el énfasis re- 
querido en las políticas públicas que orientan los currículos de la educación básica y media? Lo cierto es que los resultados de la investigación evidencian pocos avances en las propuestas didácticas que se despliegan en las aulas para favorecer el desarrollo de la competencia oral en los jóvenes. Según la autora, la distancia existente entre lo prescrito y lo realizado, entre el deseo de los docentes y las prácticas observadas en los contextos educativos, tiene su origen en las concepciones que orientan las prácticas pedagógicas sobre la oralidad.

Una primera hipótesis en relación con las concepciones plantea la inequitativa relación entre la escritura y la oralidad en cuanto a la mayor importancia concedida a la primera, ya que «en la sociedad y en la escuela contemporánea persiste un desbalance entre la valoración dada a la lengua oral frente a la lengua escrita y a otros lenguajes, proveniente de un sistema de creencias, significados y reglas de acción, es decir, de concepciones derivadas de la historia y evolución de las sociedades». Una segunda hipótesis sostiene la ausencia de conocimientos y reflexiones sistemáticas respecto a la enseñanza y aprendizaje de la oralidad, por lo cual «el estudio de las concepciones de los profesores sobre la enseñanza de la lengua oral constituye un primer paso para comprender y conceptualizar este fenómeno».

Entonces ¿qué hacer frente a estas realidades tan complejas y a la vez tan difíciles de transformar? ¿Cómo desnaturalizar lo que aparentemente es espontáneo y constituirlo no solo en objeto de estudio sino también en prácticas renovadas, significativas y trasformadoras de la enseñanza de la lengua oral?

Ese es el reto que asume la autora para aportar alternativas derivadas de la investigación e incidir en la movilización de las concepciones dominantes sobre la oralidad entre los docentes, los autores de libros, los formadores de formadores, los diseñadores de currículos e incluso muchos investigadores del lenguaje, y así promover cambios importantes en las prácticas pedagógicas sobre la oralidad. Habría que pensar, como lo señala la autora, en superar la desarticulación existente entre los marcos epistemológicos, disciplinares y metodológicos para la enseñanza de la lengua oral y los problemas de la comunicación, la cognición y la cultura existentes en las realidades educativas.

Un paso importante consiste en desentrañar los sentidos de la oralidad; un segundo paso reside en describir, comprender e interpretar esos modos, sutiles e imperceptibles como se construyen los conocimientos, las creencias y las percepciones sobre la comunicación oral en el aula. El acercamiento metodológico adoptado le permite develar las concepciones de los docentes que participaron en la experiencia investigativa e identificar las conver- 
gencias y rupturas entre concepciones y prácticas referidas a la enseñanza y el aprendizaje de la lengua oral. Finalmente, tales movimientos conducen a la configuración de una propuesta de formación y desarrollo profesional docente orientada al mejoramiento de la enseñanza de la lengua oral desde una mirada integradora de las dimensiones sociocultural, psicopedagógica, lingüística y discursiva.

Sin lugar a dudas, el presente trabajo contiene más de lo que dice, expresa las voces de variados teóricos del lenguaje y de la didáctica, de investigadores sobre la enseñanza y el aprendizaje, lleva la impronta de asesores y colegas, y expresa las necesidades de muchos docentes que actúan con mayor o menor conciencia sobre la importancia de su trabajo para el desarrollo de las capacidades lingüísticas de sus estudiantes y de tantos estudiantes que participaron de las prácticas analizadas. Toda esta polifonía se encuentra reunida en unas cuantas páginas que nos invitan a conocer cuáles son las concepciones que explican por qué las prácticas sobre la oralidad en la educación media colombiana son como se muestran en el presente trabajo, pero también de qué modo se pueden alcanzar mayores y mejores formas de uso de la palabra oral para contribuir a forjar una educación lingüística cada vez más adecuada a nuestros tiempos.

María Elvira Rodríguez Luna Ph.D. Grupo de Investigación Lenguaje, cultura e Identidad Universidad Distrital Francisco José de Caldas 


\section{LA ORALIDAD COMO OBJETO DE ESTUDIO}

En una sociedad donde la comunicación y la información son tan importantes, los conocimientos, el uso adecuado del lenguaje y el acceso privilegiado al discurso público son recursos de poder y formas de riqueza. Hoy en día no sólo es pobre aquel que no tiene recursos materiales, sino también quien no maneja los códigos

básicos de la cultura vigente y, por tanto, no puede conseguir una voz pública para expresar sus reivindicaciones (Beltrán, 1999, p. 2).

\section{LA ORALIDAD EN EL CONTEXTO SOCIOCULTURAL ACTUAL}

El escenario social actual revela una serie de fenómenos históricos y culturales complejos y contradictorios. En las últimas décadas, los ámbitos de la vida pública y privada se han visto inmersos en continuos cambios, cifrados en el fenómeno de la globalización y el avance del capitalismo posindustrial, la difusión del modelo democrático como forma ideal de organización de la polis, acompañados por incontables avances tecnológicos y comunicativos que constituyen la sociedad de la información. En educación se realizan es- 
fuerzos considerables para reducir el alto índice de analfabetismo y formar al ciudadano desde la perspectiva de la eficacia; asimismo se observan avances importantes a nivel científico, cultural, social, económico y político.

Estudiar el lenguaje en este escenario implica reconocer su adaptación a lo vertiginoso de estos cambios, además de su papel como instrumento de intelección, acción y poder en las prácticas sociales, que en realidad lo son de producción de discursos en situaciones de interacción. En este sentido, se comparte con Bourdieu (2001, p. 11) que «las relaciones de comunicación son intercambios lingüísticos y sobre todo son relaciones de poder simbólico donde se actualizan las relaciones de fuerza entre los locutores y sus respectivos grupos». En esta estructura se naturaliza el papel dominante del lenguaje y se legitima y reproduce el orden social y la distribución desigual del capital cultural (Foucault, 1973, 1978; Bourdieu, 2001; Lyotard, 2004).

En efecto, el sujeto posmoderno transita entre el poder y la riqueza del lenguaje, y se torna frágil e indefenso cuando no desarrolla su competencia discursiva, quedando expuesto -según Bourdieu (2001) - a la marginación y exclusión, pues su propio capital verbal y comunicativo no tiene valor en los mercados oficiales (escolar, político, administrativo, etc.) ni en aquellos donde esté comprometida su producción verbal. Esta es una situación lamentablemente recurrente en países como Colombia, donde la mayor parte de la población prefiere que otros hablen por ella y lleven su voz ante quienes ejercen el poder político o judicial, antes que usar su derecho a expresarse y a ser escuchados, según lo confieren la Constitución y la Ley.

Así, se instituye la voz del más fuerte como portadora de la realidad de los hechos y se desconoce la de quien, a pesar de ser víctima de su entorno, no tiene la competencia oral para describirla y aportar soluciones. Por ello, se entienden las prácticas lingüísticas como inmersas en un conjunto de relaciones de fuerza y dominación simbólica que Bourdieu representa como un campo ${ }^{1}$ de interacción con leyes propias que determinan la aceptabilidad o el rechazo de los discursos que allí se producen, generándose así un habitus ${ }^{2}$ preconsciente.

I Determinante social estructurado donde el mundo social se produce circunscrito a espacios de prácticas efectivas, a partir de relaciones entendidas como interacciones.

2 Las condiciones de vida diferentes producen habitus distintos, ya que la existencia de cada clase social impone maneras distintas de clasificar, apreciar, desear y sentir lo necesario. 
De este modo, el poder lingüístico y simbólico del discurso se refleja en la capacidad de los agentes para imponer, validar y favorecer sus productos lingüísticos; por tanto, es en la acción social donde los hablantes adquieren y desarrollan su competencia discursiva. Esta obra centra la mirada en el papel del lenguaje como instrumento de creación, construcción de saber e interacción.

Esta perspectiva del lenguaje como instrumento emergente es defendida en diversos campos disciplinares, a partir de los cuales se considera que los cambios propios de la posmodernidad generan nuevas exigencias de diálogo entre las culturas, y entre los sujetos y su realidad; condiciones fundamentales para el desarrollo de medios de reinvención, democratización y revolución (Freire, 1969; Rodríguez, 2000; Brünner, 1998; De Certeau, 1979; Martínez, 1991, Bronckart, 1980, 2004). En virtud de lo anterior, la creación es considerada la actividad vital y emancipadora del hombre contemporáneo; una capacidad que lo fortalece frente al juego de fuerzas en tensión, existente entre la ciencia, la tecnología y la sociedad (Lyotard, 2004).

Esta capacidad creadora también es reconocida por Castoriadis (1997) cuando define como dimensión instituyente del lenguaje aquella que no solo lo considera como un sistema de dominación social (Bourdieu, 2001), sino también como praxis conflictiva que se produce en la vida cotidiana. En esta complejidad de relaciones, el lenguaje ratifica su papel como mediador en la representación que los sujetos hacen de su entorno, en las interrelaciones con el otro y en la estructuración de las operaciones de razonamiento, decisivas en los procesos y actividades propias de la construcción del conocimiento. Esta actividad lingüística compromete ineludiblemente a la oralidad como un acto comunicativo de carácter humano, presente en las distintas épocas y contextos sociohistóricos.

\section{DIMENSIÓN INSTITUYENTE DE LA ORALIDAD}

Situar la oralidad como objeto de estudio en la dimensión instituyente implica indagar por su naturaleza y las distintas maneras como se ha venido actualizando en el contexto sociocultural a lo largo de la historia. Sin pretensiones de exhaustividad, a continuación se acude a algunas fuentes que permiten 
comprender el devenir de la oralidad en la premodernidad, modernidad y posmodernidad, con sus consecuentes formas de emancipación.

Contreras (2009) describe cómo la mayoría de los grupos sociales han ido pasando de pensar y representar el mundo a través del lenguaje de la acción (cultura oral), al lenguaje de las ideas (cultura escrita) y, de allí, al lenguaje de la imagen (cultura virtual). Se trata de una transición consecuente con los desarrollos de la ciencia y las tecnologías de la palabra (imprenta, computadora, medios de comunicación e información, etc.). En este proceso es importante identificar los vestigios que ha dejado la oralidad -valorados por la misma autora- a partir de la contrastación entre la distancia que reclama la escritura sobre la condición real de la existencia humana y la cercanía de la oralidad caracterizada por la palabra viva, conocida y cotidiana:

Esta preocupación o necesidad por describir e indagar lo que la palabra escrita oculta con respecto al acto oral, con respecto a esa oralidad pronunciada frente a los escuchas, frente a los otros, es, con seguridad, lo que ha impulsado a nuevas generaciones de artistas a inventar formas novedosas de expresión artística como la performance, la narración oral escénica o el teatro comunitario o grupal, entre otras; las que, a través de su facultad performativa, puedan devolver a la palabra aquella fuerza vital comunicadora de antaño, que ha estado silenciada por mucho tiempo bajo el atractivo de la representación gráfica de las palabras (2009, p. 53-54).

De este planteamiento se infieren al menos tres elementos sustanciales de la oralidad. Primero, se otorga sentido a la capacidad de sensación en el contacto que genera la interacción oral; la fascinación de estar cara a cara, de reconocer cierto sabor, olor y fluidez de la palabra, hacen que la oralidad despierte mayor actividad sensorial frente a la escritura. Esta vitalidad de la oralidad -determinada por una necesaria copresencialidad- lleva a pensar que es difícil concebirla únicamente como el acto humano de hablar o referirse solo al hablante, ya que más bien se trata de un interlocutor o, como lo retrata Alcántara (2009), un actor o actriz, pues la acción, implícita en su discurso, rebasa los límites del discurso oral y activa otros discursos. Este carácter performativo de la oralidad da paso a un segundo elemento emergente: el alcance semántico de los gestos, posturas y actitudes como signos culturales de valor simbólico3 (Poyatos, 1994).

3 Además, da cuenta del carácter complementario de la teatralidad (performatividad de la oralidad) y la oralidad. 
Por esto, la oralidad no puede entenderse como simple enunciación, sino como acción de enunciar, lo cual supone un discurso permeado por elementos sociohistóricos, culturales, políticos, semióticos, etc. Además, la paralingüística, la kinésica y la proxémica ${ }^{4}$, a más de tratar recursos propios de la oralidad, son ciencias que estudian saberes culturales, simbólicos y extralingüísticos que hacen posible que las personas pertenecientes a determinados grupos sociales logren establecer una comunicación oral efectiva e, incluso, intercultural. Ello confirma el carácter multicanal de la oralidad, en cuanto no se queda en lo puramente lingüístico, sino que conjuga lo paraverbal, lo quinésico y lo proxémico.

Así, pues, una condición sine qua non de la oralidad en la modernidad es su determinación de lo humano, mediante el contacto, la presunción de cercanía y la acción. Este es el tercer aspecto inferido del planteamiento de Contreras (2009), quien considera que el sujeto contemporáneo no puede sustraerse solo a pensar la palabra escrita, sino que ha de convertirla en acciones acabadas, es decir, dejarse atrapar por la acción que expresa la oralidad. Esta naturaleza actuativa e interactiva se sustenta en la perspectiva bajtiniana que entiende el uso de la lengua como un diálogo vivo y no como un código; esto es, reconocer que en situaciones de interacción oral entre los sujetos se hacen presentes en un mismo discurso voces de otros ${ }^{5}$, y en la secuencia de enunciados se revelan tipos de organización textual y/o discursiva. Por ello, el discurso es una manifestación práctica, social y cultural ${ }^{6}$ que se desarrolla a partir de la interacción entre enunciados propios y ajenos. De ahí la presunción de usos discursivos dominantes y de resistencia.

Ahora bien, siguiendo con la búsqueda de elementos emergentes de la oralidad configurados en la evolución y las formas de la sociedad contemporánea, se encuentra en Galindo (2006) un aporte importante derivado del estudio de

4 Son ciencias sistemáticamente estudiadas en las últimas décadas, que dan cuenta del valor de ciertos recursos fonéticos durante los intercambios verbales orales (paralingüística), de actitudes, posturas y hábitos culturales que constituyen signos que pueden variar de un grupo social a otro (proxémica), y del caudal comunicativo a cargo de los gestos y movimientos corporales de percepción visual, auditiva o tangible (kinésica).

5 El hablante, según Bajtín (1982), no acude al diccionario para encontrar palabras cuando habla, sino que las busca en la boca de otras personas, cuando estas se produjeron en otros contextos y con otras intenciones.

6 Este enfoque del discurso como acción social permanente es el que propone Van Dijk (2000), quien plantea no entenderlo solamente como una serie ordenada de palabras, cláusulas y proposiciones, sino también como secuencias de actos mutuamente relacionados. 
las formas de la oralidad ritualizada en la premodernidad7, con la repetición y reproducción de una textualidad construida por los conformadores del mundo, donde la religión es garante de todas las respuestas a lo incuestionable. De este mundo sin historia y estable, pasa a la historia en movimiento del mundo moderno, caracterizado por una vida social basada en la interacción y la configuración del sentido por consenso dialógico. En este marco de democracia e intercambio con normas fijas surge la posmodernidad, donde todo criterio de orden y verdad es sometido a juicio y no es posible concebir la existencia y el progreso sin la comunicación; entonces, aflora una preocupación por lo diverso, lo complejo y lo creativo.

A pesar de los cambios sociales, la oralidad sigue presente moldeando la cosmovisión humana, mediando en las situaciones de invención y ruptura, actualizando modos de vida y formas de ritualización, replicando ideas, melodías, hábitos, habilidades, historias, teorías, creencias, modas, prejuicios, resentimientos y diversas maneras de representar el mundo. Por ende, la oralidad es una entidad sociocultural y, en consecuencia, lingüística, cuya concreción ocurre en la lengua oral ${ }^{8}$. Si bien ciertos usos orales requieren de la memoria y de la repetición, es evidente que en la evolución y estructuración social la oralidad adquiere un carácter metarreflexivo y pragmático que posibilita a los sujetos observar y contrastar diversas formas de representación presentes en la vida social, de tal forma que logran asumir posiciones críticas, cooperativas y dominantes.

La oralidad llega, de esta manera, a la era de la comunicación o a la era posmoderna, un espacio que le exige aliarse con otras formas de construcción de sentido. De ahí que las relaciones con la escritura sean consecuentes con la misma intención de reflexividad, creación e interacción. En esta era todos hablan, todos crean y todos construyen haciendo uso de la tecnología -tecnologización de la palabra (Ong, 1987) - a lo que se le añade la modalidad de la oralidad mediática, presente en las nuevas formas de pensar y significar de las comunidades discursivas virtuales.

Por todo lo anterior, estudiar la oralidad actualmente requiere de su vinculación a la universalización de los mercados, la democracia, los avances

7 De ahí provienen formas de la oración, de la canción, del proverbio, del libro sagrado, del conjuro, de la poesía y demás discursos fijos de ritualización.

8 Desde Bajtín (1982), se entiende la lengua como un objeto viviente, concreto y socio-ideológico. 
tecnológicos y comunicativos, por lo que resulta innegable su protagonismo en la construcción social del conocimiento, la creatividad e innovación (Brünner, 1998). Existe, empero, un evidente dominio de la escritura, hegemonía que reduce notablemente el espacio de la oralidad y, en últimas, invisibiliza el valor de la palabra oral en la construcción de la cultura, en las relaciones sociales y en la percepción de la realidad. En suma, la oralidad en la modernidad adquiere un sentido pleno de interacción, desarrollo y construcción de saber, lo cual genera un inusitado auge en pro de su rescate y defensa.

\section{PERSPECTIVAS TEÓRICAS Y CONTEXTOS DE DESARROLLO DE LA ORALIDAD CONTEMPORÁNEA}

La investigación de la oralidad es relativamente reciente. Empieza a usarse el término desde las postrimerías del siglo xx y poco a poco se ha ido filtrando de manera natural, aunque a veces con un sentido teórico difuso (en cuanto entidad abstracta) en el discurso de los estudiosos de esta modalidad del lenguaje (Abascal, 2004).

Así, con referencia a la oralidad, se alude a «cultura oral», «mundo oral», «composición oral», «cuestión oral», «lo oral», «expresión oral», «comunicación oral», «palabra hablada», «lengua hablada», «el habla», entre otras expresiones. Estas se relacionan con la actividad lingüística, artística, social y cultural, cuya complejidad obedece a que la noción de oralidad se encuentra diseminada en diferentes campos disciplinares relacionados con las ciencias sociales, las ciencias del lenguaje y la comunicación, la literatura y la educación. En lo que sigue, se presentan de manera sucinta las perspectivas teóricas identificadas a partir del estudio de la oralidad en los campos disciplinares mencionados (Gutiérrez, 2010).

\section{Perspectiva Antropológica y sociocultural}

Los estudios realizados en la última década por antropólogos, sociólogos, lingüistas e investigadores interesados en las culturas ancestrales y en los grupos sociales particulares de Iberoamérica, demuestran la estrecha relación existente entre lengua, cultura e identidad, la cual entraña un fuerte plu- 
ralismo cultural, reflejado en el multiculturalismo, el bilingüismo, el racismo y la interculturalidad 9 . A manera de ejemplo, las investigaciones se focalizan en la alfabetización en las lenguas autóctonas (Moore y Vilácy, 2006; Mattéi, 2007); la oralidad como medio de recuperación de la historia y las tradiciones (Caballero, 2005; Quiñones, 2005); el habla como rasgo definitorio de identidad étnica (Mattéi, 2007); la revitalización lingüística y cultural (Santos, 2007; García y Jacobo, 2007); la elocuencia de los silencios, gestos, tambores, ritos y danzas (Friedemann, 1997; 2002); y la dialéctica entre oralidad y escritura en el discurso indígena (Romero, 2003; Ferreira, 2007).

En general, se observa un reconocimiento de la lengua materna y sus funciones comunicativa e interactiva, fundamentales en los procesos de estructuración social; es decir, se asumen las prácticas lingüísticas como prácticas sociales. Además se infiere que el surgimiento de una concepción global del mundo fortalece la coexistencia de culturas y pone en discusión, entre otros temas, la diversidad cultural y lingüística, los fenómenos de inclusión y exclusión y los enfoques pluralistas centrados en la diversidad. En virtud de lo anterior, se deduce que la oralidad es esencial para fortalecer las identidades colectivas y la transmisión generacional (de conocimientos, prácticas tradicionales, mitos, concepciones, formas de vida, costumbres...); además, es central en el arte verbal. Asimismo, opera como instrumento de mediación y de resistencia, por cuanto promueve el desarrollo, favorece la coexistencia pacífica y activa la memoria cultural y moral en situaciones de violencia o agresión.

La perspectiva antropológica y sociocultural de la oralidad se nutre de un enfoque pragmático de carácter intercultural, en razón de que las investigaciones ofrecen una serie de contextos, grupos sociales y recursos lingüísticos que estrechan la relación entre culturas y lenguas; aunque también se acude frecuentemente a enfoques de tipo etnolingüístico, sociolingüístico y discursivo para analizar el discurso oral en situación o recuperar sus elementos sociodiscursivos.

9 Diversos trabajos auspiciados por la Oficina Regional de Cultura para América Latina y el Caribe (2006), sobre culturas indígenas latinoamericanas, dan cuenta de la lucha por la supervivencia de las lenguas aborígenes y sus hablantes, así como de formas de discriminación vigentes, acrecentando el riesgo de su desaparición y olvido. Otras investigaciones retratan el fenómeno del bilingüismo en comunidades indígenas, negras, rom y sordas, donde los rasgos de la oralidad son fundamentales en la adquisición y/o pervivencia lingüística. 


\section{Perspectiva de los estudios literarios}

La oralidad no es el objeto central de los estudios literarios; sin embargo, desde este campo a menudo se analiza el uso oral de la lengua en diversos contextos sociales para comprender aspectos de orden comunicativo, cultural y estético. Esta base antropológica de la literatura es el punto de partida de sus contribuciones al conocimiento de los pueblos e indica la vigencia de la lengua oral en la comprensión de la cultura y las relaciones sociales (el lugar del hombre en el mundo, sus tradiciones, rituales y formas de conocer), en la recreación de mundos posibles (a través de cuentos, leyendas, mitos e historias de vida) y, en general, en el juego de las relaciones oralidad-lenguaje, oralidad-cultura, oralidad-sociedad y oralidad-subjetividad (Gutiérrez, 2010).

Así, se reconoce el peso de la oralidad tanto en su manifestación genuina (no planeada y en producción) como en la estructura, estilo y contenido de los discursos transcritos (planeados). Ello no quiere decir que se desconozca la existencia de la escritura ni que esta signifique ausencia de sonoridad vocal; sin embargo, sí importa más el contenido, la riqueza y emotividad que encarna la palabra oral en un grupo y contexto social. Es evidente que se busca la interacción cara a cara (mirar, oír, sentirse observado, observar al otro, interpretarlo, etc.) y la posibilidad de sentir la palabra efectivamente pronunciada que alimenta el recuerdo y la emoción. Es la naturaleza de los signos verbales orales (flujo sonoro, habla, ritmo, rima, asonancia, etc.) la que reclama la actividad lingüística. Para referirse a esta poética cultural que constituye lo creado y transmitido, se utilizan indistintamente términos como «literatura oral», «tradición oral», «literatura popular», «folklórica o primitiva», que son aspectos o formas de producir y transmitir la literatura en la oralidad.

Los investigadores y compiladores de relatos, mitos, leyendas e historias orales, así como de dichos, refranes, coplas, trovas, rondas, poemas, propios de las comunidades indígenas, negras, rom y campesinas (Zumthor, 1987; Mercado, 1993; Pérez, 1998; Zires, 1999; Boito, 2000; Ostria, 2001; Cipolletti, 2006; Contreras, 2006; Vergara, 2006; Dévieux, 2007; Maglia, 2007...) reconocen que la literatura oral aviva el sentimiento y la memoria, afianza los lazos entre sus miembros y les permite reconocer su potencial creador, la riqueza de su cultura y su organización social y económica. Se reivindica, entonces, el «valor de la palabra oral» y específicamente de la palabra oral artística. Claro es que la tradición oral procura, de una parte, conservar conocimientos 
ancestrales a través de relatos, cantos, poesías, rezos, conjuros o discursos; y de otra, comunicar y recrear una realidad mediante la lengua oral.

\section{Perspectiva Retórica, Lingüística y discursiva}

Los aportes de la retórica a la oralidad son indiscutibles y además constituyen el campo disciplinar que primero se interesó por configurar un estudio sistemático de la palabra oral, con aportes relacionados con la voz, la memoria y las artes de la retórica; estos han contribuido a darle un estatus basado en el contacto intelectual, donde el poder persuasivo de la palabra implica conocimiento, búsqueda de recursos retóricos para hacerse entender, libertad en el intercambio de ideas y, en últimas, acción lingüística.

Desde esta perspectiva retórica y filosófica de la oralidad, se ha realizado un gran número de estudios e investigaciones en diferentes campos disciplinares (comunicaciones, jurídico, religioso...), percibiéndose la fuerza de la acción ejercida en la palabra, la reafirmación de la colectividad y la permanencia de una base argumentativa que, por momentos, adquiere tintes teatrales de escenificación, júbilo, motivación, oposición, arrepentimiento, etc. En ámbitos de la comunicación como la radio y la televisión, se hacen análisis lingüístico-discursivos de producciones informativas, publicitarias, etc., a partir de los cuales se da cuenta del poder simbólico del lenguaje y los recursos de la oralidad (Massi, 2000; Cepeda, 2000; Méndez y Leal, 2006; Valderrama y Velásquez, 2004; Urbina, 2008, entre otros). También en comunicación hay investigaciones sobre formas virtuales, donde se propone una oralidad mediática que requiere de una base electrónica para lograr efectos de simultaneidad, percepción y reacción (Constantino, 2005; Paulín, 2006; Noguera, 2006; Arango, 2007...).

En la perspectiva lingüística, se destacan las investigaciones sobre variación lingüística como fenómeno del lenguaje natural, en diversos planos ${ }^{10}$, $\mathrm{y}$ se tratan aspectos como clase social, género, edad, grupo profesional u ocupacional, grupo cultural, etc. La variable de género, p. ej., ha dado lugar a

10 Patiño Roselli (2003) explica estos planos o ejes de variación que caracterizan e identifican socialmente el habla. El eje diatópico indica la región de donde proviene el que habla; el diastrático, revela la ubicación sociocultural; y el diafásico señala el contexto o situación en que se usa el lenguaje. Una de las producciones más destacadas en Colombia sobre la clasificación dialectal, es la de Montes (1999). 
trabajos sobre comportamiento lingüístico de hombres y mujeres ${ }^{11}$, señalando la existencia de variaciones lingüísticas que actúan como marcas en el habla, femenina y masculina.

El estudio del fenómeno lingüístico muestra el paso de una organización lingüística oracional a una discursiva; en este sentido, es indudable la contribución de teóricos del lenguaje (Benveniste, 1977; Bajtín, 1982) que en su metalingüística plantean entender el discurso como interacción verbal y diferenciar los usos orales y escritos de la lengua mediante enunciados. De este modo, los enunciados constituyen la unidad de intercambio verbal que los hablantes utilizan en las diversas esferas o campos de la vida social e intelectual.

La producción del sentido del enunciado ocurre en dos dimensiones complementarias: verbal y extraverbal o contextual (situación existencial, afectiva, social...). Por tanto, algunos trabajos inscritos en la línea del análisis del discurso empiezan a interesarse por los rasgos diferenciales de la oralidad con respecto a la escritura, p. ej., el género discursivo al que pertenece (conversacional, entrevista, debate...), el registro (coloquial, jurídico, de aula...), el tipo de texto (narrativo, descriptivo, argumentativo.... ${ }^{12}$.

En síntesis, la gran diversidad de matices teóricos y metodológicos de los trabajos relativos a la oralidad (perspectivas retórica, lingüística, pragmática y analítica del discurso oral) complejiza la intención de delimitar sus tendencias teóricas y, a la vez, enriquece su estudio.

II Cabe señalar, que trabajos anteriores como los de Tannen (1994) y Bengoechea (2003), han hecho importantes aportes al análisis del habla de las mujeres y los hombres y son referente de estas investigaciones.

12 En las investigaciones con perspectiva lingüística y discursiva es evidente la influencia de los aportes liminares de corrientes como la sociolingüística variacionista (Labov, 1983 y otros) e interaccional (Gumperz, 1982), la etnografía del habla (Hymes, 1974), la teoría de los códigos elaborados y restringidos (Bernstein, 1975), la lingüística de la comunicación (Halliday, 1989; Tannen, 1994...), la escuela de Birmingham (Sinclair y Coulthard, 1978; Stubbs, 1978...), las escuelas etnometodológicas (Sacks, Schegloff \& Jefferson, 1974...), de Lyon (Kerbrat-Orecchioni, 1996) y de Ginebra (Roulet, 1991; Moeschler, 1992), el proyecto filosófico de Bajtín (1982) y los estudios sobre lingüística textual (van Dijk, 2000). En la última década, las investigaciones iberoamericanas muestran un interés por estudiar el uso oral de las lenguas desde la oralidad espontánea o en producción, apoyándose en categorías de análisis de orden contextual (situación comunicativa), lingüístico (fonológicas, morfosintácticas, semánticas, pragmáticas), discursivo (discurso, género discursivo, discursividad) e ideológico. 


\section{Perspectiva educativa}

Los desarrollos investigativos sobre la oralidad como objeto de investigación y su concreción en la enseñanza de la lengua oral, evidencian la paulatina consolidación de una comunidad de investigadores que, sin ser concertada, realiza importantes aportes al objeto en cuestión, desde distintas aproximaciones y diversos contextos y realidades ${ }^{13}$.

El análisis de esta perspectiva educativa en el contexto iberoamericano y europeo ${ }^{14}$ revela que la mayoría asume la oralidad como manifestación de la lengua y actividad del lenguaje, potente y mediadora en la comunicación, recreación, interacción y constitución del sujeto. De ahí que sus aportes se orienten a entender y explicar aspectos relacionados con la complejidad intrínseca de los procesos de comprensión y producción oral, y con su naturaleza, usos e intencionalidades. Además, reconocen que las lenguas son, al mismo tiempo, medios y objetos de aprendizaje; es decir, la lengua se considera como actividad que existe en y por las prácticas lingüísticas de quienes la usan.

Esta noción permite situar la lengua oral en un plano interaccionista, en cuanto se desarrolla en el seno de las actividades sociales que implican intercambio, reconocimiento de sí y del otro, negociación, coconstrucción, contextualización, movimiento y saber expresivo. A esto se añade la adopción de una posición integradora, ya que se valoran la lengua oral y escrita como dos modos distintos de producción del lenguaje, cada uno con sus características y, sobre todo, con sus reglas propias de funcionamiento (Benveniste, 1998), lo cual indica que su enseñanza y aprendizaje se puede plantear en estrecha interacción -aunque con las variaciones propias de su uso sociodiscursivo-, en función de mantener un tratamiento equilibrado.

Adviértase, pues, que los desarrollos identificados en los distintos campos disciplinares -ciencias sociales, ciencias del lenguaje y la comunicación,

13 Entre otros: Calsamiglia, 2006; Tusón, 2006; Nussbaum, 2006; Lugarini, 2006; Lomas, 2006; Reyzábal, 1993; Abascal, 1993; Abascal, Beneíto y Valero, 1993; Rodríguez, M. E., 1995; Calsamiglia y Tusón, 1999; Jaimes y Rodríguez, M. E., 2000; Núñez, 200I, 2003; Núñez y Romero, 2003; Rodríguez, M. E. 2002, 2006; Plane y García-Debanc, 2004; Jaimes, 2005; Vilá, Ballesteros, Castellá, Cros, Grau y Palou, 2005; Camps, 2005; Palou, Bosch, Carreras, Castanys, Cela, Colomer, Giralt Jové, Olivé, Ripoll y Teixidor, 2005).

14 Es importante señalar que entre la comunidad científica española y francesa se encuentran los desarrollos más potentes en relación con la didáctica de la lengua oral en los diferentes niveles de escolaridad, especialmente en la educación infantil y primaria. 
literatura (que abarcan una multiplicidad de disciplinas) y educación- respecto de la oralidad contemporánea son realmente reveladores y, aunque su objeto central de estudio no es la oralidad, la han abordado desde diferentes perspectivas que connotan problemáticas vigentes, posibles de ser consideradas en el contexto de la escuela y de ser transformadas en conocimientos «enseñables y aprendibles».

Sentadas las anteriores premisas, es evidente el estatuto dado a la oralidad como campo interdisciplinar, lo cual implica pensar la enseñanza de la lengua oral desde un conjunto de condiciones ontológicas, gnoseológicas, axiológicas, antropológicas, lingüísticas, discursivas, pedagógicas y didácticas que posibiliten su valoración y comprensión en la sociedad y la escuela de hoy.

\section{LA ORALIDAD EN EL CONTEXTO ESCOLAR ACTUAL}

En los últimos años se percibe un interés creciente por lo oral en el ámbito escolar. Este puede atribuirse, como señalan Plane y García-Debanc (2004), a la capacidad de la escuela de renovarse y cuestionar su papel en los profundos cambios socioculturales, y a los saberes y valores que legitima. Las investigaciones enfatizan en las condiciones requeridas para que las intervenciones de apoyo del profesor realmente contribuyan a complejizar su desarrollo discursivo, en detrimento de la corrección y la simplicidad de los enunciados. En general, se percibe un interés renovado por desarrollar la capacidad discursiva de los estudiantes, pues la expresión oral favorece el desarrollo personal y la construcción de identidad social; lo oral (del maestro) posibilita la transmisión de informaciones y la regulación pedagógica; los alumnos integran nuevos conocimientos y procesan informaciones verbales, y aprenden a comunicar y dominar los géneros orales y códigos de civilidad escolar. Por tanto, la interacción oral constituye una forma de enseñanza que pone en juego la objetivación de los intercambios verbales y la comprensión y adecuación de los discursos (Plane y García-Debanc, 2004). Al respecto, en el Marco Común Europeo de Referencia para las lenguas (2002) se plantea:

Los procesos que conlleva la interacción oral se diferencian de la simple sucesión de actividades de expresión oral y de comprensión oral de varias formas: a) los procesos de expresión y de comprensión se superponen. Mientras se está procesando el enunciado del interlocutor, que es todavía 
incompleto, se inicia la planificación de la respuesta del usuario sobre la base de una hipótesis respecto a la naturaleza del enunciado, su significado y su interpretación; b) el discurso es acumulativo. Mientras continúa una interacción, los participantes convergen en sus lecturas de una situación, desarrollan expectativas y se centran en asuntos relevantes. Estos asuntos se reflejan en la forma de los enunciados producidos (Ministerio de Educación, Cultura y Deporte, 2002, p. 90).

Así, se plantea una enseñanza de la lengua oral centrada en la interacción propia de la actividad social de los hablantes en sus contextos particulares. El uso oral de la lengua se inscribe en esferas de acción (personal, pública, profesional, educativa) donde se organiza la vida social. De allí también la necesidad de fortalecer el enfoque sociocultural del uso lingüístico en la perspectiva de una conciencia intercultural y una formación de estudiantes con dominio expresivo y comprensivo.

\section{DIMENSIÓN INSTITUIDA DE LA ORALIDAD}

Esta dimensión connota el predominio de prácticas de lectura, escritura, gramática y ortografía, una tarea que ha entendido muy bien la sociedad, quien se ha encargado de recordarle a la escuela que su función es «enseñar a leer y a escribir», lo cual indica que no se reconoce ampliamente la necesidad de desarrollar el uso, la función y la comprensión de la lengua oral en los contextos escolares y no escolares, como tampoco su papel en el desarrollo individual, escolar, social y cultural de los ciudadanos en su etapa escolar. No obstante, es evidente el clamor general de lingüistas y pedagogos de la lengua frente a la urgencia de superar la inadecuación y falta de fluidez en el uso de la lengua oral por parte de los estudiantes, así como los usos orales enfocados en discriminar y excluir al otro.

En Colombia, esta problemática no ha sido tratada con suficiencia por los programas de formación docente en el campo del lenguaje; por el contrario, es común observar en estos un marcado distanciamiento entre la teoría y la práctica pedagógica, saberes que fundamentan la labor docente. Sin desconocer que los programas de docencia en lengua materna y literatura en las últimas décadas han pasado de una formación centrada en la gramática y la estructura de la lengua a una formación con énfasis en el humanismo 
filosófico y la investigación social, siguen en gran medida desarticulados de la realidad escolar y, en consecuencia, de la necesidad de incorporar y profundizar aspectos problemáticos de las realidades educativas en sus marcos epistemológicos, disciplinares y metodológicos.

Ahora bien, en la formación docente inicial, además, se percibe un disminuido reconocimiento de la identidad didáctica y profesional, el cual se manifiesta en un rechazo al otorgamiento de un estatuto epistemológico a la didáctica y una apatía hacia el discurso pedagógico y la actividad docente (Cárdenas, Quitián y Gutiérrez, 2005). Del análisis de estas y otras tensiones se infiere la incomprensión de la oralidad como objeto de enseñanza y de aprendizaje. Sin embargo, no se desconoce que uno de los grandes objetivos de las reformas educativas y los documentos de política curricular para la enseñanza de la lengua materna y la literatura, es el dominio de la expresión oral y escrita, por lo que se cumple, a primera vista, con el cometido de su renovación y adecuación a los intereses y necesidades del momento.

De lo anterior se desprende el tratamiento ocasional e intuitivo dado a la enseñanza y aprendizaje de la lengua oral en la escuela por parte de un profesorado que no cuenta con una formación sólida que oriente estas prácticas (Gutiérrez y Rosas, 2008a, 2008b). Por ello, es necesario avanzar en la construcción de un marco de referencia que dé lugar a una actividad didáctica de la oralidad, fundamentada y contextualizada. Cuando se alude a enseñar ${ }^{15}$ lengua oral, se hace de manera intencionada con la pretensión de otorgar sentido a este postulado, ya que para algunos resulta paradójico pensar en «enseñar a hablar», sobre todo si se refiere a niveles escolares avanzados, como en esta obra que indaga por la enseñanza de la lengua oral en el nivel medio de educación en Bogotá. Se trata, desde luego, de enfrentar desde la institución escolar el reto de reflexionar, comprender y proponer alternativas para interactuar en una sociedad en constante cambio, hecho que implica reflexionar sobre lo instituido, romper sus certezas, cuestionar sus teorías,

I5 Se entiende la enseñanza, no en su sentido básico y causal propio del resultado de una acción unidireccional (enseñanza-aprendizaje), donde la actividad de enseñanza va seguida de la adquisición de un saber por parte del estudiante, sino en su sentido ontológico, referido a propiciar unas condiciones y unos medios para establecer una interacción con otro(s) y permitirle realizar las tareas del aprendizaje. Se trata más de ser estudiante que de aprender cómo aprender, de tal forma que el aprendizaje sea una consecuencia directa del estudiante, de su actividad de estudiar y no un efecto que sigue de la enseñanza como causa (Fenstermacher, 1989). 
desnaturalizar sus normas y resignificar la metáfora de progreso (Pineau, Dussel y Caruso, 2001).

\section{FUENTES PARA LA ENSEÑANZA SISTEMÁTICA Y PROCESUAL DE LA LENGUA ORAL FORMAL}

Durante décadas, según Vilá (2004), se consideró que en el transcurso de la educación infantil la adquisición de la lengua oral lograba cierto nivel de atención en el ámbito familiar y social y en los primeros grados de escolaridad; no obstante, a medida que esta avanzaba, el desarrollo de las habilidades orales dejaba de formar parte relevante del ámbito académico. Esta situación, de alguna manera, justificaba la ausencia de objetivos y de una evaluación sistemática en los programas de enseñanza. Sin embargo, destaca que un sector del profesorado siempre se haya interesado por orientar actividades orales en las aulas, aunque una mayoría da prioridad a objetivos puramente lingüísticos. En este sentido Abascal, Beneito y Valero sostienen que:

En el mejor de los casos, cuando el profesor se interesa por el desarrollo de las destrezas de comprensión y expresión oral, las actividades de aprendizaje del uso oral son escasas y poco variadas -debates más o menos espontáneos, asambleas de aula y exposiciones orales son las únicas que suelen citar los profesores-, ocupan espacios marginales y están desligadas de otros aspectos del trabajo lingüístico (1993, pp. 11-12).

Al respecto, Tusón (2006) hace énfasis en lo difícil que resulta para los maestros establecer objetivos y actividades que permitan fortalecer y evaluar la competencia discursiva, situación que es completamente natural si se tiene en cuenta la exigua formación recibida en este campo en las instituciones encargadas de formar maestros. La ausencia de marcos teóricos y metodológicos que orienten y den sentido a esta tarea de cualificar el discurso oral de los estudiantes, explica la dificultad para construir conciencia frente a esta necesidad y, en últimas, para realizar una intervención didáctica sistemáti$\mathrm{ca}^{16}$. En palabras de Lugarini:

16 Véanse: Abascal, et ál., 1993; Núñez, 2003; Núñez y Romero, 2003; Vilá, et ál., 2005; Palou, et ál., 2005; Lomas, 2006; Calsamiglia y Tusón, 1999; Nussbaum, 2006) 
Las necesidades de la escucha y del habla en la vida real son lo suficientemente amplias como para que sea bastante difícil hacer una lista, incluso parcial, de las mismas. A pesar de todo, el alumno llega a la Enseñanza Secundaria, y en buena parte también a la Enseñanza Primaria, siendo capaz de satisfacer ya sus necesidades cotidianas. En consecuencia, la escuela no tiene la misión de enseñar a hablar sin más, sino que, por una parte, debe ampliar la conciencia del alumno sobre sus propias elecciones lingüísticas y comunicativas y con respecto a la relación existente entre éstas y la situación; por otra parte, debe ampliar las capacidades de escucha y de habla también en situaciones menos «cotidianas» (2006, pp. 110-111).

Estas exigencias hacen que, como señala Lomas (2006), sea necesario concebir el aula como un escenario comunicativo, donde sea posible crear situaciones reales de interacción oral que convoquen a los estudiantes a comprender y producir enunciados acordes con diferentes contextos e intenciones comunicativas. Además, no basta con proclamar la necesidad de alcanzar estos fines comunicativos, pues también se requiere adecuar los contenidos escolares, las formas de la interacción en el aula, los métodos de enseñanza y las tareas de aprendizaje, con el fin de escenificar el intercambio comunicativo y fortalecer los usos orales y cotidianos de la lengua. Núñez comparte el anterior planteamiento y agrega:

Pensamos que por esta vía debe caminar la enseñanza de lo oral en la educación obligatoria para contribuir al objetivo de mejorar la competencia comunicativa global del alumnado, si bien, también nos parece irrenunciable reclamar una sólida fundamentación científica de las decisiones que se tomen en las aulas para evitar el riesgo de caer en un didactismo formal que deje de lado la dimensión afectiva y psicológica de la oralidad, y el de empezar a trabajar sin unos principios didácticos que fundamenten estos aprendizajes (2003, p. 59).

Como vemos, estos autores coinciden en la complejidad de una enseñanza de la lengua oral que oriente el fortalecimiento de la competencia discursiva oral, en cuanto implica lograr una construcción conjunta y cooperativa, aprender a ejercer un control sobre lo que se dice y cómo se dice, de acuerdo con el contexto comunicativo. Esto implica, al mismo tiempo, planificar la progresión del discurso, valiéndose de estrategias para captar la atención de los oyentes y mantener las relaciones cordiales y respetuosas. Resulta, pues, que los procesos cognitivos, creativos, metacomunicativos y metalingüísticos - propios de la comprensión y emisión de los discursos orales- necesitan ser 
motivo de estudio y reflexión en la escuela, como también las implicaciones de una formación de estudiantes conscientes de su actuación discursiva, participativa y reflexiva.

En este sentido, desde la década del $70^{17}$, con el surgimiento del enfoque comunicativo, ha ido apareciendo de manera paulatina una serie de trabajos con reflexiones teóricas y experiencias innovadoras como punto importante de referencia para la acción docente. El aporte de Vilá (2010), por ejemplo, se orienta a considerar la lengua oral formal como objeto de enseñanza, por cuanto los estudiantes tienen una amplia experiencia en el habla espontánea e informal (situaciones orales plurigestionadas), mientras que no reconocen o dominan usos formales más complejos (situaciones orales monogestionadas), razón por la cual es necesario que la acción didáctica se oriente de modo sistemático hacia el acceso a usos formales de la lengua oral, con el propósito de desarrollar la competencia comunicativa oral, clave para la integración social de los jóvenes de la educación media y su progreso profesional.

Para Vilá $(2004 ; 1994)$ la adquisición de la competencia comunicativa oral se garantiza desde la potenciación de los distintos usos de la lengua, los cuales, además, incluyen la producción y escucha, especialmente, desde la enseñanza de los usos monológicos en contextos de formalidad media-alta y desde la reflexión previa y posterior al uso de la lengua. Por ende, tipifica las formas que toma la intervención pedagógica en el aula de la siguiente forma:

a. Se habla para gestionar la interacción social: la cotidianidad de la clase transcurre gracias a los intercambios orales del profesor y los estudiantes. Se habla para aclarar instrucciones, comentar ejercicios, establecer normas de funcionamiento, resolver conflictos, respetar los turnos de palabra, aprender a escuchar, etc. Generalmente, en estas situaciones se enfatizan aspectos pragmáticos y lingüísticos. Lo anterior implica un contexto donde circulan los géneros orales conversacionales, inherentes a la vida social del aula.

b. Se habla para realizar actividades: narrar, describir, argumentar e instruir: para ello se requiere que los estudiantes aprendan a analizar la situación comunicativa (intención, relación entre los participantes, espacio en el que tiene lugar la comunicación y tiempo del que

17 Con una concepción pragmática de las lenguas, procedente de la etnografía de la comunicación y materializada en la competencia comunicativa (Hymes, 1972). Su tesis central es que el aprendizaje de la lengua es social por excelencia, y por tanto, enseñar lengua es enseñar a comunicarse en las diversas situaciones en las que interviene el hablante. 
dispone para hablar), así como a dominar mecanismos de cohesión y coherencia. Esta dinámica requiere de la enseñanza de la planificación del discurso oral y de la adecuación del mismo al contexto de uso. Dominar todo el conjunto de elementos lingüísticos, discursivos y retóricos de los discursos monologados es una tarea compleja y lenta que implica la participación activa del profesor.

c. Se habla para aprender, es decir, para negociar significados y construir conocimientos: en el aula se habla sobre lo que se sabe de los temas, las dudas, las creencias, las percepciones, y se construyen nuevos conocimientos a través del diálogo y la discusión. Por tanto, se requiere enseñar de manera significativa a los educandos a interrelacionar los conocimientos previos con la nueva información y ayudarles a verbalizar los conocimientos que construyen de manera coherente y adecuada.

d. Se habla para aprender a pensar: se trata de enseñar a los estudiantes a transmitir, representar y construir ideas, pensamientos, sentimientos y conocimientos.

El cumplimiento de estos propósitos implica considerar la planificación y revisión de los discursos orales formales. Para ello, Vilá et ál. (2005) proponen tres componentes que, al interrelacionarse, contribuyen a «enseñar a hablar mejor de como ya se habla», o sea, a fortalecer la competencia discursiva oral:

- Componente lingüístico-discursivo: control de la coherencia y cohesión del discurso oral, dominio de géneros discursivos orales formales, y de la voz y las estructuras morfosintácticas.

- Componente contextual: reconocimiento de reglas sociales, control del tiempo y uso de un registro lingüístico con el grado de formalidad adecuada al contexto social.

- Componente estratégico-retórico: estrategias para incrementar la eficacia comunicativa. De este modo, se enfatiza en el análisis funcional de los géneros discursivos orales formales desde una relación de continuum entre la oralidad y la escritura.

Frente a este mismo objetivo, encaminado a desarrollar la competencia ${ }^{18}$ discursiva oral de los estudiantes, Núñez, Fernández y Romero (2009) propo-

I8 Núñez (2003) define la competencia como una construcción social del conocimiento -compuesta de aprendizajes significativos- en donde se combinan atributos, tales como: conceptos, capacidades, habilidades, actitudes y valores con las tareas que se tienen que desempeñar en determinadas situaciones. 
nen un modelo didáctico y unas estrategias de aprendizaje de la lengua oral desde un enfoque comunicativo y funcional de carácter interdisciplinario ${ }^{19}$ que contiene los componentes de la competencia discursiva oral, configurados en cuatro categorías con sus correspondientes subcategorías, tal como lo ilustra la Tabla 2, y unas subcompetencias que la conforman, a saber:

a. Competencia lingüística: capacidad correspondiente al saber elocutivo o al saber hablar con coherencia en función de procesos de comprensión y conocimiento del mundo.

b. Competencia lingüística particular: capacidad de aplicar las reglas de los diversos subsistemas de la lengua (fónico, sintáctico o léxico) a la producción textual.

c. Competencia lingüística textual: capacidad que posibilita al hablante adaptar una de las posibilidades que ofrece la lengua a una situación comunicativa particular.

d. Competencia sociocultural e interactiva: capacidad de interrelación e interacción oral con otros.

Tabla 1. Componentes de la competencia discursiva oral.

\begin{tabular}{|l|l|}
\hline \multicolumn{1}{|c|}{ Categorías } & \multicolumn{1}{c|}{ Subcategorías } \\
\hline Coherencia & $\begin{array}{l}\text { 1. Lógica del discurso } \\
\text { 2. Construcción del discurso }\end{array}$ \\
\hline & $\begin{array}{l}\text { 3. Morfosintáctica } \\
\text { 4. Lexicosemántica } \\
\text { Corrección }\end{array}$ \\
& $\begin{array}{l}\text { 5. Foneticofonológica } \\
\text { 6. Presentación }\end{array}$ \\
\hline \multirow{3}{*}{ Adecuación } & $\begin{array}{l}\text { 7. Al objeto de que se habla } \\
\text { 8. A la situación } \\
\text { 9. Al interlocutor }\end{array}$ \\
\hline \multirow{2}{*}{ Interacción } & 10. Cooperación interactiva \\
sociocultural & 11. Cortesía \\
& 12. Actitud \\
\hline
\end{tabular}

Fuente: Núñez et ál. (2009).

19 Además de la lingüística funcional, Núñez (2003) se apoya en los postulados de la filosofía del lenguaje, la psicolingüística, la psicopedagogía de la comunicación y la didáctica específica de la lengua. 
Esta propuesta resulta significativa por cuanto brinda unas coordenadas teóricas que facilitan la construcción de diseños didácticos sobre la oralidad en los diferentes grados de escolaridad. Se infiere que para producir textos orales complejos se requiere del dominio, por una lado, del aparato formal lingüístico y, por otro, del instrumental del lenguaje. Cabe señalar que las categorías propuestas (Núñez et ál., 2009; Núñez, 2003) serán abordadas en profundidad más adelante, a partir de los planteamientos del interaccionismo sociodiscursivo. Por ahora, es importante añadir que tanto Vilá como Núñez et ál. (2009) coinciden en la complejidad de enseñar lengua oral e insisten en la necesidad de definir contenidos y objetivos específicos, así como criterios de evaluación. Para evaluar la competencia discursiva oral es necesario registrar situaciones de desempeño oral para volver sobre ellas y analizarlas, con el fin de mejorarlas; de igual forma, es vital contar con criterios claros y diseñar instrumentos acordes con la situación didáctica (Núñez y Romero, 2009), pues a través de estos se pueden valorar, según Vilá:

los mecanismos de adecuación a la situación y al contexto comunicativo, el uso de elementos que rigen la coherencia y la cohesión de los diferentes textos orales, el dominio en la regulación de la interacción y el uso adecuado de elementos extralingüísticos como la entonación, el ritmo, la gesticulación, etc., y, finalmente, el conocimiento del tema que es objeto del texto oral (1994, p. 50).

En todo caso, para hacer posible el desarrollo de propuestas didácticas sobre la oralidad como las de Vilá o Núñez, es decisivo no solo una toma de conciencia sobre la importancia de la enseñanza y el aprendizaje de esta actividad del lenguaje (o contar con un programa de lengua oral), sino también lograr identificar los aspectos que obstaculizan dicho propósito y poner en marcha acciones pedagógicas para su superación. En definitiva, estas investigaciones se orientan a transformar la enseñanza de la lengua materna, vinculando la enseñanza y el aprendizaje sistemático y progresivo de la oralidad, a partir de la creación de situaciones reales de intercambio oral donde resulte necesario exponer, argumentar, explicar, formular, solicitar, demandar, debatir, etc., así como comprender, producir y analizar textos orales con diversos propósitos comunicativos en diversas situaciones sociales. 


\section{ENFOQUE SOCIODISCURSIVO PARA EL DESARROLLO DE LA COMPETENCIA DISCURSIVA ORAL EN EL AULA}

Este estudio se inscribe en la perspectiva teórica del interaccionismo sociodiscursivo, pues otorga al lenguaje y a las lenguas un estatuto epistemológico y centra su análisis en la manera como diversas y complejas intervenciones humanas orientan los aprendizajes, dándose en cada individuo un proceso de desarrollo lingüístico-discursivo distinto, acorde con las condiciones particulares del contexto de aprendizaje. Por tanto, se focaliza el análisis del desarrollo humano en un marco social articulado a un marco escolar (Bronckart, 2004).

\section{ENFOQUE INTERACCIONISTA SOCIODISCURSIVO}

Dada la complejidad de la didáctica de las lenguas y la constante búsqueda de paradigmas disciplinarios que fundamenten la naturaleza holística y transversal del lenguaje, muchos especialistas en este campo (Bronckart, 2004; Dolz, Gagnon y Mosquera, 2009) coinciden en la pertinencia de los postulados y los cuestionamientos del «interaccionismo social» ${ }^{20}$-del cual deriva el «interaccionismo sociodiscursivo»-, caracterizado por demostrar cómo las prácticas socioculturales y semióticas de los sujetos, además de generar obras y hechos colectivos, contribuyen al surgimiento y a la transformación permanente de las capacidades psicológicas individuales. Analiza este proceso en tres niveles descendentes: a) dimensiones de la vida social (formaciones y hechos sociales, actividades colectivas y verbales); b) procesos de mediación formativa (control y evaluación de conductas verbales y no verbales); c) efectos de las mediaciones formativas o transacciones sociales (adquisición, reproducción y transformación de las significaciones sociales construidas históricamente por un grupo social).

De esta corriente contemporánea e interdisciplinar surge el interaccionismo sociodiscursivo, una opción epistemológica planteada por Bronckart para ahondar en la problemática de la enseñanza de las lenguas. La adopción de este programa de investigación implica partir de la comprensión de su tesis

20 Inspirado en las obras de Voloshinov, 1929 (citado por Bronckart, 2007); Dewey, 1979; Durkheim, 1990; y Vygotsky, 1996, entre otros. 
central: «la acción constituye el resultado de la apropiación, del organismo humano, de las propiedades de la actividad social mediatizada por el lenguaje» (2004, p. 31). Se trata de reconocer el papel que cumplen las mediaciones discursivas y/o textuales en el desarrollo de las personas.

En efecto el lenguaje -como instrumento de mediación de la acción social del sujeto- connota un actuar comunicativo verbal manifestado en signos organizados en «textos y/o discursos» que le permiten construir un «espacio gnoseológico» y, a la vez, dar cuenta de una acción verbal derivada de actividades verbales (desde una perspectiva colectiva), las cuales contribuyen a garantizar el entendimiento de las actividades generales ${ }^{21}$ de los sujetos, situación que Bronckart (2004) describe en los siguientes términos:

El hombre solo tiene acceso al medio en el marco de una actividad mediatizada por la lengua, pero toda lengua se presenta como una acumulación de textos y de signos en los cuales ya están cristalizados los productos de las relaciones con el medio, elaboradas y negociadas por las generaciones precedentes. Los mundos representados han sido «dichos» mucho antes de nuestra existencia, y los textos y signos que los han constituido, siguen conservando la huella de esta construcción histórica permanente (p. 28).

De este planteamiento surgen dos elementos fundamentales: por una parte, los «mundos formales del conocimiento» citados, tienen sus raíces en el principio de Habermas (1985), que presupone un lenguaje en situación o en contexto, referido bien sea al «mundo objetivo» (concebido como totalidad de las entidades sobre las que son posibles enunciados verdaderos), al «mundo social» (concebido como totalidad de las relaciones interpersonales legítimamente reguladas) o al «mundo subjetivo» (concebido como totalidad de las propias vivencias, a las que cada cual tiene un acceso privilegiado y que el hablante puede manifestar verazmente ante un público), los cuales constituyen el marco referencial del mundo de la vida (Lebenswelt), donde cada individuo pone de manifiesto unas pretensiones de validez relativas a estos tres mundos. De esta manera, el obrar del individuo en un contexto determinado está mediatizado por su «acción comunicativa» (Habermas, 1985).

2I Este planteamiento se cimienta en Habermas (1985), quien considera que las actividades verbales son fundamentales para asegurar el entendimiento sobre la realización de las actividades generales, puesto que colaboran en su planificación, realización y evaluación. 
Por otra parte, los «textos» ${ }^{22}$ y/o «discursos» (orales o escritos) son considerados como «unidades comunicativas» que se construyen en el uso que los individuos hacen del lenguaje en situaciones concretas; por tanto, movilizan recursos de la lengua natural, a partir de modelos de organización textual disponibles en el marco de esa misma lengua y determinados por las condiciones historicosociales en las que han sido elaborados. Según Bronckart (2007), los textos son productos de la actividad humana y, en consecuencia, de la aplicación de mecanismos estructurantes diversos y, a menudo, optativos.

Generalmente, cuando un sujeto o un colectivo producen un texto, están en una situación de acción verbal y disponen de cierto conocimiento del «architexto» ${ }^{23}$ de su comunidad y de los modelos de géneros allí disponibles, de modo que con este referente adoptan un modelo de género que consideran adecuado a las particularidades de la situación. Así, los «tipos de texto»o «tipos de discurso» se inscriben en «géneros de texto», "géneros de discurso» o «géneros discursivos», siguiendo la propuesta de Bajtín (1982). Son entidades que, por su carácter dúctil y móvil -pues cambian necesariamente con el tiempo o con la historia de las formaciones socioverbales-, se resisten a clasificaciones universales. Estos no siempre logran establecer claramente sus fronteras ${ }^{24}$, por ello se presentan a los usuarios de una lengua bajo criterios complejos y relativamente estables, situación que ha llevado a confusiones entre género de texto, género de discurso, tipo de texto, tipo de discurso, etc. Ante esta problemática y desde el interaccionismo sociodiscursivo, se proponen las siguientes decisiones teóricas y terminológicas.

El texto actúa como una unidad de producción verbal, situada, finita y autosuficiente, y se inscribe en un conjunto o "género discursivo», que se entiende como el modo de clasificar tanto las actividades generales como las clases de discursos; es decir, los textos se distribuyen en múltiples géneros socialmente «indexados» o pertinentes en una situación comunicativa con-

22 Bronckart (2007) propone preferencialmente referirse al texto como actividad verbal, en tanto este supone una práctica y un producto.

23 Architextualidad, término acuñado por Genette (1986) para referirse al conjunto de categorías generales o trascendentes en las que se engloban los textos: tipos de discurso, modos de enunciación, géneros literarios.

24 Los criterios de clasificación son divergentes y parciales; por ejemplo, se proponen criterios relacionados con el tipo de actividad humana implicada (género periodístico, científico, literario, etc.); con el efecto comunicativo que se persigue (género poético, narrativo, etc.); criterios centrados en el soporte utilizado (cuento, conferencia, entrevista, etc.), o en el contenido temático (ciencia ficción, receta de cocina, etc.) (Bronckart, 2004). 
creta. Bronckart (2004) propone distinguirlos como «géneros de texto», ya que su clasificación puede ser más clara si los criterios son los segmentos que componen el texto (de relato, argumentación, diálogo...). A dichos segmentos los denomina «discursos». Ahora bien, en la medida en que se mantengan sus regularidades de estructuración lingüística, los discursos se ajustan a una tipología particular. Así, pues, los «tipos de discurso» son unidades lingǘsticas o «segmentos» primarios que se coconstruyen a partir de actitudes enunciativas y que entran en la composición de los textos, según modalidades variables. Las propiedades lingüísticas de los textos ayudan a precisar su carácter - p. ej., una conversación cotidiana puede contener segmentos de diálogo, relato, argumentación y explicación- y un análisis lingüístico de estos segmentos posibilita evidenciar formas de organización sintáctica relativamente estables.

En cuanto a los géneros discursivos, tal como lo plantea Bajtín (1982), hay que distinguir los primeros o libres de los segundos o estandarizados. Los primeros, conocidos también como géneros discursivos primarios, corresponden a interacciones orales espontáneas e informales, mientras que los segundos o secundarios implican interacciones orales más complejas, por su carácter reflexivo y formal ${ }^{25}$. Se pueden identificar, así, géneros de texto producidos en modalidad oral (conversación, entrevista, conferencia, etc.) y, por supuesto, en modalidad escrita. Asimismo, Bronckart propone comprender los distintos procesos de interacción -implícita o explícita entre textos (citas, apostillas, pastiches, etc.)- como una actividad de «intertextualidad»:

Primero, el análisis del estatuto de dichas acciones semiotizadas y de sus relaciones de interdependencia con el mundo social por una parte, y con la intertextualidad por la otra. En segundo lugar, el análisis de la arquitectura interna de los textos y del papel que desempeñan en ellos las características propias de cada lengua natural (2004, p. 45).

Bajo esta perspectiva, el análisis de los textos orales o escritos pasa por relaciones de interdependencia con el mundo social y con la intertextualidad y luego por procedimientos de observación o de lectura de sus elementos de orden semántico, lexicosintáctico y paralingüístico. En el plano semántico, se analiza el efecto global de significación que produce el texto en el interlocutor,

25 Otras clasificaciones como las de Castellá y Vilá (2005), proponen discursos intermedios para referirse a aquellos que comparten -en proporciones variadas-características de los géneros discursivos primarios y secundarios. 
el cual se traduce en indicios relativos al contenido referencial, al contexto y al modo en que el autor se sitúa en ese contexto. En cuanto a la lectura lexicosintáctica, esta revela la elección de opciones de lexemas disponibles en la lengua y la aprehensión de categorías y reglas gramaticales. Y el plano paralingüístico en los textos orales da cuenta de procedimientos, como silencios, cambios de tono, acentos prosódicos, etc.

Luego de este análisis local, es importante indagar por las segmentaciones o tipos de discurso que constituyen cada texto, desde un procedimiento que Bronckart denomina «circularidad asumida», el cual consiste en someter inicialmente el texto a un análisis cuantitativo, con el fin de objetivar la percepción intuitiva de los tipos de discurso que prevalecen. De este modo, al término del análisis, «ciertos segmentos inicialmente diferenciados pueden verse de nuevo reagrupados en una misma categoría, y otros segmentos inicialmente considerados como equivalentes pueden verse diferenciados» (2004, p. 54). Si bien este planteamiento metodológico aplica para análisis exhaustivos de los textos, lo más relevante de esta propuesta radica en la complementariedad necesaria entre los elementos lingüísticos observables y la arquitectura discursiva del texto ${ }^{26}$, es decir:

Lo que en una lengua "constituye sistema» (las categorías de unidades y las estructuras oracionales) no puede considerarse más que como el producto de un procedimiento de abstracción efectuada sobre los textos, que son las unidades funcionales y empíricamente observables: los textos son, por tanto, lo primero, y el sistema de la lengua no es más que un constructo secundario, a cuya elaboración se han dedicado, con mayor o menor fortuna, sucesivas generaciones de gramáticos (p.56).

De donde se colige que, a partir de la actividad de producir textos orales o escritos, es importante establecer relaciones con sus contextos de producción y vincularlos a las regularidades de organización y funcionamiento de los géneros textuales y tipos de discurso, para así realizar inferencias y codificaciones de sus elementos observables. Esto señala la importancia de estudiar ${ }^{27}$ sus condiciones de producción desde aspectos como:

26 Un planteamiento potente a nivel didáctico, en tanto implica el equilibrio entre una enseñanza gramatical y textual de la lengua y, en últimas, una mirada renovada a los procesos de producción e interpretación.

27 Cabe señalar que este modelo general de las condiciones de producción de los textos, en el ámbito de la enseñanza, solo puede ser adoptado como instrumento de análisis en el marco de un proyecto pedagógico, de lo contrario se corre el riesgo de tergiversarlo. 
- Criterios de elección de géneros adaptados a una acción verbal dada.

- Modalidades de organización del contenido temático (construcción de un plan de texto).

- Reglas que controlan la «señalización» de esta planificación (condiciones de empleo de los organizadores textuales).

- Modalidades de gestión de las redes isotópicas que contribuyen a la coherencia textual (condiciones de empleo de los pronombres, de los tiempos de los verbos, etc.).

- Modalidades de distribución de las voces y del posicionamiento del enunciador.

Por consiguiente, asumir la responsabilidad de la acción verbal implica que el sujeto tenga que activar algunas de sus representaciones de los mundos ${ }^{28}$, es decir, acudir a un entramado de conocimientos relacionados con el contexto de producción (lugar, momento, interlocutores, finalidad), al control pragmático y el contenido temático o referencial. Respecto a la arquitectura interna de los textos producidos, el sociointeraccionismo discursivo plantea tres niveles de análisis ${ }^{29}$ :

a. La infraestructura textual: nivel «profundo», constituido por el plan general del texto, los tipos de discurso que comporta y sus modalidades de articulación, y las secuencias que eventualmente aparecen en él (de tipo narrativo, explicativo, argumentativo...).

b. Los mecanismos de textualización: nivel «intermedio», correspondiente al análisis de los mecanismos de coherencia y cohesión nominal y verbal, fundamentales en la articulación lineal del texto, que dan cuenta de la progresión temática, de las transiciones entre tipos de discurso y de las articulaciones entre enunciados.

c. Los mecanismos de asunción de la responsabilidad enunciativa: nivel relativo a la realización de la coherencia pragmática o interactiva del texto (instancias que asumen lo enunciado en el texto, voces que le sub-

28 Se trata de conocimientos que están almacenados en la memoria bajo formas lógicas y/o jerárquicas, denominadas por la lingüística textual como macroestructuras.

29 Es importante señalar que frente a los textos orales y escritos, no hay variantes en su modalidad de producción; esta diferencia se percibe en el conjunto de propiedades de la acción verbal y del género textual escogido. 
yacen) y las diversas evaluaciones (juicios, opiniones, sentimientos) que se formulan respecto a ciertos aspectos de su contenido temático.

Sobre la caracterización de las secuencias se adopta el planteamiento de Adam (1990, citado por Bronckart, 2004), quien presenta cinco tipos: narrativa, descriptiva, argumentativa, explicativa y dialogal, resumidas de este modo:

- La secuencia narrativa, real o ficticia, activa unos personajes implicados en unos acontecimientos organizados sucesivamente en función de una intriga. Se trata de un todo dinámico con carácter de acción que articula distintas fases relativas a un inicio, un núcleo y un final (situación inicial, transformación, situación final, evaluación, moraleja). Para el caso de las secuencias narrativas reales, estas pueden contener un número limitado de fases, mientras que las ficticias pueden desencadenar nuevas acciones.

- La secuencia descriptiva contiene fases que no se organizan en orden lineal, sino que se combinan e insertan en un orden jerárquico o vertical. Generalmente están constituidas por fases: de anclaje (señala el tema), de aspectualización (aspectos del tema divididos en partes, con sus propiedades) y de puesta en relación (operaciones comparativas o metafóricas). Si bien esta secuencia permite ver acciones, también convoca a la acción misma, de ahí que se derive una modalidad de secuencia prescriptiva, instruccional o procedimental.

- La secuencia argumentativa contiene un razonamiento argumentativo que implica la existencia de una tesis, la cual se apoya o refuta mediante argumentos y/o contraargumentos orientados hacia una conclusión.

- La secuencia explicativa se origina por la constatación de un fenómeno incuestionable que requiere del desarrollo de las cuestiones que suscita. Por tanto, en ella se explicitan las causas y razones (fase de constatación inicial) de la afirmación inicial, así como las preguntas y contradicciones (fase de problematización), de tal forma que se logre una reformulación (fase de resolución) y enriquecimiento (fase de conclusión-evaluación).

- La secuencia dialogal solo se puede observar en segmentos de discursos interactivos dialogados. Se estructura en turnos de habla (en los discursos interactivos primarios son asumidos por los agentes productores y en los secundarios son atribuidos a personajes puestos en escena). Se presenta en tres fases: a) de apertura, de carácter fáctico; b) transaccional, en la cual se coconstruye; y c) de cierre, también fáctica, que da término a la interacción. 
Se observa que los tipos de discurso poseen unos niveles de organización interna propia, sujetos a los permanentes cambios de los grupos sociales. Además, cada discurso puede aparecer como elemento constitutivo de diferentes géneros; p. ej., el interactivo predomina en la conversación, la entrevista, la obra de teatro, etc., pero también puede aparecer en la novela, el cuento... La Figura 1 ilustra la compleja interrelación de los principales aspectos propuestos por el sociointeraccionismo discursivo:

Figura 1. Elementos esenciales del contexto conceptual del sociointeraccionismo discursivo

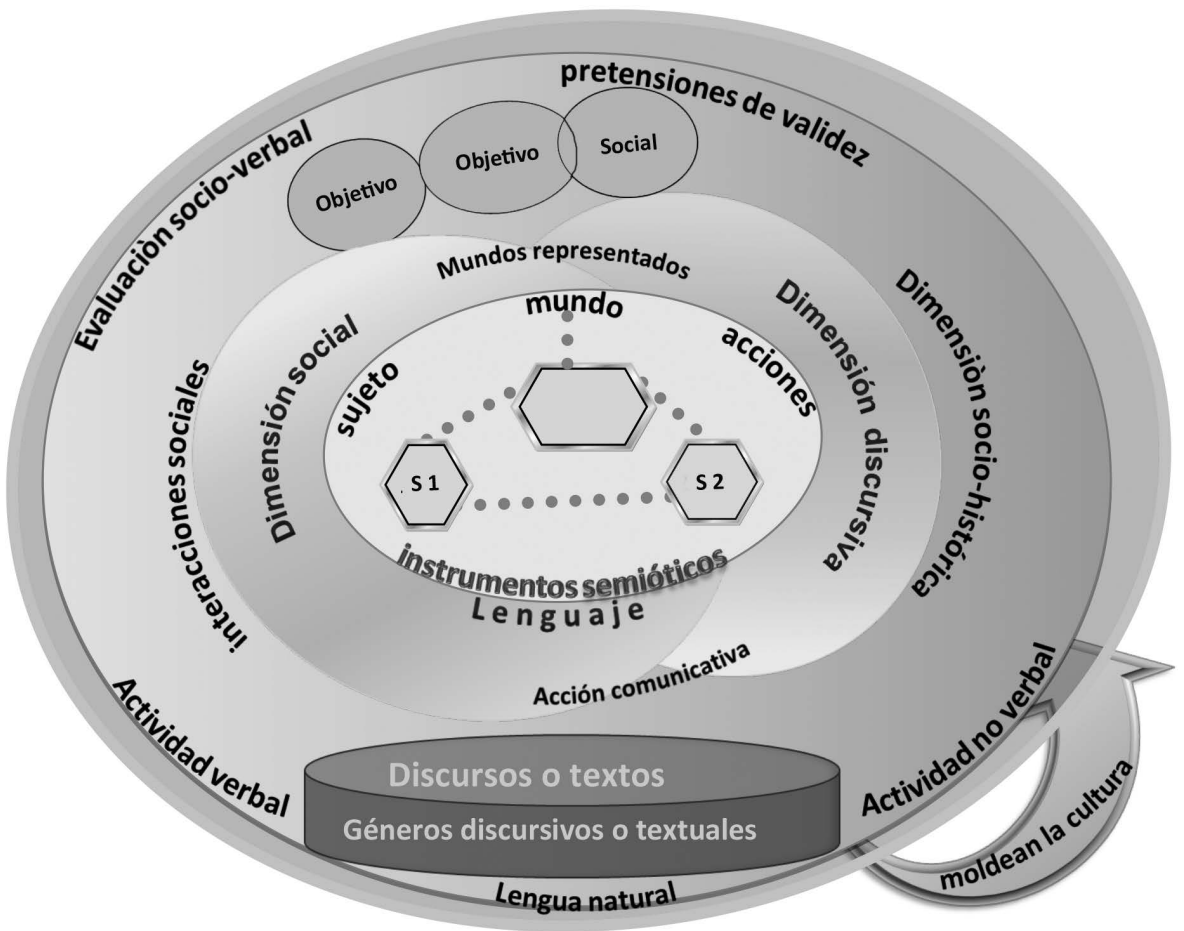

Fuente: Elaboración propia

Del anterior análisis se desprende que, a pesar de la diversidad lingüística, existe una universalidad en las prácticas verbales o textuales, y ella se puede percibir cuando los sujetos de manera consciente adoptan criterios de reflexividad sobre el funcionamiento y estructura de su lengua materna 
y sobre las implicaciones históricas, políticas e ideológicas y, en general, el efecto sociocultural presente en el uso y dominio de la lengua primera. Así, pues, la práctica de esa capacidad humana que es el lenguaje se efectúa en la interacción con una intertextualidad de naturaleza diversa, circunstancia que enriquece y complejiza las posibilidades de acción sobre este objeto de estudio.

Ahora bien, en el contexto de enseñanza de la lengua materna, la reflexión sobre la acción verbal constituye una condición inicial para llegar al estudio de la organización y funcionamiento del texto (oral o escrito), es decir, comprender los criterios de inscripción del texto en un género, la organización del contenido temático, su coherencia textual, las modalidades de distribución de las voces y del posicionamiento del enunciador... No obstante, Bronckart plantea que, en el ámbito de la enseñanza de la interpretación y/o producción de textos, la anterior propuesta teórica debería usarse solo como instrumento de análisis, ya que todo modelo teórico de la textualidad es incompleto y simplificador y, por tanto, se corre el riesgo de obviar características esenciales.

\section{CoMpeTENCIA Discursiva ORAL}

Las mediaciones formativas propuestas por el interaccionismo sociodiscursivo describen la manera como el sujeto progresa en el conocimiento de los géneros con sus propiedades lingüísticas y sociales, siempre que se inserte en redes de significaciones colectivas configuradas en modelos preexistentes y aprenda a situarse en ellos, a organizarlos y a analizarlos. De lo cual se infiere que no basta con la práctica de los géneros discursivos a través de las interacciones sociales, sino que es necesario dominar un conjunto de unidades y aspectos formales de la lengua que posibilitan el desarrollo de las propiedades de las personas (construcción de la identidad, inserción en el tiempo, dominio de los razonamientos, etc.).

Cuando el agente (re)produce un tipo de discurso, debe proceder a la planificación interna de los segmentos implicados y aprende así a poner en marcha esos procesos indisolublemente mentales y verbales que son los razonamientos: razonamientos prácticos implicados en las interacciones dialogales; razonamientos causales y cronológicos, implicados en los relatos y las narraciones; razonamientos de orden lógico y/o semiológico implicados en los discursos teóricos. En este mismo proceso, el agente 
aprende a manipular las estructuras temporales propias de los tipos y a situarse respecto a ellas. Asimismo, conoce las condiciones de distribución de las voces para ubicarse en el concierto de las diferentes posiciones sociales posibles (Bronckart, 2007, pp. 85-86).

El sociointeraccionismo -siguiendo a Bruner (1986)- propone integrar el sujeto a las redes de preconstructos colectivos elaborando «actividades conjuntas» acompañadas de «explicaciones verbales» sobre normas, valores y conocimientos constituidos en mundos formales y con relación al análisis de las características de los procesos de educación formal, mediante sus dimensiones didácticas (condiciones de transmisión de los saberes) y pedagógicas (condiciones de formación de los sujetos).

Cabe señalar que esta propiedad cronotópica de la lengua es una dimensión constitutiva de su uso, a la cual se suma en interdependencia recíproca una dimensión referencial. Toda acción verbal representada en un acto oral o escrito y situada en un espacio y un tiempo, está determinada por conocimientos prácticos y/o conceptualizados que el sujeto ha construido sobre su lengua y, particularmente, sobre los géneros y textos en uso; a este referente Bronckart lo denomina «conocimiento de la intertextualidad». Esto es, poseer un dominio de las condiciones de uso de un género textual, su pertinencia, su eficacia, es decir, su adecuación a un determinado contexto social. 


\section{LA ORALIDAD COMO OBJETO \\ DE ENSENAANZA Y APRENDIZAJE}

Que el examen de los datos sea detallado, intensivo y microscópico, con el objeto de exhibir la maravillosa complejidad que yace en ellos, detrás y más allá de ellos

(Strauss, 1989, p.10).

En este capítulo se presentan y discuten concepciones disciplinares y didácticas relativas a la oralidad. Estas fueron identificadas en trece (13) profesores que imparten la asignatura de Lengua Castellana y Literatura en instituciones de Educación Media de Bogotá, Colombia. Las concepciones se configuran tanto en el nivel del discurso como en el nivel de la acción didáctica. En el primero, mediante entrevistas, grupos de discusión y planificación de secuencias de enseñanza de la lengua oral, las cuales se sometieron al análisis de contenido. En el segundo, mediante la videoscopía de las secuencias didácticas y la autoconfrontación conjunta, técnicas de la metodología clínica de investigación en didácticas, propuesta por el equipo de investigación Semiótica-Educación-Desarrollo (SED) de la Universidad de Ginebra (Suiza), para el estudio de las dinámicas y fenómenos que ocurren en el aula. 
Dado que reconocemos la tendencia evolutiva del conocimiento y la continua trasformación de las concepciones, realizamos el proceso de análisis e interpretación de la información arrojada por las entrevistas, los grupos de discusión y la planeación de las secuencias didácticas, atendiendo al planteamiento metodológico del Proyecto IREs (Investigación y Renovación Escolar), desde la formulación de hipótesis de concepciones en distintos niveles de progresión. A continuación se explican los tres niveles de concepción, denominados Nivel inicial (N1), Nivel intermedio (N2) y Nivel deseable o de referencia (N3), los cuales actúan como hipótesis de referencia para determinar el estado de las concepciones encontradas y la forma como estas pueden continuar evolucionando durante el desarrollo profesional del docente. Especialmente, esta investigación proyecta la evolución y/o potenciación de las concepciones encontradas hacia la construcción progresiva del Conocimiento Didáctico del Contenido lingüístico-discursivo oral.

Dada la complejidad del análisis de concepciones docentes, en tanto no son exclusivamente de orden empírico sino que provienen de su formación y acción pedagógica, además de su diversidad y sus diferentes niveles de manifestación, nos proponemos caracterizarlas de acuerdo con su potencial elaboración, la cual puede ir desde un nivel de simplicidad a uno de mayor complejidad o de referencia, reconociendo así la existencia de niveles de desarrollo intermedios. Cabe señalar que esta proyección hacia el «conocimiento profesional deseable» (Porlán, 1996) no es una visión idealista sino una alternativa, representada mediante hipótesis de progresión o de referencia en cada nivel, en la perspectiva de reconocer las posibles evoluciones de las concepciones de los profesores.

Tabla 2. Constructos hipotéticos relacionados con los niveles de progresión de las concepciones sobre la enseñanza de la lengua oral

\begin{tabular}{|c|c|c|}
\hline $\begin{array}{l}\text { Niveles iniciales (N1) } \\
\text { Corresponden a la con- } \\
\text { cepción lingüística y } \\
\text { normativa de la lengua } \\
\text { oral. }\end{array}$ & $\begin{array}{l}\text { Niveles intermedios } \\
\text { (N2) } \\
\text { Corresponden a la concep- } \\
\text { ción pragmática y comuni- } \\
\text { cativa de la lengua oral. }\end{array}$ & $\begin{array}{l}\text { Niveles deseables (N3) } \\
\text { Nivel deseable correspon- } \\
\text { diente a la concepción dis- } \\
\text { cursiva de la lengua oral. }\end{array}$ \\
\hline
\end{tabular}




\begin{tabular}{|c|c|c|}
\hline $\begin{array}{l}\text { Predominan concep- } \\
\text { ciones propias de una } \\
\text { enseñanza y aprendizaje } \\
\text { academicista y transmi- } \\
\text { sionista que dan cuenta } \\
\text { de un modelo didáctico } \\
\text { tradicional (suele ser de } \\
\text { tendencia mayoritaria). }\end{array}$ & $\begin{array}{l}\text { Predominan distintas con- } \\
\text { cepciones correspondientes } \\
\text { a planteamientos o posibili- } \\
\text { dades más o menos evolucio- } \\
\text { nadas, que tienden a superar } \\
\text { el modelo tradicional de la } \\
\text { enseñanza y aprendizaje } \\
\text { (intenta superar la tendencia } \\
\text { mayoritaria). }\end{array}$ & $\begin{array}{l}\text { Predominan concepciones } \\
\text { alternativas correspon- } \\
\text { dientes a propuestas in- } \\
\text { terdisciplinares y prácticas } \\
\text { derivadas de procesos de } \\
\text { indagación preferentemente } \\
\text { colectivos. Este nivel trata } \\
\text { de superar concepciones } \\
\text { anteriores y se aproxima al } \\
\text { conocimiento lingüístico-dis- } \\
\text { cursivo oral deseable. }\end{array}$ \\
\hline $\begin{array}{l}\text { La transposición didácti- } \\
\text { ca es débil y consiste en } \\
\text { la reducción o simplifica- } \\
\text { ción del conocimiento de } \\
\text { la lengua castellana como } \\
\text { lengua materna, aten- } \\
\text { diendo exclusivamente a } \\
\text { la enseñanza de aspectos } \\
\text { formales y a una selec- } \\
\text { ción de actividades (ejer- } \\
\text { cicios) supeditadas a la } \\
\text { explicación del profesor } \\
\text { en virtud de garantizar la } \\
\text { apropiación de los conte- } \\
\text { nidos vistos. }\end{array}$ & $\begin{array}{l}\text { La transposición didáctica } \\
\text { puede caracterizarse por } \\
\text { el dominio de la estructura } \\
\text { conceptual y metodológica } \\
\text { de la disciplina, evidenciada } \\
\text { en la adaptación de materia- } \\
\text { les curriculares técnicamente } \\
\text { bien elaborados y aplicables } \\
\text { en cualquier contexto: } \\
\text { a) Capacidad del profesor } \\
\text { para formular objetivos con- } \\
\text { ceptuales, procedimentales } \\
\text { y actitudinales, articulados } \\
\text { coherentemente a una se- } \\
\text { cuencia de actividades y } \\
\text { formas de evaluación, con el } \\
\text { fin de dar cuenta de las me- } \\
\text { tas previstas. } \\
\text { La transposición didáctica } \\
\text { también puede caracterizar- } \\
\text { se por una adaptación con- } \\
\text { textual de los conocimientos } \\
\text { que provienen de diversas } \\
\text { fuentes (problemáticas vi- } \\
\text { gentes, intereses o necesida- } \\
\text { des de los estudiantes, etc.). } \\
\text { b) Capacidad del profesor } \\
\text { para coordinar las activida- } \\
\text { des y la interacción de los } \\
\text { estudiantes con el medio } \\
\text { didáctico en la perspectiva } \\
\text { de que descubran por sí mis- } \\
\text { mos el conocimiento. }\end{array}$ & $\begin{array}{l}\text { La transposición didáctica } \\
\text { es fuerte, puesto que la } \\
\text { transformación que sufre el } \\
\text { conocimiento de la lengua } \\
\text { castellana como lengua ma- } \\
\text { terna, supone una auténtica } \\
\text { y profunda reelaboración de } \\
\text { los mismos, lo cual se refleja } \\
\text { en: } \\
\text { Capacidad del profesor para } \\
\text { diseñar diferentes medios } \\
\text { didácticos, para plantear } \\
\text { situaciones didácticas aso- } \\
\text { ciadas a problemas y con- } \\
\text { tenidos articulados a una } \\
\text { secuencia de actividades } \\
\text { que, a su vez, son coheren- } \\
\text { tes con distintas formas } \\
\text { de evaluación que buscan } \\
\text { la construcción de un sa- } \\
\text { ber-hacer relacionado con el } \\
\text { uso social de la lengua oral } \\
\text { en diversos contextos y ni- } \\
\text { veles de complejidad. }\end{array}$ \\
\hline
\end{tabular}

Fuente: Elaboración propia 
El proceso de interpretación de la información arrojada por la secuencia didáctica, se realiza a la luz de los desarrollos recientes de la Teoría Antropológica de la Didáctica ${ }^{1}$ de Chevallard (1997), la Teoría de las Situaciones Didácticas de Brousseau (1990, 1991) y el Modelo de la Acción Didáctica de Mercier, et ál. (2000), Rickenmann (2007, 2009). Sus aportes liminares a la Didáctica de la Matemática, han ido construyendo y consolidando una serie de categorías que hoy constituyen conceptos de referencia ${ }^{2}$ fundamentales para comprender, desde otros campos disciplinares, los procesos relacionados con la enseñanza y aprendizaje de los saberes.

En la metodología clínica, la secuencia didáctica es la unidad de análisis, por cuanto se enmarca en una situación también didáctica, cuya articulación entre fases, actividades, objetivos y formas de evaluación, da cuenta del desarrollo de un contenido de enseñanza. En el caso de esta investigación sobre concepciones y prácticas de enseñanza de la oralidad, se analiza la lógica didáctica relacionada con las tareas que se proponen para el desarrollo de la competencia discursiva oral, la manera como se realizan y evalúan.

La observación del desarrollo de la secuencia didáctica ocurre a través de la videoscopía, un método usado para registrar las sesiones de clase mediante la videograbación, orientada a determinar micro-aspectos de la interacción verbal, no verbal y contextual de las prácticas de enseñanza. A partir de esta observación detallada se realizan «cuadros clínicos» de la secuencia didáctica. Para ello se siguen unos procedimientos específicos: a) Filmación y transcripción mediante protocolos escritos; b) Sinopsis de cada secuencia didáctica; c) Análisis de los turnos de acción de cada episodio y de las acciones del profesor; d) Análisis a priori; e) Análisis vertical y emergencia de categorías;

I Una perspectiva que establece relaciones entre los «sujetos didácticos» (profesor-estudiantes), los «sujetos culturales» (individuo singular y plural) y los objetos didácticos (saberes) propios de un contexto cultural y social particular, constituyéndose en prácticas sociales de referencia.

2 Tales como: génesis del saber, sistema didáctico, transposición didáctica, situación didáctica, contrato didáctico, medio didáctico, acción didáctica, transacciones didácticas, juego didáctico, praxeología, entre otros. Estos posibilitan la comunicación entre las disciplinas, enriquecen la asimetría de sus formas y prácticas de enseñanza, y aportan al conocimiento didáctico general y específico. 
f) Análisis transversal categorial y análisis de la interpretación. La siguiente figura, ilustra la estrategia de análisis de la información recolectada.

Figura 2. Estrategias empleadas para el análisis de la información: análisis de contenido del discurso y el análisis clínico de la acción didáctica

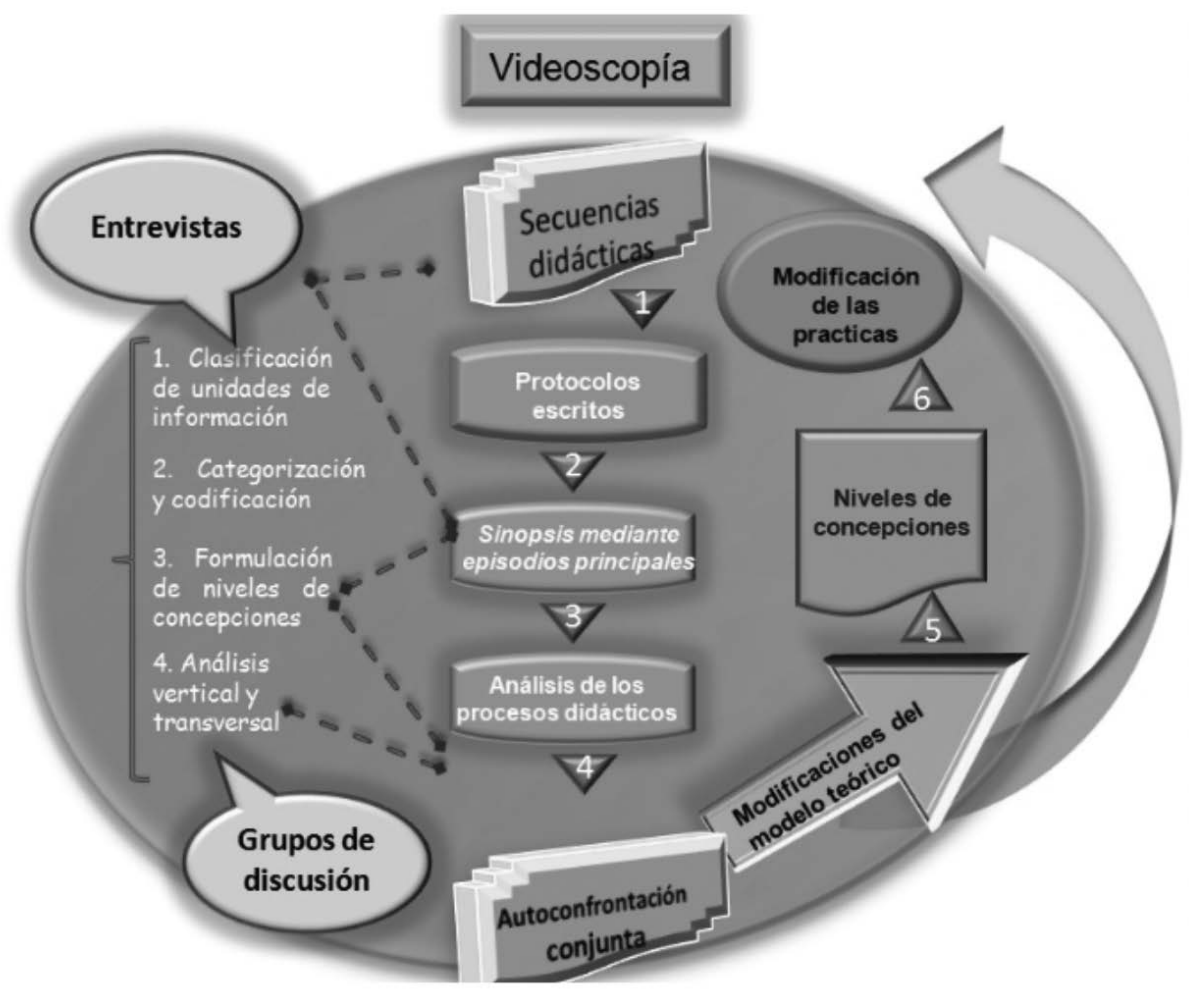

Fuente: adaptado de Rickenmann (2009)

Por consiguiente, la formulación de hipótesis de concepciones en distintos niveles de progresión y el análisis clínico de la acción didáctica fundado en la interpretación de micro-aspectos de la interacción verbal, no verbal y contextual de las prácticas de enseñanza, nos permitió interpretar la complejidad de las relaciones entre las concepciones disciplinares y didácticas presentes en el discurso y la práctica pedagógica del maestro para determinar su incidencia en una enseñanza reflexiva y sistemática de la lengua oral. 


\section{A. Concepciones y PRÁCTICAS DE DOCENTES DE ESPAÑOL Y LITERATURA SOBRE LA ORALIDAD. ASPECTOS EPISTEMOLÓGICOS}

Partimos de entender las concepciones como estructuras complejas representadas en ideas, actuaciones e interacciones con tendencia a la evolución. Las concepciones describen e interpretan la realidad, actúan como «herramientas», en algunos casos para facilitar, y en otros para obstaculizar la adopción de nuevas perspectivas o posturas críticas, o la realización de acciones transformadoras. Así, pues, las concepciones forman parte del conocimiento del profesor y actúan como filtros en sus procesos de razonamiento y toma de decisiones; por tanto, facilitan o dificultan la comprensión de ciertos fenómenos.

En esta comprensión de las concepciones subyace una perspectiva constructivista, crítica, sistémica y compleja del conocimiento (Porlán, et ál., 1997; Porlán y Rivero, 1998), que entiende la concepción más allá del individuo y la instala en la voz del grupo en forma de esquema de acción social, en el sentido planteado por Durkheim (1990), cuando representa en la voz del sujeto, la grupalidad o colectividad propia de una serie de construcciones de sentido que ponen en escena una conciencia colectiva; es decir, el consenso de un grupo frente a conceptos, significados y acciones fundados e instituidos socialmente.

Esta perspectiva cognitiva y sociocultural de las concepciones, nos permite considerar que si las concepciones de los profesores actúan como un sistema de ideas funcionales sobre las actividades de enseñanza y aprendizaje de la lengua oral, estas pueden visibilizarse y evolucionar con la ayuda de otros sujetos (colegas, formadores de profesores, investigadores) y de propuestas de formación o de actualización docente con un enfoque reflexivo en torno al proceso espiralado de transformación de la práctica-teoría-práctica.

Por lo anterior, acogemos el planteamiento del proyecto IREs en torno a la importancia de describir y analizar el contenido disciplinar y didáctico de las concepciones, en los siguientes términos: Las concepciones sobre la ciencia o 
concepciones disciplinares (Porlán, et ál., 1997) se configuran desde tres ejes que surgen de estudios de diferentes autores acerca de la imagen deformada que los profesores transmiten sobre el conocimiento y el trabajo científico. De este modo se identifican concepciones centradas en: a) el conocimiento científico de la materia (naturaleza, estatus, relación con otros conocimientos, modo de producción, cambio, etc.); b) creencias pedagógicas que incluyen un amplio repertorio de aspectos relacionados con la enseñanza y el aprendizaje en el contexto escolar; c) relaciones entre el conocimiento y su construcción, y transmisión en el contexto escolar.

En cuanto a las concepciones didácticas de los profesores, IRES distingue tres enfoques relacionados con una visión cientificista (centrada en los contenidos, el control de la clase, la participación de los estudiantes, etc.), interpretativa (centrada en el componente curricular, el ambiente de clase, la imagen del profesor, etc.) y crítica (centrada en la investigación como estrategia de transformación sobre la práctica de los profesores).

Son tres las concepciones disciplinares y didácticas de la lengua oral que identificamos en relación con aspectos epistemológicos: las concepciones sobre los significados y sentidos dados a la oralidad, las concepciones sobre las condiciones para la enseñanza de la lengua oral y las concepciones sobre los procesos de formación docente en lengua oral.

\section{SIGNIFICADOS Y SENTIDOS DADOS A LA ORALIDAD}

\section{Desde EL Discurso}

Las concepciones acerca del significado y sentido otorgado a la oralidad derivadas del discurso del profesor de español y literatura se presentan a continuación, mediante los tres niveles mencionados anteriormente junto con un ejemplo:

En el nivel inicial (N1): La oralidad es la habilidad de escuchar, transmitir mensajes y expresarse de manera verbal con corrección y con el apoyo de recursos gestuales. 
P1E: Trato de que el muchacho// por ejemplo/ $\mathrm{mm} /$ no cometa errores de/ de dicción/ no cometa errores de/ de que/ de/ de que los conectores y eso// siempre insisto/ en la temática que vamos/ que estamos viendo/ por ejemplo/ en este momento/los de décimo/ estamos viendo los conectores/ entonces/trato/ de que ellos UTILICEN/ tanto verbalmente/ como también escrito/ la temática que estamos viendo/ si/ por ejemplo/ una/ una autobiografía [carraspea]/ que ellos/ elaboren sus autobiografías/ y que las lean bien o las narren usando la expresión corporal y todos las escuchen y así aprendan de ellos mismos.

En el nivel intermedio (N2): La oralidad es la actividad de hablar y escuchar de acuerdo con los propósitos comunicativos del momento en que ocurre.

P4E: Por ejemplo/ cuando hablo/ yo muevo mucho la cabeza/ yo hago esto [mueve la cabeza]/ yo/ ¿si?/ y todo esto pues le da más significación a/ a eso/ yo entiendo que oralidad/ tiene implícita/todos estos elementos/ ¿si? del cuerpo/ o sea, uno habla con el cuerpo/y ese hablar con el cuerpo va acompañado de la palabra/ eh eso es lo que yo entiendo por oralidades el habla/ es la comunicación que se hace en un momento determinado// que se haceee/ eh/ a través deeee/ de/ de/ de la palabra/ de la palabra hablada/ es lo que yo entiendo.

En el nivel deseable (N3): La oralidad es la actividad de hablar y escuchar desde un proceso regulador y reflexivo sobre sus mecanismos de uso y efectos cognitivos, subjetivos e interactivos.

P6E: Mi relación con el otro $\rightarrow$ / se da/ como diría Maturana en ese lenguajear/ la construcción con el otro se da en ese/ en ese LENGUAJEAR es decir en ese lenguajear como verbo/ en ese en ese uso del lenguaje// entonces $\rightarrow$ / en la conversación en/ en esta medida nos posibilita/ por un lado/ las condiciones de CERCANÍA/ de conocer las condiciones de cercanía que generan/ la posibilidad del conocimiento emergente/ es decir/ que AFLORE algo que anteriormente no existía.

Por oralidad/ entiendo/ la interacción/ que establezco/ con el otro/ es precisamente la interacción COMUNICATIVAMENTE que entablo con el otro/ eeeeh/// en la cual hay una presencia// es decir/ hay esa presencia/ hay una digámoslo/ una COPRESENCIA. 
Es importante anotar que la tendencia de estas concepciones varía porque en los grupos de discusión donde participaron estos mismos docentes, las concepciones de algunos que se situaron inicialmente en el Nivel 1, parecían movilizarse con cierta facilidad al Nivel 2, caracterizado por una concepción situada en aspectos pragmáticos de la lengua oral, lo cual evidencia la influencia de los razonamientos colectivos en escenarios formales donde se privilegian unas voces sobre otras y se llega a consensos, pese a las distintas concepciones y a los tipos de pensamiento asociados a cada una de ellas.

Figura 3. Niveles de la concepción acerca del significado otorgado a la oralidad detectadas en los trece profesores de lengua castellana

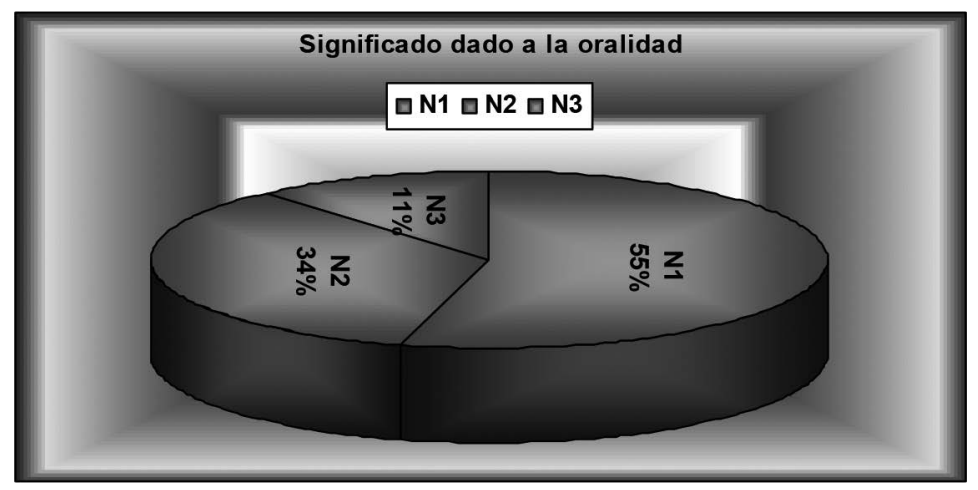

Fuente: elaboración propia

Como puede observarse, en el nivel inicial (N1) un 55\% del profesorado concibe la oralidad como la habilidad de escuchar, transmitir mensajes y expresarse de manera verbal con corrección y con el apoyo de recursos gestuales. Se enfatiza una concepción normativa y gramaticalista de la oralidad que considera el habla de los estudiantes como defectuosa, pues contiene palabras y expresiones «incorrectas» que deben eliminarse para así expresarse con claridad y propiedad. Esta concepción no contempla la adecuación al contexto en que ocurre la comunicación oral y, por tanto, tampoco la relación entre los interlocutores, sus formas de interacción y su diversidad sociocultural, características estas que determinan la pertinencia y el nivel de formalidad. 
La concepción didáctica gramaticalista de la lengua oral ha imperado en las aulas de español y literatura, buscando que los estudiantes mejoren su expresión oral mediante aspectos normativos de la lengua, es decir, la corrección de vicios de dicción, ejercicios de repetición y/o memorización de textos aislados del contexto de uso y la correcta expresión oral ajustada al canon tradicional. Aunque se realicen acertadamente ejercicios de corrección de palabras y expresiones orales, consideramos que estos no logran desarrollar ampliamente la competencia discursiva oral de los estudiantes.

En Colombia, esta concepción tradicionalista de la lengua encontró asidero en el campo educativo, fortaleciéndose con la instauración de la instrucción pública gratuita y obligatoria ${ }^{3}$, en razón a que se aspiraba que, tanto los estudiantes de las escuelas públicas como privadas, lograran una escritura y oratoria ajustadas a la norma convencional. Además, se consideraba el arte literario de la palabra como medio de expresión de belleza, dándose así un énfasis a las preceptivas literarias consecuentes con el dominio de las reglas y las convenciones de la «lengua culta» (Rey, Borja, Jaimes y Rodríguez, 2011, en prensa). De este modo, cobran sentido:

\begin{abstract}
Los ejercicios de memorización de frases, sentencias y versos clásicos sin resignificación de los contenidos representados. Igualmente se presentan modelos de habla que ejemplifican las normas, cánones y reglas, $y$, en consecuencia, el papel de la escuela se centra en hacer las correcciones de las formas de denominación empleadas por los niños, que no se adaptan al habla culta o de las expresiones que no se corresponden con el modelo del adulto (Jaimes, 2008, p. 20).
\end{abstract}

Es así como en el aula, la actividad lingüística del estudiante pasa a ser el centro de atención y debe orientarse al desarrollo de habilidades para hablar, escuchar, leer y escribir «correctamente», lo cual implica que el profesor deba generar una serie de mecanismos para lograr dicha pretensión. Así, pues, la enseñanza se ocupa de la descripción de la estructura y función de la lengua y, especialmente, de la descripción de sus niveles fonético, fonológico, morfológico y -en menor medida- sintáctico y semántico. Estas prácticas de enseñanza de la lengua materna se mantienen hasta hoy, a pesar de las diversas críticas realizadas por especialistas en cuanto a la educación lingüística,

3 En el gobierno radical de Aquileo Parra (1876-1878) se decretó en Colombia la enseñanza primaria como laica, gratuita y obligatoria, aunque con una influencia notable de la Iglesia Católica, lo que explica, en parte, el carácter conservador de la enseñanza de la lengua. 
los distintos intentos por fundar la reflexión gramatical sobre la lengua y la actividad verbal del estudiante en contextos comunicativos, y eliminar los ejercicios memorísticos estereotipados, carentes de significación.

En el nivel intermedio (N2), un 34\% de los profesores entrevistados conciben la oralidad como la actividad de hablar y escuchar de acuerdo con los propósitos comunicativos del momento en que ocurre. Se trata de una complejidad intermedia (N2) entre los niveles inicial y de referencia, centrada en una perspectiva comunicativa y pragmática de la lengua oral, ya que en algunos momentos sus intervenciones recogen elementos de orden socio-crítico. Por ello, se opta por situarlo en el nivel de concepción en el que se presentan mayores convergencias entre sus nociones y juicios de valor sobre la oralidad. Además, porque reconocen que si bien los procesos de hablar y escuchar juegan un papel fundamental en el momento en que ocurren, es necesaria la adecuación de los usos orales a las circunstancias comunicativas de los interlocutores, es decir, la producción y comprensión oral remite, por una parte, a la práctica lingüística, y por la otra, al aprendizaje específico de mecanismos y recursos lingüístico-discursivos para mejorarla.

En el nivel deseable (N3), un 11\% concibe la oralidad como la actividad de hablar y escuchar desde un proceso regulador y reflexivo sobre sus mecanismos de uso y efectos cognitivos, subjetivos e interactivos. Se trata de una concepción comunicativa y pragmática con énfasis en la interacción social que está presente en el discurso de pocos profesores, quienes fijan la mirada en aspectos socio-afectivos; cognitivos, comunicativos e interactivos, en tanto reconocen la co-construcción discursiva oral. Se trata de una concepción ligada a la idea de compartir los significados y construir elementos a partir de la conversación en favor de la comprensión global del discurso; no obstante, solo se considera la oralidad cara a cara, desconociendo aquella que a pesar de no compartirse un espacio común, sigue siendo un fenómeno oral.

En Colombia, hacia la década del ochenta, se plantean propuestas encaminadas al mejoramiento de la enseñanza del español como lengua materna, a partir de los planteamientos de Luis Ángel Baena ${ }^{4}$, orientados hacia la integración de los diversos niveles y dimensiones de la lengua (nivel semántico,

4 Sus planteamientos fueron conocidos en la Renovación Curricular, impulsada en la década del 80 a través de proyectos liderados por el Ministerio de Educación Nacional, las Secretarías de Educación y el Instituto Colombiano para la Evaluación de la Educación (ICFES). 
sintáctico, fonológico y pragmático-retórico), en función de reconocer su capacidad semántica y, en consecuencia, su potencial interactivo, cognitivo y estético.

Es así como las políticas curriculares colombianas de las dos últimas décadas (vigentes hasta hoy) para la enseñanza de la Lengua Castellana y la Literatura ${ }^{5}$, se fundan en principios de la lingüística textual que sitúan las prácticas lingüísticas en una pluralidad de esferas o dominios sociales y contextos que dan lugar a una diversidad de textos y/o discursos, cuya apropiación refleja la competencia comunicativa del sujeto. De este modo, se señala la importancia de asumir la comprensión y producción oral y escrita de los estudiantes como procesos susceptibles de cualificación. En tal sentido, se observa una preocupación por fortalecer la competencia comunicativa de los estudiantes en los diferentes niveles de escolaridad, mediante la adquisición y desarrollo de los procesos de hablar, escuchar, leer y escribir, según las diversas funciones y variedades de la lengua.

No obstante, en la realidad del aula, sigue predominando una práctica normativa de la lengua materna, en tanto se sigue privilegiando la enseñanza prescriptiva de sus aspectos formales y -en algunas situaciones- se da prioridad únicamente a la lectura y la escritura, lo cual podría explicar la escasa atención prestada a la enseñanza y aprendizaje de la lengua oral. Respecto a esta, tanto los Lineamientos Curriculares como los Estándares sobre la enseñanza de la Lengua Castellana y la Literatura, si bien tienen en cuenta la oralidad representada en las habilidades de escuchar y hablar, no profundizan sobre su naturaleza, sus modos de articulación intrínseca, sus posibilidades de complejización, progresión y complementariedad con otras actividades del lenguaje; como tampoco brindan pautas a los docentes para ampliar y transformar postulados teóricos de la lengua oral en representaciones didácticas comprensibles. Por tanto, la institucionalización de estos referentes de política curricular no garantiza por sí sola una recontextualización o apropiación de nuevas prácticas en torno al desarrollo de la competencia discursiva oral.

Sumado a ello, en la escuela colombiana subyace un escepticismo e insatisfacción y, en algunos casos, desconocimiento por parte de los educadores

5 Lineamientos Curriculares (1998) y Estándares (2003) para la enseñanza de la Lengua Castellana y la Literatura. 
sobre los documentos de política curricular y el desarrollo de competencias. Todo lo anterior conlleva a reconocer la ausencia de una fundamentación teórica sobre la naturaleza de la lengua oral, lo cual hace que la planificación e intervención didáctica se reduzca al uso del libro de texto o la elaboración de inventarios de temas relacionados con la expresión oral, la literatura oral, la descripción y discriminación de los sonidos de la lengua, las variaciones dialectales, regionales y sociales, las técnicas orales, etc.

Ahora bien, el enfoque semántico comunicativo es el que ha primado en las últimas décadas en la concepción de los currículos para la enseñanza del español como lengua materna (en cuanto propone el uso social de la lengua en contextos efectivos de comunicación con el fin de que el individuo pueda representar, construir y significar el mundo), no obstante, aún no logra con plenitud su cometido de articular la descripción de las estructuras, niveles y elementos lingüísticos con su funcionalidad en los diversos contextos de uso.

Esta concepción pragmática y comunicativa evidencia un interés por establecer un diálogo entre las teorías del lenguaje y los objetivos de la enseñanza de la lengua castellana en la escuela. En este orden de ideas se identifican diferentes focos de estudio, en los cuales, por ejemplo, se da prioridad al análisis de la actividad lingüística como parte esencial de la acción humana (filosofía analítica o pragmática filosófica); se enfoca la relación entre lengua y usuarios, estudiando los usos lingüísticos en el marco de contextos socioculturales específicos (antropología lingüística y cultural, etnografía de la comunicación, etnometodología, interaccionismo simbólico y sociolingüística); se abordan los procesos que subyacen en la adquisición, desarrollo y uso de la lengua materna (psicología del desarrollo, psicolingüística) y se analizan unidades discursivas en el contexto de la interacción social (lingüística del texto, análisis del discurso, semiótica textual) (Lomas y Osoro, 1998).

Sin dejar de reconocer los elementos semióticos, pragmáticos y comunicativos, se valora la incidencia de las teorías del discurso en las últimas décadas. Los teóricos de los géneros discursivos, basados en los aportes liminares de Bajtín (1982), tienen en cuenta cómo los sujetos construyen saberes en la interacción con otros, en contextos que demandan estrategias discursivas.

Generalmente, cuando un sujeto o un colectivo producen un texto, están en una situación de acción verbal, disponen de cierto conocimiento del 
«architexto» ${ }^{6}$ de su comunidad y de los modelos de géneros allí disponibles; sobre este referente adopta un modelo de género que considera adecuado a las particularidades de la situación. En este orden de ideas, los «tipos de texto» o «tipos de discurso» se inscriben en «géneros de texto» o «géneros de discurso» o «géneros discursivos», siguiendo la propuesta de Bajtín (1982). Son entidades que por su carácter dúctil y móvil (en razón a que cambian necesariamente con el tiempo o con la historia de las formaciones socioverbales) se resisten a clasificaciones universales. Estos no siempre logran establecer claramente sus fronteras ${ }^{7}$, por ello se presentan a los usuarios de una lengua bajo criterios complejos y relativamente estables, situación que ha llevado a generar confusiones entre género de texto, género de discurso, tipo de texto, tipo de discurso, etc. Ante esta problemática y desde el interaccionismo sociodiscursivo se proponen las siguientes decisiones teóricas y terminológicas.

El texto actúa como una unidad de producción verbal, situada, finita y autosuficiente. Este se inscribe en un conjunto o "género discursivo», que se entiende como el modo de clasificar, tanto las actividades generales como las clases de discursos; es decir, los textos se distribuyen en múltiples géneros socialmente «indexados» o pertinentes en una situación comunicativa concreta. Bronckart (2004) propone distinguirlos como «géneros de texto», en razón a que su clasificación puede ser más clara, si los criterios son los segmentos que componen el texto (segmentos de relato, argumentación, diálogo, etc.). A dichos segmentos los denomina «discursos». En sus palabras: «Esos segmentos diferentes que entran en la composición de un género son producto de un trabajo especial de semiotización o de modelación discursiva y, por ello, a partir de ahora los llamaremos discursos» (Bronckart, 2004, p. 50).

Bajo esta perspectiva, el análisis de los textos orales o escritos pasa por relaciones de interdependencia con el mundo social, por una parte, y con la intertextualidad, por la otra. Luego, por procedimientos de observación o de

6 La architextualidad, término acuñado por Genette (1986) para referirse al conjunto de categorías generales o trascendentes en las que se engloban los textos: tipos de discurso, modos de enunciación, géneros literarios.

7 Los criterios de clasificación son divergentes y parciales; por ejemplo, se proponen criterios relacionados con el tipo de actividad humana implicada (género periodístico, científico, literario, etc.); con el efecto comunicativo que se persigue (género poético, narrativo, etc.); criterios centrados en el soporte utilizado (cuento, conferencia, entrevista, etc.), o en el contenido temático (ciencia ficción, receta de cocina, etc.) (Bronckart, 2004). 
lectura de sus elementos de orden semántico, léxicosintáctico y paralingüístico. En el plano semántico, se analiza el efecto global de significación que produce el texto en el interlocutor, el cual se traduce en indicios relativos al contenido referencial, al contexto y al modo en que el autor se sitúa frente a ese contexto. En cuanto a la lectura léxico-sintáctica, esta revela la elección de opciones de lexemas disponibles en la lengua y la aprehensión de categorías y reglas gramaticales. Y el plano paralingüístico en los textos orales da cuenta de procedimientos, tales como silencios, cambios de tono, acentos prosódicos, etc.

Luego de este análisis local, es importante indagar por las segmentaciones o tipos de discurso que constituyen cada texto, desde un procedimiento que Bronckart (2004) denomina «circularidad asumida», el cual consiste en someter inicialmente el texto a un análisis cuantitativo, con el fin de objetivar la percepción intuitiva de los tipos de discurso que prevalecen. De este modo, al término del análisis, «ciertos segmentos inicialmente diferenciados pueden verse de nuevo reagrupados en una misma categoría, y otros segmentos inicialmente considerados como equivalentes pueden verse diferenciados» ( $\mathrm{p}$. 54). Si bien este planteamiento metodológico aplica para análisis exhaustivos de los textos, lo más relevante de esta propuesta radica en la complementariedad necesaria entre los elementos lingüísticos observables y la arquitectura discursiva del texto ${ }^{8}$.

\section{DeSDe La ACCión DIDÁCTICA}

La tabla que a continuación se presentan se obtiene del análisis de la videoscopía de la acción didáctica del grupo de profesores. Se plantea a los docentes planear, desarrollar y evaluar una secuencia didáctica relacionada con la oralidad, con el fin de identificar los significados y concepciones de oralidad que subyacen en la acción didáctica de cada uno. Se seleccionan unidades de información donde el profesor alude de manera explícita o implícita a la oralidad:

8 Un planteamiento potente a nivel didáctico, en tanto implica el equilibrio entre una enseñanza gramatical y textual de la lengua y, en últimas, una mirada renovada a los procesos de producción e interpretación. 
Tabla 3. Sentido otorgado por los profesores de Lengua Castellana a la oralidad como objeto de aprendizaje en la educación media.

\begin{tabular}{|c|c|}
\hline Concepciones identificadas & Tendencias \\
\hline P2: La oralidad es portadora de movimientos y gestos. & \\
\hline $\begin{array}{l}\text { P5: El debate y la conversación pertenecen al discurso dia- } \\
\text { lógico donde siempre ocurren intercambios de ideas y de } \\
\text { roles entre el emisor y el receptor. }\end{array}$ & \multirow{6}{*}{$\begin{array}{l}\text { Concepciones } \\
\text { relacionadas con } \\
\text { la planeación de } \\
\text { actividades orales }\end{array}$} \\
\hline $\begin{array}{l}\text { P13: Argumentar es hacer una reflexión de interpretación } \\
\text { personal con rigor y fundamento, que los estudiantes de- } \\
\text { ben exponer apoyados en el libro, la consulta y la guía. }\end{array}$ & \\
\hline $\begin{array}{l}\text { P7: Para el programa radial escolar y específicamente para } \\
\text { el reportaje, se necesita tener en cuenta el tipo de oyente y } \\
\text { la manera como se inicia, se desarrolla y se cierra el pro- } \\
\text { grama. }\end{array}$ & \\
\hline $\begin{array}{l}\text { P9: Para describir la emisora Radioactiva es necesario te- } \\
\text { ner en cuenta a quién pertenece y a quién se dirige, la ten- } \\
\text { dencia ideológica, política y comercial. }\end{array}$ & \\
\hline $\begin{array}{l}\text { P10: Para escuchar se requiere pensar en el tipo de comen- } \\
\text { tarios que se hacen en clase y si son capaces de quedarse } \\
\text { en silencio, escucharse y encontrar un sentido a lo que se } \\
\text { dice. }\end{array}$ & \\
\hline $\begin{array}{l}\text { P6: Es necesario que conversen bastante sobre la temática } \\
\text { de cada texto y las características del lenguaje. }\end{array}$ & \\
\hline $\begin{array}{l}\text { P8: Es necesario que observen el manejo del vocabulario y } \\
\text { para mejorarlo saber usar los sinónimos y la lectura. }\end{array}$ & \multirow{6}{*}{$\begin{array}{l}\text { Concepciones } \\
\text { relacionadas con } \\
\text { el análisis de } \\
\text { actividades orales }\end{array}$} \\
\hline $\begin{array}{l}\text { P4: Es necesario utilizar ciertas palabras y expresiones ade- } \\
\text { cuadas a determinada situación comunicativa oral. }\end{array}$ & \\
\hline $\begin{array}{l}\text { P12: Es necesario tomar conciencia y reflexionar sobre el } \\
\text { trabajo de hablar en público, ya que requiere de una pla- } \\
\text { neación que tenga en cuenta la intención, el público, el } \\
\text { tiempo y el lenguaje específico. }\end{array}$ & \\
\hline $\begin{array}{l}\text { P3: La oralidad no es simplemente hablar, es también te- } \\
\text { ner conciencia de la interacción, el espacio, los gestos, el } \\
\text { tono de voz, la intencionalidad, el contenido y la forma de } \\
\text { hablar. }\end{array}$ & \\
\hline $\begin{array}{l}\text { P11: El concepto de oralidad se profundiza poco, pensar si } \\
\text { la oralidad y la escritura son diferentes a oralidad escrita. }\end{array}$ & \\
\hline $\begin{array}{l}\text { P1: La palabra oral es el principal vehículo de interacción y } \\
\text { cultura, es el momento de hablar, hablen. }\end{array}$ & \\
\hline
\end{tabular}

Fuente: elaboración propia 
De este modo, emergen dos tendencias relacionadas con la planeación y realización de actividades orales.

a. Concepciones relacionadas con la planeación de actividades orales. $\mathrm{Al}$ inicio de una secuencia de actividades alrededor de la oralidad, el 60\% del profesorado opta por explicar previamente a su grupo de estudiantes el concepto de oralidad o determinados conceptos relacionados con los usos orales; por consiguiente, anticipan nociones relativas al objeto de aprendizaje. Este grupo de profesores concibe entonces que los aprendizajes relativos a la oralidad, parten de una explicación teórica y práctica con la cual el profesor considera que acompaña y orienta el proceso de comprensión y producción oral.

Tanto la planeación de una secuencia didáctica, como la planeación de un proceso de comprensión y producción oral, pasa por unas etapas que atribuyen sentido a la estructura y al contenido de lo que se va a exponer, argumentar, narrar o dialogar. Además su apropiación nos permite reconocer que crear o simular una situación oral formal, requiere de un proceso de lectura y escritura que una vez se tenga, es importante ensayar lo que se va a decir y la manera como se va a decir, si se quiere garantizar el éxito de las actividades orales que proponen a sus estudiantes. Sin embargo, no es frecuente encontrar profesores que orienten y acompañen la preparación de un debate, una exposición oral, una conferencia, etc.

Esta situación da lugar a una hipótesis de progresión de nivel inicial (N1): El desarrollo ocasional de las capacidades relativas a hablar y escuchar, se realiza desde un discurso declarativo centrado en la conceptualización y descripción del funcionamiento de distintas prácticas discursivas orales.

b. Concepciones relacionadas con el análisis de actividades orales. Las concepciones identificadas referidas al significado dado a la oralidad corresponden a momentos en que los estudiantes y el profesor han participado en una actividad oral y proceden a reflexionar sobre este acontecimiento. Un 20\% del profesorado analiza ciertos aspectos de la expresión oral susceptibles de ser mejorados (vocabulario y expresiones adecuadas) y otro 20\%, luego de una actividad oral, propone construir la noción de oralidad. Es importante 
destacar que se promueven reflexiones sobre las actividades orales realizadas en el aula en la perspectiva de una toma de conciencia sobre las características de situaciones orales.

De esta situación se deriva la hipótesis intermedia (N2) referida a cómo el desarrollo ocasional de las capacidades relativas a hablar y escuchar se realiza, mediante el acercamiento a una reflexión pragmalingüística, alrededor de algunas prácticas discursivas orales creadas o simuladas en el aula.

Aunque se considera ausente el nivel de referencia (N3), teniendo en cuenta el significado dado a la oralidad en el nivel anterior y su posibilidad de que se concrete en una práctica continua y sistemática, se propone una hipótesis en los siguientes términos: El desarrollo progresivo de las capacidades de hablar y escuchar, se realiza mediante la preparación y la reflexión guiadas, alrededor de distintas prácticas discursivas orales creadas y/o simuladas en el aula.

La ausencia de esta concepción en los profesores participantes denota la importancia de transformar sus concepciones previas hacia otras que impliquen procesos reflexivos sobre las prácticas discursivas cotidianas.

\section{AnÁlisis CONTRASTIVO: CORRESPONDENCIAS Y CONTINGENCIAS}

Sigue la confrontación de los resultados correspondientes a los niveles de la concepción sobre el significado y sentido dado a la oralidad en los dos planos del análisis (discurso y acción didáctica), y posteriormente se analizan y relacionan con los resultados de otras investigaciones referidas a la enseñanza de la lengua oral: 
Tabla 4. Hipótesis de progresión para el análisis de las concepciones sobre el significado otorgado a la oralidad

Concepciones detectadas sobre el significado otorgado a la oralidad

\begin{tabular}{|c|c|}
\hline Derivadas del discurso del profesor & $\begin{array}{c}\text { Derivadas de la acción didáctica } \\
\text { del profesor }\end{array}$ \\
\hline $\begin{array}{l}\text { Concepción inicial (N1) } \\
\text { (P10, P12, P1, P2, P3, P7, P9, P13) } \\
\text { La oralidad es la habilidad de escuchar, } \\
\text { transmitir mensajes y expresarse de } \\
\text { manera verbal con corrección y con el } \\
\text { apoyo de recursos gestuales. }\end{array}$ & $\begin{array}{l}\text { Concepción inicial (N1) } \\
\text { (P2, P5, P13, P7, P9, P10, P6) } \\
\text { El desarrollo ocasional de las capaci- } \\
\text { dades relativas a hablar y escuchar, se } \\
\text { realiza desde un discurso declarativo } \\
\text { centrado en la conceptualización y } \\
\text { descripción del funcionamiento de } \\
\text { distintas prácticas discursivas orales. }\end{array}$ \\
\hline $\begin{array}{l}\text { Concepción intermedia (N2) } \\
\text { (P10, P12, P4, P5, P6, P13, P11) } \\
\text { La oralidad es la actividad de hablar y } \\
\text { escuchar de acuerdo con los propósitos } \\
\text { comunicativos del momento en que } \\
\text { ocurre. }\end{array}$ & $\begin{array}{l}\text { Concepción intermedia (N2) } \\
\text { (P3, P8, P4, P11, P1, P12) } \\
\text { El desarrollo ocasional de las capaci- } \\
\text { dades relativas a hablar y escuchar, se } \\
\text { realiza mediante el acercamiento a una } \\
\text { reflexión pragmalingüística, alrededor } \\
\text { de algunas prácticas discursivas orales } \\
\text { creadas o simuladas en el aula. }\end{array}$ \\
\hline $\begin{array}{l}\text { Concepción deseable (N3) } \\
\text { (P6) } \\
\text { La oralidad es la actividad de hablar y } \\
\text { escuchar desde un proceso regulador y } \\
\text { reflexivo sobre sus mecanismos de uso } \\
\text { y efectos cognitivos, subjetivos e inte- } \\
\text { ractivos. }\end{array}$ & $\begin{array}{l}\text { Concepción deseable (N3) } \\
\text { (ninguno) } \\
\text { El desarrollo progresivo de las capaci- } \\
\text { dades de hablar y escuchar se realiza } \\
\text { mediante la reflexión pragmalingüís- } \\
\text { tica guiada alrededor de la planeación } \\
\text { y la producción de distintas prácticas } \\
\text { discursivas orales creadas y/o simula- } \\
\text { das en el aula. }\end{array}$ \\
\hline
\end{tabular}

Fuente: elaboración propia

Existe una gran variación entre las concepciones previas del profesor respecto a la oralidad y las que emergen de su acción didáctica. La simultaneidad de las concepciones derivadas del discurso, indican la coexistencia de ideas referidas a elementos descriptivos de la lengua oral (con un marcado énfasis normativo) con elementos comunicativos-funcionales y, en menor medida, se tocan aspectos socio-culturales y críticos presentes en la comunicación 
oral. Este carácter híbrido de las concepciones refleja la influencia lingüística recibida durante la formación inicial y posgradual de la población docente estudiada.

En esta subcategoría de análisis se demuestra la fluctuación permanente de las concepciones que connota su continua evolución. De ahí la importancia de identificar los niveles de gradación por los cuales transitan y desde los cuales puede obtenerse la concepción más marcada de este grupo de profesores de lengua castellana, con respecto a la lengua oral. Por ejemplo, el sentido dado a la oralidad oscila entre dos perspectivas (inicial e intermedia): aquellos que la asumen como objeto de conocimiento (para describirla y entender su funcionamiento) y aquellos que la entienden como objeto de actuación (para hacer cosas y usarla de manera consciente).

Por tanto, en el grupo de profesores algunos conciben la oralidad como una habilidad lingüística, y otros como la actividad de hablar y escuchar, y todos convergen en que en el aula se deben apropiar sus aspectos fonéticos, morfo-sintácticos, léxicos y pragmáticos; por ello, consideran la oralidad como la destreza que posee el ser humano para hablar y escuchar. Aunque luego, algunos se refieran a «oralidad y escucha», asumiendo la oralidad solo como la expresión oral. La confirmación de estas convergencias y disparidades, lejos de pretender una toma de posición a favor de una u otra perspectiva, se orienta al análisis de su concreción en la práctica pedagógica, a fin de identificar hasta dónde el estudio de los aspectos señalados es susceptible de integración y complejización.

Ahora bien, la acción didáctica también refleja dos ángulos divergentes que se suponen complementarios, la fase de la planeación y la producción de las actividades orales. Se advierte una visión fragmentada de la lengua oral, ya que las prácticas pedagógicas se orientan más al desarrollo de actividades orales y en algunos casos a reflexionar sobre ellas. Esta perspectiva es problemática, por cuanto se traduce en la ausencia de una enseñanza sistemática de los discursos orales; por ende, los propósitos comunicativos no logran interrelacionar de manera global el conjunto de elementos conceptuales, pragmáticos e interactivos, socio-culturales y estéticos de la lengua oral. Tras encontrar estos ejes en la acción didáctica de los trece profesores, así como los mencionados en el discurso, se llega a las siguientes reflexiones: 
a. La lengua oral se entiende y asume como una actividad sobre la cual es necesario explicar su noción, características y funcionamiento, así como las características propias de cada situación de uso. Esta concepción se refleja en distintos episodios de clase donde concurren diversas explicaciones y recomendaciones, en su mayoría sin gran profundidad y sin llevarse a la actividad práctica guiada. Se explica el significado e importancia de la oralidad, se describen los pasos para preparar un debate, se identifican los componentes de una situación comunicativa, se explican el valor, las características y las reglas de la escucha, se usa lo oral para reflexionar sobre aspectos de lo escrito, se lee en voz alta, etc.

b. La lengua oral se entiende y asume como una práctica discursiva, susceptible de ser manipulada y analizada. A diferencia de la concepción anterior, en esta los estudiantes participan en la simulación o creación de una situación comunicativa oral, a partir de la cual se reflexiona sobre el léxico, el uso de expresiones adecuadas e inadecuadas, algunos aspectos paralingüísticos y las opiniones sobre experiencias de expresión oral en público. Esta concepción refleja el dominio de ciertos elementos básicos de la competencia comunicativa y la toma de conciencia sobre la importancia de preparar las prácticas orales, aunque no se observa ni el acompañamiento ni la orientación para tal planificación.

Los niveles de concepción identificados en torno al significado otorgado a la oralidad evidencian una serie de incomprensiones derivadas de la complejidad de su noción. Por ejemplo, en algunos profesores se mantiene la idea sobre el supuesto «crecimiento» de la lengua oral (Vilá, 1994; Gutiérrez y Rosas, 2008b) y en consecuencia se da mayor posibilidad de hablar a los estudiantes; en otros, se crean o simulan situaciones orales con la convicción de fortalecer la competencia comunicativa mediante la omnipresencia de diversos elementos lingüísticos y paralingüísticos. Se trata de un nivel de conciencia sobre la oralidad que va más allá de concebirla como una forma de comunicarse con los demás y se encara como un modo de pensar, interactuar y comportarse en el mundo de una manera distinta, de acuerdo con los contextos de uso.

Las incomprensiones observadas con respecto al sentido de la oralidad, se relacionan con la falta de conciencia y profundidad sobre aspectos lingüísticos y discursivos, el desconocimiento de tópicos relativos a la planeación y producción de actividades orales, así como al diseño de estrategias orientadas al 
fortalecimiento de la competencia discursiva oral de los estudiantes. Algunas de estas dificultades epistemológicas pueden obedecer al desconocimiento de la materia -específicamente de la oralidad-y/o son tributarias de sus mismas concepciones sobre la enseñanza de la lengua materna.

Se coincide con Vilá (1994) en las implicaciones de estas concepciones inadecuadas sobre el desarrollo de las capacidades relativas a la lengua oral, porque quizás constituyen una de las causas fundamentales por las cuales la lengua oral está ausente en las programaciones de la lengua materna, o si aparece enunciada, no se cuenta con los recursos metodológicos necesarios para abordarla de forma sistemática.

Ahora bien, la interrelación y/o dominio de los aspectos mencionados en el discurso del maestro y su transformación a la realidad del aula depende, entre otros factores, de la construcción de un «conocimiento didáctico del contenido lingüístico-discursivo oral». Este proceso puede comportar la reflexión sobre la naturaleza de sus concepciones y la toma de conciencia sobre la necesidad de su evolución.

Por lo anterior, una condición necesaria pero no suficiente en la acción didáctica, especialmente de profesores de secundaria o de aquellos que se especializan en un campo disciplinar específico, es la apropiación de sus saberes intrínsecos; además del «qué» enseñar, también se requiere el «cómo», en virtud de hacer comprensible un tópico determinado a unos aprendices con unas características particulares. Esta verdad de Perogrullo, cifrada en la búsqueda de un equilibrio entre estos dos aspectos, se ha abordado casi siempre como una categoría separada de otras implicaciones de orden social, cultural e individual que dan sentido a la práctica pedagógica docente.

Muchos programas de formación docente ofrecen cursos de didáctica orientados a proporcionar elementos teóricos y metodológicos sobre la enseñanza de una materia específica, aunque son motivo de múltiples cuestionamientos, tales como: chasta qué punto el curso de formación del profesor en una materia específica influye en el desarrollo del conocimiento didáctico en profesores principiantes?, ¿̇un gran conocimiento de la materia proporciona por sí solo la comprensión pedagógica de la materia necesaria para la enseñanza? (Grossman, 1990), a los cuales se suma la pregunta por ¿́qué ocurre cuando al profesor no se le ha preparado para abordar la enseñanza de algún tópico particular de la materia? 
El sentido otorgado a la oralidad trae a colación las anteriores reflexiones y pone en escena la categoría de conocimiento, la cual señala un nuevo derrotero en las investigaciones, en tanto en la última década se percibe un interés progresivo por el contenido del pensamiento del profesor, reflejado en sus concepciones y, en general, en ideas y modalidades del conocimiento enmarcado en unas condiciones contextuales determinadas. En realidad se trata de condicionantes que determinan el saber del maestro, el cual también se relaciona con su identidad, su experiencia de vida, su historia profesional, su relación con los estudiantes y los actores escolares (Tardif, 2004). Es decir, existe una serie de elementos constitutivos del ejercicio profesional del docente que inciden en el sentido que este le otorga a determinados tópicos de saber.

Se trata entonces, de reconstruir y atribuirle sentido a un saber susceptible de ser potenciado y apropiado, lo que para algunos puede ser un «sinsentido», capaz de resignificarse en la medida en que se propicie una reflexión manifestada en la conciencia metalingüística y la capacidad comunicativa y crítica del sujeto. De este modo, se confiere importancia a la reflexión del maestro sobre su práctica pedagógica, la cual contribuye a construir teoría y, por ende, posibilita la transformación o confirmación de sus principios y formas de acción (Shön, 1992).

Cuando se hace referencia a la concepción docente alrededor de lo que significa la oralidad, es inevitable aludir a su carácter pedagógico. Se trata entonces de pensar la oralidad como objeto de enseñanza y, en consecuencia, elaborar un conocimiento sobre este tópico de la materia. Es aquí donde emerge el desarrollo del Conocimiento Didáctico del Contenido (CDC), una tarea que corresponde a las instituciones formadoras de maestros principiantes y en ejercicio. Los profesores pueden adquirir el CDC de una variedad de fuentes potenciales, además de los centros de formación docente, del conocimiento del currículum de un ámbito particular, del conocimiento de materiales curriculares y de las concepciones sobre la enseñanza de la materia (Grossman, 2005). También, pero con menor frecuencia, desde prácticas investigativas y reflexivas conjuntas, cuya posibilidad de concreción requiere de políticas educativas que brinden las condiciones necesarias para el desarrollo del conocimiento profesional docente. 


\section{CONDICIONES PARA LA ENSEÑANZA DE LA ORALIDAD}

\section{DESDE EL DISCURSO}

Las concepciones sobre las condiciones para la enseñanza de la lengua oral es una categoría que surgió de su recurrencia en la información proporcionada por los profesores de lengua materna que hicieron parte de esta investigación, y específicamente en las respuestas dadas en la entrevista. Enseguida se presentan algunos ejemplos y resultados del análisis.

En el nivel inicial (N1): Para enseñar lengua oral se requiere que el profesor sea modelo del bien hablar.

P3E: (...) sin embargo creo/ rotundamente que el maestro debe ser el prototipo de/ hablador/ o sea/nosotros los maestros hablamos demasiado y a veces decimos/repetimos muchas cosas/y los chicos ya lo saben/ ellos ya saben nuestras muletillas/ ya saben todos los errores.

P5E: hacer diferenciar a los chicos/ qué es proyectar la voz/ qué es regañar/ qué es llamar la atención/ el, con el tono de voz/ porque nosotros no estamos haciendo diferencia/sino todo el mundo entiende que gritó/ que regañó/ pero a veces/ tal vez es/ el no manejo de/ de/ de la voz/ y de las entonaciones/ el no manejo de la oralidad/ definitivamente.

En el nivel intermedio (N2): Para enseñar lengua oral se requiere que el profesor la incorpore en el currículum escolar y le asigne tiempos y espacios académicos.

P12E: lectura/ escritura y oralidad/ diría uno que la oralidad/ claro个/ es importante/ pero a veces/ eeeh/ o no hay un espacio $\uparrow /$ porque $\rightarrow$ los tiempos también en/ en las distribuciones académicas/ le parecen a uno cortos/ o la va uno sintiendo/ como incorporadas a los dos procesos anteriores/ entonces/ pareciera/ que/ pues/de todo un poquito/ que con todo y todo/ apunta a todo/ pero no es así/ yo sí/ sí creo queeee el trabajo/y es una cosa que estoy diciendo producto de las/ eeeh/ reflexiones que uno va haciendo/ en los procesos en los que nos hemos involucrado/ durante el año anterior/ pero creería que para la oralidad/ no hay/siendo un espacio al que también hay que gastarle/ como proceso de lenguaje/ dentro 
del desarrollo de la lengua/castellana/ eeeh/no tiene o no cuenta/ con un espacio específico $\uparrow /$ intencionado.

En el nivel deseable (N3): Para enseñar lengua oral se requiere que el profesor apropie saberes disciplinares y didácticos que le faciliten abordarla como objeto de enseñanza y aprendizaje desde situaciones reales de uso.

PE13: creo que necesitaríamooooos una/formación/frente a/ qué significa la oralidad// qué diferencia hay entre a hablar por ejemplo/ yyyy// no/ porque es que hablar/ también está relacionado con la oralidad/ no/ qué/ qué carac-/ QUÉ ES LA ORALIDAD/ qué caracteriza la oralidad/ quéeee elementos lingüísticos necesita uno/

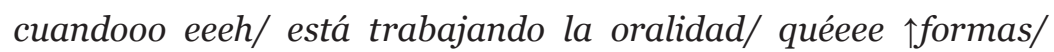
eeeeh/ ¿cómo se le llama a eso?/ expresión or-/ eeeeh/ técnicas de expresión oral/ puede uno trabajar con los estudiantes y de qué manera/ de qué manera puedeeee ayudar $a \rightarrow$ / crear/ como en ellos esa conciencia/ lingüística $\uparrow$ diría yo/ y/ o metalingüística de reflexionar sobre cómo/ cómo hablo/ cómo/ cómo hablo y qué me falta/y quéfortalezas tengo frente a eso/ o sea/como que digamos ese marco teo-/ ese marco teórico grande/ en relación con la oralidad/ con todo lo de oralidad/ ¿si? cuáles son los propósitos/lo que hablaba ahora hace un momento de-los tipos de discursos orales/ eeeh su diferencia con/ eh/ la escritura/ pienso que/ lo inici- (( ))/ importantísimo $\uparrow$ saber/ qué $\uparrow$ diferencia la oralidad de la escritura/ tanto en su teoría como en su práctica.

Por vez primera, se encuentra en la panorámica de los niveles de concepción que el nivel deseable es mayoritario, pese a que se trata de una necesidad y no de una fortaleza. Un 54\% considera que para enseñar lengua oral se requiere que el profesor apropie saberes disciplinares y didácticos que le faciliten abordarla como objeto de enseñanza y aprendizaje desde situaciones reales de uso; con respecto al nivel intermedio, un 29\% considera que se requiere incorporar la oralidad en el currículum escolar y asignarle tiempos y espacios académicos, mientras que en el nivel inicial un 17\% piensa que para enseñar lengua oral se necesita que el profesor sea modelo del bien hablar.

Nótese que en el nivel deseable planteado, subyace la necesidad de una apropiación del «conocimiento didáctico del contenido disciplinar» por parte del profesor. Esta condición incluye las expresadas en el nivel inicial e intermedio: 
Figura 4. Niveles de la concepción acerca de las condiciones para la enseñanza de la lengua oral detectadas en los trece profesores de lengua castellana

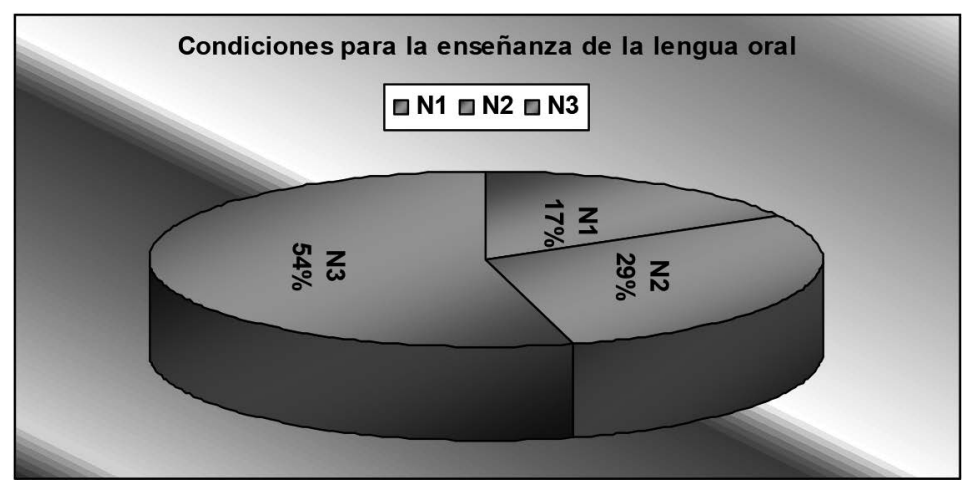

Fuente: elaboración propia

Las condiciones para la enseñanza de la oralidad, revela que los profesores no cuentan con unos saberes disciplinares y didácticos que faciliten abordar la oralidad como objeto de enseñanza y aprendizaje desde situaciones reales de uso. Esta situación puede obedecer a que Facultades de Educación y Normales Superiores, responsables de la formación inicial de docentes, también adolecen de presupuestos teóricos y metodológicos y, en consecuencia, de líneas de investigación en este campo. Por consiguiente, esta ausencia de bases teórico-prácticas para la enseñanza de la lengua oral en la educación inicial, básica, media y superior en Colombia, requiere ser tratada con hondura por los programas de formación docente en el campo del lenguaje. Teniendo en cuenta que la tercera concepción de tipo disciplinar y didáctico que sigue se relaciona también con la formación docente, profundizaremos en ella, más adelante.

\section{DeSde la ACCión DIDÁCtica}

Una de las funciones de la acción docente abordadas con frecuencia en la investigación didáctica, es la manera como se definen las condiciones o reglas de la actividad general. Esta subcategoría está directamente relacionada con las concepciones sobre la enseñanza de la lengua oral y se concreta mediante reglas y convenciones, que funcionan como si fuesen cláusulas de un contrato. 
El conjunto de estas reglas que norman la relación profesor-alumno-saber, es lo que constituye el «contrato didáctico» (concepto acuñado por Brousseau, 1990, 1991). En este estudio el análisis del contrato didáctico busca explicar su ocurrencia, no solo porque subyace en el sistema didáctico, sino porque en cada aula predominan ciertas condiciones explícitas o implícitas que varían de acuerdo con la manera como el profesor propone el desarrollo de las tareas de aprendizaje.

La siguiente tabla presenta un panorama de los presupuestos, actitudes y normas que cada docente definió de manera explícita como las condiciones y reglas del juego predominantes en las diferentes sesiones de clase que conformaron su secuencia didáctica:

Tabla 5. Condiciones o reglas generales requeridas por los profesores de Lengua Castellana, para la enseñanza de la lengua oral en la educación media.

\section{Las condiciones o reglas de la actividad didáctica}

P6: Trabajo en grupos «naturales», interacción oral con los amigos y el maestro. Debe primar el respeto por el turno de la palabra.

P13: Mínimos para lograr una interacción crítica. Organización del aula y de los grupos, y seguimiento de pautas dadas para la organización interna de cada grupo y sus formas de interacción.

P2: Trabajo en grupos de 5 personas alrededor de las temáticas del proyecto y su representación mediante situaciones orales.

P8: Organizarse en grupos y analizar el corpus transcrito e intervenir pidiendo el turno de la palabra.

P1: Organizarse en grupos para la dramatización y los que participan en calidad de público, expresar sus percepciones.

P3: La primera condición es la realización de la lectura previa; la segunda corresponde a la dinámica misma del desarrollo de la clase: escuchar y participar en la conversación con aportes y reflexiones que conduzcan a la comprensión del tema.

P4: El estudiante debe intervenir no a petición del profesor, sino cuando considere que está preparado para intervenir, entonces solicita el turno de la palabra. 
$\mathrm{P}_{5}$ : El estudiante debe tomar nota de las explicaciones dadas por el profesor, responder cuando se realicen preguntas y solicitar el turno de la palabra.

P7: Escuchar las explicaciones, responder cuando se realicen preguntas y participar en la elaboración del reportaje.

P9: Una regla previa e implícita es que no haya saboteo durante la clase. Se acepta el chiste, pero moderado. Deben portar el uniforme completo, el salón debe estar aseado y no pueden comer en clase. Es importante el tono moderado de voz y la autorregulación del grupo en torno a su organización.

P10: No emitir comentarios descalificadores e innecesarios. No realizar trabajos o actividades diferentes a las propuestas para la clase. Manifestar una actitud corporal de acogida. Participar activamente en la propuesta.

P11: La organización del grupo en el espacio. El maestro en el lugar habitual y los estudiantes en bloque mirando al tablero. Se mantiene el protocolo de turnos de habla, donde el maestro es el moderador de la discusión.

P12: Organización del grupo en el espacio de la clase (ubicación en forma de letra $u$, donde en la parte abierta se ubica el tablero y se desplaza el docente). Se mantiene el protocolo de turnos de habla, donde el maestro es el moderador de la discusión, por lo tanto los silencios y las intervenciones son mediados por él mismo.

\section{Fuente: elaboración propia}

Al observar las interacciones entre los principales agentes del sistema didáctico, se advierte que las condiciones o reglas de la actividad enfatizan en tres aspectos:

a. Adecuación del espacio del aula y aplicación de normas de «buen» comportamiento.

b. Uso de reglas para la interacción oral.

c. Trabajo colaborativo y en equipo.

A partir del análisis de estas condiciones se detecta una concepción de orden inicial (N1) que a pesar de ser minoritaria, también subyace en los demás niveles: los intercambios comunicativos entre maestro y estudiantes ocurren con mediaciones en favor del predominio de la voz del docente.

Se trata de situaciones didácticas donde el profesor se arroga el uso de la palabra, y cuando la cede a los estudiantes, estos realizan intervenciones cortas y poco contextualizadas, lo cual genera cierta rigidez en la interacción oral 
y, en consecuencia, se dificulta la progresión de intercambios orales, lo cual también obstaculiza la construcción y transformación del objeto enseñado.

No ocurre lo mismo en el desarrollo de otras secuencias didácticas en las cuales prevalecen formas menos rígidas y más horizontales en la relación entre profesores y estudiantes, debido al cambio de responsabilidades entre los participantes. Se trata de un nivel de concepción mayoritario, de carácter intermedio (N2), donde las condiciones para la enseñanza de la lengua oral en el aula enfatizan en que los intercambios comunicativos entre maestro y estudiantes ocurren con mediaciones a favor del trabajo en equipo y la interacción oral.

En la Secuencia Didáctica del profesor nueve (SD-P9), este inicia la segunda sesión de clase con la contextualización de la tarea consistente en realizar el análisis de un programa de radio, con el fin de construir una propuesta para el lanzamiento de la emisora escolar y la solicitud a un estudiante de leer los propósitos a alcanzar durante esta sesión y las siguientes. Entre otros, lograr una lectura analítica y crítica de un programa radial con el ánimo de identificar las características, funciones e intenciones de los discursos que circulan a través de los medios de comunicación masiva; y reflexionar en forma crítica acerca de los actos comunicativos, los componentes del proceso de comunicación, los agentes, los discursos, los contextos y el funcionamiento de la lengua, en tanto sistemas semióticos, y sus reglas de uso, entre otros.

Seguidamente, solicita la lectura de dos definiciones de radio consignadas en un material que tenían los estudiantes, para luego instarles a identificar la diferencia entre ellas. Hasta aquí, el docente acude a la memoria didáctica como recurso para lograr que los estudiantes compararen el proceso de aprendizaje precedente -llevado a cabo con otros medios de comunicacióncon el de ese momento, relacionado con la radio. A juzgar por las respuestas dadas, los estudiantes logran una asociación al parecer convincente, con lo cual el docente procede a indicar que su intención ha consistido en ver cómo

la RADIO no se puede entender como la distribución de señales de audio/ que TRANSMITEN programas de acción y entretención/ a una audiencia/ que eso es una definición/ no es una simple TECNOLOGÍA/ que es lo que he tratado de rescatar en esa primera definición/ chicos/ sino una agrupación de PRÁCTICAS sociales/ culturales/ COMERCIALES/ institucionales/ e industriales (...). 
Desde luego, estas condiciones para la enseñanza de la lengua oral en el aula constituyen un indicio de una concepción deseable (N3): los intercambios comunicativos entre los participantes ocurren con mediaciones en favor de un equilibrio entre el uso de la lengua oral y la reflexión metalingüística como forma de potenciar la competencia discursiva oral. Los estudiantes y el profesor conciben la tarea de aprendizaje como una actividad conjunta; por tanto, el contrato didáctico se caracteriza por ser más simétrico e igualitario.

\section{ANÁlisis CONTRASTIVO: CORRESPONDENCIAS Y CONTINGENCIAS}

La tabla que se presenta a continuación revela la confrontación de los resultados correspondientes a los niveles de la concepción sobre las condiciones requeridas para la enseñanza de la lengua oral en los dos planos del análisis (discurso y acción didáctica). Posteriormente, se analizan y relacionan con los resultados de otras investigaciones referidas a la enseñanza de la lengua oral:

Tabla 6. Hipótesis de progresión para el análisis de las condiciones requeridas para la enseñanza de la lengua oral

Concepciones detectadas acerca de las condiciones requeridas para la enseñanza de la lengua oral

\section{Derivadas del discurso del profesor}

\section{Concepción inicial (N1)}

( $\left.\mathrm{P}_{3}, \mathrm{P}_{5}\right)$

Para la enseñanza de la lengua oral se requiere que el profesor sea modelo del bien hablar.

\section{Concepción intermedia (N2)}

(P11, P12, P7, P9, P13)

Para la enseñanza de la lengua oral se requiere que el profesor la incorpore en el currículum escolar y le asigne tiempos y espacios académicos.
Derivadas de la acción didáctica del profesor

Concepción inicial (N1)

( $\left.\mathrm{P}_{5}, \mathrm{P}_{10}\right)$

Las condiciones para la enseñanza de la lengua oral en el aula, giran en torno a los intercambios comunicativos entre maestro y estudiantes con mediaciones a favor del predominio de la voz del docente.

\section{Concepción intermedia (N2)}

(P1, P2, P3, P4, P7, P8, P9, P11, P12, $\mathrm{P} 13)$

Las condiciones para la enseñanza de la lengua oral en el aula, giran en torno a los intercambios comunicativos entre maestro y estudiantes con mediaciones a favor del trabajo en equipo y la interacción oral. 
Concepción deseable (N3)

(P10, P12, P4, P5, P6, P13 )

Para la enseñanza de la lengua oral se requiere que el profesor apropie saberes disciplinares y didácticos que le faciliten abordarla como objeto de enseñanza y aprendizaje desde situaciones reales de uso.

\section{Concepción deseable (N3)}

( $\left.\mathrm{P}_{2}, \mathrm{P}_{3}, \mathrm{P}_{4}, \mathrm{P} 8, \mathrm{P} 9, \mathrm{P} 11, \mathrm{P}_{12}, \mathrm{P}_{13}\right)$

Las condiciones para la enseñanza de la lengua oral en el aula, giran en torno a intercambios comunicativos entre los participantes con mediaciones en favor de un equilibrio entre el uso de la lengua oral y la reflexión metalingüística como forma de potenciar la competencia discursiva oral.

Fuente: elaboración propia

Pese a las condiciones para la enseñanza de la lengua oral que emergen del discurso del grupo de maestros, se observa que en el aula estas se subrogan a los acuerdos explícitos o implícitos establecidos entre el educador y sus educandos. Esto revela la importancia de atender a los modos de gestión de la clase y su contribución a develar las concepciones disciplinares y didácticas del profesor.

En primer lugar, se advierte el predominio de ciertas condiciones de carácter normativo, a las cuales los profesores atribuyen una importancia capital. El manejo de los tiempos, espacios, contenidos, objetivos y discursos, sigue siendo regulado por el profesor, ya sea de manera explícita o implícita. En este contexto, algunos docentes buscan activar la función metadiscursiva mediante el análisis de discursos orales (programas radiales o televisivos, por ejemplo), lo cual supone un reconocimiento a la reflexión sobre el uso de la lengua oral.

Frente a este tipo de reflexión metadiscursiva, Vilá (2005) sugiere equilibrarla con la creación de situaciones de uso de la lengua oral, esto es, considerar que se aprende a hablar, sobre todo, si se enseña a planificar los discursos orales, más aún, si son situaciones monologadas como en el caso de una exposición oral, un programa de radio, etc. En efecto, consideramos que orientar la planeación de un discurso oral monologado es una tarea compleja que exige del docente no solo un acompañamiento durante el proceso, sino una intervención que se traduzca en lograr que el estudiante incorpore en su discurso académico una forma particular de habla en la que subyacen con- 
ceptos y planteamientos, cuya apertura, desarrollo y cierre refleje un dominio en torno al objeto cultural de referencia.

Ahora bien, las situaciones dialogadas de uso formal (entrevista, debate, etc.), también requieren de un acompañamiento en su planeación, producción y evaluación, por cuanto pueden propiciarse situaciones de interacción verbal donde los estudiantes motu proprio, logren asumir posturas explícitas. Además, puede ser oportuna la implementación de estrategias que garanticen el sostenimiento de la discusión hacia un grado de formalidad propio del contexto académico o social particular.

Un primer principio didáctico observado en el desarrollo de la mayoría de secuencias didácticas analizadas tiene que ver con el principio de la creación deliberada de situaciones de comunicación oral, el cual se fortalece en un clima de confianza que favorece un ambiente apropiado para la interacción oral. Es aquí donde se reconoce con mayor fuerza la importancia del contrato didáctico en los procesos de enseñanza y aprendizaje de la lengua oral y, en consecuencia, en el éxito de la situación didáctica. Estudiar las formas de interacción entre profesor y estudiantes en relación con un saber, ayuda a determinar los efectos de una relación contractual en un aula tradicional y en un aula con características innovadoras, como en el caso de la SDP-5 y la SD-P6. En SDP-5, ante los constantes llamados de atención del docente y el predominio de su discurso, emerge cierta resistencia, y en la segunda, ante el planteamiento sugerente del docente, surge en los estudiantes la tendencia hacia la deliberación y negociación. Sin duda, estas situaciones obedecen a la manera como los participantes acuerdan las interacciones con el medio didáctico.

En este sentido, Núñez (200o) establece distinciones entre dos formatos de interacción en los procesos de enseñanza y aprendizaje: la clase magistral y la discusión en el aula. La primera, caracterizada por una comunicación unidireccional en la que el profesor ocupa el mayor tiempo en el uso de la palabra y la otorga a los estudiantes para que respondan a sus preguntas frente al tema en curso, con el fin de corroborar su comprensión y actitud atenta. La segunda, ajustada a una planificación previa que contempla, entre otras condiciones, una intencionalidad comunicativa, estrategias de discusión, roles de los participantes y metas susceptibles de valoración. 
Si bien no se trata de determinar el valor pedagógico de uno u otro formato discursivo, es necesario analizar cómo cada uno, garantiza o no, la construcción de unas condiciones favorables para el desarrollo de la competencia discursiva oral de los estudiantes. En este sentido es importante analizar que la mayoría de secuencias didácticas comportan características de una clase magistral que incorpora situaciones de discusión grupal. Esta situación se traduce en la combinación de tiempos didácticos destinados, por una parte, a explicar, aclarar, profundizar y/o definir los contenidos de aprendizaje y las reglas del juego, y por la otra, a crear situaciones que promuevan entre los participantes posturas de disenso, consenso y actitud propositiva.

Para garantizar el funcionamiento de la actividad dialógica en el aula, y en consecuencia la progresiva cualificación del desempeño lingüístico de los jóvenes, se requiere del diseño y apropiación de una serie de condiciones y estrategias didácticas como prerrequisito para el desarrollo del discurso oral. En este sentido, Dolz, Pasquier y Bronckart (1993), apoyados en los presupuestos bajtinianos, abogan por tener presente las condiciones e intencionalidades discursivas. Esto es, tomar conciencia de la dimensión interactiva del discurso oral y, específicamente, de los distintos géneros discursivos y las condiciones de producción que cada uno asume.

Estas concepciones sobre las condiciones de enseñanza de la lengua oral, ponen nuevamente en escena la discusión sobre la monopolización de la palabra en el aula, las estrategias didácticas para la consecución de propósitos específicos, la secuencia de actividades propuestas y sus formas de evaluación, esta vez, en función de asumir la oralidad como objeto de enseñanza.

Un segundo principio didáctico derivado de las secuencias didácticas analizadas tiene que ver con el principio de la creación deliberada de un contrato didáctico para el desarrollo de la competencia discursiva oral. La importancia que reviste el contrato didáctico en la enseñanza de la lengua oral insinúa cambios en la noción de esta categoría propuesta por Brousseau (1990, 1991), en razón a que el desarrollo de la competencia comunicativa oral requiere, en lo posible, que se acuerde un contrato (y no que se establezca). Un contrato didáctico que dé lugar a situaciones didácticas, donde los estudiantes sean los protagonistas y gestores de la interacción oral, lo cual es potencialmente 
favorable pero, indudablemente, requiere de la mediación de condiciones y reglas. Además, plantea un cambio en la noción de interacción, puesto que no se trata solamente de intercambiar ideas, sino de provocar intercambios negociables respecto al conocimiento que está en juego. Además, busca que los intercambios verbales en sí mismos, sean potentes y conlleven a la apropiación de un conocimiento determinado.

En este escenario donde los roles se representan de manera distinta a la habitual, subyace el concepto vygotskiano del andamiaje mutuo, un fenómeno bastante frecuente en situaciones de aprendizaje colaborativo donde la interacción de dos sujetos, uno con mayor experticia que el otro, favorece la construcción de nuevos conocimientos. En la interacción oral, la intervención periódica de un tercer sujeto cuando se requiera (en este caso, el profesor), es decisiva en la legitimación o institucionalización de dichos conocimientos.

Estos modos de interacción oral efectiva, atenúan las relaciones asimétricas del aula y otorgan al estudiante la potestad para activar procesos y estrategias discursivas que no solo le faciliten la construcción de sentidos, sino que también constituyan herramientas para el reconocimiento de sí y del otro, y la reflexión sobre sus interacciones orales. Se trata de un juego didáctico donde se producen estrategias ganadoras para los participantes, bien sea cuando asumen el rol de estudiantes o de profesores; es decir, gana quien puede hacer uso de la palabra y comprender la del interlocutor, y gana también quien orienta, propone, desestabiliza, aporta y actúa como mediador. Así, el juego de hablar y escuchar constituye un juego de saber en sí mismo.

Todo lo anterior implica prever un tiempo didáctico adecuado, ya que se trata de avanzar en el proceso de preparación y producción oral, el cual requiere no solo de materiales específicos, sino también de posibles ajustes en la distribución de tiempos y espacios necesarios para favorecer una enseñanza explícita, sistemática y evaluable de los usos orales. Es esta una condición pedagógica que tiene ocurrencia en el discurso de algunos profesores, quienes abogan porque la oralidad realmente tenga una presencia significativa en los currículos escolares y cuente con las condiciones necesarias para enseñar y aprender a comprender y producir textos orales. 


\section{PROCESOS DE FORMACIÓN DOCENTE EN ORALIDAD}

\section{DeSDE EL DISCURSO}

Las concepciones alrededor de los procesos de formación docente en lengua oral es una categoría previamente establecida y analizada en la información proporcionada por los profesores de lengua materna, mediante las entrevistas y los grupos de discusión. Frente la formación recibida por los profesores en relación con la oralidad, se encontró que:

En el nivel inicial (N1): los procesos de formación docente en lengua oral no son recordados $y / o$ tenidos en cuenta.

P12E: ninguno, Yolima/ ninguno/ ninguno/ pese a que yo tuve un pensum/ de formación// donde había mmm/ dijéramos/ los distintos espacios tradicionales de campos de la lengua/ la fonética/la fonología/ la morfología/ la sintaxis/ la/ mmm/ de lo que menos tuvimos/ o de lo que menos hubo/ en ese espacio de formación/ académico de pregrado/ estoy hablando del pregrado/ eh/fueron espacios/ en función/ de cómo/ vehiculizar todos esos dominios de conocimiento/ ya en el aula/ o sea/ nosotros no recibimos trabajos en didáctica/ del lenguaje/ nosotras no recibimos/seminarios de apoyo alll/ al maestro/ además del lo-/ del año de práctica/ que eso es allá una cosa/ o era/ en ese momento una cosa artificiosa/muy/muy mal planeada/ no hubo una orientación/ dedicada de manera ESPECÍFICA/ al campo didáctico/ en ninguno de las realizaciones de lengua/ solo formación/ en lo disciplinario.

En el nivel intermedio (N2): los procesos de formación docente en lengua oral son de carácter sociocultural, lingüístico, sociolingüístico, comunicativo y/o pragmático.

PE13: cuando uno veía sociolingüística/ y de alguna manera también cuando uno veía pragmalingüística/ ento(n)ces que hablaba de los usos del $\uparrow$ lenguaje $\downarrow /$ lo ilocutivo/lo perlocutivo/ pero eso ya era algo/ TEÓRICO QUE/HASTA AHORA/ o esto/ durante la maestría-/ durante la especialización es que entendí/ todo eso que yo veía en la universidad/lo ilocutivo $\uparrow$ lo perlocutivo $\uparrow /$ tatata $\uparrow / /$ cómo/ eeeh/ q-/ cómo aterrizarlo a la/ a la vida escolar/ o a mi trabajo con los estudiantes/ pues/ creo que quien-/ eeeh/ 
la formación que me aportó a mi/ en relación con/ con la oralidad/ fue laaa/la especialización $\downarrow$.

Aunque ningún profesor de los trece entrevistados consideró que fue formado ampliamente con bases teóricas y didácticas sobre la oralidad, recogimos de las necesidades expresadas la siguiente concepción para el nivel deseable (N3): los procesos de formación docente en lengua oral son de carácter sociocultural, lingüístico, sociolingüístico, comunicativo $y / o$ pragmático y es necesaria su interrelación y transformación a la práctica del aula.

El panorama anterior se ilustra en la siguiente gráfica. El nivel mayoritario es el inicial (N1) con respecto al intermedio (N2) y deseable (N3), respectivamente:

Figura 5. Niveles de la concepción acerca de los procesos de formación docente en lengua oral detectados en los trece profesores de lengua castellana

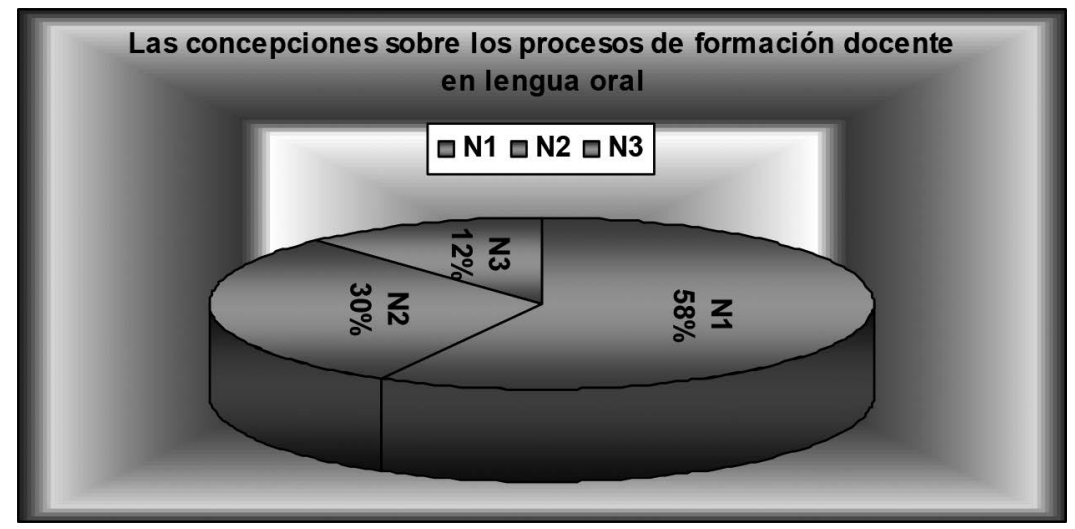

Fuente: elaboración propia

Es importante anotar que la tendencia de estas concepciones no varió cuando se contrastó con los grupos de discusión donde participaron estos mismos docentes, lo cual evidencia cierta inmovilidad en la concepción de formación docente en torno a la oralidad. Un 58\% considera que no fue formado a nivel disciplinar y didáctico en el campo de la oralidad, siendo fundamental desarrollar la oralidad en cualquier nivel educativo; un 30\% considera 
que algunas materias o seminarios del pregrado y el posgrado aportaron saberes socioculturales, lingüísticos, sociolingüísticos, comunicativos y/o pragmáticos, no obstante no recuerdan orientaciones de tipo pedagógico, y un $12 \%$ manifiesta que mediante un proceso de autoformación ha logrado comprender aspectos teóricos y didácticos de la oralidad.

En otras palabras, durante la formación docente han construido algunos fundamentos sobre la oralidad, pero no su forma de enseñarlos. En tal sentido, las investigaciones de Zeichner y Gore (1990) dan cuenta de cómo los conocimientos y actitudes que los programas de formación docente ofrecen a los estudiantes tienen escasas probabilidades de ser incorporadas en el repertorio cognitivo del futuro profesor.

Esta situación coincide con lo descrito por Marcelo (1993) en relación con que los profesores conocen los fundamentos pedagógicos, didácticos y psicológicos desde un nivel genérico; es decir, sin especialización disciplinar. Se trata de unos saberes profesionales, cuya transposición es decisiva cuando se enfrentan al desarrollo de un contenido de aprendizaje y su comprensión, tanto de su estructura sustantiva o declarativa (conceptos derivados de ámbitos de saber socioculturales, lingüísticos, sociolingüísticos, comunicativos, pragmáticos, entre otros.), como sintáctica o procedimental (enfoque comunicativo-funcional, análisis del discurso, etc.), junto con el conocimiento del contexto (cuál es su audiencia, cuáles son las características de los educandos). Se trata de los conocimientos transmitidos en el ámbito de la formación universitaria, que requieren de una selección, transformación y adaptación al aula para ser comprendidos por los estudiantes (Tardif, 2004).

Esta necesidad de articular el conocimiento disciplinar de la oralidad con el didáctico, es el que en esta investigación planteamos como el desarrollo de un «conocimiento didáctico del contenido lingüístico-discursivo oral», que está presente así sea de forma intuitiva, pues si bien la mayoría de profesores no había reflexionado sobre la oralidad como objeto de enseñanza y aprendizaje, al solicitarle planear, desarrollar y evaluar secuencias de enseñanza, logran plantear situaciones interesantes, aunque se perciben dificultades en el proceso sistemático y progresivo del conocimiento didáctico del contenido en oralidad, lo cual genera activismo en el aula. 
Ahora bien, nótese que prevalece la concepción de una escasa formación docente en pedagogía de la oralidad. Cuando una concepción predomina, significa que hay una «conciencia colectiva» que en este caso supera una «concepción ingenua» e implica la comprensión del fenómeno y su constatación en la interacción con otros. Se trata entonces de una toma de conciencia, cuya consecuencia es la disposición a cambiar una realidad o a transformarla; esto quiere decir que la preponderancia de ciertas concepciones en el ámbito educativo puede garantizar cambios progresivos.

\section{DESDE LA ACCIÓN DIDÁCTICA}

El análisis de la formación docente en oralidad, se realiza mediante la secuencia didáctica propuesta por cada docente. Allí encontramos el desarrollo de algún aspecto relacionado con la oralidad. Los profesores reconocen que para ello tuvieron que acudir a fuentes teóricas, a manuales o textos de español y literatura, debido a que la oralidad no es un proceso que aborden cotidianamente en sus clases.

Tabla 7. Los alcances de la secuencia didáctica sobre oralidad desarrollada por los profesores de Lengua Castellana en la Educación Media.

El aporte potente de la propuesta

P1: La experiencia de dramatizar una escena de una obra clásica.

P2: El reconocimiento de los distintos usos de la oralidad en diferentes contextos.

P3: La reflexión sobre el papel de la oralidad en la vida académica.

$\mathrm{P}_{4}$ : El reconocimiento de distintos argumentos que ayuda a sustentar puntos de vista.

$\mathrm{P}_{5}$ : El reconocimiento por parte de los estudiantes de las características y la importancia del debate.

P6: La conversación entre estudiantes alrededor del contenido de dos textos poéticos.

P7: Las características y finalidades del reportaje en la emisora escolar. 
P8: La identificación de elementos comunicativos orales en el foro.

P9: La identificación de interlocutores, intenciones y propósitos en un programa radial.

P10: La participación de los estudiantes en las actividades sobre la escucha.

P11: La importancia de la comunicación oral en la vida cotidiana y escolar.

P12: La reflexión sobre el papel del discurso oral en la vida social y escolar.

P13: El reconocimiento de la argumentación oral como una estrategia colaborativa, documentada e interactiva.

\section{Fuente: elaboración propia}

En la tabla anterior se puede observar cómo tres de los trece profesores (P13, P9 y P10) se refieren a la importancia de transferir a la práctica del aula sus conocimientos, y coinciden en que la planeación de su secuencia didáctica sobre oralidad demanda la apropiación y adaptación de conceptos como el de argumentación oral (para el caso de P13), elementos de la situación comunicativa (P9) y la noción de escuchar (P10). Esta afinidad declarativa es congruente con el nivel de acción. No obstante, la transferencia ocurre en la comprensión de los conceptos específicos señalados y su identificación en la actividad realizada, pero no es visible cuando se relaciona con otros conceptos. Por lo que es difícil establecer si en el aula circula un sistema de ideas (Porlán y Rivero, 1998).

Un $45 \%$ de los docentes centran su mirada en aspectos formales de la lengua, como el orden de los enunciados, la pronunciación, la velocidad, el volumen o la entonación. También promueven la puesta en escena de aspectos proxémicos y kinésicos. Cabe señalar que la gran mayoría de este grupo, da mayor importancia al dominio del tema y/o contenido de aprendizaje que ha sido objeto de la interacción verbal. Por tanto, se da cuenta de una visión instrumental de la lengua oral, la cual ubicamos en el nivel inicial (N1) en los siguientes términos: el conocimiento lingüístico-discursivo oral del profesor de lengua castellana se caracteriza porque aborda la oralidad como un instrumento para vehiculizar otros saberes $u$ otras actividades discursivas como la lectura y la escritura. 
El otro 55\% de la población docente, en el desarrollo de sus secuencias didácticas, prestan mayor atención a la construcción de sentido en el contexto en el que se desarrolla la comunicación oral; tienen en cuenta la adecuación de los distintos registros al contexto, el propósito comunicativo y la actitud del interlocutor. Por ello, se ubican en un nivel intermedio (N2) expresado así: el conocimiento lingüístico-discursivo oral del profesor de lengua castellana se caracteriza porque en el aula, alude a aspectos de la lengua oral de naturaleza comunicativa, pragmática, ideológica, estética y/o interactiva.

Desde una perspectiva constructivista y evolutiva del desarrollo profesional, planteamos la concepción de nivel deseable (N3), que en este caso no se refleja en ninguno de los profesores pertenecientes a la población estudiada, no obstante se formula atendiendo a su posible evolución. El conocimiento lingüístico-discursivo oral del profesor de lengua castellana se caracteriza porque alude e integra o traspone al aula saberes de naturaleza comunicativa, pragmática, ideológica, estética e interactiva.

\section{ANÁlISIS CONTRASTIVO: CORRESPONDENCIAS Y CONTINGENCIAS}

Las intersecciones que se dan entre los niveles de la concepción disciplinar y didáctica de la oralidad, derivadas del discurso del profesor de lengua castellana, son de co-ocurrencia alta, mientras que en su acción didáctica se percibe un relativo sostenimiento.

Tabla 8. Hipótesis de progresión para el análisis de las concepciones acerca de los procesos de formación docente en lengua oral

\begin{tabular}{|l|l|}
\hline \multicolumn{2}{|c|}{$\begin{array}{c}\text { Concepciones detectadas acerca de los procesos de formación docente en } \\
\text { lengua oral }\end{array}$} \\
\hline $\begin{array}{l}\text { Derivadas del discurso del profesor } \\
\begin{array}{l}\text { Concepción inicial (N1) } \\
\text { (P10, P11, P12, P2, P3, P4, P5, P6, P7, P8, }\end{array}\end{array}$ & $\begin{array}{l}\text { Derivadas de la acción didáctica } \\
\text { del profesor }\end{array}$ \\
$\begin{array}{l}\text { P9, P13) } \\
\text { (P1, P4, P5, P6, P7, P8, }\end{array}$ \\
$\begin{array}{l}\text { Los procesos de formación docente en } \\
\text { lengua oral no son recordados y/o teni- } \\
\text { dos en cuenta. }\end{array}$ & $\begin{array}{l}\text { El conocimiento lingüístico-discursivo } \\
\text { oral del profesor de lengua castellana } \\
\text { se caracteriza porque aborda la oralidad } \\
\text { como un instrumento para vehiculizar } \\
\text { otros saberes u otras actividades discur- } \\
\text { sivas como la lectura y la escritura. }\end{array}$ \\
\hline
\end{tabular}




\begin{tabular}{|c|c|}
\hline $\begin{array}{l}\text { Concepción intermedia (N2) } \\
\left(\mathrm{P}_{10}, \mathrm{P}_{1}, \mathrm{P}_{2}, \mathrm{P}_{3}, \mathrm{P}_{4}, \mathrm{P}_{5}, \mathrm{P}_{6}, \mathrm{P}_{7}, \mathrm{P}_{13}\right)\end{array}$ & $\begin{array}{l}\text { Concepción intermedia (N2)La } \\
\left(\mathrm{P}_{2}, \mathrm{P}_{3}, \mathrm{P}_{9}, \mathrm{P}_{10}, \mathrm{P}_{11}, \mathrm{P}_{12}, \mathrm{P}_{13}\right)\end{array}$ \\
\hline $\begin{array}{l}\text { Los procesos de formación docente en } \\
\text { lengua oral son de carácter sociocultural, } \\
\text { lingüístico, sociolingüístico, comunicati- } \\
\text { vo y/o pragmático. }\end{array}$ & $\begin{array}{l}\text { El conocimiento lingüístico-discursivo } \\
\text { oral del profesor de lengua castellana } \\
\text { se caracteriza porque en el aula alude a } \\
\text { aspectos de la lengua oral de naturaleza } \\
\text { comunicativa, pragmática, ideológica, } \\
\text { estética y/o interactiva. }\end{array}$ \\
\hline $\begin{array}{l}\text { Concepción deseable (N3) } \\
\left(\mathrm{P}_{10}, \mathrm{P}_{6}, \mathrm{P}_{7}, \mathrm{P}_{9}, \mathrm{P}_{13}\right)\end{array}$ & $\begin{array}{l}\text { Concepción deseable (N3) } \\
\text { (ninguno) }\end{array}$ \\
\hline $\begin{array}{l}\text { Los procesos de formación docente en } \\
\text { lengua oral son de carácter sociocultural, } \\
\text { lingüístico, sociolingüístico, comunicati- } \\
\text { vo y/o pragmático, y es necesaria su in- } \\
\text { terrelación y transformación a la práctica } \\
\text { del aula. }\end{array}$ & $\begin{array}{l}\text { El conocimiento lingüístico-discursivo } \\
\text { oral del profesor de lengua castellana } \\
\text { se caracteriza porque alude e integra o } \\
\text { traspone al aula saberes de naturaleza } \\
\text { comunicativa, pragmática, ideológica, } \\
\text { estética e interactiva. }\end{array}$ \\
\hline
\end{tabular}

Fuente: elaboración propia

En primer lugar, es importante señalar que en el discurso de los profesores que colaboraron en este estudio se aprecia cómo algunos reconocen el estado de su propio conocimiento profesional, es decir, dan cuenta de las dificultades y vacíos relacionados con la oralidad como objeto de enseñanza. Por el contrario, otros tratan de evadir esta situación mediante rodeos y reflexiones que no responden a la pregunta formulada. Se trata de la concepción que tiene el profesor sobre su propio conocimiento; en este caso, los trece profesores coinciden en que si bien no tuvieron una formación sobre la enseñanza y el aprendizaje de la oralidad, han enriquecido sus conocimientos teóricos y metodológicos desde su experiencia como docentes de lengua materna y a partir de indagaciones personales.

Además, las concepciones encontradas en el nivel de la acción didáctica tienden hacia la construcción de conocimientos procedimentales, seguidos de los actitudinales y en último lugar los conceptuales. Se hace mayor énfasis en la actuación oral del estudiante en detrimento de la comprensión de dicha actuación y el tratamiento de aspectos conceptuales implicados. Los conocimientos procedimentales se refieren fundamentalmente a la intervención en situaciones orales, en una perspectiva funcional-comunicativa. 
Es importante señalar que la perspectiva comunicativa y contextual se orienta a aprender a realizar una actividad determinada en la lengua materna o en la lengua que se aprende, y a comprender su funcionamiento en la vida social (Lomas y Osoro, 1998). Lo anterior significa que si bien se promueve el uso (oral) de la lengua en un contexto específico, este debe avanzar hacia la comprensión e interrelación de los elementos en tal contexto de sus rasgos lingüísticos, paralingüísticos y discursivos.

En este punto conviene agregar que la tradición académica de la escuela ha mostrado un mayor énfasis en el desarrollo de contenidos conceptuales y en menor medida en los contenidos actitudinales y procedimentales. Sin embargo, el objeto de estudio de esta investigación contradice este fenómeno, ya que la enseñanza de la lengua oral tiene un carácter instrumental que lo aleja de la consideración de ser «enseñado y aprendido», por lo cual requiere ser cualificado desde el nivel conceptual y específicamente desde la reflexión sobre los usos orales de la lengua.

En cuanto a la gestión de la clase, la mayoría de profesores tienen en cuenta el tiempo de aprendizaje y orientan el trabajo en pequeños grupos (conocimiento pedagógico general); en relación con la situación y estrategias didácticas, se observan dificultades en su instrumentación originadas en el tratamiento epistemológico y metodológico dado a las actividades, las técnicas y las estrategias (conocimiento didáctico general) y respecto al conocimiento disciplinar; también se perciben dificultades para transformar conocimientos de la lengua oral como significativos y asimilables para los estudiantes.

En suma, diversos estudios dan cuenta de cómo el «conocimiento didáctico de contenido» (CDC) se desarrolla a lo largo del ejercicio docente, y durante este proceso y su consiguiente reflexión sobre la experiencia, influyen notablemente las concepciones del profesor sobre la materia que enseña. Ahora bien, en esa reflexión sobre la práctica es posible generar CDC y construir elementos teóricos y metodológicos que favorezcan la enseñanza y aprendizaje de la materia o de un tópico específico. Esta situación deseable es coherente con el desarrollo del «conocimiento didáctico del contenido lingǘstico-discursivo oral» y la pretensión de pasar de ser un conocimiento intuitivo a un conocimiento estructurado y estructurante. 
Si bien solo tres profesores se refieren a la importancia de la transposición didáctica, y por tanto a la necesidad de adecuar los contenidos disciplinares al currículo escolar, queda claro que la integración y transformación didáctica es fundamental, sobre todo si trata de seleccionar e integrar contenidos procedentes de sistemas de ideas 9 . La traslación del conocimiento de la materia per se en conocimiento de la materia para la enseñanza (Grossman, et ál., 2005), puede lograrse desde una perspectiva del pensamiento complejo, mediante la recursividad, complementariedad, visión sistémica y una serie de nociones metadisciplinares que actúan como categorías organizadoras del conocimiento.

\section{B. ASPECTOS CURRICULARES}

Este apartado es muy interesante porque revela las concepciones y prácticas identificadas en torno a la manera como el profesor de español y literatura piensa y actúa frente a la enseñanza de la oralidad. Son cinco las concepciones analizadas: concepciones sobre los objetivos de la enseñanza de la lengua oral, sobre los contenidos de conocimiento, sobre la actividad de enseñanza de la lengua oral, sobre las estrategias de enseñanza y en relación con la evaluación de los aprendizajes de la lengua oral.

Al igual que en el apartado anterior, se formulan hipótesis de progresión que se concretan en la formulación de diferentes niveles de complejidad de las concepciones y se sustentan en teorías lingüísticas dominantes en la enseñanza de la lengua materna y en categorías analíticas inductivas.

9 «Los sistemas de ideas son sistemas activos y abiertos, en continuo proceso de cambio» (García, 1998, p. 182). 


\section{OBJETIVOS DE LA ENSEÑANZA DE LA ORALIDAD}

\section{Desde el Discurso}

Los principales objetivos para la enseñanza de la oralidad, expresados por los docentes en su discurso, se presentan en la siguiente tabla:

Tabla 9. Objetivos propuestos por los profesores de Lengua Castellana para la enseñanza de la lengua oral en la Educación Media

\begin{tabular}{|c|c|}
\hline El objetivo de la secuencia didáctica & Carácter del objetivo \\
\hline $\begin{array}{l}\text { P2: Reconocer el manejo de la oralidad en diferentes } \\
\text { contextos. }\end{array}$ & \multirow{9}{*}{ Procedimental } \\
\hline $\begin{array}{l}\text { P5: Identificar los elementos, funciones e importancia } \\
\text { del debate. }\end{array}$ & \\
\hline $\begin{array}{l}\text { P13: Potenciar la capacidad argumentativa de los } \\
\text { estudiantes a partir de la interpretación del libro El ban- } \\
\text { quete de las moscas. }\end{array}$ & \\
\hline $\begin{array}{l}\text { P8: Analizar elementos de la oralidad presentes en la } \\
\text { transcripción de un foro realizado por los estudiantes } \\
\text { sobre el tema de la contaminación. }\end{array}$ & \\
\hline $\begin{array}{l}\text { P9: Lograr una lectura analítica y crítica de un progra- } \\
\text { ma radial, con el propósito último de construir criterios } \\
\text { para el montaje de la emisora escolar. }\end{array}$ & \\
\hline $\begin{array}{l}\text { P3: Promover la reflexión sobre las implicaciones de } \\
\text { la oralidad a partir de una temática previamente explo- } \\
\text { rada por el auditorio: la infancia. }\end{array}$ & \\
\hline $\begin{array}{l}\text { P12: Reflexionar acerca del ejercicio de hablar en pú- } \\
\text { blico a través de vivencias propias de los estudiantes, } \\
\text { enfatizando en su uso desde espacios académicos. }\end{array}$ & \\
\hline $\begin{array}{l}\text { P1: Relacionar la literatura renacentista con el contexto } \\
\text { social de la época mediante la representación escé- } \\
\text { nica de Hamlet, a fin de hacer uso de la interpretación y } \\
\text { producción de parlamentos. }\end{array}$ & \\
\hline $\begin{array}{l}\text { P6: Comparar los valores connotativos de la pala- } \\
\text { bra mediante la lectura, escucha e interpretación de dos } \\
\text { textos poéticos (poesía «Desplazados», de H. Rojas Era- } \\
\text { zo, y canción «Fértil Miseria»). }\end{array}$ & \\
\hline
\end{tabular}




\begin{tabular}{|c|c|}
\hline \multicolumn{1}{|c|}{ El objetivo de la secuencia didáctica } & Carácter del objetivo \\
\hline $\begin{array}{l}\text { P11: Elaborar un saber sobre la comunicación oral, } \\
\text { vista esta como un proceso que va más allá del intercam- } \\
\text { bio de información. }\end{array}$ & Conceptual \\
\hline $\begin{array}{l}\text { P10: Reconocer que el grupo necesita aprender a escu- } \\
\text { char para convivir en armonía. }\end{array}$ & Socio-afectivo \\
\cline { 1 - 1 } $\begin{array}{l}\text { P7: Realizar un programa radial, específicamente un re- } \\
\text { portaje sobre el 12 de octubre. }\end{array}$ & \multirow{2}{*}{ Actividades } \\
\cline { 1 - 2 } $\begin{array}{l}\text { P4: Continuar el trabajo sobre el conocimiento de estrate- } \\
\text { gias argumentativas que debe tener en cuenta un orador. }\end{array}$ & \\
\hline
\end{tabular}

Fuente: elaboración propia

La sistematización anterior presenta los términos en que fueron formulados los objetivos y las características generales de sus componentes, en la perspectiva de dar a conocer qué se propuso alcanzar el grupo de docentes al proyectar la enseñanza de la lengua oral para la Educación Media.

En el nivel inicial (N1): los objetivos de la enseñanza de la lengua oral deben considerar aspectos conceptuales y, en menor medida, procedimentales y socio-afectivos.

P3E: yo CREO que debe ser obligado/ que aprendan a ser conscientes de su oralidad, que aprendan sus características y funciones/ póngalo a leer un cuento/ y los mismos compañeros se duermen/ entonces/ pero/ póngale a alguien que matice la voz/ que lea con tonalidades/ con todo eso/ y que vocalice bien/ y que haga que su voz llegue a todos los rincones de/ de/ del salón// pues los niños no/ se le duermen / entonces/ ese ejercicio lo hemos hecho/de leer en voz alta/pero así/ para $\rightarrow$ / como un ejercicio de oralidad.

En el nivel intermedio (N2): los objetivos de la enseñanza de la lengua oral deben considerar aspectos procedimentales y, en menor medida, aspectos conceptuales y socio-afectivos.

P4E: yo les digo que/ ellos van a hablar en TODAs las asignaturas/ en todas las asignaturas van a hablar/ een/ enn/ ciencias tiene/en todas la' asignaturas van exponer y que el lenguaje es importante EN TODO/ que cuando salgan del/del colegio van a una empresa/tienen que/ o se presentan a la 
universidad/TIENEN que presentar entrevista/ entonces la importancia de hablar/ de hablar en público.

En el nivel deseable (N3): los objetivos de la enseñanza de la lengua oral deben interrelacionar aspectos procedimentales, conceptuales y socio-afectivos.

P6E: aprender a usar la oralidad para sí mismo y para las demás/ para sus peticiones/más en estos momentos por ejemplo/ para construir en es-

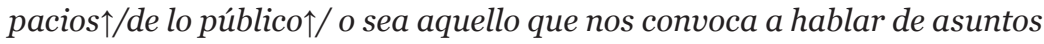
de todos/ cierto $\downarrow$ / entonces nos toca aprender a hablar/ a expresarnos/ porque// eemmm/ aprender a-/aprender a intervenir/ aprender a argumentar $\rightarrow$ / a rescatar los elementos de lo RETÓRICO para llegar a otros.

Se percibe entonces la intención de establecer una relación comunicativa, conceptual y socio-afectiva con el objeto de conocimiento, interés que evidencia el paso de una orientación teórica y normativa a otra más centrada en aspectos semánticos, pragmáticos y axiológicos de la lengua, tal como lo ilustra la gráfica que sigue. En ella se muestra el resultado del análisis de los tres niveles de la concepción detectada, donde la concepción deseable (N3) es minoritaria y corresponde a un 17\% de la población docente entrevistada con respecto a la inicial (N1), representada en un $22 \%$, y a la intermedia (N2) en $61 \%$, respectivamente.

Figura 6. Niveles de la concepción acerca de los objetivos de la enseñanza de la lengua oral detectados en los trece profesores de lengua castellana

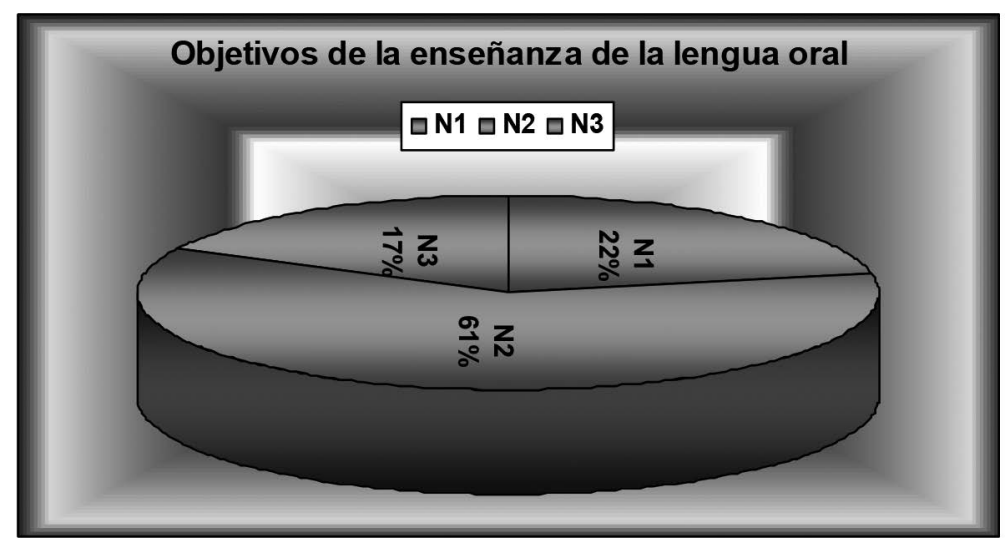

Fuente: elaboración propia 
Es evidente la tendencia a privilegiar en la enseñanza de la oralidad aspectos comunicativos de la lengua. Así, los docentes se proponen simular o crear diversas situaciones de comunicación oral como el debate, foro, programa radial, dramatización, entre otras, cuyo dominio presupone el favorecimiento de la expresión oral y la capacidad de escucha de los estudiantes. Llama la atención cómo, en la formulación de objetivos, acuden a verbos que prevén operaciones cognitivas propias de la actividad de aprendizaje: comparar, reflexionar, analizar, identificar, potenciar, reconocer, producir, elaborar, etc.; no obstante, cuando se analiza la acción didáctica, pocos profesores logran proporcionar elementos de reflexión y de ayuda frente al discurso en producción, lo cual plantea la pregunta por ¿cómo enfrentar los procesos de comprensión y producción oral en contextos académicos?

Tanto en el plano de la expresión como en el de la escucha se da prioridad al componente actuativo de la oralidad, lo cual indica que el aprendizaje se orienta a la ejercitación y/o al dominio de destrezas comunicativas en determinados contextos de uso. Además, es evidente el interés del profesor porque su grupo de estudiantes realice una acción práctica de carácter discursivo derivada de la activación de las operaciones cognitivas mencionadas. Una acción que compromete distintas modalidades del discurso (explicar, exponer, argumentar, contar, dialogar), las cuales se sitúan en el espacio público de lo oral, por tanto requieren de un proceso que pasa por una etapa previa (planear, preparar y ensayar) y una posterior a la intervención oral (analizar, interpretar y evaluar).

Nos encontramos entonces frente al discurso académico oral, una práctica social que la mayoría de docentes plantea en sus programaciones, planes académicos o syllabus, bien sea de manera directa o indirecta, pero que pocas veces sigue y acompaña de manera rigurosa y sistemática, sino que delega a sus educandos con la convicción de que poseen un saber propio de su profesión de estudiante. A nuestro modo de ver, la riqueza del proceso previo a la interacción en el aula es determinante en la aceptación o rechazo del discurso del profesor por parte de los estudiantes, situación que obedece en gran medida al modo como se ha construido o planeado este discurso.

En otro momento propusimos (Gutiérrez, 2009) analizar el proceso de planificación del discurso oral académico del profesor, mediante las operaciones discursivas que estudia la Retórica (inventio, dispositio y elocutio, memoria y actio); en operaciones que se pueden considerar cuando el profesor elabora 
un discurso que encarna el diseño o la creación de su propuesta de trabajo o su actividad para la clase, se está haciendo uso de la invención (inventio); cuando toma decisiones o realiza elecciones conscientes para planear situaciones de la clase, está actuado bajo unos criterios de organización y disposición (dispositio) y cuando expresa su pensamiento, acude a las modalidades del lenguaje y a las herramientas que selecciona (elocutio); en este proceso adquiere una comprensión e interiorización de unos conocimientos y acciones (memoria), comprensión que le posibilita llegar a la enunciación o al momento en que socializa e interactúa con los estudiantes (actio). Las partes constitutivas del discurso propuestas por la Retórica, son configuradas en torno al discurso académico oral del maestro, un discurso que este construye a partir de su pensamiento profesional y su acción pedagógica, proceso que como vemos puede ser objeto de reflexión a partir de la interrelación de los elementos que hacen parte de la estructura retórica.

\section{DeSDe LA ACCIÓN DIDÁCTICA}

Este apartado es muy interesante porque da cuenta del nivel de alcance de los objetivos propuestos por el grupo de docentes a través de la secuencia didáctica, y su concreción en las tareas de aprendizaje. Se selecciona como unidad de análisis las dificultades y aciertos identificados durante el desarrollo de dichas tareas, los cuales son confirmados por el mismo grupo docente mediante la autoconfrontación conjunta:

Tabla 10. Posibles aciertos y dificultades en el desarrollo de las secuencias didácticas propuestas por los profesores de lengua castellana alrededor de la enseñanza de la lengua oral

\begin{tabular}{|l|l|}
\hline \multicolumn{1}{|c|}{$\begin{array}{c}\text { Posibles dificultades en el } \\
\text { desarrollo de las actividades }\end{array}$} & $\begin{array}{c}\text { Posibles aciertos en el } \\
\text { desarrollo de las actividades }\end{array}$ \\
\hline $\begin{array}{l}\text { P1: No entendieron que la dramatiza- } \\
\text { ción pretendía que hicieran uso de su } \\
\text { creatividad para improvisar y relacio- } \\
\text { naran la literatura del renacimiento con } \\
\text { el contexto social. }\end{array}$ & $\begin{array}{l}\text { P1: Lograron aprenderse el libreto co- } \\
\text { rrespondiente a la escena de Hamlety } \\
\text { representarlo, también disfrutaron la } \\
\text { experiencia. }\end{array}$ \\
\hline $\begin{array}{l}\text { P2: La incomprensión de la consigna } \\
\text { por parte de algunos estudiantes. La } \\
\text { impuntualidad de los estudiantes y su }\end{array}$ & $\begin{array}{l}\text { P2: El manejo de tiempos y activida- } \\
\text { des de sensibilización y evaluación. }\end{array}$ \\
$\begin{array}{l}\text { dispersión ante la presencia de las cá- } \\
\text { maras. }\end{array}$ & \\
\hline
\end{tabular}




\begin{tabular}{|c|c|}
\hline $\begin{array}{l}\text { Posibles dificultades en el } \\
\text { desarrollo de las actividades }\end{array}$ & $\begin{array}{c}\text { Posibles aciertos en el } \\
\text { desarrollo de las actividades }\end{array}$ \\
\hline $\begin{array}{l}\text { P5: La dispersión de los estudiantes, } \\
\text { hizo que no se lograra desarrollar el de- } \\
\text { bate. }\end{array}$ & $\begin{array}{l}\text { P5: A los chicos les quedó claro el pro- } \\
\text { pósito de la actividad de debatir. }\end{array}$ \\
\hline $\begin{array}{l}\text { P7: Inicialmente, el mayor obstácu- } \\
\text { lo fue la inserción en el plan curricular } \\
\text { de esta habilidad comunicativa, ya que } \\
\text { interrumpió otros procesos, pero luego } \\
\text { le aportó al trabajo realizado en clase. } \\
\text { Faltó evaluar los resultados del ejercicio } \\
\text { oral del reportaje. El reportaje plantea- } \\
\text { do debió contar con los intereses de los } \\
\text { estudiantes. }\end{array}$ & $\begin{array}{l}\text { P7: El plantear un ejercicio diferente } \\
\text { en la institución, en donde los estu- } \\
\text { diantes pueden tener más participa- } \\
\text { ción en su propio proceso de aprendi- } \\
\text { zaje y se vuelvan críticos y transfor- } \\
\text { madores de su situación social. }\end{array}$ \\
\hline $\begin{array}{l}\text { P3: Las dificultades en la expresión de } \\
\text { algunos estudiantes, limitó su participa- } \\
\text { ción. }\end{array}$ & $\begin{array}{l}\text { P3: El hecho de haber leído previa- } \\
\text { mente el texto que era motivo de dis- } \\
\text { cusión. }\end{array}$ \\
\hline $\begin{array}{l}\text { P4: Un grupo de trabajo no participó. } \\
\text { En las mesas de trabajo no todos los es- } \\
\text { tudiantes asumieron el rol de orador. Se } \\
\text { delegó tal papel a uno o dos miembros. } \\
\text { Por esta razón solo se evaluó de forma } \\
\text { individual. }\end{array}$ & $\begin{array}{l}\text { P4: Haber comprendido el material } \\
\text { teórico en sesiones anteriores. Haber } \\
\text { dado a los estudiantes la posibilidad } \\
\text { de usar sus propios recursos sobre el } \\
\text { tema a argumentar. Las preguntas } \\
\text { acerca de la oralidad permitieron que } \\
\text { los estudiantes intentaran asumir el } \\
\text { rol de orador y que su intervención no } \\
\text { fuera invalidada sino refutada. }\end{array}$ \\
\hline $\begin{array}{l}\text { P6: El tiempo es implacable en estas dis- } \\
\text { cusiones. }\end{array}$ & $\begin{array}{l}\text { P6: Los estudiantes lograron conver- } \\
\text { sar sobre el contenido social de la can- } \\
\text { ción y el poema. }\end{array}$ \\
\hline $\begin{array}{l}\text { P8: El espacio físico de la clase y el ruido } \\
\text { exterior. }\end{array}$ & $\begin{array}{l}\text { P8: La conformación de grupos, el } \\
\text { tipo de consigna dada, la temática } \\
\text { corresponde a la cotidianidad de los } \\
\text { estudiantes. Además, posibilitar pro- } \\
\text { cesos de inferencia y argumentación } \\
\text { en los estudiantes y retroalimentar } \\
\text { los contenidos y la reflexión en torno } \\
\text { a ellos. }\end{array}$ \\
\hline $\begin{array}{l}\text { P9: Considero que no era necesario una } \\
\text { contextualización tan extensa que dejó } \\
\text { poco tiempo a la consulta, al trabajo en } \\
\text { grupo y a la socialización. De otra parte, } \\
\text { el funcionamiento deficiente de la Inter- } \\
\text { net en el aula de clase. }\end{array}$ & $\begin{array}{l}\text { P9: La evocación de otras experien- } \\
\text { cias y lecturas similares hicieron que } \\
\text { los estudiantes aprehendieran mejor } \\
\text { la actividad. La disciplina, la partici- } \\
\text { pación y el buen ambiente de trabajo } \\
\text { del grupo favorecieron el desarrollo } \\
\text { de la sesión. La planeación de la se- } \\
\text { cuencia ayudó en el desarrollo de las } \\
\text { actividades. }\end{array}$ \\
\hline
\end{tabular}




\begin{tabular}{|c|c|}
\hline $\begin{array}{l}\text { P1o: Hubo mucha exposición de mi par- } \\
\text { te. Faltó participación de los estudiantes. } \\
\text { Pude haberles dado una copia de la cari- } \\
\text { catura a todos los estudiantes. }\end{array}$ & $\begin{array}{l}\text { P1o: Fue una actividad que respondía } \\
\text { a una necesidad del grupo. El uso de } \\
\text { la cartelera mantuvo el hilo temático } \\
\text { de la clase. }\end{array}$ \\
\hline $\begin{array}{l}\text { P11: Al no evaluar la actividad puede } \\
\text { que las actividades de aprendizaje no se } \\
\text { hayan cumplido de manera certera. }\end{array}$ & $\begin{array}{l}\text { P11: Que al ser una clase discursiva } \\
\text { algunos contenidos pueden ser pro- } \\
\text { fundizados de manera diferente. La } \\
\text { importancia de la discusión como ele- } \\
\text { mento metodológico. }\end{array}$ \\
\hline $\begin{array}{l}\text { P12: No todos los estudiantes partieron } \\
\text { de escribir y luego comentar sus expe- } \\
\text { riencias personales sobre la oralidad. } \\
\text { No todos lograron involucrarse en la } \\
\text { discusión. }\end{array}$ & $\begin{array}{l}\text { P12: Generar procesos de discusión } \\
\text { a partir de vivencias personales de } \\
\text { los estudiantes frente a la oralidad en } \\
\text { contextos académicos ayuda a asumir } \\
\text { una postura y a tomar conciencia de } \\
\text { este fenómeno. }\end{array}$ \\
\hline $\begin{array}{l}\text { P13: La duración excesiva de mi inter- } \\
\text { vención inicial, hizo que los estudiantes } \\
\text { contaran con poco tiempo para deba- } \\
\text { tir. La entrega anticipada del material } \\
\text { hubiera ayudado. A los estudiantes les } \\
\text { cuesta mucho la interacción con otros. }\end{array}$ & $\begin{array}{l}\text { P13: La planeación de la secuencia di- } \\
\text { dáctica. La preparación por parte de } \\
\text { los estudiantes frente a la clase. La no- } \\
\text { vedad de la actividad. EL juego de roles. } \\
\text { Una tarea específica desde la cual cada } \\
\text { estudiante asume su posición. Mi clari- } \\
\text { dad frente a las instrucciones que doy y } \\
\text { la manera como organicé la clase. }\end{array}$ \\
\hline
\end{tabular}

Fuente: elaboración propia

La concreción de las intenciones educativas a partir de los resultados del aprendizaje, posibilita la identificación de dificultades y aciertos durante la puesta en escena de la secuencia didáctica alrededor de la oralidad. Tales avances y dificultades obedecen, según el grupo docente, a acciones realizadas por los estudiantes o por ellos mismos, acentuándose la responsabilidad de las dificultades en los primeros y de los aciertos en los segundos. Unas y otros se relacionan con:

a. La compresión de la consigna, por parte de los estudiantes.

b. La expresión oral de los estudiantes.

c. El interés de los estudiantes frente a las tareas propuestas.

d. La incorporación de la oralidad en el plan curricular y la planeación de secuencias de enseñanza por parte del maestro.

e. El manejo pedagógico de los recursos y las condiciones para la enseñanza de la oralidad.

f. El manejo del tiempo didáctico. 
a) La comprensión de las consignas por parte de los estudiantes. Obedece, según se aprecia en la tabla anterior, a la claridad de las instrucciones dadas por algunos profesores y su coherencia con las actividades previstas (P4, P6, P8, P13). Si bien los motivos que originan la incomprensión de las consignas no se hacen explícitos (P1, P2), pueden atribuirse a la ausencia de reformulaciones de las tareas propuestas, a la falta de familiarización de los educandos con el objeto de saber en cuestión y/o a la ausencia de un trabajo cooperativo entre el profesor y los estudiantes alrededor de las tareas de aprendizaje.

Se trata de una concepción minoritaria relacionada con la intención de que el estudiante siga el modelo de la lengua literaria, por tanto se representa en un nivel inicial de la hipótesis de progresión (N1); de este modo: el objetivo específico de la enseñanza de la lengua oral consiste en la comprensión de modelos del habla culta que los estudiantes deben apropiar. Subyace entonces una concepción de oralidad cifrada en la voz o en la producción del sonido; es decir, en la valoración de aspectos prosódicos del lenguaje: la calidad del timbre de voz, la entonación, la intensidad segmental, las pausas, etc.

b) La expresión oral de los estudiantes es otra de las tensiones agudas registradas en esta experiencia. Se manifiesta a la vez como dificultad ( $\mathrm{P}_{3}$, $\mathrm{P} 4, \mathrm{P} 12)$ y como avance (P7, P6, P13) en la consecución de los objetivos de aprendizaje de la lengua oral. Se indica con ello, que en la planeación de algunas secuencias didácticas probablemente no se contemplan las necesidades y progresos orales de los estudiantes como un posible punto de partida.

Se advierte la persistencia de la queja generalizada frente a la expresión oral de los estudiantes y la necesidad de que estos puedan superar las dificultades de inadecuación y falta de fluidez en el uso de la lengua oral.

c) El interés de los estudiantes frente a las tareas de aprendizaje de la lengua oral propuestas por el profesor. Pese a las tareas de sensibilización y toma de conciencia que realizan algunos profesores, se identifican dificultades $\left(\mathrm{P}_{5}, \mathrm{P}_{2}\right)$ y aciertos $\left(\mathrm{P}_{13}, \mathrm{P} 9\right)$ atribuidos por los mismos docentes a la actitud desinteresada o interesada de los estudiantes ante las actividades de la lengua oral propuestas. Estas actitudes de los estudiantes son valoradas a 
partir del modo como intervienen en las actividades orales realizadas y por su creciente participación oral en clase.

d) La incorporación de la oralidad en el plan curricular y la planeación de secuencias de enseñanza. Al solicitar al grupo de docentes el diseño de una secuencia didáctica de la lengua oral, se constata que se considera la oralidad como una actividad del lenguaje que requiere ser incorporada en el currículum y en las planificaciones del profesorado de lengua materna ( $\left.\mathrm{P}_{7}\right)$, ya que se concibe como una nueva tarea de enseñanza -tal como se aprecia en la tabla 8-, y por ende implica agregar otro componente, tanto en el currículo de lengua materna como en la programación realizada para los grados pertenecientes al nivel medio de escolaridad.

Por el contrario, tres profesores ( $\left.\mathrm{P}_{13}, \mathrm{P} 9, \mathrm{P} 2\right)$ consideran que el proceso de planificación de la secuencia didáctica les ayuda a organizar y poner en relación los contenidos de aprendizaje, propósitos, actividades, formas de evaluación y recursos, así como a tomar conciencia de los progresos en la construcción del conocimiento.

e) El manejo de los recursos y las condiciones para la enseñanza de la oralidad. Se observa que algunos de los recursos que facilitaron las tareas de enseñanza y aprendizaje de la lengua oral son el uso de textos literarios, académicos e informativos abordados previamente, y ayudas sonoras y visuales como la grabación de un reportaje y una cartelera, respectivamente ( $\mathrm{P}_{1}, \mathrm{P}_{3}$, P4, P6, P7, P10). Mientras que para otros maestros, algunos de estos recursos constituyen obstáculos como el hecho de no haber entregado a los estudiantes el material con anticipación o el uso deficiente de Internet en el aula de clase $(\mathrm{P} 13, \mathrm{P} 9)$.

f) El manejo del tiempo didáctico. De manera explícita o implícita tres profesores (P6, P9, P13) sustentan dificultades en el alcance de los objetivos debido al tiempo, mientras que un profesor (P2) aduce que uno de los aciertos fue el manejo adecuado de este.

En el caso de P13, luego del análisis de la secuencia didáctica mediante la autoconfrontación conjunta, reconoce la duración excesiva del tiempo didáctico respecto al uso de la palabra al realizar la contextualización al grupo 
sobre el tema que sería objeto de reflexión en la sesión (debate sobre el libro $E l$ banquete de las moscas y su relación con la situación de la «Calle del cartucho» de Bogotá). Esta situación de desequilibrio respecto a la proporción del uso de la palabra en el aula, es detectada por P13 como una posible dificultad en el cumplimiento del objetivo propuesto en su secuencia didáctica.

Ahora bien, de las dificultades y aciertos encontrados en relación con la compresión de la consigna, la expresión oral de los estudiantes, su interés por el aprendizaje de la lengua oral, la incorporación de la oralidad en el plan curricular, el manejo de los recursos y las condiciones para la enseñanza de la oralidad, se infiere que la mayoría de profesores tiene como objetivo específico de la enseñanza de la lengua oral, la instrucción de tópicos relativos al funcionamiento de la lengua oral y su puesta en práctica en actividades que se simulan o crean eventualmente en el aula. Esta concepción de nivel intermedio (N2) muestra un mayor grado de complejidad respecto a la concepción N1, limitada a la recreación de modelos de habla culta.

En consecuencia, para el grupo de profesores, el nivel de alcance del objetivo propuesto en la secuencia didáctica fue relativo y apenas se acercó al nivel deseable (N3) de la hipótesis de progresión, a saber: el objetivo transversal de la enseñanza de la lengua oral se orienta al dominio comprensivo y expresivo de distintos géneros orales en diversos contextos desde un proceso paulatino que implique una actitud reflexiva sobre sus mecanismos de uso y sus potenciales efectos. Esta formulación apela al criterio de interrelación y progresión de los objetivos didácticos (procedimentales, conceptuales y socio-afectivos) característicos del aprendizaje.

\section{ANÁLISIS CONTRASTIVO: CORRESPONDENCIAS Y CONTINGENCIAS}

La correspondencia entre las concepciones derivadas del discurso y las derivadas de la acción didáctica alrededor de los objetivos de enseñanza de la lengua oral, muestra cierta inestabilidad al intentar contrastar lo que piensan, hacen y dicen que hacen los profesores en el aula no siempre coincida, pues no todas las actuaciones docentes se relaciones estrechamente con sus formas de pensar, y no todas sus concepciones sobre la oraldiad se corresponden con su acción pedagógica. 
Tabla 11. Hipótesis de progresión para el análisis de las concepciones acerca de los objetivos de la enseñanza de la lengua oral

Concepciones detectadas acerca de los objetivos de la enseñanza de la lengua oral

\begin{tabular}{l}
\hline \multicolumn{1}{c|}{$\begin{array}{c}\text { Derivadas del discurso del } \\
\text { profesor }\end{array}$} \\
\hline $\begin{array}{l}\text { Concepción inicial (N1) } \\
\left(\mathrm{P} 11, \mathrm{P} 1, \mathrm{P}_{3}, \mathrm{P} 5, \mathrm{P} 8,\right)^{-}\end{array}$ \\
$\begin{array}{l}\text { Los objetivos de la enseñanza de la } \\
\text { lengua oral deben considerar aspectos } \\
\text { conceptuales, y en menor medida, pro- } \\
\text { cedimentales y socio-afectivos. }\end{array}$
\end{tabular}

Concepción intermedia (N2)

(P10, P11, P12, P2, P4, P5, P6, P7, P8, $\mathrm{P} 9, \mathrm{P} 13)$

Los objetivos de la enseñanza de la lengua oral deben considerar aspectos procedimentales, y en menor medida, aspectos conceptuales y socio-afectivos.

\section{Concepción deseable (N3)}

(P10, P3, P6, P9)

Derivadas de la acción didáctica del profesor

\section{Concepción inicial (N1)}

(P1)

El objetivo específico de la enseñanza de la lengua oral consiste en la comprensión de modelos del habla culta que los estudiantes deben apropiar.

\section{Concepción intermedia (N2) \\ (P10, P11, P12, P2, P4, P5, P6, P7, P8, P9, $\left.\mathrm{P}_{13}, \mathrm{P}_{3}\right)$}

El objetivo específico de la enseñanza de la lengua oral consiste en la instrucción de tópicos relativos a su funcionamiento y su puesta en práctica en actividades que se simulan o crean eventualmente en el aula.

\section{Concepción deseable (N3) \\ (ninguno)}

El objetivo transversal de la enseñanza de la lengua oral se orienta al dominio comprensivo y expresivo de distintos géneros orales en diversos contextos desde un proceso paulatino que implique una actitud reflexiva sobre sus mecanismos de uso y sus potenciales efectos.

\section{Fuente: elaboración propia}

El hecho de que la concepción mayoritaria de los profesores de lengua castellana que participan en este estudio, sea la formulación y desarrollo de objetivos procedimentales de naturaleza comunicativa, tanto en el discurso como en la acción didáctica del profesor, puede obedecer a la naturaleza misma de la oralidad, en tanto sugiere acción, movimiento de la palabra, cercanía e interacción. Esta dimensión dinámica, afectiva y social de la oralidad comporta 
la idea de considerarla como un medio para la comunicación, la construcción de aprendizajes, la resolución de conflictos, etc. De ahí que la finalidad dada a la enseñanza de la oralidad por la población docente estudiada, se enfoque en la inmediatez de su ejercitación, en detrimento de su poder estructurante. Es decir, se promueve una oralidad espontánea o en producción, en la cual subyacen unos propósitos comunicativos inmediatos que no contemplan procesos reflexivos sobre sus propios mecanismos de uso.

Por otra parte, la ubicación de la concepción mayoritaria en el nivel intermedio, indica que este grupo de docentes, al proponerse abordar la enseñanza de la lengua oral de manera planificada, intenta superar la tendencia tradicional de la enseñanza y aprendizaje de la lengua oral orientada a la repetición de modelos discursivos (N1) y logra situarse en una perspectiva más comunicativa y contextual (N2), aunque ocasional. De igual modo, la importancia que le conceden a la oralidad y las razones que la sustentan, coincide con este nivel de concepción, ya que una mayoría importante la considera fundamental por ser un instrumento que vehicula la comunicación en contextos escolares y sociales, y una minoría sustenta su importancia en el desarrollo de las habilidades de escuchar y hablar en público.

Tanto en el discurso como en la acción predominan, entonces, objetivos orientados a potenciar las habilidades orales del estudiante, principalmente en los papeles de productor (hablante) y de intérprete (oyente). Algunos profesores tímidamente se proponen fortalecer el papel del estudiante como gestor o moderador. Esta aproximación a la organización de los intercambios orales es un indicio del interés por potenciar la actividad de la interacción, una categoría que, abordada con profundidad, podría dar sentido a una finalidad deseable de la didáctica de la oralidad y, en consecuencia, al nivel de referencia ( $\mathrm{N}_{3}$ ), cifrada en la necesidad de lograr una mayor elaboración de los intercambios verbales de los interlocutores en determinadas situaciones de comunicación oral.

Para considerar este criterio de progresión también es necesario tener en cuenta que la competencia discursiva oral se fortalece cuando el hablante apela a distintos recursos semánticos y pragmáticos, es decir, en la medida en que el profesor prevea objetivos de aprendizaje articulados a situaciones didácticas significativas que planteen a los estudiantes interacciones orales 
exigentes y coherentes con sus posibilidades de apoyo al alcance de estos objetivos.

La interacción oral supone una creación conjunta de significado, que a su vez implica ciertas condiciones (intercambios, cooperación, características paralingüísticas y contextuales, etc.) necesarias para mantener este proceso en un plano colaborativo (Ministerio de Educación, Cultura y Deporte, 2002). Desde esta perspectiva, Núñez (2000) plantea pasar de las características formales y las normas del discurso que se producen en el aula, al estudio de los usos orales que emergen de la interacción en clase, con el fin de identificar los avances y limitaciones de la comprensión, así como las estrategias discursivas que se requieren para mejorar este aprendizaje, cuya potencialidad da lugar a otros.

Es primordial destacar la intención de desarrollar las capacidades expresivas y comprensivas de los estudiantes en la perspectiva de lograr la eficacia comunicativa. La tendencia a formular objetivos de aprendizaje de la lengua de carácter comunicativo, conceptual y/o socio-afectivo, es un paso importante hacia el abordaje articulado y sistemático de los usos elaborados de la lengua oral y la reflexión sobre estos. No obstante, en este punto es necesario precisar que tanto los objetivos formulados antes de la intervención didáctica, como los aciertos y dificultades identificados después de ella, no alcanzan el nivel de profundidad deseado.

$\mathrm{Al}$ analizar en su conjunto las dificultades y aciertos identificados por los profesores durante el desarrollo de la secuencia didáctica, resulta paradójico encontrar que se tropiece con dificultades relativas a la expresión oral de los estudiantes y se las considere un obstáculo, cuando precisamente la mayoría de objetivos apuntan a mejorar la competencia comunicativa oral de los estudiantes. A esto se añade una serie de juicios de valor que dan cuenta del progreso oral del estudiante, reflejado en su creciente participación en clase. Esta, a su vez, constituye una condición necesaria - pero no suficiente- en razón de que no se percibe si más allá del tiempo de uso de la palabra oral prevalece la calidad de las interacciones y, en consecuencia, la alternancia de roles, el intercambio real entre pares y no solo con el profesor, y la implicación de este último en momentos que requieran de dilucidación o complejización del objeto de discusión. 
También resulta interesante encontrar en el análisis de las condiciones de realización de los objetivos, que los profesores de lengua castellana consideren la enseñanza de la lengua oral como un nuevo tópico curricular. En el mismo sentido, Pérez (2009, p. 301) confirma que «la lengua cuando no ha sido olvidada de las programaciones, ha estado caracterizada por la improvisación». Por ello, al proponerse como objeto de enseñanza y aprendizaje, se requiere de un tiempo didáctico para lograr abordarla en profundidad. Este es otro de los obstáculos expresado por algunos docentes, puesto que el tiempo no favoreció el alcance total del objetivo. Cabe señalar que las actividades de enseñanza y aprendizaje evolucionan a través de un período considerable; es por esto que el tiempo didáctico es estimado como una condición necesaria en el éxito o fracaso de estos procesos.

El manejo pedagógico de los recursos y las condiciones para la enseñanza de la oralidad y cómo este se torna en dificultad para unos y en acierto para otros, concuerda con investigaciones sobre la enseñanza de la oralidad que enfatizan en la importancia de los recursos y las condiciones para que el desarrollo de la competencia discursiva oral pueda ser real. Así, por ejemplo, es fundamental contar con reproductores de voz, videocámaras y herramientas que puedan registrar las interacciones orales que ocurren en el aula, sin perder de vista que son medios y no fines en sí mismos (Abascal, et ál., 1993).

$\mathrm{Al}$ identificar que las dificultades y aciertos en la consecución del objetivo de la acción didáctica tienen que ver con la compresión de la consigna, la expresión oral de los estudiantes, su interés por el aprendizaje de la lengua oral, la incorporación de la oralidad en el plan curricular, el manejo de los recursos y las condiciones para la enseñanza de la oralidad, se constata el valor capital de las actividades de planificación, desarrollo y reflexión sobre la acción didáctica. Por ello, algunas de las dificultades y aciertos expresados por el grupo docente, no pueden obedecer necesariamente a la planeación en sí misma, sino a la manera como se formula y pretende alcanzar el objetivo de aprendizaje.

Por lo anterior, se comparte el planteamiento de Schneuwly, Di Pietro, Dolz, Erard, Aller, Kaneman, Moro y Zahnd (1997) alrededor del objetivo básico de la enseñanza de la lengua oral, orientado a lograr el paso de la producción oral espontánea a una producción más elaborada y formal, lo cual supone trabajar en la transformación discursiva de los estudiantes desde 
géneros orales formales atendiendo a sus características, contenidos, medios e intenciones.

Si se parte de considerar que una de las funciones propedéuticas del quehacer docente es la gestión del tiempo didáctico en relación con las finalidades que pretende alcanzar en el aula, se estaría frente a una lógica que obliga a planear estratégicamente cada uno de los momentos de la acción didáctica, de tal forma que se logre una interacción efectiva y equilibrada entre los participantes y el objeto de saber. Por ello, al proponérsele al grupo de docentes seleccionado para esta investigación, diseñar una secuencia de enseñanza que considere el desarrollo de la competencia discusiva oral de los estudiantes, se desafía a la fuerza de la tradición que ha delegado al maestro la tarea de hablar en el aula para mejorar la competencia escrita de los aprendices.

El papel de los objetivos didácticos en el currículum es fundamental, por cuanto concretan las intenciones educativas del profesorado. De este presupuesto han emergido múltiples propuestas por parte de diferentes especialistas en diseño curricular (De Corte, 1979; De Landsheere, 1977; Hameline, 1979; Romiszowski, 1981; citados por Coll, 1987). Estas propuestas van desde un intento por precisar los objetivos -diversificando sus tiposhasta considerar que para aclarar mejor dichas intenciones pueden tenerse en cuenta tres aspectos: a) los contenidos sobre los que versa el aprendizaje; b) los resultados del aprendizaje que se esperan obtener; y c) las actividades de aprendizaje.

En las actividades de aprendizaje, el alcance de los objetivos propuestos por el profesor depende de la implicación del estudiante en las tareas de aprendizaje, es decir, que el estudiante juegue con las reglas propuestas, interprete indicios, construya a partir de los elementos dados, etc. De ahí que sea fundamental la coherencia entre las condiciones, necesidades e intereses del grupo con los propósitos de enseñanza, las intenciones y el saber profesional del docente. Queda así planteado que la acción didáctica es orgánicamente cooperativa, lo cual significa que el desarrollo de las tareas de aprendizaje está mediado por la comunicación efectiva entre el profesor y los estudiantes.

Este intercambio, según Sensevy (2007), se caracteriza por la interpretación constante de los enunciados expresados por cada participante en el juego de saber y/o la reformulación de la consigna; es decir, en el evento en 
que se perciba la necesidad de enriquecer la actividad, conviene introducir nuevos elementos o estrategias que favorezcan las transacciones y aseguren el éxito del juego. Apelando a la perspectiva interaccionista de la enseñanza y el aprendizaje relacionada con la intencionalidad y el sentido que los participantes atribuyen a una tarea de aprendizaje, cabe precisar que no basta con poseer unos conocimientos, habilidades o experiencias previas, sino que también es fundamental establecer una dinámica de intercambios entre el profesor, el medio didáctico y los estudiantes, de tal modo que la transformación del objeto de saber esté determinada por la construcción de significados de manera progresiva (Coll, 1988).

Ahora bien, si la orientación didáctica dada por el profesorado en cuestión, a la formulación de los objetivos propuestos para enseñar la lengua oral, se inclina hacia un enfoque comunicativo, en tanto busca que los estudiantes se comuniquen oralmente de manera efectiva en diferentes contextos, es evidente que los objetivos propuestos no logran esta pretensión a cabalidad, ya que algunos se quedan en la transmisión de conceptos básicos o en la práctica de situaciones orales alejadas de una reflexión sistemática y, en general, en la no inclusión simultánea de todos los aspectos del nivel de referencia de la hipótesis. Por consiguiente, es importante reconocer la necesidad de avanzar en la comprensión del enfoque comunicativo y contextualista, cuyo dominio debe traspasar la toma de conciencia de las finalidades comunicativas espontáneas, socio-afectivas y conceptuales de la lengua oral hacia una visión integral y socio-interaccionista.

\section{CONTENIDOS DE APRENDIZAJE}

\section{DeSDE EL Discurso}

En los contenidos de aprendizaje de la lengua oral existentes en el discurso representado en la entrevista y los grupos de discusión, se identificaron tres niveles de concepción.

En el nivel inicial (N1): los principales contenidos de aprendizaje de la lengua oral deben orientarse al dominio de sus aspectos lingüísticos y normativos. 
P5E: cómo poder proyectar la voz/ para $\rightarrow$ medir el ambiente en donde se está desenvolviendo/ ¿si?/ entonces/ hay necesidad de enseñar/a manejar y a sostener la/ el tono de voz de acuerdo/ a donde se esté desarrollando/ porque mucha gente que habla demasiado bajo/ que no se entiende qué está di-/qué está diciendo/ eeeh/la/la misma audición/la pronunciación/ porque cada/ necesidad de expresión/ o má(s)/ o mejor, cada contenido necesita/ una forma de expresión/.

En el nivel intermedio (N2): los principales contenidos de aprendizaje de la lengua oral se orientan al dominio de sus aspectos pragmáticos y comunicativos.

P11E: $y$ en cuanto a la oralidad $\uparrow / /$ pues/ eeeeh/ en este momento/ estamos trabajando/ textos narrativos/ entonces/ eeeeh/ hubo un momento en queee/ los estudiantesss/ eeeeh/ pudieron traer/ eeeeh/ como relatos contados por sus padres/por sus abuelos/y $\rightarrow$ se hizo una clase muy/ muy rica y muy dinámica/ eeeh/ ya que e-/ ellos estuvieron muy entusiasmados.

En el nivel deseable (N3): los principales contenidos de aprendizaje de la lengua oral se secuencian y concretan en función del dominio paulatino de sus aspectos lingüísticos, pragmáticos, comunicativos y discursivos.

Como se puede observar en la siguiente gráfica, la concepción deseable (N3) solo alcanza un $21 \%$ con respecto a la inicial (N1), que es de un $50 \%$ e intermedia (N2), con un $29 \%$.

Figura 7. Niveles de la concepción acerca de los contenidos de aprendizaje de la lengua oral detectados en los trece profesores de lengua castellana

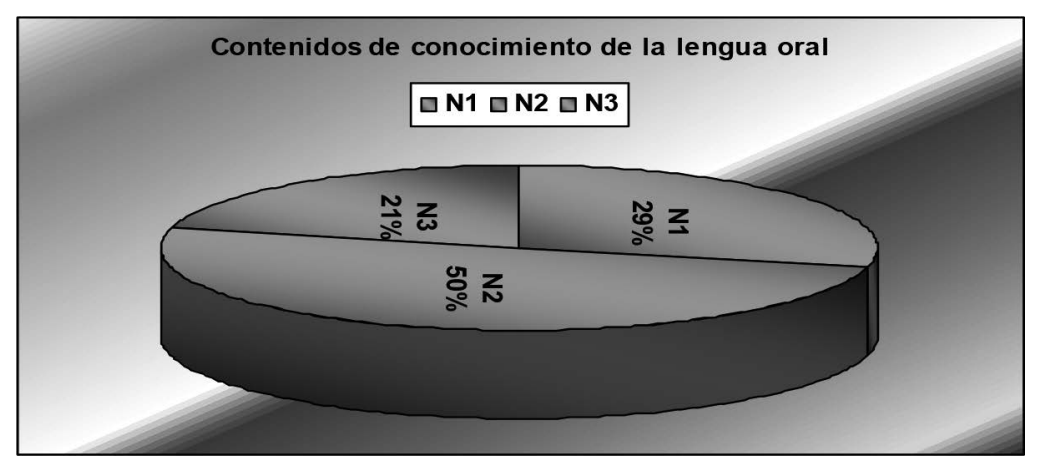

Fuente: elaboración propia 
En primer lugar, se percibe en el discurso docente una predisposición a abordar temáticas de la lengua oral y no contenidos curriculares. Esta probable confusión tiene implicaciones en la manera como se integran y desarrollan tales contenidos en una secuencia didáctica porque el desarrollo de la competencia discursiva oral de los estudiantes se logra desde situaciones globales de uso, cuyo carácter auténtico y significativo se alcance desde la interrelación de objetivos y contenidos de aprendizaje. No basta con precisar los contenidos básicos de aprendizaje de la lengua oral, necesarios para desarrollar la competencia discursiva oral de los jóvenes, sino que se requiere de un tratamiento complementario e integrador, pero sobre todo, atrayente.

En este punto, nuevamente surge la motivación del educando como una condición esencial para que se logren aprendizajes significativos. Por ello, debe tenerse en cuenta que se trata de adolescentes, cuya edad oscila entre 13 y 17 años y atraviesan por un momento en el que sus actividades personales y sociales son muy importantes, y si se recae en ellas, se vuelven desafíos realmente estimulantes. Además, es primordial una integración en el interior de estos objetivos y contenidos, de tal forma que articule procesos de comprensión y producción oral y, en consecuencia, objetivos y contenidos de carácter procedimental, conceptual y actitudinal.

Reyzábal y Sanz (1997) abogan por contenidos curriculares que se caractericen por: a) Su carácter integrado, puesto que hacen referencia a situaciones que comprenden aspectos relacionados con diferentes disciplinas; b) $\mathrm{Su}$ complejidad, pues la adecuada comprensión de los mismos requiere del desarrollo de capacidades tanto cognoscitivas como procedimentales a partir de las cuales el alumno pueda asumir actitudes elegidas de forma autónoma y racional.

Lo anterior sustenta la importancia de la concreción de los contenidos en el aula desde una perspectiva sistemática y progresiva no solo en la Educación Media, sino en todos los grados de escolaridad. Dicha perspectiva supera el reduccionismo conceptual y busca articular de manera equilibrada contenidos de aprendizaje conceptuales, procedimentales y actitudinales, favoreciendo así la interacción entre el aprendizaje conceptual, la adquisición de destrezas y el desarrollo de actitudes críticas frente a los usos orales.

Los contenidos propuestos en este estudio por el grupo docente seleccionado, corresponden mayoritariamente a la adquisición de destrezas orales, con 
lo cual se puede correr el riesgo de situar el desarrollo de los contenidos de saber de la lengua oral en actividades inconexas y aisladas de la reflexión con poca o nula construcción de conocimiento escolar. Superar este riesgo debe ser una tarea permanente, debido a la naturaleza actuativa de la oralidad. Por esto, es importante proyectar contenidos de saber que conlleven a la actividad ligada a la reflexión y su posterior aplicación en contextos diferenciados.

Los contenidos de saber inferidos de las fuentes de información situadas, tanto en el plano del decir como del hacer, coincidieron y se organizaron algunos en una perspectiva comunicativa-funcional y pragmática, y otros corresponden más a actividades que a contenidos de conocimiento de la lengua oral. En cada secuencia didáctica subyacen unos contenidos de enseñanza, cuya concreción busca primordialmente que los estudiantes sean hablantes y oyentes eficaces; por lo tanto, se actúa sobre habilidades comunicativas específicas. Es de señalar que las fuentes de elaboración de los contenidos de conocimiento de la lengua oral, se centran en el estudiante mismo (conocimientos previos), en la información que aporta el profesor y en la información que aportan algunos textos, cuyo contenido no se relaciona con tópicos de la lengua oral.

En general, se advierten contenidos comunicativos y pragmáticos de la lengua, aunque no por ello todas las actividades se ajustan a las exigencias de profundidad en estos aspectos. Esta situación puede ser usual cuando no se ha tenido en cuenta una selección y secuenciación adecuada de los contenidos que atienda al nivel de escolaridad de los estudiantes, a sus necesidades, conocimientos previos e intereses o bien a las estrategias de enseñanza diseñadas por el profesor. Como consecuencia de ello, los contenidos descuidan la construcción de conocimiento de la lengua oral y se centran en el desarrollo de actividades.

En cuanto a la manera como planean los contenidos, se advierte el predominio de una selección de temas, más no un cuerpo de conocimientos susceptibles de ser desarrollados de manera secuencial y sistemática. No obstante, se puede afirmar que los profesores intentan una progresión temática durante el desarrollo de la secuencia didáctica a través de varios momentos. En este proceso subyacen unos saberes que escapan a un proceso comunicativo integral (en sus dimensiones estructural, comunicativa y social), en tanto el interés recae en la consecución de la tarea, lo cual genera intervenciones casi siempre centradas en la corrección de la lengua oral, en sus aspectos pura- 
mente lingüísticos o en el funcionamiento de elementos como el contexto, los participantes, sus modos de interactuar, entre otros.

\section{DESDE LA ACCIón DIDÁCTICA}

En la acción didáctica de la población estudiada están presentes unos contenidos de saber alrededor de la lengua oral. Se trata de contenidos curriculares o programáticos que el profesor incluye durante las actividades de enseñanza y aprendizaje y a los cuales da un tratamiento específico.

Tabla 12. Concepciones de los profesores de lengua castellana acerca de los contenidos de aprendizaje de la lengua oral para la Educación Media.

\begin{tabular}{|c|c|c|c|}
\hline Tendencia & $\begin{array}{l}\text { Unidades de } \\
\text { información }\end{array}$ & $\begin{array}{l}\text { La consigna } \\
\text { explícita o } \\
\text { implícita }\end{array}$ & $\begin{array}{l}\text { Contenidos de } \\
\text { conocimiento de } \\
\text { la lengua oral }\end{array}$ \\
\hline సีّ & $\begin{array}{l}\text { DEV1E1P1, DE- } \\
\text { V2E1P1 }\end{array}$ & $\begin{array}{l}\text { Representen e in- } \\
\text { terpreten una obra } \\
\text { dramática literaria } \\
\text { mediante la memo- } \\
\text { rización e improvi- } \\
\text { sación. }\end{array}$ & $\begin{array}{l}\text { La dramatización e } \\
\text { improvisación. }\end{array}$ \\
\hline \multirow{3}{*}{ 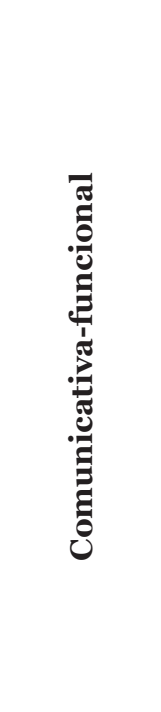 } & $\begin{array}{l}\text { REG4E2P2, } \\
\text { REG5E2P2, } \\
\text { REG6E2P2, } \\
\text { DEV5E2P2 } \\
\text { REG8E3P2, } \\
\text { REG9E3P2, } \\
\text { REG11E7P2 }\end{array}$ & $\begin{array}{l}\text { Identifiquen el papel } \\
\text { de la voz (rasgos } \\
\text { lingüísticos) en el } \\
\text { contexto y el discurso } \\
\text { en diferentes situa- } \\
\text { ciones orales. }\end{array}$ & $\begin{array}{l}\text { Situaciones orales. } \\
\text { Rasgos lingüísticos y } \\
\text { contextuales. }\end{array}$ \\
\hline & $\begin{array}{l}\mathrm{DEV}_{3} \mathrm{E}_{5} \mathrm{P}_{4}, \mathrm{RE}- \\
\mathrm{G}_{4} \mathrm{E}_{5} \mathrm{P}_{4} \\
\text { REG5E54 }\end{array}$ & $\begin{array}{l}\text { Argumenten oral- } \\
\text { mente sobre las ca- } \\
\text { racterísticas e impor- } \\
\text { tancia de la oralidad. }\end{array}$ & $\begin{array}{l}\text { La argumentación } \\
\text { oral. Características } \\
\text { (elementos, funcio- } \\
\text { nes y tipos de argu- } \\
\text { mentos). Aplicación } \\
\text { mediante el debate. }\end{array}$ \\
\hline & 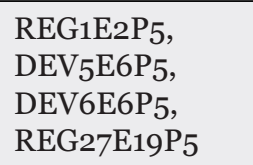 & $\begin{array}{l}\text { Identifiquen los com- } \\
\text { ponentes y funciones } \\
\text { del debate y aplí- } \\
\text { quenlos. }\end{array}$ & $\begin{array}{l}\text { Componentes y fun- } \\
\text { ciones del debate. }\end{array}$ \\
\hline
\end{tabular}




\begin{tabular}{|c|c|c|c|}
\hline \multirow{6}{*}{ 宽 } & $\begin{array}{l}\mathrm{DEV} 1 \mathrm{E} 2 \mathrm{P} 7 \\
\mathrm{DEV} 4 \mathrm{E} 2 \mathrm{P} 7 \\
\mathrm{REG} 2 \mathrm{E} 2 \mathrm{P} 7\end{array}$ & $\begin{array}{l}\text { Identifiquen elemen- } \\
\text { tos del reportaje y } \\
\text { seleccionen informa- } \\
\text { ción pertinente para } \\
\text { presentar uno. }\end{array}$ & $\begin{array}{l}\text { El reportaje. Caracte- } \\
\text { rísticas y producción. }\end{array}$ \\
\hline & $\begin{array}{l}\text { REG2E3P3, RE- } \\
\text { G7E6P3, } \\
\text { DEV9E8P3 }\end{array}$ & $\begin{array}{l}\text { Analicen la conver- } \\
\text { sación telefónica y la } \\
\text { conversación sobre } \\
\text { un texto leído como } \\
\text { insumos que permi- } \\
\text { ten abordar el estu- } \\
\text { dio de la oralidad. } \\
\end{array}$ & El papel de la oralidad. \\
\hline & $\begin{array}{l}\mathrm{DEV}_{2 \mathrm{E}} \mathrm{P} 10 \\
\mathrm{REG}_{2} \mathrm{E}_{2} \mathrm{P} \\
\mathrm{REG}_{4} \mathrm{E}_{3} \mathrm{P} 10\end{array}$ & $\begin{array}{l}\text { Determinen la im- } \\
\text { portancia de la escu- } \\
\text { cha en la vida escolar } \\
\text { y social. }\end{array}$ & La actitud de escucha. \\
\hline & $\begin{array}{l}\text { REG1E2P12, } \\
\text { REG2E4P12, RE- } \\
\text { G3E4P12 }\end{array}$ & $\begin{array}{l}\text { Identifiquen expe- } \\
\text { riencias, dificultades } \\
\text { y aciertos como ha- } \\
\text { blantes/oyentes en } \\
\text { situaciones de uso de } \\
\text { la oralidad. }\end{array}$ & $\begin{array}{l}\text { La experiencia de } \\
\text { hablar en contextos } \\
\text { académicos y sociales. }\end{array}$ \\
\hline & $\begin{array}{l}\text { DEV1E1P8, } \\
\text { REG1E1P8, } \\
\text { DEV12E10P8 }\end{array}$ & $\begin{array}{l}\text { Identifiquen los ele- } \\
\text { mentos relacionados } \\
\text { con el discurso oral. }\end{array}$ & $\begin{array}{l}\text { Características de } \\
\text { una exposición oral. }\end{array}$ \\
\hline & $\begin{array}{l}\text { DEV1E1P11, } \\
\text { REG1E2P11, } \\
\text { DEV23E10P11 }\end{array}$ & $\begin{array}{l}\text { Identifiquen los ele- } \\
\text { mentos de la comuni- } \\
\text { cación oral en el blog. }\end{array}$ & $\begin{array}{l}\text { Diferencia entre len- } \\
\text { guaje y lenguaje oral. }\end{array}$ \\
\hline \multirow{3}{*}{ 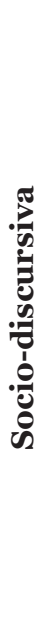 } & $\begin{array}{l}\text { REG4E2P13, } \\
\text { REG2oE12P13, } \\
\text { REG21E14P13 }\end{array}$ & $\begin{array}{l}\text { Debatan sobre la lec- } \\
\text { tura del libro El ban- } \\
\text { quete de las moscas y } \\
\text { asuman una posición } \\
\text { crítica frente a una } \\
\text { problemática social. }\end{array}$ & $\begin{array}{l}\text { La posición crítica } \\
\text { frente a una proble- } \\
\text { mática social. La ac- } \\
\text { tivación de la escucha } \\
\text { comprensiva y la in- } \\
\text { teracción crítica. }\end{array}$ \\
\hline & $\begin{array}{l}\text { REG10E6P9, } \\
\text { REG9E4P9, } \\
\text { REG12E6P9, } \\
\text { REG14E6P9 }\end{array}$ & $\begin{array}{l}\text { Analicen los aspectos } \\
\text { ideológicos del pro- } \\
\text { grama «El gallo» de } \\
\text { la emisora Radio Ac- } \\
\text { tiva de Caracol Radio. }\end{array}$ & $\begin{array}{l}\text { La radio como prácti- } \\
\text { ca social y comercial. }\end{array}$ \\
\hline & $\begin{array}{l}\text { REG2E4P6, } \\
\text { DEV}_{3}{ }_{5} \mathrm{P} 6 \\
\mathrm{REG}_{5} \mathrm{P}_{5} \\
\mathrm{DEV}_{5} \mathrm{E} 8 \mathrm{P} 6\end{array}$ & $\begin{array}{l}\text { Diferencien el len- } \\
\text { guaje poético del len- } \\
\text { guaje común median- } \\
\text { te, el análisis de un } \\
\text { poema y una canción. }\end{array}$ & $\begin{array}{l}\text { La posición crítica } \\
\text { frente al contenido } \\
\text { y usos del lenguaje } \\
\text { poético y el lenguaje } \\
\text { común. }\end{array}$ \\
\hline
\end{tabular}

Fuente: elaboración propia 
Como se aprecia, la mayoría de profesores hace énfasis en contenidos de aprendizaje de la lengua oral centrados en algunos de sus aspectos comunicativos y pragmáticos que incluyen conceptos y actitudes aplicados a actividades orales ocasionales. Esta concepción corresponde a un nivel intermedio (N2), en tanto plantea una tendencia hacia la enseñanza de los usos y formas de la comunicación oral, especialmente. Por ejemplo, en la SD-P2 denominada «Representando situaciones orales», P2 plantea tres consignas que constituyen referentes para determinar los contenidos de conocimiento de la lengua oral (identifiquen el papel de la voz [rasgos lingüísticos] del contexto y el discurso en diferentes situaciones orales). P2 apela a la memoria didáctica ${ }^{10}$.

DEF1E1P2: vamos a trabajar/a partir de la clase anterior/vamos a mirar qué nos quedó claro de la clase anterior/ sí se acuerdan lo que trabajamos la clase anterior/ que fue la socialización del taller que hicimos sobre oralidad y lo de los dos videos/ icierto?

E: sí/señora

DEV1E1P2: qué nos quedó claro de las dos clases anteriores/ sobre oralidad ¿qué nos quedó claro?

De este modo los estudiantes aluden a las características del contexto, a la importancia de la expresión corporal y a la noción que tienen sobre oralidad. Los contenidos que evoca en el primer episodio de la clase, incluyen conceptos pragmáticos y sociales así como actitudes. A partir de preguntas que formula a los estudiantes, hace que estos recuerden conceptos como contexto y oralidad, los cuales P2 va ampliando y registrando en el tablero.

En general el grupo de docentes tiene en cuenta contenidos que permiten concebir la lengua oral como un instrumento útil e indispensable para la comunicación. Así que en la mayoría de secuencias se opta por incorporar explícitamente unos contenidos referidos a lo que «deben saber» y lo que «deben hacer» (SD-P2, SD-P3, SD-P4, SD-P7, SD-P8, SD-P11), y en algunas secuencias también se vincula el «cómo deben actuar» (SD-P5, SD-P10 y SD-P12).

I0 Es decir, a la evocación de aquellas nociones que se enseñaron con anterioridad. 
Solo una secuencia de enseñanza (SD-P1) se centra en lo que «deben hacer» y su posterior valoración subjetiva de la acción realizada; por tanto, «los contenidos de conocimiento de la lengua oral se reemplazan por actividades orales ocasionales». Esta concepción corresponde al nivel inicial (N1), en razón a que da prioridad a la práctica oral carente de una finalidad de aprendizaje y, por tanto, a la construcción de conocimiento. Es decir, aunque en la consigna P1 propuso «representar e interpretar una obra dramática literaria mediante la memorización e improvisación», luego se observa que los estudiantes memorizan el libreto y lo dramatizan, pero no avanzan hacia una reflexión sobre algún contenido de conocimiento de la actividad oral:

DEV4E1P1: yo lo que pretendía era que relacionaran el contexto histórico con el momento actual, de todas maneras que si a ellos se les olvidaba el parlamento, ellos inventaran, tuvieran la posibilidad de inventar (...)

Por último, llama la atención el interés demostrado por los profesores, a través de tres secuencias didácticas (SD-P6, SD-P9 y SD-P13), por el desarrollo de contenidos de saber orientados a la reflexión sobre los usos sociales de la lengua oral, sus componentes, las formas de adaptación formal a cada contexto e interlocutor y las diferentes maneras de gestionar interacciones orales, en función de generar una actitud crítica frente a los discursos orales. Este hecho señala el acercamiento a una concepción lingüístico-discursiva e interaccionista de la oralidad, aunque requiere de un mayor nivel de correlación entre aspectos epistemológicos, procedimentales y actitudinales; por ello esta concepción deseable se sitúa en el nivel de referencia de la hipótesis de progresión (N3).

\section{ANÁLISIS CONTRASTIVO: CORRESPONDENCIAS Y CONTINGENCIAS}

A continuación se presenta un balance de los niveles detectados en la concepción relativa a los contenidos de la lengua oral en los dos planos del análisis y, posteriormente, se examinan y relacionan con los resultados de otras investigaciones referidas a la enseñanza de la lengua oral: 
Tabla 13. Hipótesis de progresión para el análisis de las concepciones acerca de los contenidos de aprendizaje de la lengua oral

Concepciones detectadas acerca de los contenidos de aprendizaje de la lengua oral

\begin{tabular}{|l|l|}
\hline \multicolumn{1}{|c|}{$\begin{array}{c}\text { Derivadas del discurso del } \\
\text { profesor }\end{array}$} & $\begin{array}{l}\text { Derivadas de la acción didáctica } \\
\text { del profesor }\end{array}$ \\
\hline $\begin{array}{l}\text { Concepción inicial (N1) } \\
\text { (P10, P12, P1, P2, P5, P4, P7, P11) }\end{array}$ & $\begin{array}{l}\text { Concepción inicial (N1) } \\
\text { (P1) }\end{array}$ \\
$\begin{array}{l}\text { Los principales contenidos de aprendi- } \\
\text { zaje de la lengua oral deben orientarse } \\
\text { al dominio de sus aspectos lingüísticos y } \\
\text { normativos. }\end{array}$ & $\begin{array}{l}\text { Los contenidos de aprendizaje de la len- } \\
\text { gua oral se reemplazan por actividades } \\
\text { orales ocasionales. }\end{array}$ \\
\hline $\begin{array}{l}\text { Concepción intermedia (N2) } \\
\text { (P10, P12, P3, P6, P4, P5, P7, P9, 13) }\end{array}$ & $\begin{array}{l}\text { Concepción intermedia (N2) } \\
\text { (P3, P2, P4, P5, P7, P8, P10, P12, P11) }\end{array}$ \\
$\begin{array}{l}\text { Los principales contenidos de aprendi- } \\
\text { zaje de la lengua oral deben orientarse al } \\
\text { dominio de sus aspectos pragmáticos y } \\
\text { comunicativos. }\end{array}$ & $\begin{array}{l}\text { Los contenidos de aprendizaje de la } \\
\text { lengua oral consideran algunos de sus } \\
\text { aspectos comunicativos y pragmáticos } \\
\text { que incluyen conceptos y actitudes, apli- } \\
\text { cados a actividades orales ocasionales. }\end{array}$ \\
\hline $\begin{array}{l}\text { Concepción deseable (N3) } \\
\text { (P6, P13, P11) }\end{array}$ & $\begin{array}{l}\text { Concepción deseable (N3) } \\
\text { (P6, P9, P13) }\end{array}$ \\
$\begin{array}{l}\text { Los principales contenidos de aprendizaje } \\
\text { de la lengua oral deben orientarse al do- } \\
\text { minio de sus aspectos lingǘsticos, prag- } \\
\text { máticos, comunicativos y discursivos. }\end{array}$ & $\begin{array}{l}\text { En la enseñanza de la lengua oral pri- } \\
\text { man los contenidos manifiestos en re- } \\
\text { flexiones sobre los usos sociales de la } \\
\text { lengua oral, sus componentes, las for- } \\
\text { mas de adaptación formal a cada con- } \\
\text { texto e interlocutor y las diferentes ma- } \\
\text { neras de gestionar interacciones orales. }\end{array}$ \\
\hline
\end{tabular}

Fuente: elaboración propia

Como puede apreciarse, las concepciones sobre los contenidos de aprendizaje de la lengua oral reflejadas en la acción didáctica de doce de los trece docentes, presentan ciertas variaciones con respecto a sus concepciones previas (en los niveles intermedio y deseable). Algunos profesores, cuya respuesta dada en la entrevista corresponde a un nivel formal de la lengua oral, en los grupos de discusión e incluso en otros momentos de la entrevista dejan ver una concepción distinta a la inicial. Más allá de pretender explicar esta variación en las concepciones de los profesores alrededor de los contenidos 
curriculares de la lengua oral, a continuación se explicitan algunas situaciones que llaman la atención:

Al comparar la intención de los contenidos identificados en el discurso con respecto a los contenidos de saber vehiculizados en la concreción de las consignas, fue posible observar cambios importantes del siguiente orden: algunos dan a conocer el tema de las clases previstas para la secuencia didáctica, como si se tratara de un nuevo contenido curricular; otros, pese a que no lo expresaron a sus estudiantes, lo ven como una sobrecarga para el programa que desarrollan, y otros valoran el hecho de pensar la enseñanza de la lengua oral a través de una secuencia didáctica y coinciden en orientar las tareas de aprendizaje en diferentes contextos comunicativos. En esta perspectiva, los contenidos de saber cobran sentido en la medida en que se materializan en unas tareas pertenecientes a la actividad cotidiana del contexto escolar. Para Dolz, Schneuwly \& Thevenaz (2001), la tarea didáctica está constituida por «un enssemble de consignes qui definnisent un but susceptible d'étre atteint dans l'activité en classe, ainsi que les conditions concrètes d'atteinte de ce but et les actions à exécuter»"11.

El hecho de que los contenidos expresados en el discurso de los profesores y desarrollados en su intervención didáctica, tengan un perfil comunicativofuncional y pragmático, no significa que se esté ante una práctica deseable, sino que se cuenta con un terreno muy fértil para articular la enseñanza de la lengua oral con la ayuda de insumos que posibiliten alcanzar un aprendizaje significativo de los usos orales, no solo en su dominio instrumental (morfo-sintáctico, fonético, semántico), sino también en su dominio comunicativo (contexto, intención comunicativa, interlocutores, etc.), de tal forma que el tránsito hacia una secuenciación y sistematicidad de propuestas planeadas $a$ posteriori sea factible.

Si se parte de considerar que los contenidos de aprendizaje tienen gran importancia en el currículo, y su selección y estructuración ha adquirido especial relevancia en las propuestas curriculares de concepción constructivista, se puede entender lo que significa incorporar un «nuevo» contenido entre los que tradicionalmente se han contemplado en la mayoría de planes

II «un conjunto de consignas que definen un objetivo susceptible de lograr en la actividad en clase, así como las condiciones concretas de lograr este objetivo y las acciones que se deben ejecutar». 
de estudio de lengua materna y literatura para los grados décimo y undécimo (nivel medio de enseñanza o ciclo 5). Cuando se solicita a los profesores participantes en este trabajo el diseño de una secuencia didáctica sobre lengua oral, la primera inquietud es la inclusión de una nueva tarea de enseñanza y aprendizaje, indicando con ello una concepción particular sobre el lugar de la enseñanza de la lengua oral en el contexto de la Educación Media colombiana.

Lo cierto es que, al decidir seleccionar, secuenciar y articular los contenidos al conjunto de componentes del proceso de enseñanza y aprendizaje o al conjunto de experiencias (planificadas o no), se percibe la intención de dar un primer paso hacia la construcción de un «conocimiento didáctico del contenido lingüístico-discursivo oral». Un avance que, desde luego, debe ir acompañado de un conocimiento sobre los componentes y circunstancias para desarrollar la competencia discursiva oral, en este caso de jóvenes que por su edad y condiciones, requieren de unos saberes particulares.

En este punto, de nuevo se observa la ausencia de un conocimiento del objeto de aprendizaje por parte del profesorado, no solo en la selección, secuenciación y concreción de contenidos de conocimiento de la lengua oral, sino en su misma construcción y razón de ser. Esto es que, a partir de los saberes previos de los estudiantes y la observación de las situaciones orales propuestas, los profesores puedan seleccionar los contenidos más adecuados en relación con sus necesidades sociales y su propia idiosincrasia y así avanzar en la reflexión lingüística y discursiva. Para tal fin, es fundamental contar con unos criterios que orienten al maestro en la selección y articulación curricular.

La selección, estructuración y secuenciación de los contenidos ha sido objeto de múltiples estudios en diferentes campos del saber pedagógico. Coll (1987) estima que para concretar los contenidos debe establecerse una correlación con los objetivos y los resultados que se esperan del aprendizaje, y Ausubel (1978) propone establecer secuencias de aprendizaje con una visión de conjunto, abordando las ideas más generales e inclusivas en primer lugar, para después elaborar cada una de ellas, regresando periódicamente a la visión de conjunto con el objeto de ampliarlas y enriquecerlas.

La anterior visión correlacional e integral que facilita una progresión desde lo más genérico e inclusivo hasta lo más detallado y específico, es enriquecida 
por la teoría de la elaboración de Reigeluth y Stein (1983), quienes prescriben criterios para secuenciar contenidos desde dimensiones conceptuales y procedimentales a partir de la idea de Gagné respecto a ciertos conocimientos que deben aprenderse antes que otros, y de Bruner frente al currículo en espiral, que postula el grado progresivo de profundización de los contenidos en distintos niveles educativos.

En todo caso, se trata de superar la tendencia encontrada en esta investigación en relación con la selección de un listado de temas para la enseñanza de la lengua oral, sin que prime una relación entre ellos. Dicha tendencia, según Porlán (1989) encarna un proceso inductivo que a juicio del profesor garantiza que los estudiantes aprendan mediante actividades prácticas desvinculadas de situaciones problémicas con mayor grado de complejidad. Es importante, transformar esta concepción reduccionista por otra donde prime, en igualdad de condiciones, la selección de contenidos de tipo procedimental, conceptual y actitudinal, enfocada al ciclo escolar en pro de facilitar la construcción de un «saber-hacer y valorar» en el marco de situaciones didácticas, cuyas problemáticas reales y prácticas situadas respondan a las necesidades de desarrollo oral de los estudiantes.

Todo lo anterior permite precisar que los avances y dificultades respecto a la formulación de contenidos de saber, están estrechamente relacionados con el conocimiento de la materia y, en particular, con el conocimiento didáctico de la lengua oral.

\section{LA ACTIVIDAD DE ENSEÑANZA DE LA ORALIDAD}

\section{DeSDe El Discurso}

La actividad de enseñanza de la lengua oral presente en el discurso de los profesores, representado en la entrevista y los grupos de discusión, da cuenta de tres niveles de concepción.

El primero corresponde al nivel inicial (N1), la enseñanza reflexiva y sistemática de la lengua oral en el nivel medio de educación no ha sido vinculada a la actividad del aula. 
P2E: no/// no/ porque todo ha sido en escritura y en lectura/ y es más, uno/ uno va y escucha/las propuestas/ o uno va $\rightarrow$ / a por ejemplo/ experiencias exitosas y todos son en/ en escritura o en lectura pero nunca he escuchado oralidad.

El segundo corresponde al nivel intermedio (N2), la enseñanza de la lengua oral en el nivel medio de educación eventualmente se realiza en el marco de determinadas situaciones comunicativas.

P13E: yo trabajé-/ eh/ inicié pero no lo terminé/ era un trabajo que se llamaba $\rightarrow / /$ eh/ tenía que ver como con la argumentación en el aula/ entonces/se titulaba/ profesora usted por qué habla tanto/ eeeh/ porque fue un cuestionamiento que en algún momento/ una niña me hizo eh/ como $\rightarrow$ que siempre el maestro/ es el que-/ tiene como la mayor/ eeh/ parte deeel// uno es que está hablando la mayor parte del tiempo/ en el aula $\uparrow$ / entonces una niña me dijo: profesora usted por qué habla tanto/ que si yo no me cansaba de hablar tanto/y en ese momento yo estaba haciendo la especialización/ entonces yo dije/ oiga/ como que es por ese lado, y entonces empecé/ a plantear todo mi proyecto hacia ahí/ y era sobre la argumentación/ no me acuerdo el/ objetivo claro/ pero era sobre eso/ y en ese año yo alcancé/ a hacer algo muy sen-/ como organizar estrategia frente a-/ desarrollo de la argumentación/ con problemáticas que se vivían en este momento/ en ese espacio escolar $\rightarrow /$ pero...

El tercero concierne al nivel deseado (N3), la enseñanza reflexiva $y$ sistemática de la lengua oral en el nivel medio de educación permanentemente plantea posibles hipótesis de trabajo relacionadas con el dominio comprensivo y expresivo de distintos géneros orales en diversos contextos. Verbigracia:

P2E: analizar digamos textos del discurso oral/ entonces por ejemplo traer eeh programas de radio/ eeh de pronto la conversación informal que uno tenga con alguien/ eeh ponerlos a escuchar y que ellos mismos/ ELLOS mismos/antes de uno enseñarles/ vayan evidenciando/ qué problemas en la oralidad se tienen/ o cómo es ese discurso oral/ y a partir de ahí/ entonces uno puede hacer talleres/guías/ en donde les vaya enseñando/ cuáles son esas pautas para’l discurso oral/.

La siguiente gráfica ilustra el panorama general encontrado en el discurso de este grupo de docentes. La concepción inicial (N1) está representada por 
un 55\% de la población docente entrevistada, seguida por la intermedia (N2), con un $35 \%$ y la deseable $\left(\mathrm{N}_{3}\right)$ con un $10 \%$.

Figura 8. Niveles de la concepción acerca de la actividad de enseñanza de la lengua oral detectados en los trece profesores de lengua castellana

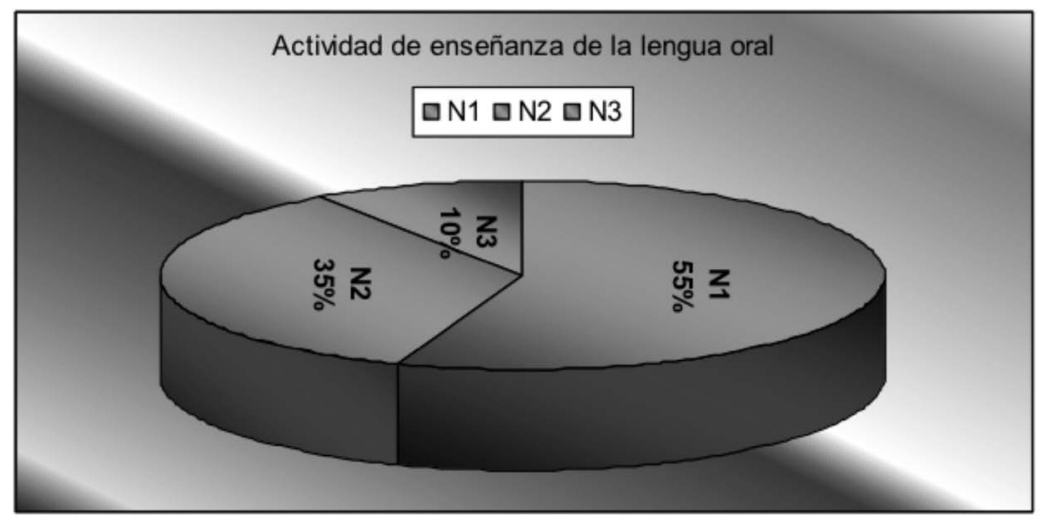

Fuente: elaboración propia

Se destaca, entre otras posibilidades, la de emprender el enriquecimiento expresivo de los educandos; proporcionar herramientas adecuadas para fortalecer la interacción oral, usar los medios de comunicación para generar un espíritu crítico. En fin, se percibe una intención comunicativa, funcional, pragmática y socio-discursiva. Estos niveles de concepción derivados del decir sobre la didáctica de la oralidad, a simple vista pueden parecer plausibles, pero solo la acción misma podrá corroborarlos o no.

\section{DESDE LA ACCIÓN DIDÁCTICA}

Se identifican las concepciones sobre la actividad de enseñanza de la lengua oral a partir de la configuración de las situaciones didácticas presentes en las trece secuencias de enseñanza. Tales situaciones, posteriormente, fueron confirmadas con cada uno de los profesores participantes en el estudio mediante la autoconfrontación conjunta. 
Tabla 14. Situaciones de enseñanza de la lengua oral para Educación Media propuestas por los profesores de Lengua Castellana

\section{SitUACIÓN DIDÁCTICA}

\section{SD-P1: Dramatización de una escena de Hamlet}

Siguiendo la consigna dada por $\mathrm{P} 1$, los estudiantes se organizaron en grupos y seleccionaron una escena de la obra teatral titulada Hamlet. Prepararon su dramatización y la presentaron ante sus compañeros. Luego de cada presentación hablaron sobre esta experiencia.

\section{SD-P2: Representando situaciones orales}

P2 dio indicaciones para realizar un juego de reconocimiento del papel de la voz (rasgos lingüísticos). Dos estudiantes relataron una experiencia al grupo y a un estudiante al que previamente le habían vendado los ojos. Este último tuvo la misión de identificar a las personas que hablaron y sustentar dicho reconocimiento. Frente a esta situación $P_{3}$ destacó la importancia de elementos prosódicos (tono, ritmo, duración, estilo...). Luego, asignó a los estudiantes diferentes situaciones orales (conversación informal, conferencia, debate, lectura en voz alta, noticiero, etc.) y solicitó que fueran representadas a partir de temáticas indagadas previamente. Finalmente, interrogó a los grupos sobre las condiciones que tuvieron en cuenta para la preparación de las representaciones y la presencia de las características de la oralidad.

\section{SD-P3: Entre la oralidad y la escritura}

P3 dió las indicaciones para que, por parejas de estudiantes, simularan un diálogo telefónico y fueran observados por otra pareja que registrara sus características. Luego de la puesta en común y el análisis, P3 procedió a formular las preguntas que guiaron las intervenciones de los estudiantes en torno a un texto leído previamente. Finalmente, propuso tres aspectos para la reflexión entre oralidad y escritura: cognitivos, dialógicos y pragmáticos.

\section{SD-P4: La argumentación oral}

P4 formuló preguntas sobre la argumentación para comprobar la apropiación del tema por parte de los estudiantes. Luego les explicó que cada grupo debía sustentar la pregunta asignada relacionada con la oralidad a partir de una tesis y premisas. Durante el desarrollo de esta actividad, $\mathrm{P} 4$ abandonó su rol de moderador para aportar, aclarar y cuestionar acerca de las tesis y premisas presentadas por los estudiantes. Finalmente, orientó la evaluación y conclusiones.

\section{SD-P5 Preparando un debate}

Se planteó el desarrollo de un debate a partir de la reflexión sobre su importancia y funcionamiento. Para ello P5 explicó sobre la finalidad, la necesidad de entender el discurso dialógico, los argumentos a favor y en contra, los turnos de la palabra, etc. 


\section{SD-P7 Preparando un reportaje para la emisora escolar}

P7 partió de proponer a E escuchar un reportaje sobre una temática de interés social (el suicidio), con el fin de que los estudiantes lograran identificar sus características, y procedieran con ello a planear un reportaje sobre el descubrimiento de América, el cual presentarían a través de la emisora escolar. Luego de escuchar el reportaje, P7 explicó un listado de características registradas en el tablero: información, selección de la información, música, tiempo, orden, uso del lenguaje apropiado (tener en cuenta quién es el oyente), tipo de entrevista o programa y elementos impactantes. Finalmente, dio paso al trabajo en grupo, recordando el tema del reportaje (el 12 de octubre) y explicando la importancia de desarrollar el esquema propuesto.

\section{SD-P8 Análisis de un foro escolar}

P8 lista en el tablero cada uno de los aspectos que fueron propuestos para desarrollar un foro: gestos, posturas, modo, calidad, dominio del público y del tema. Realizó esta lista con los aportes de los estudiantes y procedió a preguntar sobre su uso en términos de dificultades y aciertos. Luego, P8 relacionó esta puesta en común con aspectos que debían guiar el trabajo sobre oralidad en el cuarto periodo: calidad de la información (documentación, citas), seguridad por parte del expositor (gestos, postura, ademanes), orden en el discurso, preparación, el papel del moderador. Finalmente, indicó que la finalidad de analizar el primer foro era identificar los inconvenientes desde un ejercicio consciente.

\section{SD-P9 Análisis de un programa radial}

P9 inició con la contextualización del trabajo (análisis de un programa de radio), solicitando la lectura de dos definiciones de radio consignadas en un material que tenían los estudiantes, para luego indicar que su intención era ver cómo la radio es una tecnología y parte de la industria de la realidad. Luego P9 amplió los elementos a analizar a través de preguntas que funcionaron como pistas para lograr indagar sobre el contexto macro (Caracol Radio) del programa El gallo. Con la puesta en común de lo que indagó cada grupo, P9 señaló la intención de construir un texto que dé elementos de análisis.

\section{SD-P10 ¿Escuchamos u oímos?}

P10 presentó al grupo de estudiantes su preocupación por la dinámica de violencia generada al interior del grupo (problema) y estableció una relación entre esta situación y el objetivo fundamental de su materia (estrategia), orientado a cualificar las habilidades comunicativas (escuchar, hablar, leer y escribir), por tanto, señaló que en esta sesión de clase se centraría en la escucha (objeto de aprendizaje). Para tal fin, P1o propuso al grupo el ejercicio de escuchar lo que estaba pasando fuera del salón y enfatizó en la necesidad de diferenciar entre escuchar y oír porque «cuando se escucha no solo se oye, sino también se interpreta». Esta y otras afirmaciones estaban plasmadas en una cartelera que dispuso en el tablero (medio didáctico) y que ofició como guía de la explicación que P1o realizó durante esta sesión de clase. 


\section{SD-P11 La comunicación cotidiana y virtual}

P11 inició con la presentación del tema (la comunicación) y el propósito de la clase (entender que la comunicación no es solo la transmisión de información, sino que posee una intención y un sentido), para dar paso a la pregunta ¿̇cuáles son los componentes de la comunicación? De este modo, P11 fue graficando en el tablero los aportes de los estudiantes (mensaje, emisor, receptor, retroalimentación, contexto, canal y código). Posteriormente, P11 hizo transito a otra pregunta, luego de señalar que hay dos clases de lenguaje (verbal y no verbal): ¿̇cuál es la intención de comunicarnos? e introdujo esta situación en el trabajo realizado durante la clase anterior, donde los estudiantes interactuaron virtualmente a través de un blog. Con esto aludió a la importancia de identificar el contexto, tiempo y participantes.

\section{SD-P12 La experiencia de hablar en público}

P12 inició con la invitación a responder, de forma individual, la siguiente pregunta: ¿́cuál es la mayor dificultad que usted tiene cuando se trata de hablar en público? Terminado el tiempo para el trabajo individual, les indicó que compartieran lo escrito con el compañero (a) del lado e identificaran elementos comunes. A medida que los estudiantes iban expresando los elementos comunes, P12 los fue registrando en el tablero, a la vez que fue interpelando y ampliando algunos de los aportes. Finalmente, P12 presentó cinco recomendaciones y solicitó a los estudiantes sustentar cuál les interesaba más, bien fuera porque sentían que la dominaban o porque necesitaban mejorar en ese aspecto: 1) Tener una intención, 2) Definir o reconocer al destinatario o público, 3) Tener en cuenta la coherencia entre las ideas para garantizar la claridad, 4) Planear el discurso oral, y 5) Reconocer la estructura formal del discurso oral que va a producir.

\section{SD-P13 Análisis de una obra literaria}

P13 contextualizó al grupo sobre la actividad a realizar: debate sobre el libro El banquete de las moscas y su relación con la situación de la calle «del Cartucho» de Bogotá, y entregó a cada estudiante un documento que contenía los propósitos y tareas a desarrollar. Luego invitó a los estudiantes a organizarse en grupos de acuerdo con unos criterios establecidos por P13, con el fin de realizar una actividad con dos etapas; la primera consistía en discutir a nivel grupal en torno a las preguntas preparadas previamente. Cada grupo debía elegir un líder identificado por su capacidad para organizar el grupo y asegurar que todos participaran y trabajaran activamente en la tarea propuesta. La segunda, consistió en fijar una posición grupal alrededor de las preguntas abordadas y preparar los argumentos necesarios para interactuar con los demás grupos.

\section{SD-P6 Análisis de dos textos poéticos}

P6 invitó a los estudiantes a leer un poema y a escuchar una canción para que luego discutir acerca de la temática, las características del lenguaje y la selección del verso más impactante. Inicialmente, los estudiantes intercambiaron ideas sobre aspectos sociales, ideológicos y contextuales relacionados con los dos textos sin la intervención de P6. Finalmente, intervino retomando los aportes dados por E y profundizando en algunos de ellos. 
La descripción y comprensión de la evolución de la actividad didáctica implica partir de los cambios «mesogenéticos» (o las transformaciones del medio didáctico y de los objetos de saber) los cuales se perciben a través de los gestos de «regulación» del profesor sobre la actividad del estudiante y del medio didáctico en función de sus objetivos didácticos. De igual forma, los cambios «topogenéticos» (o los desplazamientos de las posturas de acción de los participantes alrededor de las diferentes fases de la tarea), se describen mediante gestos de «devolución» del profesor al involucrar al estudiante en las responsabilidades que le competen. Ahora bien, la «cronogénesis» (o proceso mediante el cual se «definen» las tareas), por lo general corresponde a la manera como el profesor introduce el objeto de saber y las condiciones con las que se cuenta para su construcción.

Esta tripleta de procesos didácticos y sus correspondientes descriptores (mesogénesis-regulación, topogénesis-devolución y cronogénesis-definición e institucionalización), propuestos en este modelo de la acción docente (Sensevy, et ál., 2000; Sensevy, 2007; Rickenmann, 2006b), permiten dar cuenta de la gramática interna de los juegos de saber y, en últimas, comprender mejor los modos de construcción del saber en la clase. En esta investigación, los dos primeros ${ }^{12}$ contribuyen a responder las preguntas por las disposiciones, gestos, posturas y concepciones de los participantes ${ }^{13}$ y el proceso cronogenético permite identificar la consigna; es decir, la manera como el profesor introduce el objeto de enseñanza.

Se selecciona la situación de enseñanza como unidad de información, teniendo en cuenta que corresponde a la interacción de los agentes (educador y educando) con un medio didáctico, cuya transformación favorece la construcción de un saber determinado. La interacción se representa en transacciones didácticas o intercambios de carácter comunicativo o jerárquico.

Debido a la dimensión del corpus correspondiente a la acción didáctica del profesor, representado en trece secuencias didácticas, a continuación se presenta el análisis de un episodio de una secuencia didáctica (SD-P10) se-

12 Devolución y regulación son las dos nociones que nos muestran más claramente la dimensión semio-pragmática de la relación didáctica. La relación didáctica se construye a partir de un sistema de expectativas mutuas.

I3 Cuando el profesor enseña un saber de su disciplina, crea los medios para lograr un aprendizaje efectivo. En esta tarea juegan un papel importante, tanto su concepción sobre el objeto de enseñanza, como su capacidad para gestionar el contrato y las transacciones didácticas, etc. 
leccionada intencionalmente, con el fin de analizarla desde los tres procesos didácticos mencionados y señalar cómo este análisis contribuye a configurar las concepciones predominantes respecto a las situaciones de enseñanza de la lengua oral.

La SD-P1o fue planeada atendiendo a la realidad de un grupo de estudiantes con dificultades de escucha. La necesidad de resolver este problema constituye un desafío intelectual que P10 asume a través de la situación didáctica conformada por varias actividades: a) ejercicio de escucha, b) explicación relacionada con la diferencia entre escuchar y oír, c) situación hipotética relacionada con un evento del colegio, d) explicación de la situación anterior, e) lectura y explicación de una caricatura relacionada con el valor de las palabras y la escucha, f) interacción con los estudiantes frente al tema del «comentario», y g) explicación relacionada con los factores que afectan la escucha.

Específicamente, en el episodio número dos, desde el punto de vista de los procesos mesogenéticos se advierte la manera como se combina la explicación del profesor diez (P10) con los saberes previos de los estudiantes (E). En dicho episodio y a lo largo de la secuencia didáctica, P1o orienta la clase, indicando con ello la intención permanente de controlar la interacción oral de los participantes (situación didáctica de control); además, es usada para asegurar la comprensión de $\mathrm{E}$ frente a la diferencia entre escuchar y oír, la cual se fue concretando a través de las preguntas formuladas por P10 y que corresponden a devoluciones encaminadas a facilitar la comprensión del valor de la escucha. De este modo emergen, simultáneamente, procesos mesogenéticos y topogenéticos, como se observa en el cuadro clínico que sigue.

Por su parte, los procesos cronogenéticos se materializan mediante la definición de la tarea, la cual da lugar a un encadenamiento de actividades que, a su vez, ponen en marcha la situación didáctica. En síntesis, la dinámica general de la SD-P1O se caracteriza por regulaciones y devoluciones continuas de P1o hacia los estudiantes, lo cual se traduce en un limitado espacio para la 
interacción oral de los estudiantes, siendo evidente el control permanente de P10 frente a las tareas de aprendizaje. A tal punto que el uso de la palabra de P10 ocupa un tiempo importante. La regulación excesiva de las interacciones le impide identificar determinadas oportunidades de intervención de $\mathrm{E}$ en virtud de construir una acción didáctica más colaborativa.

Sin duda, la acción didáctica de P10 fluctúa entre la reflexión metalingüística como contenido de conocimiento y por ende refleja una conciencia sobre la actividad de escuchar y el medio didáctico -en este caso el tipo de interacción que genera con los estudiantes- corresponde a un modelo de enseñanza tradicional. En general, en las trece secuencias de enseñanza subyace una fluctuación entre situaciones didácticas donde la responsabilidad del aprendizaje parece ser exclusiva del profesor (N1) y situaciones donde se intenta una construcción significativa del conocimiento (N2). En otras palabras:

En el nivel inicial, el profesor de lengua castellana plantea eventualmente situaciones didácticas asociadas a temas articulados a ejercicios; algunos coherentes con los medios didácticos diseñados en función de la explicación del profesor, relacionada con el uso social de la lengua oral en diversos contextos.

Y en el nivel intermedio, el profesor de lengua castellana plantea eventualmente situaciones didácticas asociadas a temas articulados a una secuencia de actividades, en su mayoría, coherentes con los medios didácticos diseñados en función de que los estudiantes tomen decisiones por sí mismos frente al uso social de la lengua oral en diversos contextos.

Las expectativas frente a un nivel de concepción alternativo o deseable (N3) se configuran de este modo: el profesor de lengua castellana plantea de manera sistemática situaciones didácticas asociadas a problemas y contenidos articulados a una secuencia de actividades que, a su vez, son coherentes con los medios didácticos diseñados y con las distintas formas de evaluación que buscan la construcción de un saber-hacer relacionado con el uso social de la lengua oral en diversos contextos y niveles de complejidad. 


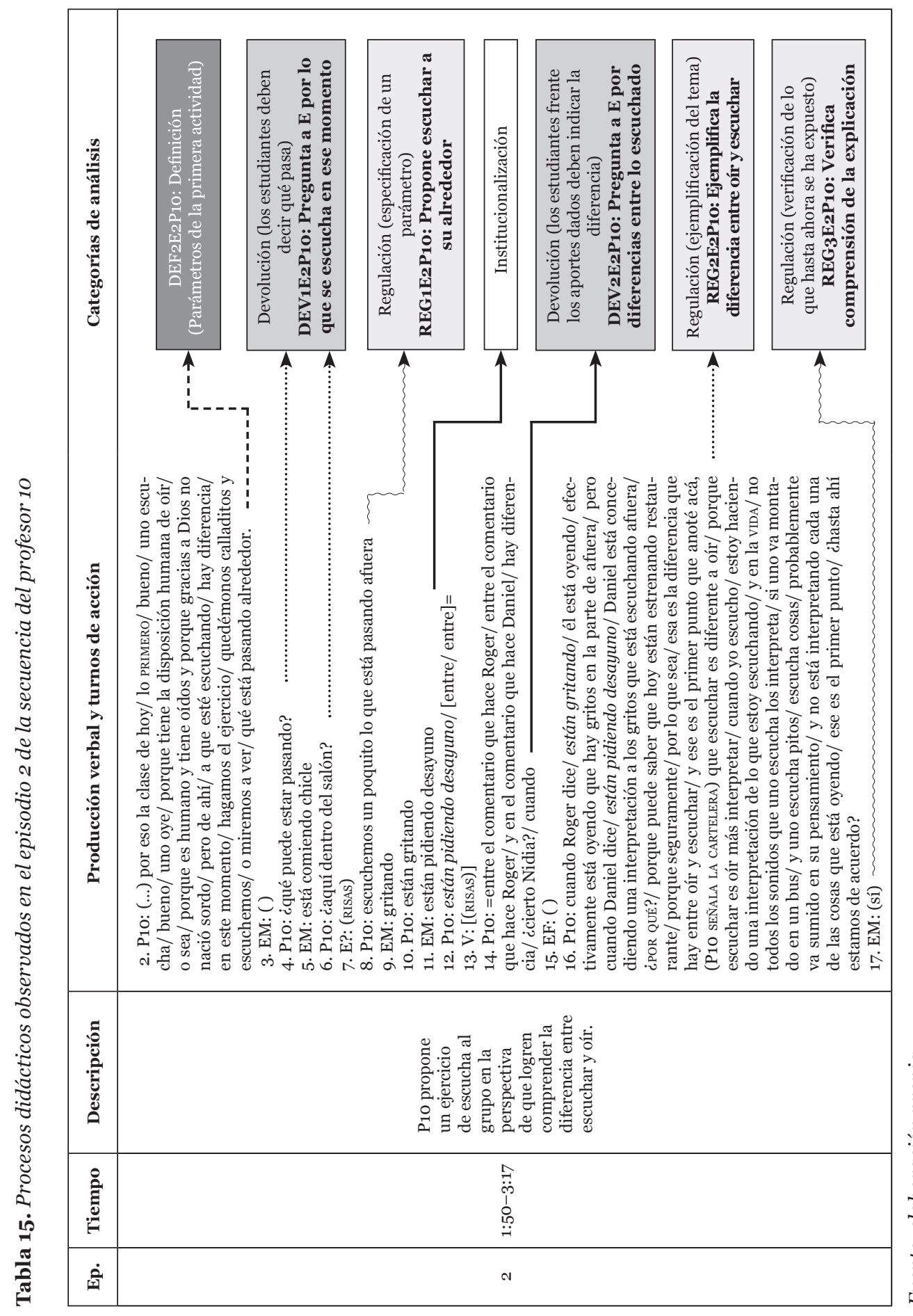

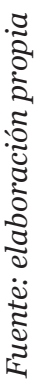


Ahora bien, la interrelación entre el profesor, los estudiantes y el medio didáctico configura una serie de situaciones didácticas donde la presencia de dicho medio didáctico constituye un indicio clave en los procesos de construcción del conocimiento (mesogenéticos), ya que facilita o no los procesos de enseñanza y aprendizaje de la lengua oral. En este estudio se procede a identificarlo, compararlo y categorizarlo en las propuestas de intervención de los trece profesores.

Tabla 16. Medios didácticos propuestos por los profesores de Lengua Castellana para la enseñanza de la lengua oral para Educación Media

\section{El medio didáctico instaurado}

P3: Preguntas elaboradas por los mismos estudiantes a partir de un texto leído previamente y un esquema que recoge las inferencias principales sobre el tema.

P4: Material de lecturas científicas/especializadas. Explicación y preguntas para retomar lo hecho en días anteriores. La asignación del rol: cada mesa de trabajo es un orador.

P6: Lectura de un poema y una canción y consigna.

P7: Lectura acerca de cómo hacer reportajes radiales y reportaje en audio sobre un tema determinado.

P13: El libro: El banquete de las moscas, guía orientadora donde aparece el sentido de argumentar y las funciones de los participantes en un proceso argumentativo y preguntas para debatir.

P8: Transcripción de producciones orales de los estudiantes a partir de la filmación.

P11: Transcripción de la conversación a través del blog.

$\mathrm{P}_{5}$ : El tablero donde se registraron ideas sobre el debate.

P9: El tablero donde recogieron las ideas más importantes del tema, luego la guía escrita y la Internet.

P10: Cartelera elaborada por la profesora, exposición de la profesora, lectura de una caricatura, ejercicios y preguntas.

P12: Cuaderno de clase con relato de situaciones de uso oral.

P2: Actividad de sensibilización, consigna y fichas.

P1: Dramatización de escena de Hamlet.

Fuente: elaboración propia 
Así, pues, se identifica el medio didáctico por su contenido y por sus formas de uso y organización, encontrándose que el empleado por los profesores que le apuestan a la enseñanza de la lengua oral, corresponde a:

A. La pregunta es uno de los elementos fundamentales en la interacción en el aula y en la acción didáctica del profesor. Como medio didáctico central, está presente en mayor medida en la SD-P3, donde el profesor formula ciertas preguntas alrededor de un texto que los estudiantes han leído previamente. De este modo, cada pregunta conlleva a un intercambio de ideas, constituyéndose en un elemento dinamizador de la interacción.

Esta concepción de la interrogación como medio para motivar la comunicación oral en algunas de las secuencias didácticas analizadas, sitúa al estudiante en el papel de agente pasivo y receptivo del saber del profesor, situación que contrasta con la idea de que las preguntas del profesor se constituyan en modelo y estímulo para las preguntas de los educandos. Esta concepción de la interrogación se orienta a comprobar un saber establecido con fines evaluativos. Sin embargo, las preguntas siguen siendo el medio didáctico por excelencia; su efectividad depende del tipo de preguntas y del modo como las realiza el profesor, determina los grados de libertad del estudiante para indagar en otros campos y para efectuar operaciones lógicas y, en consecuencia, fomentan la participación, la discusión, y en general, la interacción oral.

B. Las consignas actúan como instrumentos mediadores de la actividad de enseñanza y, en particular, median en la interacción entre el docente y los educandos. Cabe señalar que la consigna emerge en el proceso de planeación de la acción didáctica y se materializa en enunciados orales o escritos. En las consignas subyacen concepciones relacionadas con la enseñanza y el aprendizaje de la oralidad. Para una mayor comprensión de este fenómeno, se presentan en el apartado correspondiente a los contenidos de formación, por ello no son motivo de profundización aquí.

C. Los materiales curriculares como textos académicos, guías, textos literarios, transcripciones, carteleras, tablero, cuadernos, etc., los cuales ofician como medios didácticos, se encuentra que son asumidos como medios, instrumentos o soportes que facilitan las tareas de aprendizaje, y su contenido da cuenta de saberes institucionalizados. 
Es importante precisar que el tablero y la cartelera recogen saberes que los participantes van legitimando, mientras que las transcripciones y el cuaderno, en este caso, corresponden a experiencias relacionadas con situaciones comunicativas orales de los mismos participantes, por tanto, operan como objetos de reflexión. En el caso de los textos académicos y literarios, actúan como pretextos para realizar diferentes actividades orales, entre ellas conversar, dramatizar, debatir, etc.

En general, se observa que los medios didácticos empleados tienen un carácter pedagógico (estrategias individuales o colectivas), semiótico (sistemas de conceptualización materializados) y pragmático (tiempo, esfuerzo y dedicación). Esta naturaleza del medio didáctico, según Rickenmann (2007), sugiere el uso de una «mediación semiopragmática» donde cada participante tiene como fin asumir su rol y acciones sobre el medio didáctico, de tal forma que se opte por una «responsabilidad en la acción compartida».

\section{ANÁliSIS CONTRASTIVO: CORRESPONDENCIAS Y CONTINGENCIAS}

A continuación se presenta un balance de los niveles identificados en la concepción sobre la actividad de enseñanza de la lengua oral en los dos planos del análisis: el discurso y la práctica pedagógica.

Tabla 17. Hipótesis de progresión para el análisis de las concepciones sobre la actividad de enseñanza de la lengua oral

\begin{tabular}{|l|l|}
\hline \multicolumn{2}{|c|}{ Concepciones detectadas sobre la actividad de enseñanza de la lengua oral } \\
\hline \multicolumn{1}{|c|}{ Derivadas del discurso del profesor } & Derivadas de la acción didáctica del profesor \\
\hline $\begin{array}{l}\text { Concepción inicial (N1) } \\
\text { (P10, P11, P12, P1, P2, P3, P4, P5, P6, }\end{array}$ & $\begin{array}{l}\text { Concepción inicial (N1) } \\
\text { (P1,P8, P10) }\end{array}$ \\
$\begin{array}{l}\text { P7, P8, P9, P13) } \\
\begin{array}{l}\text { La enseñanza reflexiva y sistemática } \\
\text { de la lengua oral en el nivel medio de } \\
\text { educación no ha sido vinculada a la ac- } \\
\text { tividad del aula. }\end{array}\end{array}$ & $\begin{array}{l}\text { El profesor de lengua castellana plantea } \\
\text { eventualmente situaciones didácticas } \\
\text { asociadas a temas articulados a ejerci- } \\
\text { ciosunos, coherentes con los medios } \\
\text { didácticos diseñados en función de la ex- } \\
\text { plicación del profesor relacionada con el }\end{array}$ \\
$\begin{array}{l}\text { uso social de la lengua oral en diversos } \\
\text { contextos. }\end{array}$ \\
\hline
\end{tabular}




\section{Concepción intermedia (N2) \\ (P10, P11, P12, P1, P3, P4, P5, P6, P7, $\mathrm{P} 9, \mathrm{P} 13)$}

La enseñanza de la lengua oral en el nivel medio de educación eventualmente se desarrolla en el marco de determinadas situaciones comunicativas.

\section{Concepción deseable (N3)}

(P10, P1, P2, P3, P4, P5, P6 )

La enseñanza reflexiva y sistemática de la lengua oral en el nivel medio de educación permanentemente plantea posibles hipótesis de trabajo relacionadas con el dominio comprensivo y expresivo de distintos géneros orales en diversos contextos.

\section{Concepción intermedia (N2)}

(P1, P6, P3, P4, P5, P6, P7, P8, P9, P10, $\mathrm{P} 11, \mathrm{P} 12, \mathrm{P} 13)$

El profesor de lengua castellana plantea eventualmente situaciones didácticas asociadas a temas articulados a una secuencia de actividades, en su mayoría, coherentes con los medios didácticos diseñados en función de que los estudiantes tomen decisiones por sí mismos frente al uso social de la lengua oral en diversos contextos.

\section{Concepción deseable (N3) \\ (ninguno)}

El profesor de lengua castellana plantea de manera sistemática situaciones didácticas asociadas a problemas y contenidos articulados a una secuencia de actividades que, a su vez, son coherentes con los medios didácticos diseñados y con las distintas formas de evaluación que buscan la construcción de un saber-hacer relacionado con el uso social de la lengua oral en diversos contextos y niveles de complejidad.

\section{Fuente: elaboración propia}

Los resultados muestran que los niveles de concepción acerca de la actividad de enseñanza de la lengua oral, tanto en el decir como en el hacer del grupo docente, reflejan tal complejidad debido a su fluctuación e hibridación -principalmente entre los niveles inicial e intermedio-, que se opta por dar mayor relevancia a algunos aspectos propios de la actividad didáctica.

Se encuentra que las transacciones didácticas se efectúan especialmente mediante regulaciones y devoluciones, las cuales se caracterizan por su diversidad en los modos de concreción. Las regulaciones van desde la explicación directa de un saber específico de la lengua oral, hasta la puesta en escena de una serie de actividades orientadas a modificar la actividad cognitiva de los estudiantes. Las devoluciones van desde la transferencia total de la responsabilidad del aprendizaje, pasando por la interacción cooperativa a partir de preguntas retóricas e intercambios frecuentes, hasta aquellas devoluciones 
que generan actuaciones decididas de los estudiantes frente al objeto de aprendizaje y, en consecuencia, a su progresión. De todas formas se mantiene la función docente descrita por Bolívar y Domingo (2007) como una autoridad que disemina conocimientos a los estudiantes, mediante intercambios verbales o textos y la relevancia de la gestión topogenética, cronogenética y mesogenética de las actividades de enseñanza y aprendizaje de la lengua oral.

El análisis de uno de los episodios de las tres secuencias didácticas referidas, da cuenta de las diferencias notables respecto a lo que hacen los maestros y los estudiantes en torno a un mismo objeto de aprendizaje. Mientras en la SD-P1 se delega toda la responsabilidad del aprendizaje al estudiante, del cual se espera que al estar motivado por las tareas de comprender, memorizar y dramatizar una escena de Hamlet, logre hacer uso de la improvisación, sin que el maestro intervenga durante la fase de aprendizaje, en la SD-P6 se delega a los estudiantes la responsabilidad de conversar acerca de la temática, las características del lenguaje y la selección del verso más impactante de un poema y una canción, sin que el maestro intervenga inicialmente. En las dos secuencias se advierte la intención de que el docente adopte una actitud pasiva $^{14}$ durante la interacción de los estudiantes con el medio didáctico, detectándose estas diferencias:

a) En la SD-P1 los estudiantes interactúan por sí mismos con un medio didáctico, cuya transformación debe favorecer el aprendizaje. El profesor interviene en el momento de la evaluación mediante continuas devoluciones.

b) En la SD-P6 los estudiantes interactúan por sí mismos con un medio didáctico que les ofrece información tendiente a favorecer un momento del aprendizaje. El profesor interviene en los demás momentos mediante algunas regulaciones y devoluciones.

Si bien se trata de situaciones creadas por los profesores con el objetivo didáctico de construir un saber, en las dos secuencias se perciben intenciones diferenciadas respecto al papel docente. Esto es, en la SD-P1 el profesor no interviene en la orientación del estudiante porque considera que este puede, por sí solo, construir dicho saber; por tanto, supedita la institucionalización ${ }^{15}$ del conocimiento a los avances logrados por el estudiante. Mientras que en

I4 En el sentido de no develar el conocimiento en juego.

I5 Se trata de la validación del conocimiento delegada al juicio del maestro. 
la SD-P6 el profesor no interviene en la orientación del estudiante durante el momento de la comprensión del medio didáctico porque considera que es importante que primero el estudiante confronte su punto de vista con el de sus compañeros e intente asumir una posición crítica frente al objeto de saber; por tanto, algunos acercamientos a la institucionalización del conocimiento ocurren posteriormente, durante la intervención docente.

Este tipo de situaciones son denominadas por Brousseau (1990 y 1991) «adidácticas», en tanto se caracterizan por la no intervención del maestro durante un momento del aprendizaje (y no de la enseñanza), con el fin de que los estudiantes encuentren por sí mismos relaciones entre sus elecciones y los resultados que obtienen, constituyendo un paso importante en la evolución del conocimiento. Las consecuencias de esta transferencia de responsabilidades son asumidas por el maestro.

Ahora bien, si se tienen en cuenta las dificultades expresadas por P1 y P6 en relación con la finalidad de sus respectivas secuencias de enseñanza, estas se refieren a que los estudiantes no toman en cuenta la consigna global, y el tiempo se considera como un obstáculo en las discusiones de aula, respectivamente. Se puede inferir entonces, que la situación de aprendizaje de la SD-P1 no logra responder a las expectativas de P1, en tanto la puesta en escena de una situación adidáctica requiere del diseño previo de una situación didáctica global, donde si bien se ofrece la posibilidad al estudiante de construir por sí mismo un saber en un espacio y tiempo propios, no se le puede delegar totalmente esta tarea, dada la responsabilidad social del profesor frente a la orientación en la evolución de dicho saber.

Ahora, frente a la tarea de improvisar o crear parlamentos, esta requiere de una profunda planificación y de tiempo suficiente para seleccionar, ampliar, ordenar las ideas, saber comunicarlas y adecuarlas a la situación y estilo personal (Vilá, 2010). Por tanto, al recaer toda la responsabilidad del aprendizaje sobre el educando, se desvirtúa el papel de la devolución didáctica y, con ello, la consecuente progresión en la apropiación del objeto de saber. Este hecho se constata en la ausencia de procesos cronogenéticos, configurados en el manejo inadecuado del tiempo didáctico y en la falta de gestos de regulación, cuya finalidad es transformar el medio didáctico. Desde luego, el predominio de gestos de devolución en contraste con la ausencia de gestos profesionales de regulación, resta eficacia a los primeros, ya que no se apoyan sobre la gestión 
del profesor en la construcción de nuevos aprendizajes, sino que se quedan en el conocimiento previo de los estudiantes.

Por una parte, P1 no considera un tiempo didáctico que le permita reflexionar sobre las potencialidades y limitaciones del medio didáctico (dramatización) en función de la tarea de aprendizaje y, en consecuencia, no le es posible proporcionar a los estudiantes las condiciones y recursos que favorezcan sus habilidades actorales. Por otra, P1 no interviene en las etapas de acercamiento, comprensión y memorización del texto en función de transformar el medio didáctico. Esta falta de acompañamiento y apoyo al proceso de aprendizaje, imposibilita la modificación e interrelación efectiva con el objeto de aprendizaje (la improvisación). Además, refleja un saber docente poco sólido sobre el objeto de referencia, tanto en la desarticulación entre el objeto y la praxis como en la planificación y en la acción didáctica.

Además, la ausencia de regulaciones tendientes a construir el saber, indica que se asume la oralidad como un instrumento para dramatizar, improvisar, preguntar y responder, sin que medie una reflexión sobre su objeto y función. Esto porque la tarea de aprendizaje no se considera compleja y, por ende, se asume que no requiere de acompañamiento. Collados y Rickenmann (2010) explican esta situación a partir del reconocimiento de la existencia de una dificultad para concebir la tarea como un lugar complejo en el que muchos tipos de acciones y estrategias son posibles. Por tanto el docente, mediante sus acciones reguladoras, debe orientar la actividad de los alumnos hacia la comprensión de los contenidos de enseñanza-aprendizaje propuestos.

Por todo lo anterior, en la actividad didáctica de la SD-P1, subyace una concepción «activista» del aprendizaje y se confirma la creencia en torno a que el desarrollo de la capacidad expresiva de los estudiantes puede lograrse a través de sus experiencias con el lenguaje oral y el uso de su creatividad. Se trata de un espontaneísmo que, de acuerdo con Milian y Camps (1990), también ocurre en otras situaciones relacionadas con la enseñanza de manifestaciones lingüísticas, lo que en realidad poco contribuye a mejorar la competencia discursiva de los estudiantes.

Caso contrario ocurre en la SDP-6, donde se advierten responsabilidades más o menos recíprocas y P6 está presente durante la interacción de los estudiantes con el objeto de saber. Aunque la SD-P6 logra una efectiva interacción 
entre estudiantes, requiere de una reflexión sobre la calidad de las regulaciones y devoluciones realizadas. Por ejemplo, P6 promueve la conversación entre los estudiantes, pero esta solo se utiliza como medio para intercambiar ideas y no como objeto per se (características, funcionamiento, estrategias, etc.).

En las dos secuencias el estudiante es el protagonista del aprendizaje, lo cual supone que ante la tendencia de enseñar los aspectos formales de la lengua, algunos profesores como P6 se centran en aspectos procedimentales e instrumentales. No obstante, conviene señalar la importancia de la reflexión metalingüística en la producción oral, no solo porque también incide en la construcción de sentido de los textos, sino porque posibilita la comprensión del funcionamiento y estructura de las unidades lingüísticas en los distintos formatos discursivos. No se trata de desechar el análisis lingüístico de la acción verbal, sino de situarla en contextos que le otorguen sentido.

De todas formas, se valora ampliamente la gestión topogenética lograda por P6 en relación con la interacción oral de los estudiantes, la cual pudo obedecer a que durante la secuencia de trabajo, tanto la definición de la tarea, como la finalidad de la misma y la manera de operar fueron claras y significativas. Respecto a la discusión en grupo, Arnó, Cots y Nussbaum (1999) advierten la emergencia de dos horizontes posibles. Más allá de la resolución de la tarea o de la actividad de comprensión, los participantes deben tener claras unas finalidades locales o particulares que son fundamentales para otorgar sentido al aprendizaje, y si se trata de potenciar la capacidad de liderazgo o fomentar la interacción oral, de igual forma es importante tener clara la finalidad académica.

Caso contrario sucede en las demás secuencias didácticas donde, si bien el profesor es quien gestiona el aprendizaje, los estudiantes solo cuentan con algunas posibilidades de participación y dependen en gran medida del profesor para realizar las tareas encaminadas a mejorar su capacidad de expresión oral y su escucha. En el ejemplo referido a través de la SD-P10, se encuentra que las situaciones de aprendizaje diseñadas por el profesor dependen de este todo el tiempo. Su gestión se orienta hacia la toma de conciencia sobre la actividad de escuchar, mediante una lección magistral, complementada con experiencias ilustrativas sobre la importancia de una escucha comprensiva. Para Vilá, et ál. (2005), escuchar significa reconstruir el significado de las 
palabras, proceso que implica partir de la literalidad de lo que se escucha y pasar a interpretar la información, teniendo en cuenta los factores que han intervenido en la construcción del discurso. Se trata entones de un proceso cognitivo, que requiere de un abordaje sistemático.

Otro resultado derivado del análisis del conjunto de actividades didácticas, es la tendencia de este grupo de profesores a trascender los usos orales cotidianos, casi siempre dialógicos, para situarse en contextos de formalidad media-alta donde operan usos orales casi siempre monológicos que requieren de una reflexión metadiscusiva previa y posterior. Para Vilá (1994), este hecho se sustenta en que el maestro toma conciencia de la necesidad de mejorar la expresión oral y la escucha de los jóvenes, y reconoce que estos tienen una amplia experiencia de habla espontánea e informal, mientras que su capacidad de reflexión, adecuación y pertinencia de su discurso a usos formales más complejos, es limitada. Por tanto, a la escuela le compete «abordar de manera sistemática el aprendizaje de estos usos lingüísticos orales menos presentes en la cotidianidad de los alumnos, porque son imprescindibles para su futuro académico, profesional y social» (p. 2).

Pese al interés del grupo de docentes por abordar, mediante una secuencia didáctica, algunos usos orales en contextos formales, no logran articularlos a situaciones didácticas significativas, asociadas a problemas y contenidos posibles de concretar en una secuencia de actividades que, a su vez, implica el diseño de medios didácticos y distintas formas de evaluación. Este resultado encuentra sustento en las investigaciones de Porlán y Martín (1994), quienes hacen evidente la desconexión entre los conocimientos de la disciplina con los de la didáctica correspondiente y, en consecuencia, la necesidad de enriquecer el conocimiento profesional docente.

Si se representan los procesos didácticos identificados en un contiuum, la concepción centrada en el profesor que actúa como autoridad del conocimiento y procede a crear situaciones de aprendizaje que coadyuven a proporcionar en forma directa una información determinada, estaría en un punto inicial. En un punto medio, estaría la concepción centrada en el profesor que involucra a los estudiantes en las actividades de aprendizaje que crea y diseña, buscando que puedan construir un sentido propio del objeto de saber en cuestión. En el otro extremo estaría la concepción basada en la exploración e investigación 
del estudiante, guiado por la acción docente, desde la creación de un complejo entorno de aprendizaje socio-cultural e interpersonal articulado a una secuenciación de actividades.

Lo que resalta en la anterior representación es que los puntos identificados en la actividad didáctica estudiada no operan de manera diferenciaday «pura»; por el contrario, se traslapan, acercándose a una enseñanza y aprendizaje de la lengua oral caracterizada por lo que se ha denominado «activismo», cuyo riesgo básico es la desconexión con respecto a los procesos de aprendizaje y/o a los contenidos de enseñanza (García, 1998). Ahora bien, si las situaciones didácticas que ocurren en las aulas donde se planea intencionalmente la enseñanza de la lengua oral se centran en la acción e institucionalización de saberes instrumentales de la lengua oral, ¿̇qué se requiere para transformar tal dificultad en una posibilidad?

El análisis contrastado de las situaciones didácticas en atención al diseño, desarrollo y evaluación de las secuencias didácticas, pone en relación estas y otras categorías de la «teoría de la acción didáctica conjunta» (Mercier, et ál., 2007) a partir de los procesos de mesogénesis, topogénesis y cronogénesis, los cuales permiten describir y comprender la evolución del medio didáctico y el rol del profesor y los estudiantes en esta transformación (Collados y Rickenmann, 2010).

En el caso de la gestión topogenética de la población docente estudiada, es fundamental entender su importancia en el diseño de situaciones didácticas en términos de las relaciones explícitas e implícitas que se establecen entre estudiantes y profesor alrededor del objeto de saber. La tendencia a construir una atmósfera más interactiva en clase, sitúa las actividades de enseñanza y aprendizaje en un ámbito más dialógico y autónomo. Por ello, es substancial que las devoluciones superen la simple comunicación de un saber o la delegación total de la responsabilidad de aprendizaje y planteen situaciones problémicas que procuren motivar al estudiante a aceptar el desafío de su resolución colectiva.

Este proceso didáctico depende, en gran medida, de la gestión cronogenética, que en la mayoría de secuencias didácticas, se percibe de manera explícita mediante la definición de los objetos de conocimiento, las consignas, las 
reglas del juego y el medio didáctico. Cabe señalar que aunque estos elementos han sido incorporados, también se observa la necesidad de formularlos con mayor claridad y articularlos entre sí. Asimismo, la gestión mesogenética depende de la manera como los profesores recurren a gestos de regulación de la actividad del estudiante (formular preguntas, moderar las intervenciones) para avanzar en las tareas de aprendizaje propuestas.

En cuanto al papel del medio didáctico en la actividad docente, cabe señalar que es fundamentalmente mesogenético, en tanto participa en la interacción del profesor y los educandos. El medio didáctico, desde la perspectiva vigotskyana, constituye una herramienta capital para acercarse a la construcción del conocimiento. Es evidente que los medios materiales y simbólicos conectan a los aprendices con realidades que el sujeto experimenta o desconoce, pero que, en todo caso, le posibilitan la comprensión o apropiación del objeto de saber.

En la realidad estudiada, el texto escrito sigue siendo el medio didáctico privilegiado (cuando se acude a medios materiales). Existe, empero, una disposición a la incorporación de otros recursos, en tanto mediaciones que posibilitan nuevas construcciones culturales y psicológicas. Así, el uso de la transcripción de situaciones orales registradas con instrumentos de reproducción de la imagen y la voz, la grabación de programas radiales, el uso del blog y del chat, etc., sugieren un nuevo universo simbólico que pone en contraste el monopolio de la palabra escrita con los discursos orales que forman parte de la realidad cotidiana de la escuela y de la sociedad actual.

\section{ESTRATEGIAS DE ENSEÑANZA}

\section{DeSDe el Discurso}

El primer nivel de concepción identificado en el discurso de los profesores (N1) corresponde a: en la enseñanza de la lengua oral se deben contemplar estrategias y técnicas para desarrollar habilidades de memorización. A modo de ejemplo: 
P3E: todo lo que tenga que ver con/ con ejercicios de retención y metacognición/ puede explicar por qué/ por qué esto/ y poder hablar sobre lo que uno mismo// por ejemplo/ cuando se graban y/y uno se escucha/ ser capaz de pensar/ sobre lo que dijo y cómo lo dijo/y hacer auto reflexión sobre esa misma posibilidad de expresión/

En el nivel intermedio (N2): en la enseñanza ocasional de la lengua oral se deben contemplar estrategias para adquirir y/o desarrollar habilidades metacognitivas, procedimentales y socio-afectivas. Así, por ejemplo:

PE13: recurrir a las diferentes técnicas que ex-/ que existen $\uparrow /$ entonces sería/ por ejemplo/ el debate/ el/ eeeh/ algo que yo hago mucho/ siento que hago el debate/ aunque decían que es muy sistematizado/ pero todo el tiempo los estudiantes están/ eeh/ interactuando entre ellos/ eeh/ el poder conversar alrededor de/ o discutir alrededor de una lectura $y$ eeeh/ interactuar $\uparrow$ y expresar sus diferentes puntos de vista/ eeeeehmm/ ciertas situaciones que les permitan// eeeeehm// expresar $\uparrow /$ expresarse/ pero que también les permitan escuchar lo que el otro/ DICE/ para mirar mi posición FRENTE a lo que el otro dice $\downarrow /$ imm?

En el nivel deseable (N3): en la enseñanza sistemática de la lengua oral se debe contemplar la interrelación de estrategias metacognitivas, procedimentales y socio-afectivas.

P6E: es decir, hay cuatro concepciones/ cuál es la verdadera/ todas $\uparrow /$ todas hasta ahora evidentemente/ cierto $\downarrow /$ pero entonces// de todos modos hay/VISIONES/ interpretaciones/ que son unas más válidas que otras// unas más validas que otras/ entonces me parece que lo que/ hay que hacer ahí/ es/ es uno cambiar la concepción del conocimiento/ (...)

si yo me paro por ejemplo en una perspectiva/ en el cual/ el conocimiento no se recibe pasivamente/ ni a través de los sentidos/ni por medio de la comunicación $\rightarrow /$ sino que es construido por el sujeto// cierto $\downarrow /$ entonces/ $\mathrm{mmm} /$ ahí me paro ya en una/ en otra perspectiva/ que posibilitaría precisamente el trabajo que hago desde lo oral/ porquee ya lo que está en juego ahí/ son la construcción de los hechos internos de interpretación.

Las estrategias para la enseñanza de la lengua oral, hasta ahora propuestas, se relacionan con la implementación de técnicas, actividades y uso de 
algunos recursos orientados a facilitar la comunicación oral. En general, los profesores mencionan estrategias de distinto orden y las posibles maneras de concretarlas en el aula.

La siguiente gráfica da cuenta del estado general de las concepciones relacionado con las estrategias para una didáctica de la oralidad. La concepción deseable (N3) está representada solo en un $3 \%$, el nivel inicial (N1) corresponde al 16\%, mientras que el nivel intermedio (N2) corresponde al $81 \%$.

Figura 9. Niveles de la concepción acerca de las estrategias de enseñanza de la lengua oral detectadas en los trece profesores de lengua castellana

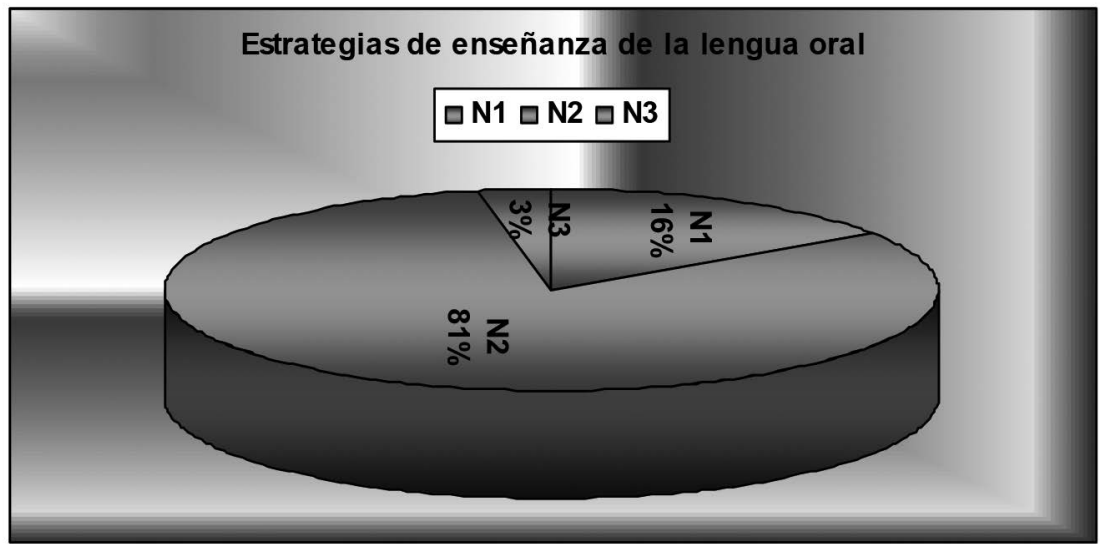

Fuente: elaboración propia

Es preciso aclarar que la concreción de las estrategias está supeditada a su interrelación con los contenidos, las finalidades y demás componentes curriculares.

El diseño de estrategias didácticas es probablemente más eficaz cuando se adscribe a una concepción de aprendizaje determinada. Por ejemplo, al ubicarse en las perspectivas actuales de la enseñanza y del aprendizaje, no se puede obviar la consideración de las estrategias didácticas a la hora de diseñar una propuesta de enseñanza y aprendizaje. Estas se inspiran en procesos constructivos, situados, autorregulados, cooperativos, dirigidos al alcance de 
metas y al tratamiento de diferencias y matices socioculturales e individuales, en el que se elaboran de manera progresiva significados potentes, complejos y adecuados.

Por ello en todo juego didáctico, las estrategias se relacionan orgánicamente con la finalidad explícita o implícita, con unos contenidos y unos medios didácticos, y se concretan en unas actividades de enseñanza en las que «se maneja cierta información procedente de unas determinadas fuentes, mediante procedimientos concretos» (García y Cañal, 1995, p. 7).

\section{DeSde LA ACCIÓN DIDÁCTICA}

Cabe señalar que la secuencia didáctica en este caso no solo actúa como instrumento para recolectar, analizar e interpretar la información, sino también como una estrategia didáctica en sí misma, la cual acoge cada profesor para planear de manera consciente y deliberada una secuencia de acciones y estrategias didácticas específicas orientadas a alcanzar metas de enseñanza y aprendizaje. Cabe aclarar que la estrategia didáctica se refiere al cómo de la enseñanza y, por tanto, admite una secuencia de planes operativos de acción que buscan potenciar dicho proceso y propender por un papel más dinámico en la relación maestro-alumno.

Tabla 18. Estrategias didácticas empleadas por los profesores de Lengua Castellana para la enseñanza de la lengua oral para Educación Media

\section{Las estrategias que guiaron los aprendizajes}

P1: Interesé a los estudiantes con la idea de dramatizar una obra literaria.

P2: Motivé a los estudiantes mediante una actividad de sensibilización y una consigna atrayente y articulada a condiciones de planeación, socialización y evaluación.

P3: Acudí a las necesidades formativas de los estudiantes (apropiar un tema de interés) como insumo para otra asignatura, lo cual exige qué decir como condición para la auto y la reflexión colectiva y, de este modo, motivar la reflexión sobre la oralidad y su relación con la escritura.

P4: Dí al estudiante la posibilidad de elaborar preguntas metacognitivas y asumir el papel de orador que refuta lo dicho acerca de la temática. 
$\mathrm{P}_{5}$ : Suscité una retroalimentación de los elementos y funciones propuestos para realizar un debate.

P6: Suscité la discusión a partir de la lectura del poema y de escuchar la canción.

P7: Se les suministró una información con anterioridad para que los estudiantes exploraran el tema. En segunda medida, se dio a conocer un reportaje, como ejercicio inicial en el aula de clase. Después de escucharlo, los jóvenes opinaron al respecto $y$ se les fue explicado el tema.

P8: Analicé el papel desempeñado por los estudiantes en el foro realizado.

P9: La organización del curso en grupos de trabajo y su experiencia previa de análisis de medios. La novedad estaba en definir las categorías para analizar un medio oral como lo es la radio y proporcionar instrumentos para ello.

P10: La clase estuvo mediada fundamentalmente por la exposición, y las tareas propuestas tenían como finalidad reflexionar acerca de la idea que se estaba exponiendo:

- Cuando se les pide que escuchen lo que sucede al exterior la idea, es reflexionar en torno a la diferencia entre oír y escuchar.

-Cuando se hace el ejercicio de las etiquetas, la idea es reflexionar a cerca de cómo nos configuran las palabras.

-Cuando se lee la caricatura se busca mostrar los componentes del acto de habla (locución, intención, perlocución).

- Cuando se pide escribir el comentario, se busca reflexionar por qué se hizo y qué efecto produjo.

P11: Analicé los mensajes y la interacción virtual del grupo de estudiantes.

P12: Generé una pregunta directa que llevó al estudiante a proyectar juicios valorativos de su performance oral y confrontarlos con un compañero(a), participando como agente del problema planteado. Además, se permitió que este tomara posturas frente al ejercicio.

P13: El trabajo intergrupal. El espacio para la construcción de las respuestas a las preguntas, contra preguntas e intervenciones. El papel mediador de la profesora durante el debate y de los instrumentos proporcionados.

Fuente: elaboración propia

Como puede observarse, para hacer posible el desarrollo de los aprendizajes previstos, los profesores proponen una serie de tareas y técnicas que presentan como estrategias. Tal dificultad representa un obstáculo epistemológico y metodológico concerniente al objeto de saber, lo cual da lugar a una concepción inicial (N1): el profesor de lengua castellana demuestra dificultades en la comprensión, formulación e instrumentación de estrategias didácticas, y 
en su lugar propone actividades y técnicas para mejorar la comprensión y/o producción oral de los estudiantes en el contexto académico.

En general, las estrategias registradas a partir de la observación de la acción didáctica de los trece profesores, se agrupan y caracterizan en los siguientes términos:

a. Actividades grupales. Asignación de tareas a pequeños grupos, por parejas, trabajo intergrupal y trabajo con el gran grupo (SDP-1, SDP-2, SDP-3, SDP-4, SDP-7, SDP-9, SDP-10, SDP-12, SDP-13).

b. Disposición del aula. Organización de los estudiantes en el aula por mesas de trabajo, organización en mesa redonda, en forma de asamblea y en filas (SDP-1, SDP-2, SDP-3, SDP-4, SDP-5, SDP-6, SDP-7, SDP-8, SDP-9, SDP-10, SDP-11, SDP-12, SDP-13).

c. Simulación de situaciones orales. Basadas en las actividades orales de conversar, debatir, entrevistar, dramatizar, leer en voz alta, etc. (SDP-1, SDP-2, SDP-3, SDP-4, SDP-6, SD-P12, SDP-13).

d. Uso de técnicas orales. Basadas en el intercambio de ideas entre los participantes (SDP-2, SDP-4, SDP-5, SDP-8, SDP-13).

e. Uso de la pregunta. Utilizada para fomentar la interacción comunicativa en el aula (SDP-1, SDP-2, SDP-3, SDP-4, SDP-5, SDP-6, SDP-7, SDP-8, SDP-9, SDP-10, SDP-11, SDP-12, SDP-13).

f. Uso de la consigna. Orientada a que los estudiantes asuman parte de la responsabilidad en las tareas de aprendizaje (SDP-1, SDP-2, SDP-3, SDP-4, SDP-5, SDP-6, SDP-7, SDP-8, SDP-9, SDP-10, SDP-11, SDP-12, SDP-13).

g. Uso de materiales curriculares y diseño de instrumentos. Tratamiento de textos de lectura y diseño de carteleras e instrumentos para facilitar las tareas de aprendizaje (SDP-1, SDP-2, SDP-3, SDP-4, SDP-5, SDP-6, SDP-7, SDP-8, SDP-9, SDP-10, SDP-11, SDP-12, SDP-13).

h. Planeación de las sesiones de clase. Cada clase establece un propósito, unas actividades y formas de evaluación (SDP-1, SDP-2, SDP-3, SDP-4, SDP-5, SDP-6, SDP-7, SDP-8, SDP-9, SDP-10, SDP-11, SDP-12, SDP-13).

Indudablemente, las estrategias implementadas y confirmadas por el grupo de profesores mediante la autoconfrontación conjunta, se articulan estrechamente con las actividades planteadas y han sido diseñadas de manera 
consciente e intencionada, aunque no todas hayan cooperado en la finalidad de enseñanza y aprendizaje esperada. Por ejemplo, algunas estrategias favorecen la organización del grupo y de las tareas de aprendizaje (SD-P13, SDP4, SD-P9), pero generan dificultades en la autorregulación de los estudiantes respecto al sentido de los intercambios verbales. Es decir, las discusiones en su mayoría se circunscriben a las preguntas formuladas por los profesores; por tanto, se concretan en respuestas cortas y poco elaboradas, intervenciones aisladas o desconectadas de las anteriores e intercambios entre profesor y estudiantes en mayor proporción, que entre los mismos estudiantes.

De lo anterior, surge una concepción intermedia (N2): el profesor de lengua castellana logra diseñar eventualmente algunas estrategias didácticas encaminadas a mejorar la comprensión y/o producción oral de los estudiantes en el contexto académico. En cada uno de los momentos de la actividad didáctica, los trece profesores buscan fundamentalmente la implicación de los jóvenes en las actividades dialogales como conversar, debatir, dramatizar, opinar, responder a preguntas, entre otras. Estas acciones constituyen el pretexto para incentivar la producción oral, sin embargo se observan ciertas tensiones, especialmente, en la organización de la interacción oral.

Sin duda, en cada una de las aulas observadas, el profesor logra que sus estudiantes hablen o expresen sus opiniones frente al tema en cuestión, pese a que no siempre consiguen una dimensión más interactiva, crítica o propositiva. Esto es, el maestro en su papel de moderador logra que los estudiantes opinen, resuman, describan, narren etc., más no que interactúen efectivamente a partir de contradecir, ratificar, dudar, proponer, ampliar o, en síntesis, involucrándose en un intercambio verbal. En cierta medida en la SD-P6, el profesor consigue que sus estudiantes soslayen su presencia y hagan uso de las normas básicas que rigen los intercambios lingüísticos (esperar el turno de palabra, prestar atención, intervenir de acuerdo con lo que se está planteando, etc.), con lo cual logran realizar una valoración crítica de una canción y de un poema que el profesor les ha suministrado.

Esta consideración fundamenta la emergencia de una concepción deseable (N3) alrededor de las estrategias de enseñanza de la lengua oral, relacionadas con la necesidad de comprender y diseñar de manera sistemática estrategias para el desarrollo de la competencia discursiva oral de los estudiantes encaminadas a lograr mayores niveles de apropiación del discurso 
en diversos contextos, construcción colectiva de los aprendizajes y cualificación de la discusión cooperativa. Tal tarea implica considerar la relación estrecha entre las estrategias de enseñanza y aprendizaje de la lengua oral en función de atenuar la regulación permanente del profesor en la consecución de los objetivos de aprendizaje.

\section{ANÁLISIS CONTRASTIVO: CORRESPONDENCIAS Y CONTINGENCIAS}

A continuación se presenta un balance de los niveles identificados en la concepción acerca de las estrategias de enseñanza de la lengua oral en los planos del discurso y la acción didáctica:

Tabla 19. Hipótesis de progresión para el análisis de las concepciones sobre las estrategias de enseñanza de la lengua oral

\begin{tabular}{|c|c|}
\hline \multicolumn{2}{|c|}{$\begin{array}{l}\text { Concepciones detectadas alrededor de las estrategias de enseñanza } \\
\text { de la lengua oral }\end{array}$} \\
\hline Derivadas del discurso del profesor & $\begin{array}{c}\text { Derivadas de la acción didáctica del } \\
\text { profesor }\end{array}$ \\
\hline $\begin{array}{l}\text { Concepción inicial (N1) } \\
\left(\mathrm{P}_{3}, \mathrm{P}_{7}, \mathrm{P}_{12}\right)\end{array}$ & $\begin{array}{l}\text { Concepción inicial (N1) } \\
\left(\mathrm{P}_{1}, \mathrm{P}_{5}, \mathrm{P}_{11}\right)\end{array}$ \\
\hline $\begin{array}{l}\text { En la enseñanza de la lengua oral se de- } \\
\text { ben contemplar estrategias y técnicas } \\
\text { para desarrollar habilidades de memo- } \\
\text { rización. }\end{array}$ & $\begin{array}{l}\text { El profesor de lengua castellana de- } \\
\text { muestra dificultades en la comprensión, } \\
\text { formulación e instrumentación de es- } \\
\text { trategias didácticas y en su lugar propo- } \\
\text { ne actividades y técnicas para mejorar la } \\
\text { comprensión y/o producción oral de los } \\
\text { estudiantes en el contexto académico. }\end{array}$ \\
\hline $\begin{array}{l}\text { Concepción intermedia (N2) } \\
\left(\mathrm{P}_{11}, \mathrm{P}_{12}, \mathrm{P}_{1}, \mathrm{P}_{3}, \mathrm{P}_{4}, \mathrm{P}_{5}, \mathrm{P}_{6}, \mathrm{P}_{7}, \mathrm{P}_{8}, \mathrm{P}_{9}\right. \\
\left.\mathrm{P}_{13}\right)\end{array}$ & $\begin{array}{l}\text { Concepción intermedia (N2) } \\
\left(\mathrm{P}_{2}, \mathrm{P}_{3}, \mathrm{P}_{4}, \mathrm{P}_{5}, \mathrm{P}_{7}, \mathrm{P}_{8}, \mathrm{P}_{9}, \mathrm{P}_{10}, \mathrm{P}_{12},\right. \\
\left.\mathrm{P}_{13}\right)\end{array}$ \\
\hline $\begin{array}{l}\text { En la enseñanza ocasional de la lengua } \\
\text { oral se deben contemplar estrategias } \\
\text { para adquirir y/o desarrollar habilida- } \\
\text { des metacognitivas, procedimentales y } \\
\text { socio-afectivas. }\end{array}$ & $\begin{array}{l}\text { El profesor de lengua castellana even- } \\
\text { tualmente diseña algunas estrategias } \\
\text { didácticas encaminadas a mejorar la } \\
\text { comprensión y/o producción oral de los } \\
\text { estudiantes en el contexto académico. }\end{array}$ \\
\hline
\end{tabular}




\section{Concepción deseable (N3)}

(P6)

En la enseñanza sistemática de la lengua oral se debe contemplar la interrelación de estrategias metacognitivas, procedimentales y socio-afectivas.

\section{Concepción deseable (N3)}

(P6)

El profesor de lengua castellana comprende y diseña de manera sistemática estrategias encaminadas a lograr mayores niveles de apropiación del discurso en diversos contextos, construcción colectiva de los aprendizajes, cualificación de la discusión cooperativa.

Fuente: elaboración propia

Como se aprecia, los niveles de concepción de las estrategias didácticas de la oralidad, reflejadas la acción didáctica de la mayoría de docentes, tienen cierto correlato con sus concepciones previas (en el nivel intermedio y deseable). Esto confirma la tendencia a concebir la oralidad como medio o instrumento de comunicación que contribuye a democratizar el espacio del aula que, por tanto, brinda oportunidades de participación al estudiante.

Esta concepción espontaneísta y empírica de la oralidad permea ampliamente el contexto escolar y se traduce esencialmente en poner a los estudiantes a hablar sobre diferentes asuntos, bajo el presupuesto de fortalecer su competencia comunicativa. Se supone entonces, que la práctica del discurso oral en distintas situaciones comunicativas es suficiente para que los estudiantes logren una interacción oral más eficaz. Cabe reiterar que no basta con crear situaciones de comunicación oral y reconocer la espontaneidad de algunos estudiantes; aunque es un paso necesario, no se puede perder de vista el propósito de un aprendizaje reflexivo y sistemático de la oralidad.

Para tal fin, se requiere de un diseño y aplicación de estrategias de enseñanza sistemáticas y reflexivas. Es decir, si el profesor es consciente del uso estratégico de unos procedimientos de aprendizaje que coadyuvan en la realización de una tarea, es porque tiene claridad sobre la intención de los mismos en la finalidad del aprendizaje. Esta pretensión, según Monereo, Castelló, Clariana, Palma y Pérez (2007), requiere de una formación específica al respecto. Se trata de formar y/o actualizar a un docente estratégico, en este caso, en la enseñanza de la lengua oral. Una formación docente estratégica implica un proceso de reflexión de la acción didáctica propia, lo cual presupone introducir cambios en el quehacer cotidiano y en vencer las posibles 
resistencias a la transformación de determinadas concepciones de enseñanza y aprendizaje.

Ahora bien, en el marco de la secuencia de enseñanza considerada como estrategia didáctica, en la medida en que contempla diversas formas organizativas de orden temporal y conceptual dependiendo del grado de complejidad de los conocimientos a elaborar y los objetivos perseguidos, el profesor puede actuar estratégicamente en todos los momentos previstos en dicha secuencia.

En un intento por superar la visión tradicional de la enseñanza, la población docente estudiada propone una serie de actividades o técnicas encaminadas a mejorar la expresión y/o comprensión oral de los estudiantes, aunque se detectan limitaciones en su instrumentación originadas en el tratamiento epistemológico y metodológico dado a las actividades, las técnicas y las estrategias. Esta falta de claridad en la planeación e implementación de estos dispositivos se traduce en las limitadas maneras de estimular, promover, gestionar o transferir el aprendizaje de la lengua oral.

En todas las categorías analizadas hasta el momento, subyace la importancia del diseño didáctico, solo que la formulación y/o selección de la estrategia didáctica determina en gran medida el enfoque de enseñanza. La mayoría de estrategias de enseñanza de la lengua oral propuestas por el grupo de profesores de lengua castellana y literatura son particularmente de índole procedimental, en cuanto se enfocan en las formas de trabajo y organización del aula, el uso de materiales y la puesta en escena de actividades orales.

Este modo de concebir las estrategias de enseñanza de la lengua oral, permite inferir la necesidad de su adecuada articulación a la secuencia de actividades, como también apuntar al diseño de estrategias cognitivas, metacognitivas y socio-afectivas. La naturaleza cooperativa de la oralidad se fortalece mediante la implementación de estrategias concretas, rigurosas e interesantes en la perspectiva de posibilitar que los estudiantes, a su vez, diseñen y desarrollen sus propias estrategias de aprendizaje.

Más allá de que géneros orales como el debate, la mesa redonda, el foro, entre otras, sean considerados por la mayoría de la población docente estudiada como técnicas de expresión y estrategias didácticas, su realización requiere de una planificación específica que implica la presencia y orientación 
permanente del profesor. En la preparación de un discurso oral intervienen elementos propios de la oralidad formal que los estudiantes pueden aprender a controlar y dominar, a través de la situación didáctica propuesta por el docente. De lo contrario, los estudiantes pondrán en escena las habilidades orales que ya poseen, sin que realmente se haya logrado afectar su competencia discursiva oral.

Esta situación corresponde en alguna medida a la que Vilá (2004, p. 116) analiza respecto a la manera como el profesor o la profesora, luego de proponer unos temas de exposición y unas orientaciones generales, da un tiempo prudencial a los estudiantes para preparar dicha intervención oral. A menudo sucede que los jóvenes concurren a clase con la exposición oral escrita, elaborada con unos parámetros muy próximos a los que les sirven de base para elaborar los textos escritos.

Por lo general, en este tipo de actividades, el expositor se ciñe tanto al texto que va a oralizar, que corre el riesgo de disipar la naturalidad de la oralidad y olvidar el uso de estrategias retóricas para mantener la atención de los compañeros. Esta limitante, junto con la poca referencia al contexto y la densidad informativa desequilibrada, hacen que el discurso oral sea una reproducción literal del escrito y que la falta de estrategias inherentes a la oralidad genere en el aula una atmósfera poco dispuesta a la escucha atenta.

Así, la enseñanza de la lengua oral puede ser guiada por estrategias didácticas fundadas en las nuevas visiones epistemológicas y pedagógicas en la perspectiva de asumirse como hipótesis de trabajo y no como simples recetas o técnicas de enseñanza. En las últimas décadas se han propuesto diferentes estrategias (resolución de problemas, núcleos temáticos, talleres, secuencias didácticas, proyectos de aula, etc.) que buscan resignificar las prácticas pedagógicas. Sin embargo, estas no garantizan el logro de los objetivos de aprendizaje. Así mismo, el desarrollo de secuencias didácticas exige además de la adecuación de unos conocimientos disciplinares y didácticos, una revisión de las orientaciones curriculares para la enseñanza de la lengua castellana como lengua materna y específicamente, como lengua oral.

En este sentido, la implementación de estrategias didácticas para la enseñanza de la lengua oral, requiere de un cambio cultural de carácter colectivo derivado de los intereses, experiencias y expectativas de los maestros. En efecto, las estrategias didácticas o de enseñanza necesitan ser comprendidas 
como procedimientos y acuerdos que los agentes de la enseñanza emplean de manera flexible, inteligente e intencionada para construir aprendizajes significativos (Díaz-Barriga, 1998).

\section{EVALUACIÓN DE LOS APRENDIZAJES}

\section{DesDe el Discurso}

El primer nivel de concepción identificado en el discurso de los profesores (5 de 13) es el inicial (N1) y corresponde a: la evaluación de los aprendizajes de la lengua oral debe centrarse en la participación oral del estudiante y específicamente, en aspectos lingüísticos. Para ilustrar mejor:

P11E: Según la participación// por participación/más que todo/y $\uparrow /$ pues al final de/de cada sesión/ pues se les dâ unnn/ como/ como conclusiones/ o como cosas/ a las que se puede llegar/ o las que se ha llegado en la sesión.

En el nivel intermedio (N2) coinciden en que: la evaluación ocasional de los aprendizajes de la lengua oral debe centrarse en la comprensión y producción oral y, específicamente, en aspectos lingüísticos y pragmáticos. Como lo muestran estos ejemplos:

P8E: uno evaluaría/teniendo en cuenta/ los aspectos que yo les proporciono a los estudiantes/ los evaluaría de acuerdo a la manera que yo estaría trabajando con ellos// dos/ tendría en cuenta// la manera como los muchachos expresan las ideas/y la coherenciaa/y la coherencia y cohesión de cómo esas ideas han sido expresadas/// otro aspecto miraría/ por ejemplo/ qué tanto utilizan los muchachos conectores/ marcadores textuales/ qué tanto/ qué tan importante son para ellos/ cómo los utilizan/ cómo ese discurso es coherente según las propuestas/ o según las preguntas/ que nosotros tengamos/.

El nivel deseable (N3) se enriquece en los siguientes términos: la evaluación sistemática y procesual de los aprendizajes de la lengua oral debe centrarse en el proceso comprensivo y expresivo de distintos géneros orales en 
diversos contextos y, específicamente, en aspectos lingüísticos, pragmáticos e interactivos.

P6E: para hablar de la evaluación de oralidad/ de los muchachos/ tiene que tenerse en cuenta son la INTERACCIONES que se generan y que se presentan dentro del aula/ cierto/ la interacción que se presenta con el maestro/ la interacción que se presenta estudiante estudiante/ estudiante PROBLEMÁtICA/ estudiante problemática/ estudiante estudiante/ estudiante maestro/ así $/$ entonces/ también/ en/ esa evaluación está orientado también el/ de acuerdo con/ LA INTENCIONALIDAD/ cuál es la intencionalidad por ejemplo que tenemos/ en esta/ en este tipo de actividades/ eeeh// en algunos muchachos por ejemplo/ eeeh/vemos que/ chicos que anteriormente no se expresaban/de/nos llaman la atención/los chicos que anterior/ que siempre participaban los mismos/y muchos que no participaban/ entonces nos llama la atención cuando esos muchachos comienzan a hablar/y comienzan a hablar/ entonces no solamente hay que ver es diríamos/ el caso puntual $\uparrow$ de ese chico/ sino las condiciones en que se da/las condiciones para que estos muchachos/se manifiesten.

La siguiente gráfica muestra una panorámica general del nivel de la concepción sobre la evaluación de la lengua oral, donde la concepción deseable (N3) es de un $11 \%$ con respecto a la intermedia (N2), que es de $52 \%$ e inicial (N1), de $37 \%$.

Figura 1o. Niveles de la concepción acerca de la evaluación de los aprendizajes de la lengua oral detectados en los trece profesores de lengua castellana

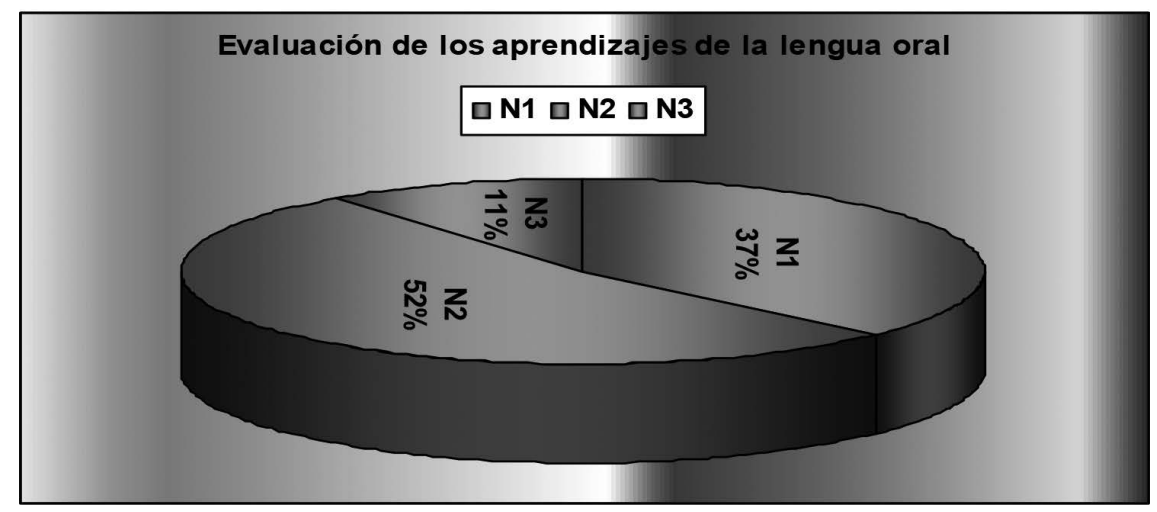

Fuente: elaboración propia 
Se encuentra una tendencia a la evaluación de la voz, es decir, se busca que el estudiante hable y una vez se consigue, se evalúan elementos prosódicos (entonación, pausas, timbre), es decir, particularidades sonoras de la lengua en el discurso, así como la carga de expresividad y emocionalidad que el hablante agrega a la palabra. Otros profesores expresan que evalúan aspectos relacionados con el nivel morfosintáctico, referido al control de la coherencia y la cohesión (muletillas, falsos cierres, frases inacabadas, dispersiones, falta de conectores etc.).

Unos pocos se refieren a la evaluación del discurso formal como una actividad planeada y no solamente espontánea, y por tanto, aluden a la importancia de evaluar la forma y contenido del discurso o de la producción oral.

\section{DeSDe la ACCIón DIDÁCTICA}

Los siguientes criterios de evaluación de la lengua oral se obtienen de la videoscopía de las secuencias didácticas y luego se confirman con los respectivos profesores, mediante la autoconfrontación conjunta:

Tabla 2o. Criterios empleados por los profesores de Lengua Castellana para la enseñanza evaluar los aprendizajes de la lengua oral en la Educación Media

\begin{tabular}{|l|}
\hline \multicolumn{1}{|c|}{ Los criterios de evaluación empleados } \\
\hline P1: No hay criterios para evaluar la oralidad. \\
\hline P2: Valoración de las respuestas a las preguntas formuladas. \\
\hline P3: No hay criterios para evaluar la oralidad. \\
\hline $\begin{array}{l}\text { P4: Valoración de los argumentos más fuertes y mejor elaborados (co-evaluación). } \\
\text { Valoración de la participación en el debate. }\end{array}$ \\
\hline P5: Valoración de la participación en el debate. \\
\hline P6: Valoración de las intervenciones de los estudiantes. \\
\hline P7: Valoración de la presentación del programa radial como el producto del trabajo. \\
\hline P8: Valoración de la participación en el análisis del corpus oral. \\
\hline
\end{tabular}


P9: Se evalúa la lectura crítica e intertextual del contexto del programa radial.

P10: No hay criterios para evaluar la oralidad.

P11: No hay criterios para evaluar la oralidad.

P12: Valoración de los juicios u opiniones.

P13: Valoración de la intervención del otro (co-evaluación) y de los juicios sobre la actividad.

\section{Fuente: elaboración propia}

Los anteriores criterios dejan ver por lo menos tres hipótesis de progresión:

La concepción minoritaria es de nivel inicial (N1): la evaluación de los aprendizajes de la lengua oral en el nivel medio de enseñanza no siempre se realiza. Si bien, los profesores de secundaria, en este caso de Educación Media, manifiestan la importancia de evaluar los aprendizajes relativos a la lengua oral, todos, antes de planear la secuencia didáctica, expresaron que no la evaluaban, y por lo menos cuatro de los trece, no la tuvieron en cuenta durante el desarrollo de su secuencia de enseñanza. Con ello se confirma la ausencia parcial de una tradición docente en la enseñanza progresiva y sistemática de la lengua oral y, en consecuencia, en la apropiación de instrumentos y pautas para evaluar los avances relacionados con el desarrollo de la competencia discursiva oral de los estudiantes.

De otra parte, se advierte una concepción de nivel intermedio (N2) correspondiente a la generalidad de este grupo de profesores. Dado el consenso en torno a la planeación y desarrollo de una secuencia didáctica sobre la enseñanza de la lengua oral, se observa que nueve de los trece profesores, tienen en cuenta el componente de evaluación. La evaluación ocasional de los aprendizajes de la lengua oral en el nivel medio de enseñanza contempla algunos aspectos pragmáticos limitados a las características del contexto de uso.

En la SD-P2 se propone una evaluación sobre las tareas realizadas antes y durante la simulación de distintas situaciones orales (noticiero, entrevista, lectura en voz alta, conversación informal, conferencia, etc.). Específicamente 
P2 propone a sus estudiantes que valoren aspectos relacionados con el rol de cada grupo, su apropiación del contexto oral, dominio del tema y expresión oral y corporal. De este modo, P2 procede a escuchar los juicios valorativos de los estudiantes, los cuales se convierten en descripciones de lo hecho en cada contexto oral. Esta descripción se legitima o invalida por P2, mediante una serie de comentarios sobre aspectos pragmáticos y lingüísticos generales, los cuales derivan en explicaciones sobre las características de estas actividades orales:

DEV7E7P2: (...) entonces/ primero/ los de la conversación informal tuvieron en cuenta unos pasos para realizar la conversación informal o simplemente dijeron hagámoslo.

EF: pues nosotras/ como era informal/teníamos que (argumentar) lo que habíamos dicho/diariamente lo que hablamos nosotras/ cuando nos mostramos a los otros/ cuando nos faltan las tareas/ así/ entonces tomamos como referencia (lo que yo estaba haciendo) () y así fue como empezamos a hablar sobre las tareas/fue depronto/no decir tantas cosas sino cuando sale una conversación/ pues tratamos de improvisar.

EF: ( )

DEV8E7P2: por ejemplo/ los de la conferencia/ ustedes tenían que preparar/ cómo hicieron ese primer paso/ qué tuvieron en cuenta para hacer su presentación.

EF: primero elegir el tema/ segundo organizar cómo íbamos hablar/ organizar las preguntas y ya.

INST4E7P2: muy bien/ vamos a tomar esos dos básicamente/ en la espontánea/ uno solamente escogimos el tema/ y vamos a trabajar eso/ entonces/ a eso se le conoce como textos informales/ textos orales/ ¿no?/ informales/ hay textos orales informales como la conversación informal/ valga la redundancia/y los textos orales formales que hacen parte/ todos estos/ ¿no?/ 
En la mayoría de secuencias didácticas se propone el estudio de algún género oral (conversación, debate, foro, exposición, etc.) o se emplea como medio para abordar el tratamiento de otros asuntos (SD-P2, SD-P3, SD-P4, SD-P5, SD-P6, SD-P7, SD-P12), pero en ninguna se considera la necesidad de profundizar en la fase de preparación del género oral seleccionado. Por otra parte, algunos profesores destacan su intención de lograr la apropiación de una evaluación con finalidades formativas y no sumativas, aunque en el desarrollo de la mayoría de secuencias de enseñanza no se percibe este tipo de evaluación, como tampoco se determina si los objetivos de aprendizaje se alcanzan o no, y qué acciones se requiere implementar para continuar cualificando el desempeño de los educandos.

Como puede apreciarse, existe un interés por construir aprendizajes de la lengua oral de orden conceptual, procedimental y actitudinal desde la creación de una producción oral o tomando parte en alguna actividad; por ello, se considera que la evaluación de la lengua oral que realiza este grupo de profesores se basa en la actuación. Se trata de evaluar las tareas en las que se pone a prueba la comprensión de la información y/o la explicación que el profesor suministra previamente. Por lo anterior, se propone una concepción deseable (N3): la evaluación sistemática y procesual de los aprendizajes de la lengua oral en el nivel medio de enseñanza contempla aspectos pragmalingüísticos y socio-discursivos, y actúa como estrategia para reflexionar sobre los mecanismos de uso oral.

\section{ANÁlisis CONTRASTIVO: CORRESPONDENCIAS Y CONTINGENCIAS}

A continuación se presenta una leve variación entre las concepciones previas del profesor respecto a la evaluación de la oralidad y las que emergen de su acción didáctica. Tanto la ausencia de una evaluación de la actividad oral, como la evaluación centrada en la producción del discurso oral más que en el proceso de composición, reitera la necesidad de fortalecer la relación del profesor con su saber y su práctica pedagógica. 
Tabla 21. Hipótesis de progresión para el análisis de las concepciones acerca de la evaluación de los aprendizajes de la lengua oral

\begin{tabular}{|l|l|}
\hline \multicolumn{2}{|c|}{$\begin{array}{l}\text { Concepciones detectadas acerca de la evaluación de los } \\
\text { aprendizajes de la lengua oral }\end{array}$} \\
\hline $\begin{array}{l}\text { Derivadas del discurso del profesor } \\
\text { Concepción inicial (N1) }\end{array}$ & $\begin{array}{l}\text { Derivadas de la acción didáctica } \\
\text { del profesor }\end{array}$ \\
\hline $\begin{array}{l}\text { (P11, P1, P2, P3, P4) } \\
\text { La evaluación de los aprendizajes de la } \\
\text { lengua oral debe centrarse en la partici- } \\
\text { pación oral del estudiante y, específica- } \\
\text { mente, en aspectos lingüísticos. }\end{array}$ & $\begin{array}{l}\text { La evaluación (N1) } \\
\text { lengua oral en el nivel medio de ense- }\end{array}$ \\
\hline $\begin{array}{l}\text { nanza no siempre se realiza. } \\
\text { Concepción intermedia (N2) }\end{array}$ & $\begin{array}{l}\text { Concepción intermedia (N2) P3, P5, P6, P7, P8, P9) } \\
\text { (P2, P4, P12, P13, P5, P6, P7, P8, P9) }\end{array}$ \\
$\begin{array}{l}\text { La evaluación ocasional de los aprendi- } \\
\text { zajes de la lengua oral debe centrarse en } \\
\text { la comprensión y producción oral y, es- } \\
\text { pecíficamente, en aspectos lingüísticos y } \\
\text { pragmáticos. }\end{array}$ & $\begin{array}{l}\text { La evaluación ocasional de los apren- } \\
\text { dizajes de la lengua oral en el nivel me- } \\
\text { dio de enseñanza contempla algunos } \\
\text { aspectos pragmáticos limitados a las } \\
\text { características del contexto de uso. }\end{array}$ \\
\hline $\begin{array}{l}\text { Concepción deseable (N3) } \\
\text { (P6) }\end{array}$ & $\begin{array}{l}\text { Concepción deseable (N3) } \\
\text { (ninguno) }\end{array}$ \\
$\begin{array}{l}\text { La evaluación sistemática y procesual de } \\
\text { los aprendizajes de la lengua oral debe } \\
\text { centrarse en el proceso comprensivo y } \\
\text { expresivo de distintos géneros orales en } \\
\text { diversos contextos y, específicamente, en } \\
\text { aspectos lingüísticos, pragmáticos e inte- } \\
\text { ractivos. }\end{array}$ & $\begin{array}{l}\text { La evaluación sistemática y procesual } \\
\text { de los aprendizajes de la lengua oral en } \\
\text { el nivel medio de enseñanza contem- } \\
\text { pla aspectos pragmalingǘsticos y so- } \\
\text { cio-discursivos y actúa como estrategia } \\
\text { para reflexionar sobre los mecanismos } \\
\text { de uso oral. }\end{array}$ \\
\hline
\end{tabular}

Fuente: elaboración propia

La ausencia de una evaluación permanente de la lengua oral responde, entre otras razones, al desconocimiento del carácter pedagógico de la oralidad como actividad del lenguaje, a la tradición de limitar la evaluación de la lengua oral a sus aspectos formales o a la concepción que se tiene sobre su naturaleza acústica, efímera, agramatical e informal producida en un tiempo real y en un contexto compartido, cuya construcción de sentido es compleja. Otra razón por la cual en el profesorado de lengua materna se genera cierto rechazo hacia la evaluación del desempeño oral de los estudiantes, es la difi- 
cultad para evaluarlo; sobre todo, si se trata de la escucha. De ahí que exista la creencia de que las actividades orales que se realizan en el aula son una forma de pasar el rato en la escuela. En suma, encontramos tres concepciones de evaluación de la oralidad predominantes:

a) La concepción lingüística. Se centra en la evaluación del dominio de la voz; es decir, en aspectos prosódicos de la expresión oral, tales como la pronunciación, la entonación y proyección de la voz; la articulación, el ritmo, las pausas y silencios. Además, se concentra en analizar la fluidez verbal en términos de la agilidad para seleccionar vocabulario y el número de palabras empleadas.

b) La concepción pragmática y comunicativa. Centra su mirada en la construcción de sentido en el contexto en el que se desarrolla la comunicación oral, para lo cual conviene tener en cuenta el uso real de la lengua oral; esto es, la adecuación de los distintos registros al contexto en el cual ocurre la comunicación oral, la actitud del interlocutor, el control de la coherencia y cohesión de su discurso, lo cual implica reconocer la aparición de muletillas e incoherencias (fragmentaciones, ausencia de conectores, dispersiones) y sus posibilidades de autorregulación, si se atiende a qué se hace realmente cuando se habla y escucha en determinadas situaciones comunicativas.

La concepción discursiva. Se instala en el dominio de los géneros orales y en el reconocimiento de su informalidad o formalidad. Así pues, la conferencia, la exposición oral o la mesa redonda, sugieren ciertos requerimientos lingüísticos, pragmáticos, comunicativos e incluso retóricos que distan en gran medida de una conversación familiar, por ejemplo. Se trata entonces de una evaluación que además valora la particularidad de las reglas sociales de cada contexto (cortesía lingüística, modalización, convenciones, etc.). Asimismo reconoce el carácter multicanal de la oralidad, en tanto no se queda en lo puramente lingüístico, sino que lo conjuga con lo paraverbal, lo kinésico (gestos, movimientos, miradas) y lo proxémico (actitudes, posturas, hábitos culturales y, en general, la distancia respecto al interlocutor).

Evaluar la comprensión y producción oral desde una concepción discursiva implica reconocer el nivel de desarrollo de la competencia discursiva oral del estudiante que, a su vez, requiere del diseño de herramientas heurísticas que hagan posible la reflexión lingüístico-discursiva, a fin de que se garantice 
un dominio sobre lo que se dice y la manera como se dice (coherencia, adecuación, cohesión, cooperación y cortesía), incorporando recursos retóricos (secuencias narrativas, explicativas, argumentativas, conversacionales; analogías), acudiendo a estrategias de anticipación y de síntesis, como también a la armonía en el uso de recursos verbales y no verbales; al uso coherente de aperturas, desarrollos y cierres y, en consecuencia, al control de las emociones y miedos propios de la oralidad pública.

Desde la perspectiva del interaccionismo socio-discursivo (Bronckart, 2004), el análisis de la acción verbal equivale a asumir un carácter meta-verbal desde dos puntos de vista: externo e interno, el primero relacionado con los valores exactos atribuidos por el agente productor a cada uno de los parámetros del contexto y los elementos del contenido temático activado, y el segundo, con la responsabilidad enunciativa del agente verbal.

Ahora bien, poco se evalúan las formas de hablar y escuchar porque el profesorado no cuenta con criterios claros para el análisis del discurso oral, como tampoco con instrumentos adaptados a la concepción curricular y al modelo didáctico; además, en nuestras aula son escasos los dispositivos tecnológicos y el uso permanente de ellos, toda vez que la oralidad lo exige debido a su naturaleza evanescente, cambiante y de difícil registro. La ausencia de una evaluación permanente de la oralidad también ocurre en otros contextos escolares. En España, por ejemplo, «a la hora de concretar los ítems para la evaluación de la lengua oral, los docentes se limitan con frecuencia a aspectos generales del tipo "participa", "no participa" o "desarrolla la imaginación”" (Palou y Bosch 200, p. 540).

Se estima fundamental la evaluación de la competencia discursiva oral de los estudiantes en todos los ciclos y grados de escolaridad, y más aún en Educación Media, donde es importante valorar el grado de consecución de los objetivos establecidos, el progreso discursivo oral logrado por el estudiante y, en general, la incidencia de su desempeño discursivo oral en todo el proceso educativo. Desde esta perspectiva, la evaluación mantiene la intención de mejorar los procesos de enseñanza y aprendizaje y, por ello, se considera formativa.

Asumir una evaluación formativa de la lengua oral, significa admitir la necesidad de su carácter sistemático, fundamental para identificar las ne- 
cesidades de los educandos y dar cuenta de la progresión de su desempeño discursivo oral en función de los objetivos de aprendizaje. En este proceso son importantes los criterios orientados a la autoevaluación y autoconfianza en el marco de actividades metadiscursivas que demandan reflexión sobre la producción discursiva que circula en el aula.

\section{CARACTERIZACIÓN}

Este análisis da cuenta de los resultados relativos a lo que piensan y hacen los profesores de lengua castellana frente a la enseñanza de la lengua oral, lo cual implica ponerlos en discusión a la luz de los presupuestos teóricos de la presente investigación. Las diferentes concepciones identificadas han sido analizadas de manera individual atendiendo a las correspondencias y contingencias entre el discurso y la acción didáctica del profesor.

La correspondencia entre las concepciones disciplinares y didácticas de la lengua oral, manifiestas en las declaraciones de los profesores de Lengua Castellana y en lo que han demostrado en el aula, muestra una variación permanente que denota una alta incongruencia entre el ideal de la didáctica de la oralidad y la situación real que se vive en las aulas de Educación Media (en adelante EM). Dada la fluctuación, decididamente idiosincrásica, se opta por la representación de la generalización de las concepciones mediante hipótesis con distintos niveles de progresión.

En cuanto al contenido, se identifica la categoría de concepciones en su contenido disciplinar y didáctico. Esta articulación, por un lado, da como resultado la detección de concepciones epistemológicas sobre la oralidad, las condiciones para su enseñanza y la formación docente en lengua oral que se requiere y, por otro lado, muestra la emergencia de concepciones relativas al componente curricular: objetivos, contenidos, actividades, estrategias y evaluación de la lengua oral.

En primer lugar llama la atención el inusitado interés del profesorado participante en este estudio, por la enseñanza y el aprendizaje de la lengua oral. Si bien la concepción más explícita se relaciona con la importancia dada 
a la enseñanza de la lengua oral, esta se sitúa más en su finalidad, en lo que se persigue al pensar la oralidad como objeto didáctico. Esto significa que los profesores manifiestan la urgencia de integrarla deliberadamente al aula y su disposición para avanzar en discusiones teóricas y metodológicas que les proporcionen mayores elementos para su acción didáctica. Se trata de un estado de alerta consciente frente a la actuación didáctica, condición propicia para la construcción de nuevos saberes y/o la introducción de cambios en la práctica pedagógica.

La concepción sobre los objetivos de la enseñanza de la lengua oral como categoría de análisis, representa un «querer hacer» y un «querer aprender», más que informar sobre las actuaciones y discursos de los profesores de lengua castellana cuando deciden abordar la enseñanza de la lengua oral. Tales razones son suficientes para sustentar la ocurrencia de una transición entre la idea de saber que algo existe para mejorarlo y la intención de llevarlo realmente a la práctica con una metodología sistemática e integradora (Pujol-Berché, 1994).

Esta preocupación por lo oral, que también se da en Francia desde la década del setenta, según Plane y García-Debanc (2004, pp. 11-32), puede semejarse a una moda o a una simple toma de conciencia sobre sus beneficios, por lo cual se precisa renovar las preguntas por cómo hacer hablar a todos los alumnos y cómo hacerlos progresar, por otras relativas a cómo articular los aprendizajes comunicativos y los aprendizajes disciplinares.

En Colombia, el Ministerio de Educación Nacional y la Secretaría de Educación del Distrito han puesto en marcha, durante la última década, programas de fortalecimiento de las actividades orales, escritoras y lectoras en los diferentes ciclos y áreas del currículo escolar ${ }^{1}$; han publicado una serie de materiales relacionados con la didáctica del lenguaje, con el fin de proporcionar herramientas para trabajar en el aula (SED, 2010); y adelantan programas de apoyo a la actualización docente para llevar a cabo la reorganización curricular por ciclos, la cual busca, entre otros propósitos, enfatizar

I Algunos colegios públicos y privados del país han venido incorporando la lectura, escritura y oralidad como ejes de sus proyectos educativos institucionales (PILEO). 
en la necesidad de «leer, escribir y hablar correctamente para comprender el mundo»².

La suma de estos esfuerzos que algunos profesores, por iniciativa propia o por su vinculación a redes de maestros, grupos y proyectos de investigación han logrado ${ }^{3}$, da un panorama alentador y propicio para lograr un trabajo colegiado en la transformación de las concepciones que obstaculizan una enseñanza secuencial y sistemática de la lengua oral en EM y demás grados escolares.

Otra lectura positiva de las concepciones detectadas consiste en que, si bien los profesores manifiestan no haber enseñado la lengua oral permanente y sistemáticamente en EM, cuando deciden hacerlo demuestran ciertos planteamientos y posibilidades más o menos evolucionadas, que tienden a la superación del modelo tradicional de la enseñanza y aprendizaje de la lengua oral de orientación teórica y gramaticalista, por uno más centrado en aspectos pragmáticos. Por tal razón, sus concepciones tienden a acercarse a un nivel de progresión intermedio, lo cual indica que tanto en la noción como en la práctica, subyace una tendencia a reconocer las variedades de realización de lo oral en función de los contextos, con el fin de potenciar la comunicación y el intercambio de visiones de mundo.

También se observa que el docente tiene una actitud favorable a compartir con el estudiante el uso de la palabra oral y a propiciar interacciones orales en el trabajo grupal, tal como queda demostrado en algunas recomendaciones que los profesores hacen sobre control de turnos de habla en la interacción, escucha comprensiva y pertinencia y adecuación al contexto de uso. Ellos muestran una tendencia a propiciar ambientes más participativos a través de exposiciones, debates, conversaciones, improvisaciones teatrales, etc., que buscan reemplazar su monólogo y/o las preguntas cerradas que esperan una respuesta puntual del estudiante, aunque no siempre sean objeto de reflexión profunda y evaluación rigurosa.

2 Seminarios sobre la reorganización curricular por ciclos: http://www.redacademica.edu.co/ index.php?option=com_content\&view $=$ article\&id=462:seminarios-sobre-temas-relacionados-con-la-reorganizacion-curricular-por-ciclos\&catid=70:proyecto-de-educacion-por-ciclos\&ltemid=377

3 Cabe recordar que la mayoría de profesores seleccionados para esta investigación tenían estudios posgraduales, algunos también se desempeñaban como maestros en programas de licenciatura y otros estaban vinculados a grupos y redes de maestros interesados en asuntos pedagógicos e investigativos. 
Sin mayores herramientas de análisis e instrumentos específicos para potenciar las diversas situaciones orales que proponen en el aula, este grupo logra aproximar a los estudiantes al uso oral situado en diversos contextos donde subyacen distintas intenciones comunicativas. Sin embargo, desde las categorías de análisis propuestas en el modelo de la acción docente de dichas aproximaciones (Sensevy, et ál., 2000; Sensevy, 2007; Rickenmann, 2006b), surgen las siguientes observaciones:

A. Las situaciones didácticas que se plantean se centran en temas que no representan mayor nivel de dificultad para los estudiantes, al ser actividades orales que normalmente ellos realizan en el aula (conversar, debatir, dramatizar, exponer, etc.), debido a que no se concibe la interacción del estudiante con el medio didáctico como un dispositivo capaz de construir un conocimiento escolar.

Una de las razones de ello es la falta de elementos que permitan al profesor planear y posteriormente analizar las situaciones didácticas que diseña, en el sentido dado por Brousseau (1990, 1991), desde la reflexión sobre las incertidumbres y obstáculos que plantea el quehacer didáctico. Esta dificultad puede ser superada pedagógicamente mediante la autoconfrontación conjunta (Rickenmann, 2007), con lo que los profesores pueden identificar los obstáculos predominantes en la construcción del conocimiento escolar, lo que a su vez indica que la acción didáctica sobre el medio didáctico puede ser instrumentada.

$\mathrm{Al}$ respecto Camps (2005, p. 9) declara la urgencia de «disponer de instrumentos que nos permitan abordar la enseñanza reflexiva de la lengua oral: enseñar a los alumnos a hablar reflexivamente y a escuchar y comprender críticamente». Se trata de una necesidad que trasciende el ámbito escolar y se instala en la exigencia social de contar con ciudadanos críticos, cuyo discurso represente una actitud responsable y ética.

B. La interacción oral está sujeta a las decisiones del maestro, quien realiza explicaciones directas de saberes específicos de la lengua oral y mediante devoluciones persuade a los estudiantes a participar de manera voluntaria en las situaciones que propone, sin que ello sea objeto de reflexión.

C. Desde el punto de vista de los procesos topogenéticos, reflejados en las devoluciones o las posturas de aprendizaje (Rickenmann, 2007), la incitación a la acción verbal o a la provocación discursiva instaura entre docente y 
estudiantes un contrato comunicativo en el cual el profesor es el gestor de la palabra y los estudiantes adoptan un papel complementario, consistente en verbalizar la respuesta esperada por el profesor o en dejarse conducir hacia ella (Nussbaum, 1999). Este juego didáctico evidencia una asimetría entre los roles de los participantes en la acción verbal oral, donde los estudiantes cooperan para que el profesor logre mantenerse como autoridad docente.

D. La acción técnica de transmitir un saber relativo a la lengua oral, para que luego sea ejercitado, no cuenta con un acompañamiento en su preparación. Es decir, se advierte la carencia de recursos lingüísticos, discursivos, retóricos y contextuales que aporten a una construcción metadiscursiva y, en consecuencia, a la cualificación de la competencia discursiva oral. Para enfrentar esto, se sugiere un proceso de planificación similar al del texto escrito, basado en la elaboración de un guión esquemático que contemple tanto ideas a desarrollar como estrategias de ampliación (ejemplificación, descripción, argumentación, etc.), pues el discurso oral formal mantiene cierto grado de improvisación y de uso de elementos prosódicos, proxémicos y kinésicos, que pueden ser preparados a manera de ensayo, pero no memorizados ni concretados concluidos.

E. Desde el punto de vista de los procesos mesogenéticos reflejados en las regulaciones durante el desarrollo de las secuencias, subyace una concepción «experiencial» del aprendizaje de la lengua oral. La finalidad de la actividad didáctica se orienta a la instrucción de tópicos relativos al funcionamiento de la lengua oral y su puesta en práctica, a fin de lograr que los estudiantes hagan uso adecuado de la oralidad en contextos académicos y sociales; no obstante, los mismos profesores reconocen haber conseguido pocas modificaciones en la actividad cognitiva de sus estudiantes.

Sin embargo, la concepción espontaneísta o no planeada de la lengua oral concibe la oralidad como una actividad social que hace parte de la cotidianidad de las personas, pero que es susceptible de una elaboración y complejización en función de un mayor desarrollo discursivo oral. Por tanto, esta concepción espontaneísta obliga a prestar atención a otros formatos discursivos y reconocer el desarrollo de la oralidad como favorable a la representación y la construcción de aprendizajes.

F. La ausencia de una concepción sobre la evaluación de la lengua oral de carácter formativo que logre objetivar la integración de aprendizajes 
conceptuales, procedimentales y socioafectivos, es uno de los hallazgos más sensibles de esta obra. Si tradicionalmente la evaluación procesual no ha sido incorporada en el contexto escolar, la situación es aún más crítica cuando se trata de evaluar la lengua oral debido a su carácter omnipresente, efímero y subjetivo, lo cual refuerza la creencia de que emitir un juicio sobre la producción oral del estudiante representa formularlo también sobre su manera de ser (Palou, et ál., 2005).

Sin duda, la reflexión metadiscursiva ocupa un lugar central durante la planificación del discurso oral; por ello, solo se puede considerar la idea de rehacer o reorganizar el discurso oral durante la preparación, y no después; de ahí que la evaluación de la oralidad sea vital (Vilá, 2005).

Las concepciones relativas a la noción, los objetivos y los contenidos de conocimiento de la lengua oral permiten observar su concreción en las actividades de enseñanza y precisar la naturaleza y funcionalidad de las estrategias didácticas y de evaluación, pues se facilita la detección de las diferentes concepciones e identifica la necesidad de una interrelación entre los elementos que conforman el sistema didáctico. Esto se debe a que estos elementos hacen parte de la propedéutica curricular y a que la concepción deseable de la didáctica de la oralidad está cifrada en una enseñanza sistemática, determinada por la realidad del contexto educativo y las características de los estudiantes, lo cual facilita la selección y secuenciación de unos contenidos coherentes con el grado de dificultad de las tareas de aprendizaje y los criterios de evaluación.

\section{COMPLEJIDAD ENTRE CONCEPCIONES Y PRÁCTICAS SOBRE LA ORALIDAD}

Los progresos y los problemas que subyacen en las concepciones detectadas acerca de la enseñanza de la lengua oral son diversos, de naturaleza distinta y se relacionan con el conocimiento profesional del profesor. En las dificultades referidas anteriormente se hace evidente la ausencia de un saber que permita avanzar hacia el desarrollo sistemático y progresivo de los usos de la lengua oral, pues si el profesor no cuenta con un saber sobre la estructura de la disciplina que está enseñando o sobre alguno de sus tópicos, la enseñanza se 
verá afectada, lo cual explica que la formación docente en lengua oral no logre modificaciones cognitivas o comprensivas en esta modalidad del lenguaje.

En efecto, los mismos profesores reconocen que no cuentan con elementos teóricos y metodológicos para abordar la enseñanza sistemática de la oralidad, por ello consideran importante la construcción de un saber en torno al tema y reconocen la importancia de pasar de la implementación de actividades orales ocasionales a otras más sistemáticas y articuladas a la escritura, así como a aquellas que valoran al estudiante como sujeto discursivo capaz de reconocer el uso responsable e incluyente del discurso oral.

Investigaciones como las de Abascal (2006) demuestran que el asunto de la formación docente es mucho más complejo debido a la falta de tradición de la enseñanza del uso oral en la universidad. Los futuros maestros no reciben ninguna orientación sobre el funcionamiento del discurso oral en situaciones formales, por lo que sus saberes al respecto se reducen a aspectos generales de orden lingüístico. Así mismo se ha evidenciado en esta obra, donde los profesores en ejercicio refieren generalidades de fundamentos socioculturales, lingüísticos, sociolingüísticos, comunicativos y/o pragmáticos de la oralidad.

La carencia formativa es todavía más rotunda en lo que se refiere al conocimiento didáctico, porque el profesor de lenguaje no cuenta con una comprensión de la oralidad ni de la didáctica, necesaria para hacerla «enseñable», y se reduce a la enseñanza de aspectos formales y/o pragmáticos de la lengua oral mediante actividades (o ejercicios) supeditadas a la explicación del profesor como fuente de conocimiento.

Por ello, el profesor de lengua castellana necesita construir un «conocimiento didáctico del contenido lingüístico-discursivo oral» que le permita apropiarse de la naturaleza interdisciplinar de la oralidad, de su dimensión retórica y lingüístico discursiva, así como de su dimensión literaria, antropológica y sociocultural, para hacerlas comprensibles a los estudiantes mediante la adecuación, resignificación e integración de contenidos cuya selección y secuenciación sea coherente con las estrategias, actividades, materiales, criterios de evaluación, y que responda a las características del contexto escolar y social particular. 
Se trata de que los profesores de lengua castellana, de manera consciente, «adapten, reconstruyan, reordenen y simplifiquen el contenido para hacerlo comprensible a los alumnos» (McDiarmid, Ball y Anderson, 1989; De Vicente, 1992, citados por Marcelo, 1993, p. 7). A manera de ejemplo, y atendiendo a la caracterización de las concepciones, se citan algunas dificultades y vacíos encontrados:

a. Confusión entre la formulación de objetivos de aprendizaje de la lengua oral y el diseño de actividades orales.

b. Desarticulación de las dimensiones procedimental, cognitiva y actitudinal en la formulación de objetivos de enseñanza de la lengua oral.

c. Simplificación de la complejidad que revisten determinados contenidos lingüísticos y contextuales.

d. Confusión entre la selección de contenidos de conocimiento de la lengua oral y los de la lengua escrita en la determinación de temas.

e. Falta de adecuación de algunas actividades orales de su intención educativa, lo cual desemboca en lo que se ha denominado como activismo.

f. Trivialización del uso de metáforas, explicaciones, ilustraciones, ejemplos, etc., para hacer comprensibles conceptos, reglas de acción y actitudes implicadas en las prácticas discursivas orales.

g. Relativización del nivel de complejidad de las tareas que se efectúan en interacción con el medio didáctico (predominan tareas acerca de la descripción del funcionamiento de la actividad oral y, en menor medida, aquellas que comprometen procesos de comprensión y producción oral).

h. Ausencia de criterios para evaluar el progreso de los aprendizajes de la lengua oral.

i. Predominio del activismo cifrado en explicaciones prolijas del profesor y de la participación de los estudiantes en diversos ejercicios y técnicas orales, sin mecanismos de reflexión y secuencialidad.

j. Reconocimiento de la ausencia de un conocimiento teórico y metodológico de la oralidad, carente de toma de decisiones al respecto.

k. Preponderancia de una visión naturalista y empírica de la oralidad que se traduce esencialmente en poner a los estudiantes a hablar so- 
bre diferentes asuntos, en el presupuesto de fortalecer su competencia comunicativa oral.

1. Aceptación de la actividad de enseñanza de la lengua oral como un nuevo tópico curricular y, en consecuencia, una tarea pendiente.

m. Comprensión de las dificultades relativas a la expresión oral y a la escucha de los estudiantes como obstáculos y no como puntos de partida para el desarrollo de la competencia discursiva oral.

Lo anterior ilustra la ausencia de «conocimiento didáctico del contenido lingüístico-discursivo oral» en el profesor de lengua castellana, respaldado por sus saberes intuitivos y sus prácticas ocasionales, los cuales son insuficientes pues, como dice Freire, si bien oralidad connota acción, movimiento e interacción, «cuando la palabra hace exclusiva referencia a la acción, se convierte en activismo, minimiza la reflexión, niega la praxis verdadera e imposibilita el diálogo» (1999, p. 70). Esta falencia se supera a través de la reflexión metacognitiva, que explicite la manera en que las concepciones acerca de este campo de conocimiento pueden afectar la formación discursiva oral de los estudiantes. Esta tarea representa un gran reto, por cuanto no se trata solo de una formación genérica, sino de una propuesta que parte del estado de las concepciones de los profesores, ya que, por diversas razones (trayectoria, formación, etc.), no todos se encuentran en el mismo nivel de progresión.

Pese a la idea generalizada de unas concepciones constituyentes de cada profesor de lengua castellana, acordes con las tendencias epistemológicas, los desarrollos lingüísticos y las propuestas pedagógicas de la lengua materna en la sociedad contemporánea, las concepciones detectadas no se encuentran tal como estas se comprenden en el campo teórico del fenómeno lingüístico. Por el contrario, al ser transpuestas al ámbito escolar adquieren una serie de matices e hibridaciones que a su vez se mezclan con saberes experienciales y reglas de acción propias de la dimensión antropológica del sujeto.

Tanto en el discurso como en la acción didáctica se observa que un mismo profesor puede situarse en distintos niveles derivados de las diferentes hipótesis de progresión, lo cual revela una amplia diversidad epistémica y didáctica constitutiva de las concepciones disciplinares y didácticas de los profesores de lengua castellana alrededor de la oralidad. Por ello, el anterior compendio de concepciones organizado por niveles de progresión ofrece un panorama general de las mismas, con un carácter de movilidad permanente. 
Abascal, M. D. (2006). La lengua oral en la enseñanza secundaria. En: C. Lomas (Ed.). El enfoque comunicativo de la enseñanza de la lengua (pp. 159-179). Barcelona: Paidós.

Abascal, M. D. (2004). La teoría de la oralidad. Universidad de Málaga: Anejo XLIX de Analecta Malacitana.

Abascal, M. D. (1997). Didáctica de lo oral. En: J. Serrano y E. Martínez (Coord.). Didáctica de la Lengua y la Literatura. Barcelona: Oikos-tau

Abascal, M. D., Beneito, F. y Valero, F. (1993). Hablar, escuchar. Una propuesta para la expresión oral en la enseñanza secundaria. Barcelona: Octaedro.

Adam, J. M. (1990). Éléments de linguistique textuelle. Liège: Mardaga.

Alcaldía Mayor de Bogotá (2008). Plan Sectorial de Educación 2008-2011. Educación de Calidad para una Bogotá Positiva. Extraído de http://www. sedbogota.edu.co/archivos/SECRETARIA_EDUCACION/PLAN_SECTORIAL/PLAN\%2OSECTORIAL\%2OEDUCACION\%20DE\%20CALIDAD\%20 2008-2012.pdf

Alcántara, J. (2009). La in/tensión de la palabra: Oralidad y teatralidad. En: I. Contreras y A. D. García (Coord.). Escritos sobre oralidad (pp. 57-69). México: Universidad Iberoamericana.

Alien, J. P. y van Buren, P. (1971). Chomsky selected readings. Oxford: Oxford University Press.

Álvarez M. (2003). La oralidad en el aula: situación de la lengua oral en los sistemas educativos europeos. Ponencia presentada en Vitoria, Centro Europa.

Appel, M. W. (1989). Maestros y textos. Madrid: Paidós. 
Arango, L. (2007). ¿Cómo abordar los entornos virtuales de interacción social? Una reflexión teórico-metodológica para el estudio de las charlas sincrónicas por Internet. Investigación universitaria multidisciplinaria, Año 6 (6), pp. 16-25.

Argyris, C. y Schön, D. (1976). Theory in practice. Increasing professional effectiveness. London: Jossey-Bass Publishers.

Arnó, E., Cots, J. M. y Nussbaum, L. (1997). Peer interaction and language awarnes. In: L. Díaz y C. Pérez (Eds.). Views on the acquisition and use of a second language (pp. 367-376). Barcelona: Universitat Pompeu Fabra.

Austin, J. L. (1982). Cómo hacer cosas con palabras: Palabras y acciones. Barcelona: Paidós.

Ausubel, D. (1978). Psicología Educativa. Un punto de vista cognoscitivo. México: Trillas.

Azcárate, P. (1995). El conocimiento profesional de los profesores sobre las nociones de aleatoriedad y probabilidad. (Tesis doctoral). España: Universidad de Cádiz.

Bachelard, G. (2000). La formación del espíritu científico. México: Siglo XXI.

Bajtín, M. (1982). El problema de los géneros discursivos. En: Estética de la creación verbal (pp. 248-293). México: Siglo XXI.

Ballesteros, C. y Palou, J. (2005). Las creencias del profesorado y la enseñanza de la lengua oral. En: M. Vilá, C. Ballesteros, J. M. Castellá, A. Cros, M. Grau y J. Palou (Eds.). El discurso oral formal (pp. 101-114). España: Graó.

Ballesteros, C., Llobera, M., Cambra, M., Palou, J., Riera, M., Civera I. y Perera, J. (2001). El pensamiento del profesor. Enseñanza de lengua y Reforma. En: A. Camps, C. Ballesteros y J. L. Barrio (Eds.). El aula como espacio de investigación y reflexión: Investigaciones en didáctica de la lengua (pp. 195205). España: Graó.

Bardin, L. (1996). Análisis de contenido. Madrid: Ediciones Akal.

Beltrán, M. (1999, 10 de enero). La pobreza se come el lenguaje. En: Clarín, Argentina, pp. 1-4.

Bengoechea, M. (2003). La comunicación femenina y el mundo laboral. Emakunde, 52, pp. 10-13.

Benveniste, E. (1977). Problemas de lingüística general (7ª ed.). México: Siglo XXI.

Blanche-Benveniste, C. B. (1998). Estudios lingüísticos sobre la relación entre oralidad y escritura. Barcelona: Gedisa. 
Bernstein, B. (1975). Clase, códigos y control. Vol. II. Hacia una teoría de las transmisiones educativas. London: Routledge \& Kegan Paul.

Boito, M. (2000). La importancia de la oralidad en la cultura contemporánea. Revista Latina de Comunicación Social, 35. Recuperado de http://www.ull.es/ publicaciones/latina/Argentina200o/21 boito.htm

Bolívar, A. (2005). Conocimiento didáctico del contenido y didácticas específicas. Revista de currículum y formación del profesorado, 9 (2), pp. 1-39.

Bolívar, A. y Domingo, J. (2007). Prácticas Eficaces de Enseñanza. Madrid: PPC, Editorial y Distribuidora, S.A.

Bolívar A., Fernández, M. y Molina, E. (2004). Investigar la identidad profesional del profesorado: Una triangulación secuencial. Forum Qualitative Sozialforschung/Forum Qualitative Social Research, 6 (1), art. 12. Recuperado de http://www.qualitative-research.net/index.php/fqs/rt/printerFriend$\mathrm{ly} / 516 / 1116$

Bonilla, E. y Rodríguez, S. (2005). Más allá del dilema de los métodos: la investigación en ciencias sociales. Colombia: Editorial Norma.

Bosch, M. y Gascón, J. (2007). 25 años de transposición didáctica. En: L. Ruiz-Higueras, A. Estepa y F. J. García (Eds.). Sociedad, Escuela y Matemáticas. Aportaciones de la Teoría Antropológica de lo Didáctico (pp. 385-406). Jaén: Servicio de Publicaciones de la Universidad de Jaén.

Bourdieu, P. (2001). ¿Qué significa hablar? Economía de los intercambios lingüísticos ( $3^{\mathrm{a}}$ ed.). Madrid: Akal.

Bromme, R. (1988). Conocimientos profesionales de los profesores. Enseñanza de las Ciencias, 6(1), pp. 19-29.

Bronckart, J.-P. (2007). Desarrollo del lenguaje y didáctica de las lenguas. Buenos Aires: Miño y Dávila.

Bronckart, J.-P. (2004). Actividad verbal, textos y discursos. Por un interaccionismo sociodiscursivo. España: Fundación Infancia y Aprendizaje.

Bronckart, J.-P. (1985). Las ciencias del lenguaje: ¿Un desafío para la enseñanza? París: UNESCO.

Bronckart, J.-P. (1980). Teorías del lenguaje. Introducción Crítica. Barcelona: Herder.

Bronckart, J.-P., Bulea, E. y Bota, C. (2010). Le projet de Ferdinand de Saussure. Genève: Librairie Droz. 
Bronckart, J.-P. y Plazaola-Giger, I. (1998). La transposition didactique. Histoire et perspectivas d'une problématique fondatrice. Practiques, 97-98, pp. 35-58.

Bronckart, J.-P. y Schneuwly, B. (1996). La didáctica de la lengua materna: el nacimiento de una utopía indispensable. Textos 9, pp. 61-78.

Brousseau, G. (1993). Fundamentos y métodos de la Didáctica de la Matemática. En: Trabajos de Matemática, famaf, Universidad de Córdoba, Córdoba, Caps. I-IV. Recuperado de:

http://fractus.mat.uson.mx/papers/Brousseau/Fundamentos.pdf

Brousseau, G. (1990 y 1991). ¿Qué pueden aportar a los enseñantes los diferentes enfoques de la didáctica de las Matemáticas? (Primera parte) En Enseñanza de las ciencias, 8(3), pp. 259-267, (Segunda parte) En: Enseñanza de las ciencias, 9(1), pp. 10-21.

Brown, C. A. y Cooney, T. J. (1982). Research on teacher education: A philosophical orientation. Journal of Research and Development en Education, 15(4), pp. 13-18.

Bruner, J. (1986). El habla del niño: aprendiendo a usar el lenguaje. Barcelona: Paidós.

Brünner, J. J. (1998). Globalización cultural y posmodernidad. Chile: Fondo de Cultura Económica.

Burbules, N. (1999). El diálogo en la enseñanza. Teoría y práctica. Argentina: Amorrortu.

Caballero, N. (2005). La oralidad, parte esencial de las culturas de resistencia afroamericanas. Anuario Oralidad, para el rescate de la tradición oral en América Latina y el Caribe 13, pp. 12-13.

Calderhead, J. (1988). Conceptualización e investigación del conocimiento profesional de los profesores. En: L. M. Villar Angulo (Ed.). Conocimientos, creencias y teorías de los profesores Implicaciones para el currículum y la formación del profesorado (pp. 21-37). Alcoy: Marfil.

Calderón, D. (2000). Sobre las concepciones de los maestros que enseñan a leer y a escribir. En: R. Morales y B. Bojacá (Comp.). Maestros y concepciones sobre lenguaje (pp. 135-146). Santa Fe de Bogotá: Universidad Distrital Francisco José de Caldas - Colciencias.

Calsamiglia, H. (2006). El estudio del discurso oral. En: C. Lomas (Comp.). Enseñar lenguaje para aprender a comunicar(se) (pp. 75-91). Bogotá: Colección Redes. Editorial Magisterio. 
Calsamiglia, H. y Tusón, A. (1999). Las cosas del decir. Manual de Análisis del Discurso. Barcelona: Ariel.

Camps, A., Ríos, I. y Cambra, M. (2004). Recerca i formació en didáctica de la llengua. Lenguaje, 32, pp. 7-27.

Camps, A. (Coord.). (2006). Diálogo e investigación en las aulas. Investigaciones en didáctica de la lengua. España: Graó.

Camps, A. (2006). La didáctica de las lenguas un complejo espacio de investigación. En: A. Camps (Comp.). Diálogo e investigación en las aulas. Investigaciones en didáctica de la lengua (pp. 11-23). España: Graó.

Camps, A. (2005). La lengua oral formal objeto de enseñanza. En: M. Vilá (Comp.). El discurso oral formal. Contenidos de aprendizaje y secuencias didácticas (pp. 7-9). España: Graó.

Camps, A. (2001). Objeto, modalidades y ámbitos de la investigación en didáctica de la lengua. En: A. Camps, I. Ríos y M. Cambra. Recerca i formació en didáctica de la llengua. Lenguaje, 32, pp. 7-27.

Camps, A. (2000). Aprender gramática. En: A. Camps y M. Ferrer (Coord.). Gramática a l'aula (pp. 101-117). Barcelona: Graó.

Camps, A. (1993). Didáctica de la lengua: la emergencia de un campo científico específico. Revista Infancia y Aprendizaje, 62-63, pp. 209-217.

Camps, A. y Ballesteros, C. (2001). El aula como espacio de investigación y reflexión: investigaciones en didáctica de la lengua. España: Graó.

Canale, M. y Swaim, M. (1980). Theoretical bases of communication approaches to second language teaching and testing. Applied Linguistics, 1(1), pp. 1-47.

Cañal, P. y Porlán, R. (1988). Bases para un Programa de investigación en torno a un Modelo Didáctico de tipo sistémico e investigativo. Enseñanza de las Ciencias: Revista de Investigación y Experiencias Didácticas, 6(1), pp. 54-60.

Cárdenas, M., Quitián, S. y Gutiérrez, M. Y. (2005). La práctica docente en la formación de maestros/as de Lengua Castellana. Entre Maestros, 5, pp. 80-86.

Carr, W. y Kemmis, S. (1988). Teoría crítica de la enseñanza. Madrid: Editorial Martínez Roca.

Castellá, J. y Vilá, M. (2005). Lengua oral formal: características lingüísticas y discursivas. En: M. Vilá, C. Ballesteros, J. M. Castellá, A. Cros, M. Grau y J. Palou. El discurso oral formal. Contenidos de aprendizaje y secuencias didácticas (pp. 25-36). España: Graó. 
Castoriadis, C. (1997). El avance de la insignificancia. Encrucijadas del Laberinto $I V$. Buenos Aires: Eudeba.

Chernobilsky, L. (2006). El uso de la computadora como auxiliar en el análisis de datos cualitativos. En: I. Vasilachis de Gialdino (Coord.). Estrategias de investigación cualitativa (pp. 240-273). Barcelona: Gedisa.

Chevallard, Y. (1997). La transposición didáctica: del saber sabio al saber enseñado. Buenos Aires: Aique.

Chomsky, N. (1971). El lenguaje y el entendimiento. Barcelona: Editorial Seix Barral.

Cepeda, G. (2000). La evaluación discursiva a través del modo y la modalidad. Estudios Filológicos, 35, pp. 7-22.

Cipolletti, M. (2006). La documentación de las historias de vida en la Amazonía: necesidad y metodología. Anuario Oralidad, para el rescate de la tradición oral en América Latina y el Caribe, 14, pp. 33 -50.

Clark, C. y Peterson, P. (1990). Procesos de pensamiento de los docentes. En: Wittrock, M. (Comp.). La investigación de la enseñanza III. Cap. 6. Barcelona: Paidós.

Claxton, G. (1987). Vivir y aprender. Madrid: Alianza.

Coll, C. (1988). Significado y sentido en el aprendizaje escolar: reflexiones en torno al concepto de aprendizaje significativo. Infancia y Aprendizaje, 41, pp. 131-142.

Coll, C. (1987). Psicología y currículum. Barcelona: Paidós.

Collados, E. y Rickenmann, E. (2010). Formación docente: retos y dificultades para poner al alumno en interacción con el objeto artístico. Revista Iberoamericana de Educación, 51(5), pp. 1-15.

Comenius, J. A. (1986). Didáctica Magna. Madrid: Akal Bolsillo.

Constantino, G. (2005). Modalidades comunicativo-discursivas de participación en comunidades virtuales de aprendizaje: una propuesta para la evaluación formativa. Revista de la Asociación Latinoamericana de Estudios del Discurso, 5(2), pp. 7-32.

Contreras, I. (2009). Vestigios de la oralidad. En: I. Contreras y A. D. García (Coord.). Escritos sobre oralidad (pp. 41-56). México: Universidad Iberoamericana.

Contreras, I. (2008). Memoria oral, palabra escrita e imagen virtual. Ponencia presentada en el Segundo Coloquio Internacional Investigación en Lengua 
Materna. Oralidad y Escritura en contextos diversos. 6, 7 y 8 de octubre. Bogotá: Universidad Distrital Francisco José de Caldas.

Contreras, I. (2006). ¿De qué oralidad hablamos? Alter Texto, 4(7), pp. 9-22.

Contreras, O. (1998). Didáctica de la Educación Física. Un enfoque constructivista. Barcelona: Inde.

Cortés, L. (2002). Los estudios del español hablado entre 1950 y 1999: Períodos, disciplinas y corrientes. Anejos de la revista Oralia: análisis del discurso oral. Madrid: Arco Libros, S. L.

De Certeau, M. (1979). La invención de lo cotidiano. El arte de hacer (1 ${ }^{\mathrm{a}}$. Ed.). Tomo I. México: Universidad Iberoamericana.

Del Río, P. (1993). ¿Usos cotidianos o usos enlatados? Enseñar y evaluar la lecto-escritura a sujetos reales. Comunicación, Lenguaje y Educación, 19-20, pp. 5-24.

Dévieux, L. (2007). Los cuentos cantados de Anasi. Anuario Oralidad, para el rescate de la tradición oral en América Latina y el Caribe, 15, pp. 19-28.

Dewey, J. (1979). Philosophy of education. Middle works of John Dewey 7, pp. 297-312.

Díaz, A. (1998). La investigación en el campo de la Didáctica. Modelos históricos. Perfiles Educativos, 79/80, pp. 1-23, Recuperado de http://redalyc.uaemex. $\mathrm{mx} / \mathrm{redalyc/src/inicio/ArtPdfRed.jsp?iCve=13208002>}$

Dolz, J. (1994). Seqüències didàctiqes i ensenyament de la llengua: més enllà dels projectes de lectura i d'escriptura. Articles, 2, pp. 21-34.

Dolz, J., Gagnon, R. y Mosquera, S. (2009). La didáctica de las lenguas: una disciplina en proceso de construcción. Didáctica. Lengua y Literatura, 21, pp. 117-141.

Dolz, J y Erard, S. (2000). Las actividades metaverbales en la enseñanza de los géneros la educación. En: M. Milian y A. Camps (Comp.). El papel de la actividad metalingüística en el aprendizaje de la escritura (pp. 163-185). Argentina: Homo Sapiens.

Dolz, J. y Schneuwly, B. (1998). Pour un enseignement de l'oral. Initiation aux genres formels à l’ècole (pp. 75-89). París: ESF.

Dolz J., Schneuwly B. y Thevenaz T. (Ed.). (2001). Les tâches et leurs entours en classe de français, Actes du $8^{\mathrm{e}}$ colloque international de la DFLM, Neuchâtel: IRDP [Cédérom]. 
Dolz, J., Pasquier, A. y Bronckart, J. P. (1993). La adquisición de los discursos: ¿competencia emergente o aprendizaje de diversas capacidades verbales? Actas de las jornadas sobre la enseñanza de las lenguas de la EOI, Castellón de la Plana.

Dolz, J. y Vilá, M. (1997). L'oral formal. Articles de Didáctica de la Lengua i de la Literatura, 12, pp. 5-9.

Doyle, W. (1985). La investigación sobre el contexto del aula: hacia un conocimiento básico para la práctica y la política de formación del profesorado. Revista de Educación, 277, pp. 29-42.

Durkheim, E. (1990). Educación y pedagogía ensayos y controversias. En: I. Castaño y G. Cataño (Trad.). Bogotá: Procesos Editoriales Icfes.

Elliott, J. (1990). La investigación-acción en Educación. Madrid: Morata.

Erickson, F. (1997). Métodos Cualitativos de la investigación sobre la enseñanza. En: M. Wittrock (Comp.). La investigación de la enseñanza II. Cap. 1. Barcelona: Paidós.

Erickson, F. (1986). Métodos cualitativos de la investigación sobre la enseñanza. En: M. Wittrock (Comp.). La investigación de la enseñanza II. Cap. 1. Barcelona: Paidós.

Fenstermacher, G. R. (1986). Tres aspectos de la filosofía de la investigación sobre la enseñanza. En: M. Wittrock (Comp.). La investigación de la enseñanza, I. Enfoques, teorías y métodos (pp. 150-176). Barcelona: Paidós.

Ferreira, A. M. (2007). Noción de escritura en Los pensamientos del indio que se educó dentro de las selvas colombianas de Manuel Quintín Lame. Cuadernos de Literatura, 11(22), pp. 123-135.

Flick, U. (2004). Introducción a la investigación cualitativa. Del Amo, T. (trad.). Madrid: Morata.

Foucault, M. (1978). La voluntad de saber. Historia de la sexualidad. Vol. 1. Madrid: Siglo XXI.

Foucault, M. (1975). Vigilar y castigar (28 ${ }^{\mathrm{a}}$ Ed.). Madrid: Siglo XXI.

Foucault, M. (1973). El orden del discurso. Barcelona: Tusquets.

Freire, P. (1999). Pedagogía del oprimido. México: Siglo Veintiuno.

Freire, P. (1969). La educación como práctica de la libertad. Montevideo: Tierra Nueva. Reedición Siglo Veintiuno.

Friedemann, N. (2002). Las dos orillas del río. Anuario Oralidad, para el rescate de la tradición oral en América Latina y el Caribe, 11, pp. 31-39. 
Galindo, J. (2006). Oralidad y comunicación: exploración desde las humanidades de un objeto de la Comunicología. AlterTexto, 4(7), pp. 131-138.

García, E. (1998). Hacia una teoría alternativa sobre los contenidos escolares. Sevilla: Díada.

García, J. J. y Cañal, P. (1995). ¿Cómo enseñar? Hacia una definición de las estrategias de enseñanza por investigación. Investigación en la Escuela, 25, pp. 5-16.

García Díaz, J. E. y Porlán, R. (1990). Cambio escolar y desarrollo profesional: un enfoque basado en la investigación en la escuela. Investigación en la Escuela, 11, pp. 25-37.

García J. E. y García, F. F. (1989). Aprender investigando. Una propuesta metodológica basada en la investigación. Sevilla: Díada.

García, G. y Jacobo, M. (2007). Diversidad y patrimonio cultural inmaterial: la experiencia mexicana. Anuario Oralidad, para el rescate de la tradición oral en América Latina y el Caribe, 15, pp. 29-33.

Genette, G. (1986). Introduction à l`architexte. In: G. Genette y T. Todorov (Eds.). Théorie des genres (pp. 89-159). Paris: Seuil.

Gess-Newsome, J. y Lederman, N. (1999). Examining Pedagogical Content Knowledge. The Construct and its Implications for Science Education. Dordrecht, Boston, London: Kluwer Academic Publishers.

Gimeno, J. (1999). La construcción del discurso acerca de la diversidad y sus prácticas (I). Aula de Innovación Educativa, 81, pp. 67-72.

Gimeno, J. y Pérez, A. (1992). Comprender y transformar la enseñanza. Madrid: Morata.

Giordan, A. y De Vecchi, G. (1995). Los orígenes del saber (2 ${ }^{a}$ ed.). Sevilla: Editorial Díada.

Giroux, H. (1990). Los profesores como intelectuales. Hacia una pedagogía crítica del aprendizaje. Barcelona: Paidós.

Grau, M. y Vilá, M. (2005). La competencia prosódica y la comunicación no verbal. En: M. Vilá (Coord.). C. Ballesteros, J. M. Castellá, A. Cros, M. Grau y J. Palou. El discurso oral formal. Contenidos de aprendizaje y secuencias didácticas (pp. 25-34). España: Graó.

Grossman, P. (2005). Un estudio comparado: Las fuentes del conocimiento didáctico del contenido en la enseñanza del inglés en secundaria. Profesorado. Revista de currículum y formación del profesorado, 9(2), pp. 1-17. 
Grossman, P. (1990). The Making of a Teacher. Theacher Knowledge and Teacher Education. New York: Teachers College, Columbia University.

Grossman, P. L., Wilson, S. M. y Shulman, L. S. (2005). Profesores de sustancia: el conocimiento de la materia para la enseñanza. Profesorado. Revista de currículum y formación del profesorado, 9(2), pp. 1-24.

Gumperz, J. (1982). Discourse strategies. Cambridge: Cambridge University Press.

Gutiérrez, M. Y. (En prensa). La investigación sobre el conocimiento del profesor y sus perspectivas para el estudio de concepciones didácticas y disciplinares en la enseñanza de la lengua materna. Bogotá: Universidad Distrital Francisco José de Caldas.

Gutiérrez, M. Y. (2010). Perspectiva literaria de la oralidad. Alhucema, 23, pp. $170-183$.

Gutiérrez, M. Y. y Rosas, A. (2008a). La oralidad en la escuela: Algunas reflexiones. Hojas y Hablas, 5, pp. 46-56.

Gutiérrez, M. Y. y Rosas, A. (2008b). El lugar de la oralidad en la escuela: exploraciones iniciales sobre las concepciones de los docentes. Infancias Imágenes, 7, pp. 24-29.

Habermas, J. (1985). Conciencia moral y acción comunicativa. Barcelona: Península.

Halliday, M. A. K. (1989). Functions of language. En: M. A. K. Halliday y R. Hasan (Eds.). Language, context, and text: Aspects of language in a social-semiotic perspective (pp. 15-28). Oxford: Oxford University Press.

Hameline, D. (1998). Pédagogie. In: R. Hofstteter y B. Schneuwly (Eds.). Le pari des sciencies de l'éducation. Raisons éducatives, No. 1 y 2 (pp. 227-241). Bruxelles: De Boeck.

Hymes, D. (1974). Hacia etnografías de la comunicación. En: P. L. Garvín y Y. Lastra de Suárez (Eds.). Antología de estudios de etnolingüística y sociolingüística. México: UnAM.

Hymes, D. (1972). Models of the interaction of language and social life. In: J. Gumperz y D. Hymes (Eds.). Directions in sociolinguistics: The ethnography of communication (pp. 35-71). New York: Holt, Rinehart and Winston.

Imbernon, F. (2009). Mejorar la enseñanza y el aprendizaje en la universidad. Cuadernos de docencia universitaria 14. Barcelona: Editorial Octaedro.

Jaimes, G. (2008). Aprender a Dialogar en el aula de preescolar. Bogotá: Fondo de Publicaciones, Universidad Distrital. 
Jaimes, G. (2005). Competencias de la oralidad e inserción en la cultura escrita. Enunciación, 10, pp. 18-20.

Jaimes, G., Bojacá, B. y Morales, R. (2006). Las redes como espacios de formación. En: Secretaría de Educación Distrital, Red Distrital de Lectura y Escritura y Universidad Francisco José de Caldas. Redes del lenguaje en la acción educativa. Bogotá: Secretaría de Educación del Distrito Capital.

Jaimes, G. y Rodríguez, M. E. (2000). El desarrollo de la oralidad en el Preescolar. Práctica cognitiva, discursiva y cultural. Anuario Oralidad, 8, pp. 30-38.

Kerbrat-Orecchioni, C. (1996). La conversation. París: Seuil.

Kleine, P. F. y Smith, L. M. (1987). Personal knowledge, belief systems and educational innovators. Paper presented at the Annual meeting of the A. E. R. A., Washington.

Krippendorff, K. (1990). Metodología de análisis de contenido. Teoría y práctica. Barcelona: Editorial Paidós.

Labov, W. (1983). Modelos sociolingüísticos. Madrid: Ediciones Cátedra.

Leontiev, A. (1978). Actividad, Conciencia y Personalidad. Argentina, Buenos Aires: Ediciones Ciencias del Hombre.

Liston, D. y Zeichner, K. (1990). Teacher education and the social context schooling: Issues for Curriculum Development. American Educational Research Journal, 27(24), pp. 610-638.

Litwin, E. (1997a). Las configuraciones didácticas. Una nueva agenda para la enseñanza superior. Buenos Aires: Paidós.

Litwin, E. (1997b). El campo de la didáctica: la búsqueda de una nueva agenda. En: A. W. de Camillioni, M. C. Davini, G. Edelstein, E. Litwin, M. Souto y S. Barco. Corrientes didácticas contemporáneas (pp. 91-115). Buenos Aires: Paidós.

Llinares, S. (1992). Los mapas cognitivos como instrumento para investigar las creencias epistemológicas de los profesores. En: C. Marcelo (Comp.). La investigación sobre la formación del profesorado. Métodos de investigación y análisis de datos (pp. 57-95). Buenos Aires: Cincel.

Lomas, C. (Comp.). (2006). Usos orales en la escuela. En: C. Lomas (Comp.). Enseñar lenguaje para aprender a comunicar(se) (pp. 69-73). Bogotá: Colección Redes, Editorial Magisterio.

Lomas, C. y Osoro, A. (1998). Enseñar Lengua. En: C. Lomas y A. Osoro (Comp.). El enfoque comunicativo de la enseñanza de la lengua (pp. 17-30). España: Paidós. 
Lugarini, E. (2006). Hablar y Escuchar. Por una didáctica del "saber hablar" y del "saber escuchar". En: C. Lomas (Comp.). Enseñar lenguaje para aprender a comunicar(se) (pp. 109-120). Bogotá: Colección Redes, Editorial Magisterio.

Lyotard, J. (2004). La condición posmoderna: Informe sobre el saber. Madrid: Cátedra.

Maglia, G. (2006). Naciones culturales versus naciones imaginadas en la poesía Afrocaribe hispanófona. Cuadernos de Literatura, 11(21), pp. 119-137.

Marcelo, C. (2005). La investigación sobre el conocimiento de los profesores y el proceso de aprender a enseñar. En: G. Perafán y A. Adúriz-Bravo (Comp.). Pensamiento y conocimiento de los profesores. Debate y perspectivas internacionales. Universidad Pedagógica Nacional, Bogotá: Editorial Nomos.

Marcelo, C. (1993). Cómo conocen los profesores la materia que enseñan. Algunas contribuciones de la investigación sobre Conocimiento Didáctico del Contenido. En: L. Montero y J. M. Vez (Eds.). Las didácticas específicas en la formación del profesorado (pp. 151-185). Santiago de Compostela: Tórculo.

Marcelo, C. (1987). El pensamiento del profesor. Barcelona: CEAC.

Martín del Pozo, R. y Porlán, R. (1999). Tendencias en la formación inicial del profesorado sobre los contenidos escolares. Revista Interuniversitaria de Formación del Profesorado, 35, pp. 115-128.

Martín del Pozo, R. y Rivero, A. (2001). Construyendo un conocimiento profesionalizado para enseñar ciencias en la educación secundaria: Los ámbitos de investigación profesional en la formación inicial del profesorado. Revista Interuniversitaria de Formación del Profesorado, 40, pp. 63-79.

Martinand, J. L. (1986). Connaitre et transformer la matière. Berne: Peter Lang.

Martínez, M. C. (1991). La dimensión dialógica del lenguaje. En: Analyse du discours des manuels scolaires de sciences ou la sémantique du social et la sémantique de la nature, un écodiscours. Université de Paris XIII.

Martínez, M. y Gorgorió, N. (2004). Concepciones sobre la enseñanza de la resta: Un estudio en el ámbito de la formación permanente del profesorado. $R e-$ vista Electrónica de Investigación Educativa, 6(1), pp. 1-19. Recuperado de: http://redie.uabc.mx/vol6no1/contenido-silva.html

Massi, M. P. (2000). La conformación de los roles discursivos en la interacción televisiva. Estudios Filológicos, 35, pp. 87-104.

Mattei, M. C. (2007). ¿Lenguas y culturas amerindias en peligro? Desaciertos y logros. Anuario Oralidad, para el rescate de la tradición oral en América Latina y el Caribe, 15, pp. 9-14. 
Marx, C. y Engels, F. (1981). La Sagrada Familia. Madrid: Akal.

Méndez, E. y Leal, E. (2006). El lenguaje de los informativos entre la oralidad y la escritura(lidad). El telediario del 11 S. Oralia, 9, pp. 185-230.

Mendizábal, N. (2006). Los componentes del diseño flexible en la investigación cualitativa. En: I. Vasilachis de Gialdino (Coord.). Estrategias de investigación cualitativa (pp. 65-105). Barcelona: Gedisa.

Mercado, J. (1993). Literatura Oral del Caribe Colombiano: Narrativa. Bogotá: Fondo de Publicaciones, Universidad Distrital Francisco José de Caldas.

Mercer, N. (1997). La construcción guiada del conocimiento. España: Paidós.

Mercier, G., Sensevy, G. y Schubauer-Leoni, M. (2000). Vers un modèle de l'action didactique du professeur. A propos de la course a vingt. Recherches en didactiques des mathématiques, 20(3), pp. 263-304.

Mili, I. y Rickenmann, R. (2008). La escucha-descubrimiento y el aprendizaje de la postura de espectador. Contribuciones a una didáctica de la recepción cultural en el medio escolar. Pensamiento, palabra y obra o, pp. 12-21.

Milian, M. y Camps, A. (1990). L`espai de la Didáctica de la llengua i la literatura. Interaula, 11, pp. 22-24.

Miles, M. y Huberman, M. (1984). Qualitative data análisis. Beverly Hills: Sage.

Ministerio de Educación Nacional (2003). La Revolución Educativa. Estándares Básicos de Lenguaje. Educación Básica y Media. Disponible en: www.mineducacion.gov.co. Bogotá, D.C.

Ministerio de Educación, Cultura y Deporte (2002). Marco común europeo de referencia para las lenguas: aprendizaje, enseñanza, evaluación. (2001). Madrid: Anaya.

Ministerio de Educación Nacional (1998). Lineamientos curriculares en Lengua Castellana. Bogotá.

Moeschler, J. (1992). Théorie pragmatique, acte de langage et conversation. $R e-$ vista Cahiers de Linguistique Francaise 13, pp. 108-124.

Monereo, C., Castelló, M., Clariana, M., Palma, M. y Pérez M. (2007). Estrategias de enseñanza y aprendizaje: formación del profesorado y aplicación en la escuela. Barcelona: Graó.

Mongay, A. (2004). Cómo preparar una exposición oral en todas las áreas de secundaria. Recuperado de http://www.pnte.cfnavarra.es/publicaciones/pdf/ blitznaranja.pdf

Montes, J. J. (1999). La Dialectología. Thesaurus, Tomo LIV, 2, pp. 533-542. 
Moore, D. y Vilacy, A. (2006). Cómo pueden los lingüistas ayudar a las comunidades indígenas. Anuario Oralidad, para el rescate de la tradición oral en América Latina y el Caribe, 14, pp. 57-65.

Moreno, M. (2005). El pensamiento del profesor. Evolución y estado actual de las investigaciones. En: G. Perafán y A. Adúriz-Bravo (Comp.). Pensamiento y conocimiento de los profesores. Debate y perspectivas internacionales (pp. 63-79). Bogotá: Editorial Nomos. Universidad Pedagógica Nacional.

Morín, E. (1990). Introducción al pensamiento complejo. Barcelona: Gedisa.

Morgan, D. L. (1997). Focus groups as qualitative research. Thousand Oaks, CA: Sage.

Nieda, J. y Macedo, B. (1997). Un currículo científico para estudiantes de 11 a 14 años. Organización de Estados Iberoamericanos para la Educación, la Ciencia y la Cultura (OEI). Recuperado de http://www.oei.es/oeivirt/curricie/index.html

Noguera, J. (2006). La oralidad del chat en estudiantes universitarios. AlterTexto, 4(7), pp. 81-98.

Nonnon, E. (2000). L'enseignement de l'oral et les interactions verbales en classe: champ's de référence et problématiques. Revue francaise de pédagogie, 129, 89-103.

Novak, J. (1988). Constructivismo humano un consenso emergente. Enseñanza de las ciencias: Revista de Investigación y Experiencias Didácticas, 6(3), pp. 213-223.

Núñez, M. P. (2003). Didáctica de la comunicación oral: Bases teóricas y orientaciones metodológicas para el desarrollo de la competencia discursiva oral en la educación obligatoria. España: Grupo Editorial Universitario.

Núñez, M. P. (2001). Comunicación y expresión oral. Hablar, escuchar y leer en Secundaria. Madrid: MEc-Narcea.

Núñez, M. P. (2000). Un aspecto básico para la didáctica de la lengua oral: el papel del lenguaje en la comunicación didáctica. Lenguaje y Textos, 16, pp. 155-172.

Núñez, M. P. y Romero, A. (2003). Investigación en didáctica de la lengua e innovación curricular. España: Universidad de Granada.

Núñez, M. P., Fernández, E. y Romero, A. (2009). Adquisición de habilidades metalingüísticas y enseñanza-aprendizaje de la composición escrita en educación primaria: reflexiones didácticas sobre los resultados de un estudio experimental. Porta linguarum. Revista Internacional de Didáctica de las Lenguas Extranjeras, 12, pp. 149-169. 
Núñez, M. P. y Romero, E. (2009). Estrategias didácticas para la enseñanza de la lengua oral en la Educación Primaria. Revista de Educación de la Universidad de Granada, 22(1), pp. 125-152.

Nussbaum, L. (2006). De cómo recuperar la palabra en clase de lengua. Notas para el estudio del uso oral. En: C. Lomas (Comp.). Enseñar lenguaje para aprender a comunicar(se) (pp. 109-120). Bogotá: Colección Redes, Editorial Magisterio.

Nussbaum, L. (1999). La discusión como género discursivo y como instrumento didáctico. Textos de Didáctica de la Lengua y de la Literatura, 20, pp. 9-17.

Ong, W. (1987). Oralidad y escritura. Tecnologías de la palabra. México: Fondo de Cultura Económica.

O'shanahan, I. (1996). Enseñanza del lenguaje oral y las teorías implícitas del profesorado. [Tesis doctoral, Universidad de La Laguna]. Recuperado de http://dialnet.unirioja.es/servlet/tesis?codigo $=680$

Ostria, M. (2001). Literatura oral, oralidad ficticia. Estudios Filológicos, 36, pp. 71-8o. Recuperado de http://www.scielo.cl/scielo.php?script=sci_arttext\&pid=So071-17132001003600005\&lng=es\&nrm=iso.

Pajares, M. F. (1992). Teachers' beliefs and educational research: Cleaning up a messy construct. Review of Educational Research, 62(3), pp. 307-332.

Palou, J., Bosch, C., Carreras, M., Castanys M., Cela, J., Colomer, A., Giralt, J., Jové, M., Olivé, C., Ripoll, R. y Teixidor, M. (2005). La lengua oral en la escuela. 10 experiencias didácticas. España: Graó.

Patiño, C. (2003). Sociolectos y registros en el habla bogotana. Universia. Recuperado de http://www.universia.net.co/vigia-del-idioma/numero-5-diciembre-2003/sociolectos-y-registros-en-el-habla-bogotana.html

Paulín, G. (2006). La oralidad en el horizonte de la comunicación globalizada. AlterTexto, 4(7), pp. 59-80.

Perafán, G. (2004). La epistemología del profesor sobre su propio conocimiento profesional. Bogotá: Universidad Pedagógica Nacional.

Perafán, G. y Adúriz-Bravo, A. (2005). Pensamiento y conocimiento de los profesores. Debate y perspectivas internacionales. Bogotá: Universidad Pedagógica Nacional-Editorial Nomos.

Pérez, A. (1985) Paradigmas contemporáneos de investigación didáctica. En: S. Gimeno y A. Pérez. La Enseñanza: su teoría y práctica (pp. 95-138). Madrid: Akal. 
Pérez, C. (2009). La lengua oral en la enseñanza. Propuesta para la programación de contenidos de lengua oral y el diseño de tareas orales. Didáctica de la Lengua y la Literatura, 21, pp. 297-318.

Pérez, H. (1998). Tradición y oralidad en el refranero mexicano. En: La tradición hoy en día. Primer Foro Interdisciplinar de Oralidad, Tradición y Culturas Populares y Urbanas. Memorias (pp. 17-31). México: Departamento de Letras. Universidad Iberoamericana

Pérez, S. (2004). Palabras de filósofos. Oralidad, escritura y memoria en la filosofía antigua. México: Siglo XXI.

Pérez Gómez, Á. (1992). Comprender la enseñanza en la escuela. Modelos metodológicos de investigación educativa. En: J. Gimeno y A. Pérez. Comprender y transformar la enseñanza, cap. V, pp. 115-136. Madrid: Morata,

Pérez Gómez, Á. y Gimeno, J. (1988). Pensamiento y acción en el profesor: de los estudios sobre la planificación al pensamiento práctico. Infancia y aprendizaje, 42, pp. 37-63.

Piaget, J. (1972). El nacimiento de la inteligencia en el niño. Madrid: Aguilar.

Pineau, P., Dussel, I. y Caruso, M. (2001). La escuela como máquina de educar. Tres escritos sobre un proyecto de modernidad. Buenos Aires: Paidós.

Plane, S. y García-Debanc, C. (2004). L'enseignement de l'oral: enjeux et evolution. In: Plane, S. y García-Debanc, C. (Coord.). Comment enseigner l'oral á l'école primaire? (pp. 7-23). París: Hatier Pedagogie.

Plazaola Giger, I. (2006). Didáctica y análisis de la actividad en el trabajo: ¿qué aportan a la investigación en el aula? En: A. Camps (Coord.). Diálogo e investigación en las aulas. Investigaciones en didáctica de la lengua (pp. 205-219). España: Graó.

Ponte, J. P. (1992). Concepções dos professores de matemática e processos de formação. En: J. P. Ponte (Ed.). Educação matemática: Temas de investigação (pp. 185-239). Lisboa: Instituto de Inovação Educacional. Recuperado de http://www.educ.fc.ul.pt/docentes/jponte

Pope, M. y Gilbert, J. (1983). Personal experience and the construction of Knowledge in science. Science Eclucation, 67, 2, pp. 193-203.

Porlán, R. (1999). Formulación de los contenidos escolares. Cuadernos de Pedagogía. Cuadernos de Pedagogía, 276, pp. 65-70.

Porlán, R. (1996). El maestro como investigador en el aula. Investigar para conocer, conocer para enseñar. Cero en Conducta, pp. 80-90. 
Porlán, R. (1993). Constructivismo y escuela. Sevilla: Díada editora.

Porlán, R. (1989). Teoría del conocimiento, teoría de la enseñanza y desarrollo profesional. Las concepciones epistemológicas de los profesores (Tesis doctoral). Sevilla: Universidad de Sevilla.

Porlán, R. (1987). El maestro como investigador en el aula. Investigar para conocer, conocer para enseñar. Investigación en la Escuela, 1, pp. 63-70.

Porlán, R. y Cañal, P. (1986). Una escuela para la Investigación. Cuadernos de Pedagogía, 134, pp. 45-47.

Porlán, R., Azcárate, P., Martín, R., Martín, J. y Rivero, A. (1996). Conocimiento profesional deseable y profesores innovadores: fundamentos y principios formativos. Investigación en la Escuela, 29, pp. 23-38.

Porlán, R., García, J. E. y Cañal, P. (1988). Constructivismo y enseñanza de las Ciencias. Sevilla: Díada.

Porlán, R. y Martín Toscano, J. (1994). El saber práctico de los profesores especialistas. Aportaciones desde las didácticas específicas. Investigación en la Escuela, 24, pp. 49-58.

Porlán, R. y Rivero, A. (1998). El conocimiento de los profesores. Sevilla: Díada.

Porlán, R., Rivero, A. y Martín del Pozo, R. (1998). Conocimiento profesional y epistemología de los profesores II: Estudios empíricos y conclusiones. Enseñanza de las Ciencias, 16(2), pp. 271-289.

Porlán, R., Rivero, A. y Martín del Pozo, R. (1997). Conocimiento profesional y epistemología de los profesores I: Teoría, métodos e instrumentos. Enseñanza de las Ciencias, 15(2), pp. 155-171.

Poyatos, F. (1994). La comunicaciòn no verbal II. Paralenguaje, kinésica e interacción. Madrid: Istmo.

Pujol-Berché, M. (1994). La pedagogía del texto: Enseñanza/aprendizaje del producto final y del proceso de producción final. Comunicación, Lenguaje y Educación, 23, pp. 9-16.

Quiñones, T. (2005). Oralidad y teología en la santería cubana. Anuario Oralidad, para el rescate de la tradición oral en América Latina y el Caribe, 13, pp. 14-17.

Reigeluth, C. M. y Stein, F. S. (1983). The elaboration theory of instruction. In: C. M. Reigeluth (Ed.). Instructional Design: Theories and Models. An overview of their current status (pp. 335-381). New Jersey: Hillsdale, L. Erlbaum. 
Rey, A., Borja, I., Jaimes, G. y Rodríguez, M. E. (2011). El lenguaje en Colombia. Aspectos Pedagógicos de la lengua. II Tomo, Historia de la Filología y la Lingüística en Colombia. Colombia: Academia Colombiana de la Lengua.

Reyzábal, M. V. (1993). La comunicación oral y su didáctica. Madrid: La Muralla, S.A.

Reyzábal, M. V. y Sanz A. I. (1997). Los ejes transversales. Aprendizajes para la vida. Madrid: Escuela Española.

Richards, J. C. y Rodgers, T. S. (1986). Approaches and methods in language teaching. Cambridge: University Press.

Rickenmann, R. (2009). Metodologías clínicas de investigación en didácticas y formación del profesorado: un estudio de los dispositivos de formación en alternancia. Recuperado de http://www.unige.ch/fapse/clidi/textos/Clinica-did\%E1ctica-RR.pdf

Rickenmann, R. (2007). Investigación y formación docente: Dispositivos de formación y elementos para la construcción de una identidad profesional. EccoS, Revista Científica, Sao Paulo, 9(2), pp. 435-463.

Rickenmann, R. (2006a). Didactics in art education and appropriation of art works. Relationships between social and school practices. En: Comunicación, Congreso International de la INSEA (International Association for Learning trough Art). Diálogos Interdisciplinarios en la educación por el arte, Viseu-Portugal, du 1 au 5 Mars.

Rickenmann, R. (2006b). El rol de los artefactos culturales en la estructuración y gestión de secuencias de enseñanza-aprendizaje. Conferencia, Actas del 1er Congreso Internacional de Investigación, formación y educación docente. Medellín: Universidad de Antioquia, 30, 31 de agosto y 1ro de septiembre.

Rodríguez J. A. (2000). Posmodernidad, literatura y otras yerbas. Bogotá: Editorial Pontificia Universidad Javeriana.

Rodríguez, M. E. (2006). Consideraciones sobre el discurso oral en el aula. Enunciación, 11, pp. 59-72.

Rodríguez, M. E. (2002). Formación, interacción, argumentación. Bogotá: Fondo de Publicaciones, Universidad Distrital Francisco José de Caldas.

Rodríguez, M. E. (1995). “Hablar” en la escuela: ¿Para qué?... ¿Cómo? Lectura y Vida. Revista Latinoamericana de Lectura, Año 16(3), pp. 1-11.

Romero, F. (2003). Entre los Embera-Chamí: Aspectos educativos de la oralidad y la escritura. Anuario Oralidad, para el rescate de la tradición oral en América Latina y el Caribe, 12, pp. 35-41. 
Roulet, E. (1991). Vers une approche modulaire de l'analyse du discours. Cahiers de Linguistique Francaise 12. Geneve: Universite de Geneve.

Sacks, H., Schegloff, E. y Jefferson, G. (1974). A symplest systematics for the organization of turn-taking for conversation. Language, (50)4, pp. 696-735.

Santos, P. (2007). Revitalización de la lengua Asháninka. Alfabetización en la lengua materna de la mano con la tecnología de la información y comunicación. Anuario Oralidad, para el rescate de la tradición oral en América Latina y el Caribe, 15, pp. 34-38.

Sanz, I. (2010). Las presentaciones orales en el español profesional. Primer Congreso Internacional de Español para fines específicos. Centro Virtual Cervantes: España: Universidad Politécnica de Valencia. Recuperado de http://cvc.cervantes.es/ensenanza/biblioteca_ele/ciefe/pdf/o1/cvc_ciefe_01_0018.pdf

Saussure, F. (1961). Curso de lingüística General. Buenos Aires: Losada.

Schneuwly, B., Di Pietro, A-J-F., Dolz, J., Dufour, J., Erard, S., Aller, S., Kaneman, M., Moro, Ch. y Zahnd, G. (1997). L“'oral” s'ensenya! Prolegòmens per a una didàctica de la producció oral. En Articles de Didàctica de la Llengua i de la Literatura, 12, pp. 9-18.

Schwab, J. (1983). Un enfoque práctico para la planificación del curriculum. Buenos Aires: El ateneo.

Secretaría de Educación Distrital (2010). Herramienta para la vida: hablar, leer y escribir para comprender el mundo. Bogotá: Editorial Kimpres.

Sensevy, G. (2007). Categorías para describir y comprender la acción didáctica. Traducción de J. Duque y revisión de R. Rickenmann. En: G. Sensevy, M. Schubauer-Leoni y A. Mercier. Agir ensemble: l' action didactique conjointe du professeur et des èlèves (pp. 13-49). Francia: Presses universitaires de Rennes.

Shavelson, R. J. (1988). Statistical reasoning for the behavioral sciences. Boston: Allyn and Bacon.

Shavelson, R. J. y Stern, P. (1983). Research on teachers' pedagogical thoughts, judgments, decisions, and behavior. Review of Educational Research, 15, pp. 455-498.

Sinclair, J. y Coulthard, R. (1978). Towards an Analysis of Discourse. The English used by teachers and pupils. Londres: Oxford University Press.

Shön, D. (1992). La formación de profesionales reflexivos. Barcelona: Paidós. 
Schön, D. (1987). Educating the reflective practitioner. San Francisco: Jossey-Bass.

Schön, D. (1983). The Reflective Practitioner: How Professionals Think in Action. NY: Basic Books.

Shulman, L. S. (2005). Conocimiento y enseñanza. Fundamentos de la nueva reforma. Revista currículum y formación del profesorado. 9 (2), pp. 1-30.

Shulman, L. S. (2001). Conocimiento y enseñanza. Ensayo. Estudios públicos, 83, pp. 163-196.

Shulman, L. S. (1998). Theory, practice, and the education of professionals. The Elementary School Journal, 98(5), pp. 511-526.

Shulman, L. S. (1986a). Those who understand: Knowledge growth in teaching. In: Educational Researcher, 15(2), pp. 4-14.

Shulman, L. S. (1986b). Paradigmas y programas de investigación en el estudio de la enseñanza: una perspectiva contemporánea. En: M. Wittrock (Comp.). La investigación de la enseñanza, I: enfoques, teorías y métodos. Madrid: Paidós.

Shulman, L. S. y Elstein, A. S. (1975). Studies of problem solving, judgment, and decision making: Implications for educational research. En: F. N. Kerlinger (Ed.). Review of Research in Education, 3, pp. 5-42.

Smith, J. (1983). Quantitative versus qualitative research: An attempt to clarify the issue. Educational Researcher 12(3), pp. 6-13.

Stenhouse, L. (1984). Investigación y desarrollo del currículo. Madrid: Morata.

Stubbs, M. (1978). Mantenerse en contacto: algunas funciones de la charla del profesor. En: M. Stubbs y S. Delamont (Comp.). Las relaciones profesor-alumno (pp. 25-28). España: Oikos-tau, S.A.

Tannen, D. (1994). Gender and Discourse. Oxford University Press: Coates.

Tardif, M. (2004). Los saberes del docente y su desarrollo profesional. Manzano, P. (Trad.). Madrid: Narcea.

Thompson, A. G. (1992). Teachers' beliefs and conceptions: A synthesis of the research. In: D. A. Grouws (Ed.). Handbook of research in mathematics teaching and learning (pp. 127-146). New York, NY: Macmillan.

Trigo, J. M. (1998). Desarrollo de la oralidad en la educación secundaria. Revista Interuniv. Form. 31, pp. 35-53.

Tusón, A. (2006). Iguales ante la lengua, desiguales en el uso. Bases sociolingüísticas para el desarrollo discursivo. En: C. Lomas (Comp.). Enseñar lenguaje para aprender a comunicar(se) (pp. 93-107). Bogotá: Colección Redes. Editorial Magisterio. 
Urbina, R. (2008). Retórica de la pasión publicitaria. Nuevas aportaciones al concepto de nuclearidad pragmática. Revista Rhêtorikê, 1, pp. 1-18.

Valbuena, E. (2007). El conocimiento profesional del profesor de Biología. Estudio de las concepciones de futuros docentes de la Universidad Pedagógica Nacional (Colombia) (Tesis doctoral). Madrid: Universidad Complutense de Madrid.

Valderrama, J. y Velásquez, C. (2004). Radio y responsabilidad social en Colombia. Revista Palabra clave, 11, pp. 1-37.

Van Dijk, T. (Comp.). (2000). El discurso como estructura y proceso. Barcelona: Gedisa.

Vasilachis, I. (2006). La investigación cualitativa. En: I. Vasilachis de Gialdino. (Coord.). Estrategias de investigación cualitativa (pp. 48-49). Barcelona: Gedisa.

Vergara, G. (2006). Entre dichos y refranes: acercamiento a la lírica oral de Coahuayana. AlterTexto, 4(8), pp. 45-53.

Vilá, M.(2010). 6 criterios para enseñar lengua oralen la Educación Obligatoria. Recuperado de http://docentes.leer.es/2009/10/19/6-criterios-para-ensenar-lengua-oral-en-la-educacion-obligatoria-montserrat-vila-i-santasusana/

Vilá, M. (2004). Actividad oral e intervención didáctica en las aulas. Glosas Didácticas, 12, pp. 113-120.

Vilá, M. (1994). Acerca de la enseñanza de la lengua oral. Comunicación, Lenguaje y Educación, 23, pp. 45-54.

Vilá, M., Ballesteros, C., Castellá, J. M., Cros, A., Grau M. y Palou, J. (2005). El discurso oral formal. Contenidos de aprendizaje y secuencias didácticas. España: Graó.

Vygotski, L. S. (2001). Pensamiento y Lenguaje. Conferencias sobre psicología. Obras escogidas. Tomo II. Madrid: Antonio Machado Libros.

Vygotski, L. S. (1996). Interacción entre aprendizaje y desarrollo. En: M. Cole, V. Steiner, S. Scribner y E. Souberman (Eds.). El desarrollo de los procesos psicológicos superiores. Barcelona: Crítica.

Vygotski, L. S. (1991). Obras escogidas, vol. I. Madrid: Visor.

Vygotski, L. S. (1984). Pensamiento y Lenguaje. Buenos Aires: Editorial Pléyade.

Winne, P. y Marx, R. (1977). Reconceptualising research on teaching. Journal of Educational Psychology, 69, pp. 668-678. 
Yinger, R. (1990). The Conversation of Practice. In: R. T. Clift, W. R. Houston and M. C. Pugach (Eds.). Encouraging Reflective Practice in Education. New York: Teachers College Press, pp. 72-96.

Zambrano, A. (2006). Los hilos de la palabra. Pedagogía y Didáctica. Bogotá: Editorial Magisterio.

Zambrano, A. (2005). Didáctica, Pedagogía y Saber. Colección Seminaium. Bogotá: Cooperativa Editorial Magisterio.

Zeichner, K. y Gore, J. (1990). Teacher Socialization. En: R. Houston (Ed.). Handbook of Reasearch on Teacher Education (pp. 329-348). New York: Macmillam.

Zires, M. (1999). De la voz, la letra y los signos audiovisuales en la tradición oral contemporánea en América Latina: Algunas consideraciones sobre la dimensión significante de la comunicación oral. Razón y palabra, 15(4), pp. $5-15$.

Zuluaga, O. L. (1993). La investigación histórica en la pedagogía y la didáctica. En: Objeto y método de la pedagogía (pp. 119-125). Medellín: Departamento de Pedagogía, Facultad de Educación, Universidad de Antioquia.

Zuluaga, O. L. (1987). Pedagogía e Historia. Bogotá: Ediciones Foro Nacional por Colombia.

Zumthor, P. (1987). La letra y la Voz. Madrid: Cátedra. 


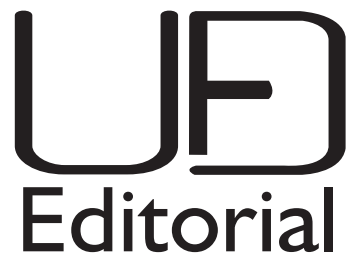

\author{
ESTE LIBRO FUE COMPUESTO EN CARACTERES \\ Georgia y Gill Sans 10/14,6 Puntos. \\ IMPRESO EN EL MES DE ABRIL DE 2014 \\ EN LOS TALLERES DE JAVEGRAF. \\ Bogotá, CoLombia. 2014
}

\title{
Gutiérrez Ríos, Mirta Yolima
}

Concepciones y prácticas sobre la oralidad en la educación media colombiana / Mirta Yolima Gutiérrez Ríos. -- Bogotá : Universidad Distrital Francisco José de Caldas, 2014.

238 p. ; $24 \mathrm{~cm}$.

ISBN 978-958-8832-58-6 / ISBN digital 978-958-8832-59-3

1. Comunicación oral 2. Comunicación en la escuela

3. Comunicación en educación 4. Sociolingüística y educación I. Tít.

302.2242 cd 21 ed.

A1437210

CEP-Banco de la República-Biblioteca Luis Ángel Arango 


\section{UP \\ Editorial}

En el primer capítulo se presentan las tensiones, aperturas y necesidades relacionadas con las diversas nociones de la oralidad, sus formas de materialización y en el contexto sociocultural y escolar.

En el segundo se expone el análisis, interpretación y discusión de las concepciones didácticas y disciplinares sobre la enseñanza de la lengua oral, se analizan las contingencias y correspondencias entre concepciones y prácticas referidas a la enseñanza y aprendizaje de la lengua oral y se discuten los resultados. De este proceso se derivan algunos lineamientos para la formulación de una propuesta de formación docente, tendiente al desarrollo de la competencia discursiva oral, los cuales serán objeto de otra publicación.

Así, pues, se presentan los resultados de un estudio que surge de la preocupación por la ausencia de una tradición pedagógica en torno a la enseñanza progresiva y sistemática de la oralidad frente a los ideales de la escuela contemporánea de formar ciudadanos, cuyo dominio discursivo oral constituya un factor de inclusión en diversos ámbitos de la acción social.

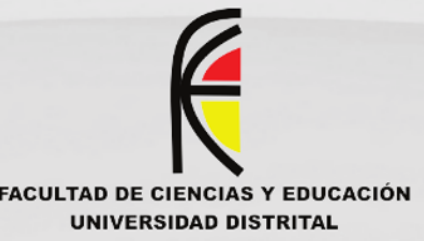

